\title{
Pilot-Scale Demonstration of a Novel, Low-Cost Oxygen Supply Process and its Integration with Oxy-Fuel Coal-Fired Boilers
}

\author{
Final Report
}

Project Period: April 1, 2006 to September 30, 2008)

\author{
Report Authors: Krish R. Krishnamurthy*, Divy Acharya+ and Frank R. Fitch* \\ * Linde North America Inc, Murray Hill, New Jersey \\ + Linde Process Plants Inc, Murray Hill, New Jersey
}

Date of Report: December 18, 2008

DOE Award Number: DE-FC26-06NT42748

Submitted by: The BOC Group, Inc. (A member of The Linde Group) 575 Mountain Ave., Murray Hill, NJ 07974

DISCLAIMER: This report was prepared as an account of work sponsored by an agency of the United States Government. Neither the United States Government nor any agency thereof, nor any of their employees, makes any warranty, express or implied, or assumes any legal liability of responsibility for the accuracy, completeness, or usefulness of any information, apparatus, product, or process disclosed, or represents that its use would not infringe privately owned rights. Reference herein to any specific commercial product, process, or service by trade name, trademark, manufacturer, or otherwise does not necessarily constitute or imply its endorsement, recommendation, or favoring by the United States Government or any agency thereof. The views and opinions of authors expressed herein do not necessarily state or reflect those of the United States Government or any agency thereof. 


\begin{abstract}
In order to achieve DOE targets for carbon dioxide capture, it is crucial not only to develop process options that will generate and provide oxygen to the power cycle in a cost-effective manner compared to the conventional oxygen supply methods based on cryogenic air separation technology, but also to identify effective integration options for these new technologies into the power cycle with carbon dioxide capture.
\end{abstract}

The Linde/BOC developed Ceramic Autothermal Recovery (CAR) process remains an interesting candidate to address both of these issues by the transfer of oxygen from the air to a recycled $\mathrm{CO}_{2}$ rich flue-gas stream in a cyclic process utilizing the high temperature sorption properties of perovskites. Good progress was made on this technology in this project, but significant challenges remain to be addressed before CAR oxygen production technology is ready for commercial exploitation.

Phase 1 of the project was completed by the end of September 2008. The two-bed 0.7 tons/day O2 CAR process development unit (PDU) was installed adjacent to WRI's pilot scale coal combustion test facility (CTF). Start-up and operating sequences for the PDU were developed and cyclic operation of the CAR process demonstrated. Controlled low concentration methane addition allowed the beds to be heated up to operational temperature $\left(800-900^{\circ} \mathrm{C}\right)$ and then held there during cyclic operation of the 2-bed CAR process, in this way overcoming unavoidable heat losses from the beds during steady state operation. The performance of the PDU was optimized as much as possible, but equipment limitations prevented the system from fully achieving its target performance. Design of the flue gas recirculation system to integrate CAR PDU with the CTF and the system was completed and integrated tests successfully performed at the end of the period.

A detailed techno-economic analysis was made of the CAR process for supplying the oxygen in oxy-fuel combustion retrofit option using AEP's 450 MW Conesville, Ohio plant and contrasted with the cryogenic air separation option (ASU). Design of a large scale CAR unit was completed to support this techno-economic assessment. Based on the finding that the overall cost potential of the CAR technology compared to cryogenic ASU is nominal at current performance levels and that the risks related to both material and process scale up are still significant, the team recommended not to proceed to Phase 2.

CAR process economics continue to look attractive if the original and still "realistic" target oxygen capacities could be realized in practice. In order to achieve this end, a new fundamental materials development program would be needed. With the effective oxygen capacities of the current CAR materials there is, however, insufficient economic incentive to use this commercially unproven technology in oxy-fuel power plant applications in place of conventional ASUs. In addition, it is now clear that before a larger scale pilot demonstration of the CAR technology is made, a better understanding of the impact of flue-gas impurities on the CAR materials and of thermal transients in the beds is required. 
$\begin{array}{ll}\text { 1. Objectives } & 1\end{array}$

2. Executive Summary 1

3. Introduction 2

4. CAR (Ceramic Auto-thermal Recovery) Technology Overview 2

5. Key Results and Conclusions from CAR Process

Development Unit (PDU) Trials (Task 1) 4

6. Key Results and Conclusions from CAR Power Plant

Techno-Economic Study (Task 2)

7. Key Results and Conclusions from Long Term

$\begin{array}{ll}\text { Sulfur Exposure Studies (Task 3) } & 8\end{array}$

8. Materials 8

9. Current Status of CAR Technology Development 10

10. Overall Conclusions and Recommendations for Future Work 11

11. Project Overview: Budget and Timeline 11

$\begin{array}{ll}\text { 12. Project Management } & 13\end{array}$

\section{ATTACHMENTS}

Task 1 Report prepared by Thomas Barton and Beau Braunberger:

Western Research Institute, Laramie, Wyoming.

Task 2 Report prepared by Gregory N. Liljedahl and Nsakala ya Nsakala:

Alstom Power Plant Laboratories, Windsor, Connecticut

(Task 3 report incorporated into Task 2)

Task 4 Report prepared by Khalid Omar:

Western Research Institute, Laramie, Wyoming. 


\section{Project Objectives}

Overall Objective: Conduct pilot-scale testing of BOC's CAR oxygen generation process, when integrated with a coal-fired combustor to produce a $\mathrm{CO}_{2}$-rich flue gas.

\subsection{Phase 1 Objectives (18-months, $1^{\text {st }}$ Budget Period):}

1. Evaluate the performance of a 0.7 tons/day $\mathrm{O}_{2}$ pilot-scale CAR system, when fully integrated with a pilot-scale coal combustor and determine the optimum operating conditions of this unit.

2. Perform a techno-economic evaluation of a commercial-scale oxygen-fired power plant that utilizes a CAR system to provide the oxygen.

3. Perform long-duration tests on the CAR unit to determine long-term effects of the CAR bed materials.

Key decision point at end of Phase 1: Go-No Go based on demonstration of CAR process performance, economics for oxy-combustion retrofit application and flue gas handling capability.

\subsection{Phase 2 Objectives (18-months, $2^{\text {nd }}$ Budget Period):}

1. Design and construct a 10 ton/day $\mathrm{O}_{2}$ pilot-scale CAR unit.

2. Evaluate the performance of the pilot-scale CAR unit when integrated with both a pulverized coal-fired and a CFB combustor.

3. Refine the techno-economic study and develop a detailed commercialization plan.

\section{Executive Summary}

Phase 1 was completed by the end of September 2008. The two-bed 0.7 tons/day $\mathrm{O}_{2} \mathrm{CAR}$ process development unit (PDU) was installed adjacent to WRI's pilot scale coal combustion test facility (CTF). Start-up and operating sequences for the PDU were developed and cyclic operation of the CAR process demonstrated. Design of the flue gas recirculation system to integrate CAR PDU with the CTF and the system was completed and integrated tests performed.

A detailed techno-economic assessment of the CAR process applied in a coal-fired oxycombustion power plant was completed and the performance and costs were compared against the cryogenic ASU option for supplying the oxygen. Based on the finding that the overall cost potential of the CAR technology compared to cryogenic ASU is nominal at current performance 
levels and that the risks related to both material and process scale up are still significant, the team recommended not to proceed to Phase 2.

\section{Introduction}

This project is aligned with the carbon capture initiatives of NETL carbon sequestration program. It supports CCS goals by providing an option for low-cost oxygen supply. Oxy-combustion is a leading option for power plants with $\mathrm{CO}_{2}$ capture, but the cost of $\mathrm{O}_{2}$ is a critical factor in making the economics viable. The $\mathrm{O}_{2}$ production unit typically contributes up to $33 \%$ of capital and $67 \%$ of the power consumption of a power plant with $\mathrm{CO}_{2}$ capture. Cryogenic air separation is currently the leading option for providing the large scale oxygen requirements for an oxycombustion based coal-fired power plant. This technology is mature and improvements are likely only by increasing the single-train capacity for this application.

Ceramic Auto-thermal Recovery (CAR Process) is an emerging technology for oxygen supply based on high temperature oxygen storage properties of perovskites. Key features of the CAR technology are that: it operates at low pressure; uses $\mathrm{CO}_{2}$-rich flue gas and/or steam as regeneration gas; allows optimization of the $\mathrm{O}_{2}$ concentration to the boiler; and that it can achieve lower power consumption and lower capex compared to cryogenic ASU options.

\section{CAR (Ceramic Auto-thermal Recovery) Technology Overview}

The CAR technology option makes use of the oxygen "storage" property of perovskites at high temperatures. This results in highly selective $\mathrm{O}_{2}$ extraction from the feed air. It is based on conventional pelletized materials such as those illustrated in Figure 1.

Ceramic Auto-thermal recovery is a cyclic steady state process as schematically illustrated in Figure 2. The perovskite sorbent is alternately exposed to feed air and regeneration gas flows. Partial pressure swing (using a sweep gas) enables production of an $\mathrm{O}_{2}$-enriched stream. Internal regenerative heat transfer is used to maintain temperature (the perovskite zone in each bed is sandwiched between two zones of heat transfer material). 


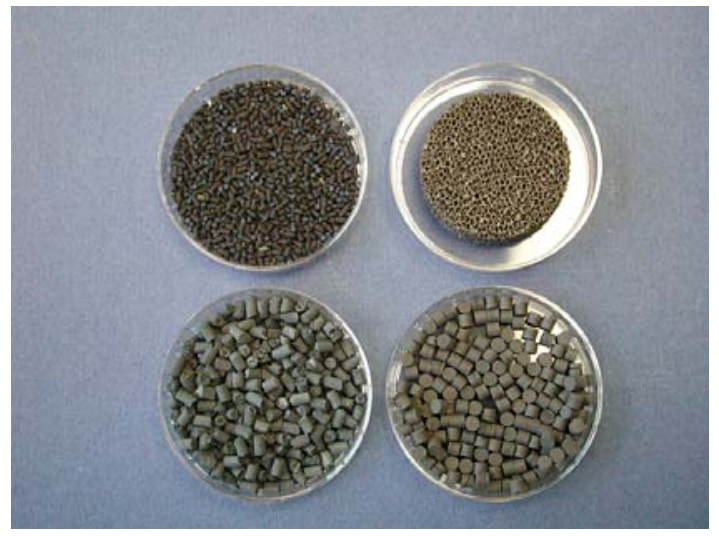

Figure 1: Typical Pellets of Perovskite

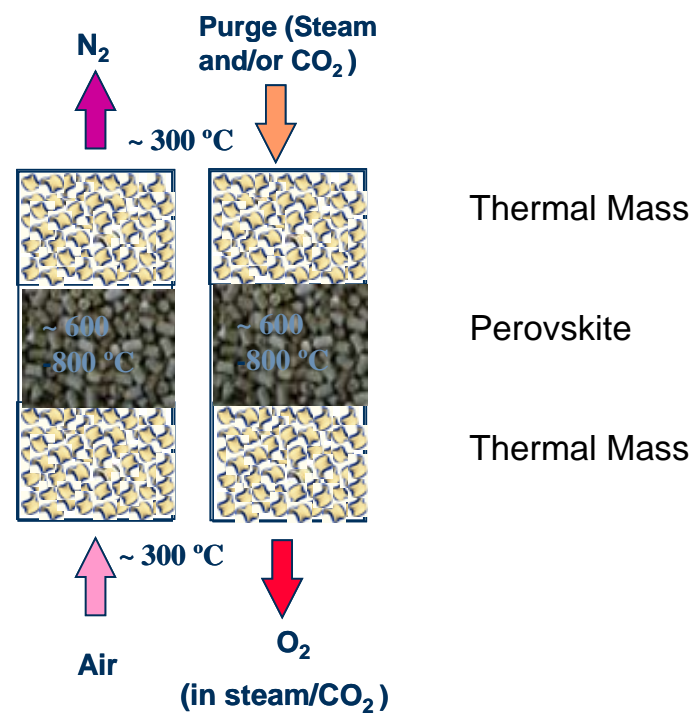

Figure 2: Schematic of CAR Process

At the beginning of this project an analysis was made of the limits to the intrinsic power requirements and the potential economic benefits of CAR oxygen production versus cryogenic ASUs. This is shown for reference in Figure 3.

Advanced cryogenic air separation cycles (employing for example multiple re-boilers and internally heat integrated distillation) can operate down to $\sim 3.6$ bars reducing operating costs, but at the expense of significantly increased capital costs.

CAR technology requires the use of a sweep gas (50-70\% of air flow at 1.6 bars) and a means, for example combustion of an added fuel gas, to compensate for heat losses.

These considerations gave rise to the preliminary assessment of the potential benefits of CAR versus ASUs that is shown in Figure 4 (Basis:700 MW power plant design study, low pressure steam regeneration in CAR process cycle, $726 \mathrm{MWe}$ vs $687 \mathrm{MWe}$ for cryogenic ASU). 


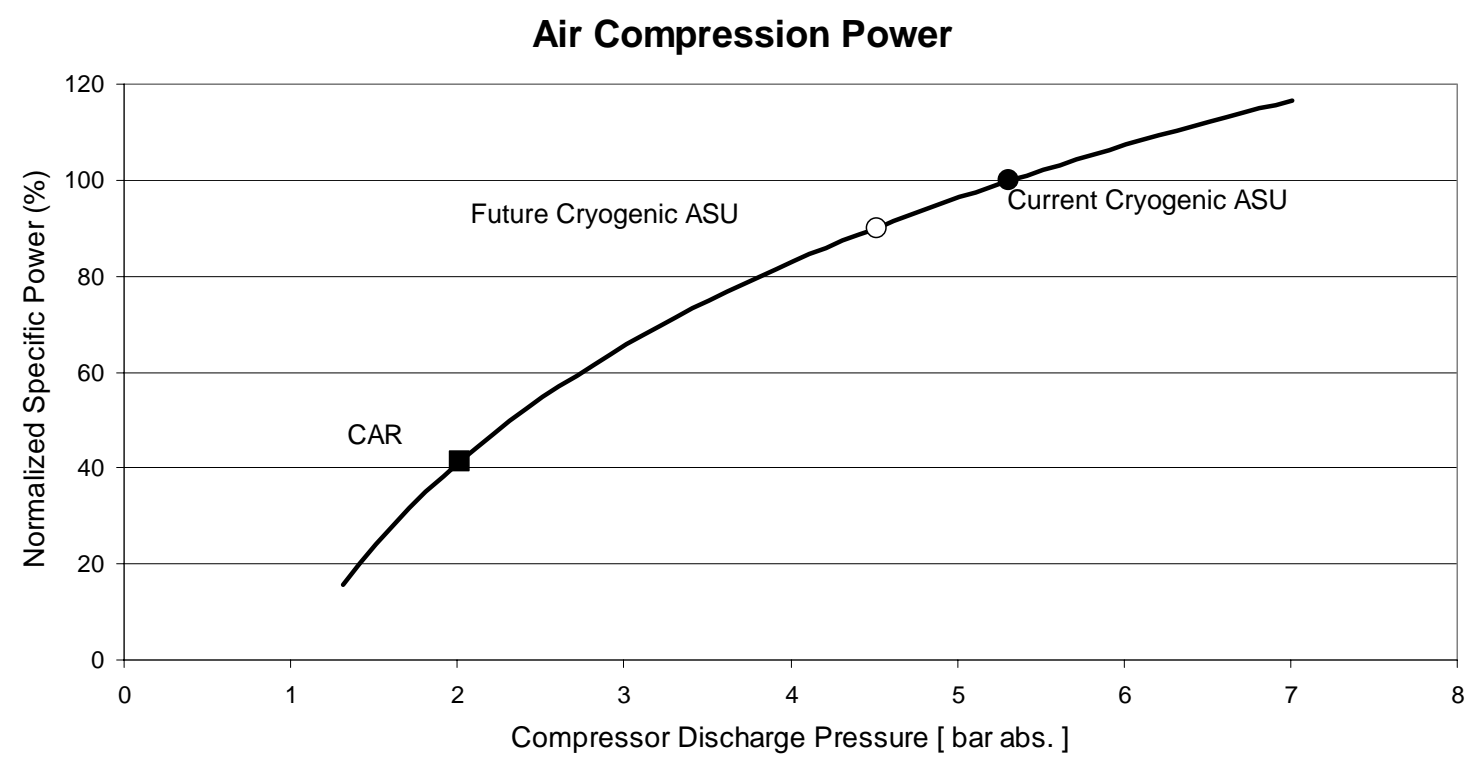

Figure 3: Projected Power Requirements for CAR versus Cryogenic ASUs

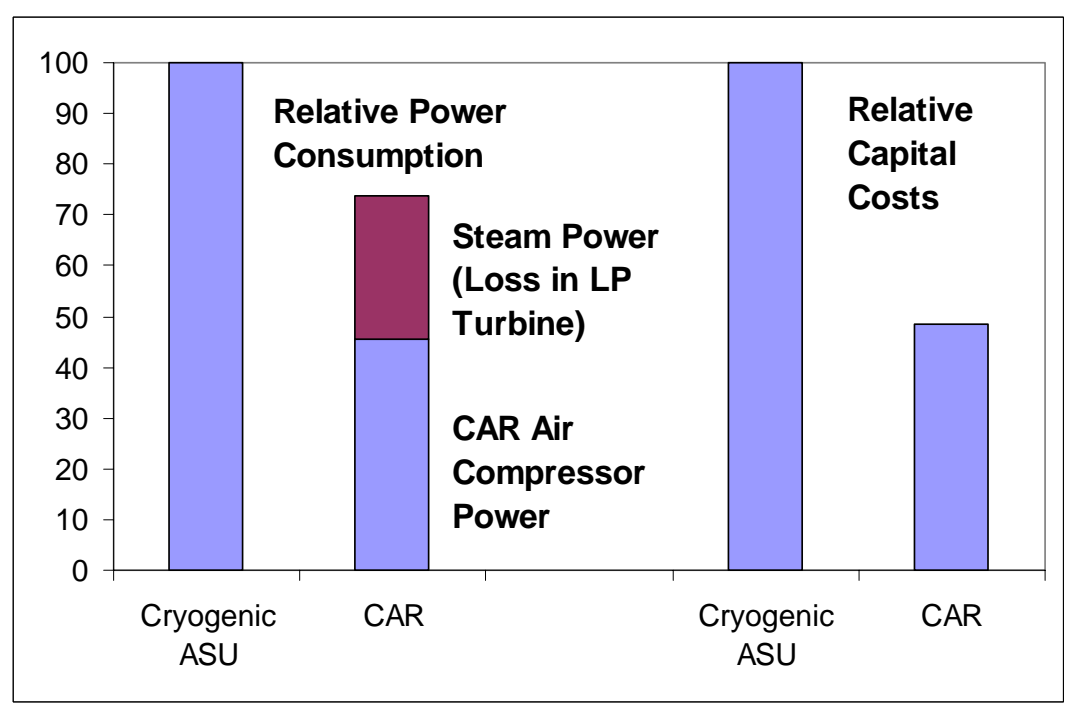

Figure 4: Projected Economic Benefits of CAR versus Cryogenic ASUs

\section{Key Conclusions from CAR Process Development Unit (PDU) Trials (Task 1)}

The two-bed 0.7 tons/day $\mathrm{O}_{2}$ CAR process development unit (PDU) was installed adjacent to WRI's pilot scale coal combustion test facility (CTF) in August of 2006. Significant progress was made in demonstration of the CAR process for oxygen production in power plant oxy-fuel combustion applications, but significant challenges remain to be overcome before larger scale 
demonstration projects can be commercially justified. Details of the PDU rig and experiments undertaken at WRI are described in the attached Task I Report.

Start-up and operating sequences for the PDU were developed and continuous oxygen production in a self sustained 2-bed CAR system was demonstrated for the first time. Controlled low concentration methane addition allowed the beds to be heated up to operational temperature $\left(800-900^{\circ} \mathrm{C}\right)$ and then held there during cyclic operation of the 2-bed CAR process, in this way overcoming unavoidable heat losses from the beds during steady state operation. The performance of the PDU was optimized as much as possible, by adjusting the air and $\mathrm{CO}_{2}$ flow rates, the methane injection locations and rates and the process temperature and cycle time.

Limitations imposed by the controls for the air and carbon dioxide flow rates and methane injection rates as well as by the physical location of the methane injection points prevented uniform axial temperatures profiles from being generated in the PDU beds. In addition, large radial temperature profiles were observed because of the unfavorable aspect ratio of the PDU beds compared to commercial scale beds, an effect that was exacerbated by the internal insulation of the beds being less effective than design. As a result of this only the middle and top parts of the perovskite beds could be held at operational temperatures during steady state operation, effectively limiting oxygen production to roughly 50\% of planned levels and limiting product oxygen concentrations.

In a commercial scale plant the axial temperature profile in the beds could be better controlled by manipulating the methane injection positions and catalytic activity of the packing at different locations in the bed as well as by optimization of the upper and lower thermal masses relative to the perovskite mass for the given process flow rates. In this way the performance of the plant might be expected to reach the expected oxygen production rates of $0.30-0.50 \mathrm{wt} \%$. A clear outcome of Task 2 of this project is that at this level of performance the benefits of the CAR technology would be marginal over cryogenic ASUs in the retrofit oxy-fuel power plant application.

Whilst the necessary modifications were being made to integrate the CAR PDU with the WRI Combustion Reference Facility (CTF) it was agreed with the DOE project manager that air fired tests and oxy-combustion tests should be made in the CTF. Comparing oxy-combustion $\left(27 \% \mathrm{O}_{2}\right.$ in $\mathrm{CO}_{2}$ ) to air firing, high flue gas $\mathrm{CO}_{2}$ concentrations were observed with minimum $\mathrm{N}_{2}$ in-leak, lower $\mathrm{NOx}$ and $\mathrm{Hg}$ emissions but similar $\mathrm{SO}_{2}$ emissions, together with similar levels of unburned carbon in the fly ash, as well as similar temperature profiles and heat rejections. These results are described in detail in a presentation entitled, "Oxy-combustion versus air blown combustion of coal", that was made by T. Barton of WRI at the AIChE Annual Meeting in Salt Lake City, UT on November 6, 2007.

The CAR PDU and the WRI CTF were successfully tested in integrated fashion in June 2008. 


\section{Key Conclusions from CAR Power Plant Techno-Economic Study (Task 2)}

Techno-economic analysis of the CAR process in oxy-fuel combustion retrofit option using AEP's 450 MW Conesville, Ohio plant has been performed and parametric sensitivity using key variables determined. Details of the techno-ecomomic analysis performed by Alstom Power Technology Laboratories are described in the attached Task 2 Report.

Design of a large scale CAR unit has been completed to support the techno-economic assessment. Details of this Linde study are also given in the Task 2 Report.

The key results and conclusions are summarized below.

\subsection{Large Scale Design Considerations}

A multi-bed process cycle was developed that allows continuous air feed and purge flows to the system, thus eliminating the need for buffer storage as well as for idling of the machines.

A low pressure drop horizontal vessel design was developed to minimize power consumption.

Heat is retained in the system by the use of inert thermal regeneration layers placed directly above and below the active perovskite material within each bed. This not only enables efficient heat transfer between the cold inlet streams and the hot streams exiting the beds, reducing the requirement for external heat input, but also enhances the efficiency and reliability of the process stream switch over valves by minimizing the temperatures at which they must operate.

\subsection{CAR System Techno-Economic Analysis.}

The oxygen production power costs and total retrofit costs associated with the various CAR options evaluated in this study together with those of the updated ASU base case are depicted in Figures 6 and 7, respectively. In total 8 cases were evaluated:

The Base Case - Air fired "business as usual" without $\mathrm{CO}_{2}$ recovery;

Case $1-\mathrm{O}_{2}$ fired retrofit (cryogenic type ASU) adapted from the original OCDO study (2001) with $\mathrm{CO}_{2}$ recovery - for reference only;

Case 2 - Update of Case 1 to "state of the art" cryogenic ASU and gas processing unit (GPU) with $\mathrm{CO}_{2}$ recovery - the Benchmark Case;

Cases $3 a, 3 b, 3 c-O_{2}$ fired retrofit using the CAR process, with flue gas as the sweep gas for the CAR unit, with $\mathrm{CO}_{2}$ recovery;

Cases $4 \mathrm{a}, 4 \mathrm{~b}-\mathrm{O}_{2}$ fired retrofit using the CAR process, with steam used as the sweep gas for the CAR unit, with $\mathrm{CO}_{2}$ recover 


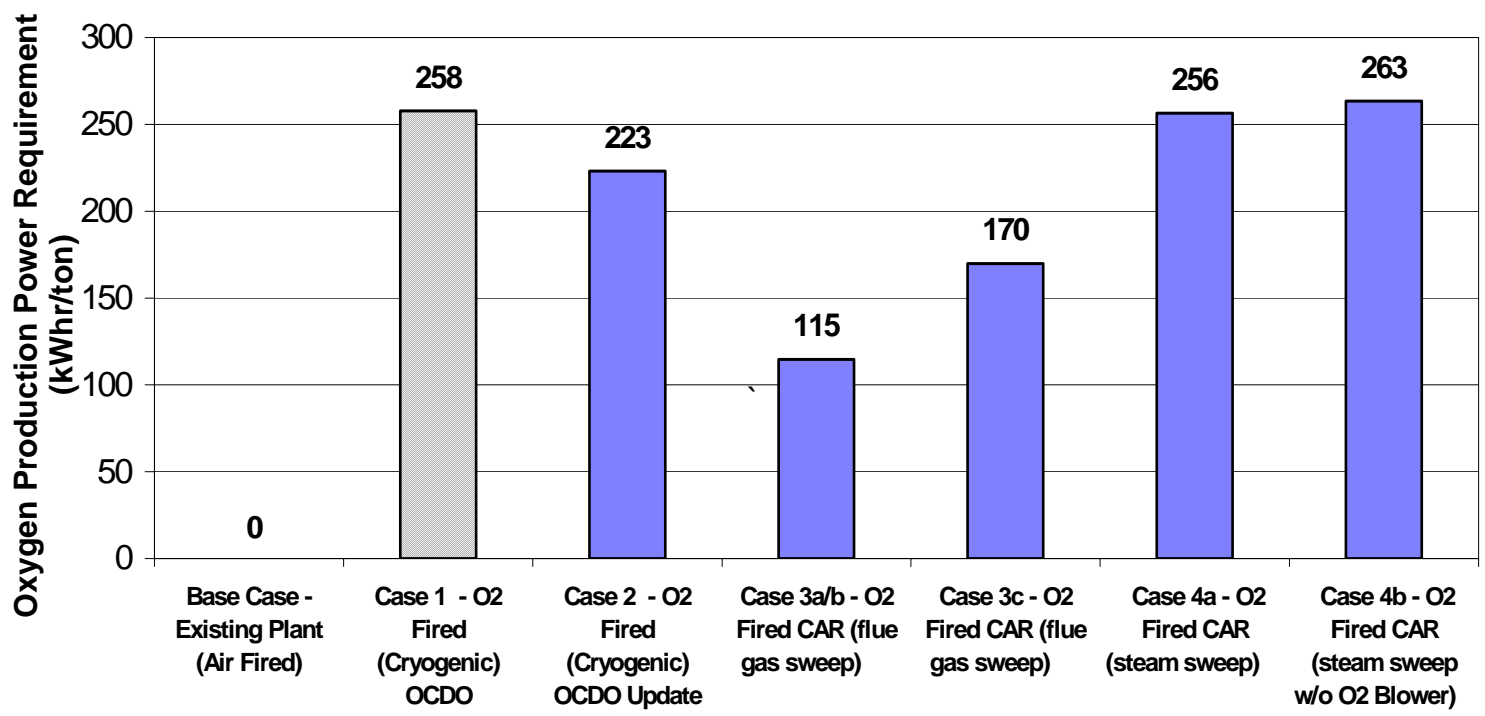

Figure 5: Oxygen Production Power Requirement

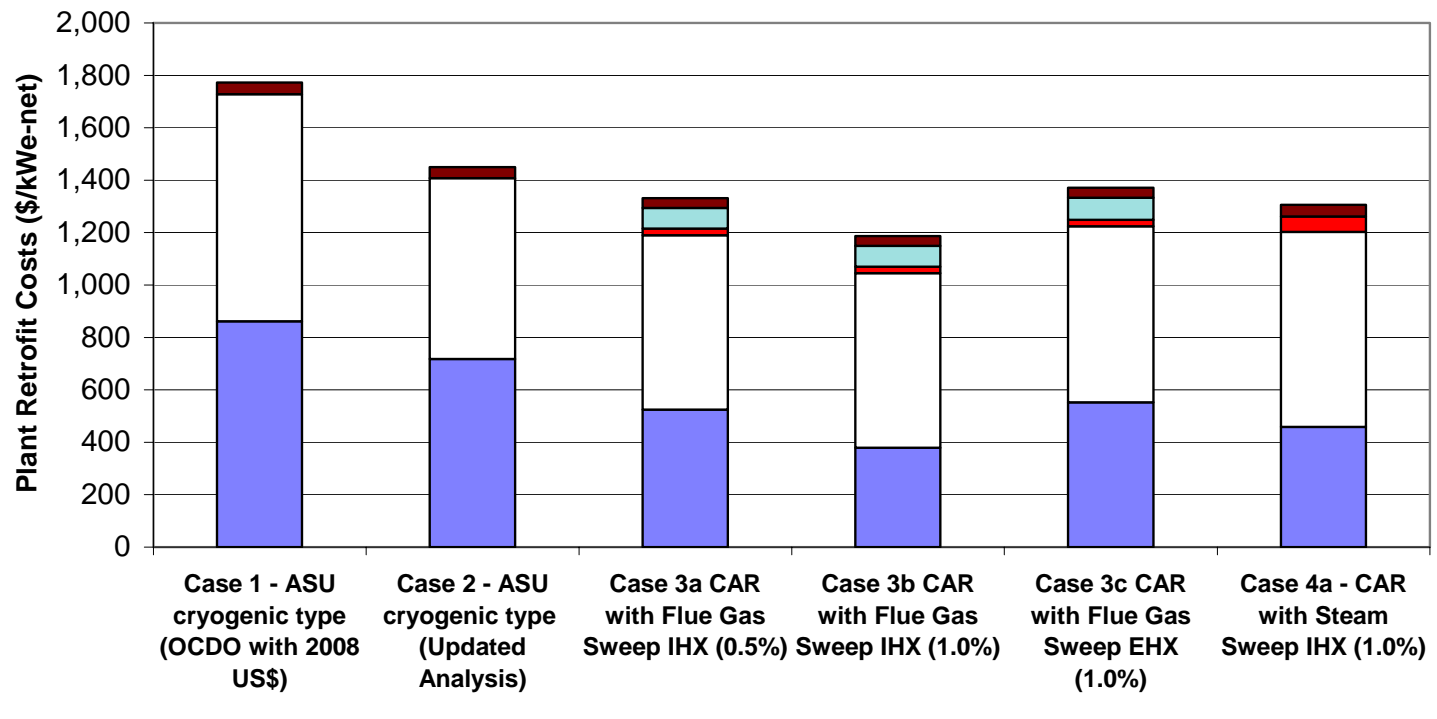

$\square$ Oxygen Production $\square$ Gas Processing Unit $\square$ Letdown Turbine Generator $\square$ Secondary FGD $\square$ Boiler Modifications

Figure 6: Retrofit Costs (Basis - March 2008 US\$)

CAR-3b utilizing flue gas sweep, internal heat exchangers and perovskite with the target $1.0 \%$ oxygen capacity was the best CAR case evaluated. In comparison with the benchmark ASU case, the specific $\mathrm{O}_{2}$ production power requirement is almost $50 \%$ less, the specific $\mathrm{O}_{2}$ production cost is about $40 \%$ less and the total plant retrofit cost is about $20 \%$ lower. At this performance level that corresponds to improved materials the CAR technology option is significantly better than the cryogenic ASU option in terms of both cost and performance. If this level of performance can be achieved then the CAR technology provides an attractive option for low cost oxygen supply. 
The equivalent CAR-3a case in which the effective oxygen capacity of the perovskite was reduced to $0.5 \mathrm{wt} \%$ (the best level of performance that has been consistently confirmed in laboratory experiments) shows substantially less cost advantage over the benchmark ASU case. This level of cost advantage is insufficient to justify the time and effort that would be required to scale up and commercialize CAR technology at this time.

The steam sweep CAR cases had both lower performance and higher costs than the equivalent flue gas sweep options as significant quantities of steam had then to be diverted from power generation. The use of internal regenerative heat exchange (IHX) was shown to be significantly more cost effective than the use of high temperature external heat exchange (ETX).

\section{Key Conclusions from Long Term Sulfur Exposure Studies (Task 4)}

A slip-stream test unit to measure the impact of flue gas exposure on CAR perovskite materials was assembled and tests completed with both high and low SOx containing flue gas. Details of these trials are reported in the attached Task 4 Report.

Exposure of the perovskite bed to high levels of flue-gas contaminants severely impacts CARprocess performance. $\mathrm{SO}_{2}$ is "sorbed" by perovskite (little was found in the product or waste streams), whereas NOx is found essentially only in the product stream. From analysis of the exposed materials it appears that surface sulfate formation may block the oxygen exchange reaction, leaving much of the perovskite intact, but unavailable for the CAR process.

Exposure of the perovskite to the $10 \mathrm{ppm}$ levels of SOx representative of some commercial fluegas sulfur removal options was also found to impact the performance of the perovskite.

Fundamental work is necessary to identify more sulfur tolerant oxygen transfer materials and/or means to effectively protect the CAR bed from flue-gas contaminants.

\section{Materials}

As part of the European Union funded ENCAP program more than one hundred different compositions were evaluated by BOC/Linde for use in the CAR process. These included: many different perovskites and perovskite-like compositions as well as reducible metal oxides and composites of these materials. The CAR-process performances of compositions containing high levels of alkaline earths, particularly barium, are much diminished in $\mathrm{CO}_{2}$ purge runs compared to LSCF compositions due to the formation of bulk or surface carbonates. Even for compositions less affected by $\mathrm{CO}_{2}$, temperatures greater than $750^{\circ} \mathrm{C}$ are needed in order to obtain good CARprocess performance in the presence of $\mathrm{CO}_{2}$. In contrast, many alkaline earth containing compositions behave well in steam purge runs, with maximums in performance at $600^{\circ} \mathrm{C}$. 
The oxygen sorbent materials used in the CAR-process trials and economic assessment of the current project were lanthanum (La), strontium (Sr), cobalt (Co), iron (Fe) (LSCF) perovskites. The reference material used in the initial PDU trials was an LSCF composition, BOC-2, that was extruded and then sintered into porous cylindrical pellets. Following extensive trials, another LSCF perovskite composition, BOC-10, and different sorbent geometry (hollow cylinders) was then selected for the CAR pilot plant trials within the EU funded ENCAP program and the key PDU trials undertaken in this project (see Task 1 Report). This powder composition was selected as it gave the best trade off in CAR rig performance versus chemical stability for use in the CAR oxy-fuel application and because it could be readily manufactured using well established commercial procedures. Pellets with an open porosity level of $25-35 \%$ were selected as this level gives the best trade-off between the CAR-process performance and the mechanical properties of the ceramic pellets on exposure to flue gas. The hollow cylindrical pellet shape was chosen as it can readily be extruded at commercial scale, is mechanically stable, and gives about a $50 \%$ higher gravimetric CAR-process performance than does the original geometry (full cylinders).

$150 \mathrm{~kg}$ of BOC-10 powder was prepared by a commercial supplier using new purpose-built pilot powder manufacturing equipment. Linde and its partners were then able to finalize plans for full scale production of perovskite powders and to make a more accurate cost estimate for production of large scale quantities of powder ( $€ 50-80$ per $\mathrm{kg}$ dependent on chemical composition and scale). The powder was extruded into the selected hollow cylindrical shape using a new extrusion tool purchased by Linde. Although pilot scale extrusion equipment was used for this scale-up trial, the extrusion tool itself was made by a commercial ceramics manufacturing company and is designed for use on full scale commercial extruders. We are confident that the current perovskite material can be manufactured at large scale and that sufficient manufacturing capacity could be brought on line in time to meet expected commercial needs. We have also had preliminary discussions with a well recognized US manufacturer of catalysts and adsorbents for producing LSCF perovskites to our specification and obtained pricing if commercial volumes are required. The prices obtained were used in the technoeconomic evaluations summarized in the Task 2 Report.

Low levels of sulfur in the flue gas sweep gas stream pose a more severe challenge to the materials used in the CAR process as the stability of metal sulfates is much higher than those of the corresponding carbonates. In addition to the studies summarized in the Task 3 Report, fundamental studies of the impact of sulfur containing impurities on the oxygen exchange properties of perovskite materials are being made by Linde and its partners in the ENCAP program.

Options for higher potential oxygen capacity materials have been evaluated; including materials that undergo phase transitions within the CAR-process envelope and reducible transition metal oxides supported on active, e.g., perovskite, or inert high surface area supports. Leading experiments have also been carried out to investigate more complex pellet geometries, such as massive monoliths. 


\section{Current Status of CAR Technology Development}

\begin{tabular}{|c|c|c|c|c|}
\hline $\begin{array}{l}\text { Performance } \\
\text { Attribute }\end{array}$ & & $\begin{array}{l}\text { Reference } \\
\text { Case }\end{array}$ & Current Best & Validation Comments \\
\hline $\mathrm{O}_{2}$ capacity Ref. case & $\mathrm{Nm}^{3} / \mathrm{h}$ & 400000 & 400000 & \\
\hline $\begin{array}{l}\text { Effective Oxygen } \\
\text { load }\end{array}$ & $\%$ wt. & 1 & 0.5 & Actual measurement $0.2-0.4$ \\
\hline Half cycle Time & $\mathrm{s}$ & 30 & 15 & $\begin{array}{l}\text { Results from PDU } \\
\text { experiments }\end{array}$ \\
\hline Adsorbent & $\mathrm{t}$ & 637 & 529 & \\
\hline Void fraction adsorbent & $\mathrm{m}^{3} / \mathrm{m}^{3}$ & 0.3 & 0.3 & \\
\hline Heat transfer material & $\mathrm{m}^{3}$ & 1045 & 1045 & \\
\hline $\begin{array}{l}\text { Void fraction heat } \\
\text { transfer material }\end{array}$ & $\mathrm{m}^{3} / \mathrm{m}^{3}$ & 0.6 & 0.6 & \\
\hline Rinse step flow* & $\begin{array}{l}\text { Mio. } \\
\mathrm{Nm}^{3} / \mathrm{h}\end{array}$ & 0.33 & 0.14 & \\
\hline Purge gas & & $\mathrm{CO} 2$ & Steam & \\
\hline Air/purge flow & vol. & 1,554 & 2 & $\begin{array}{l}\text { Negative influence on } \\
\text { temperature profile and NG } \\
\text { demand }\end{array}$ \\
\hline Purge/air flow & vol. & 0,643 & 0.5 & \\
\hline $\begin{array}{l}\text { Purge gas } \\
\text { contaminants }\end{array}$ & ppm & $<10$ SOx & 0 & $\begin{array}{l}\text { SOX retention on the bed at } \\
\text { low concentrations requires } \\
\text { change in bed material over } \\
\text { time. }\end{array}$ \\
\hline Adsorber temperature & ${ }^{\circ} \mathrm{C}$ & 800 & $\begin{array}{l}600 \text { (with } \\
\text { steam } \\
\text { regeneration) }\end{array}$ & \\
\hline $\begin{array}{l}\text { Ignition temperature of } \\
\mathrm{CH} 4 \text { on Perovskite }\end{array}$ & ${ }^{\circ} \mathrm{C}$ & 300 & 450 & $\begin{array}{l}\text { Mapag valves up to } 600 \text { are } \\
\text { available. Incorporation of } \\
\text { combustion catalyst with the } \\
\text { perovskites is expected to } \\
\text { reduce the ignition } \\
\text { temperature. }\end{array}$ \\
\hline Oxygen Recovery & $\%$ & 90 & 90 & \\
\hline $\mathrm{CH}_{4}$ conversion & $\%$ & 100 & & $\begin{array}{l}\mathrm{CH}_{4} \text { conversion at lower } \\
\text { temperatures than } 800^{\circ} \mathrm{C} \text { has } \\
\text { to be confirmed }\end{array}$ \\
\hline Pressure drop & mbar & 300 & 300 & \\
\hline $\begin{array}{l}\text { CAR adsorbent } \\
\text { material, Type }\end{array}$ & Type & BOC II & $\begin{array}{l}\text { Annular } \\
\text { cylinders } \\
\text { BOC- } 10\end{array}$ & $\begin{array}{l}\text { Annular shape for improved } \\
\text { kinetics. }\end{array}$ \\
\hline
\end{tabular}




\section{Overall Conclusions and Recommendations for Future Work}

Phase 1 of the project was completed and the associated reports prepared by 9/30/2008.

The team recommended not proceeding to phase 2 on the basis of:

- The overall cost potential compared to cryogenic ASU being nominal at current levels of performance.

- The risks related to both material and process scale up being still significant

The potential for CAR to achieve significantly lower overall costs compared to ASU remains (as highlighted by the Techno-economic parametric study) but this requires further materials and process development efforts prior to pilot testing.

\section{Project Overview: Budget and Timeline}

\subsection{Budget and Actual Spend:}

Total project funding DOE share:

Team share:

Phase 1 project budget: Project spend:Phase 1 Actual, Sep 30, 2008:

Actual DOE share:

Team share:
$\$ 6,132,613$

$\$ 4,906,089$

$\$ 1,226,524$

$\$ 1,467,090$

$\$ 1,335,554$

$\$ 1,068,443$

$\$ 267,111$

\subsection{Timeline:}

Project award date - April 1, 2006

Project kick-off date - June 16, 2006

Project phase 1 end date - Sep 30, 2008( $\left.{ }^{\star}\right)$

${ }^{*}$ ) following extension in Feb 2008. 


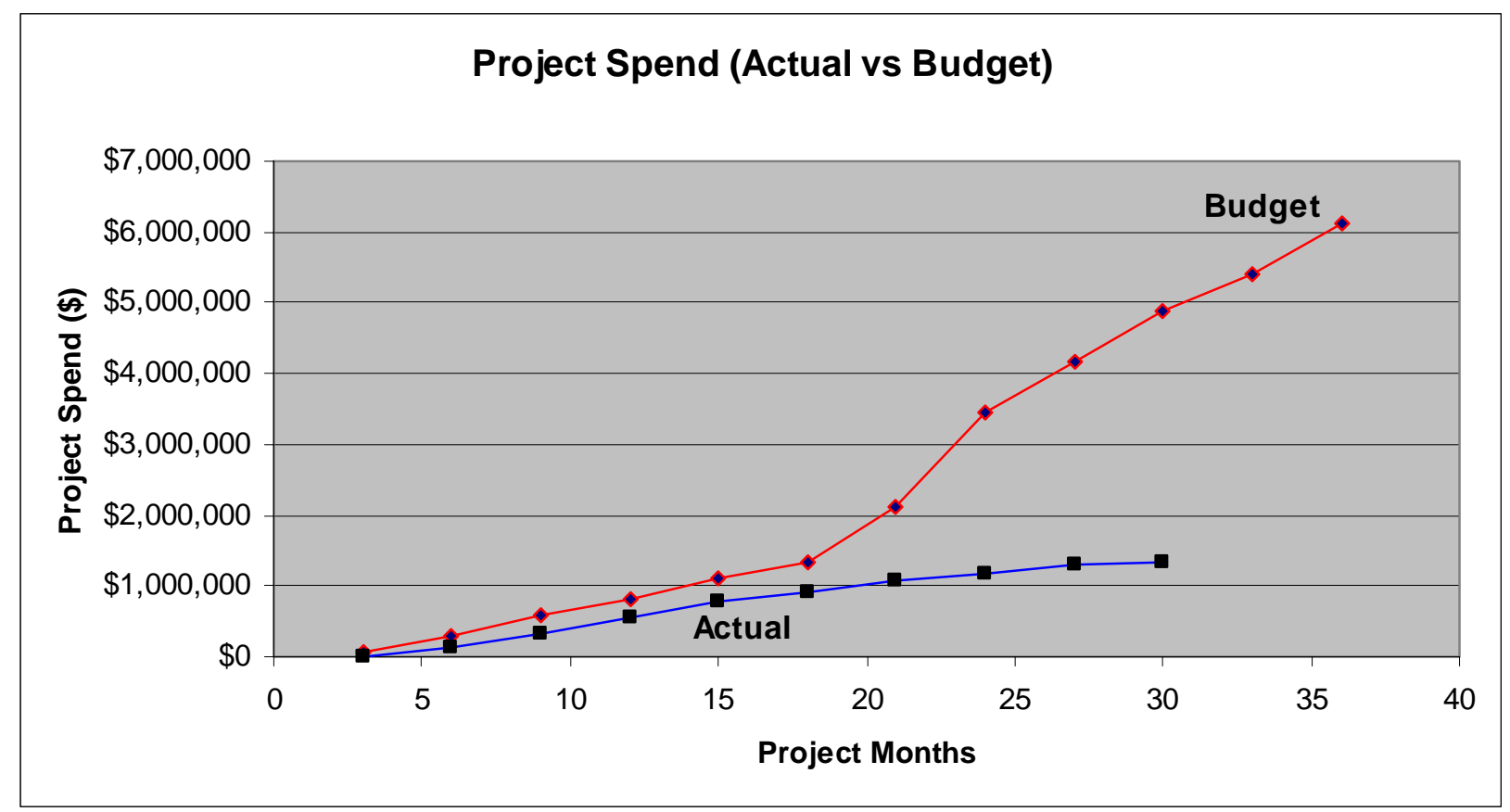

Figure 7: Project Spend versus Budget

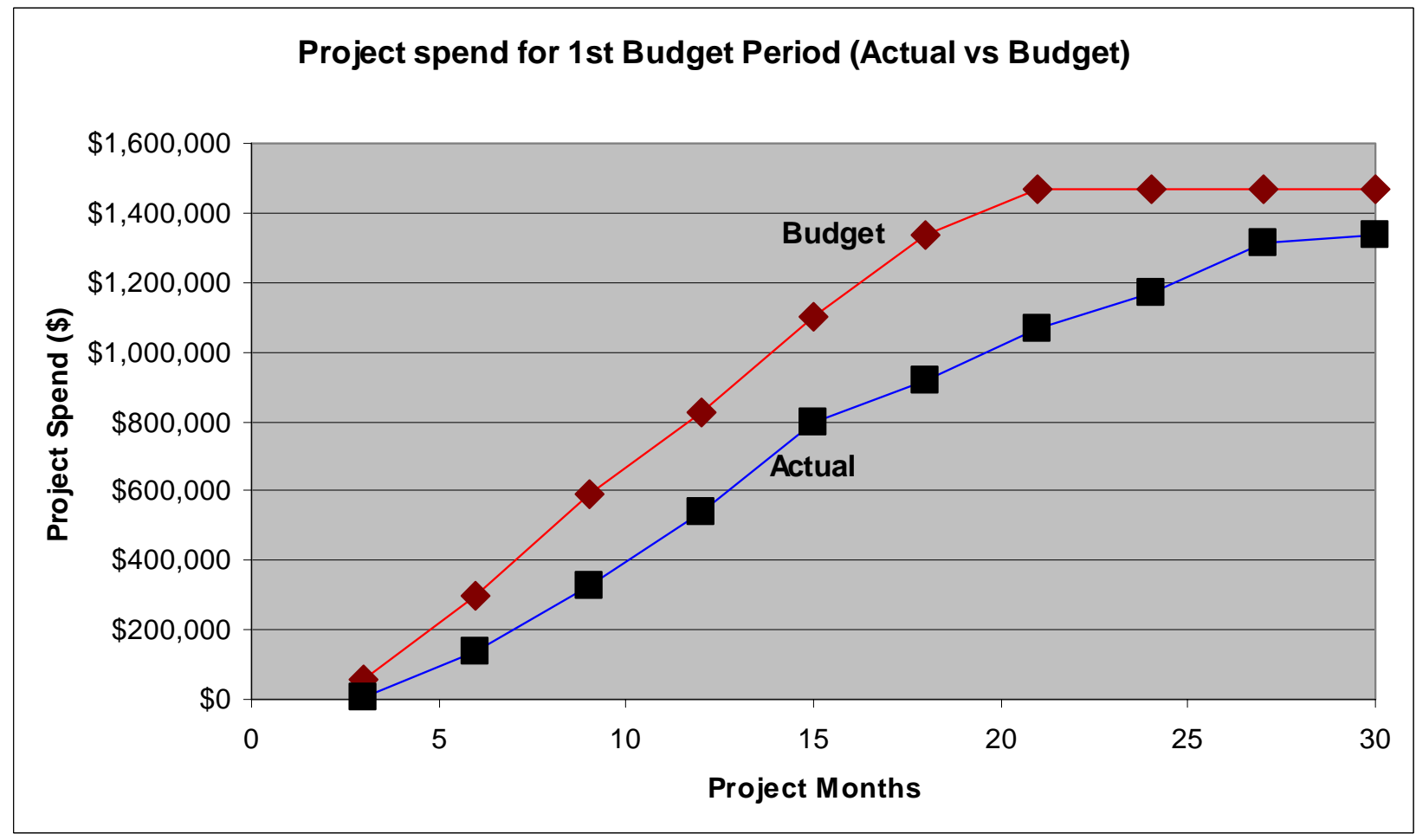

Figure 8: Project Spend versus Budget 


\section{Project Management:}

The Phase 1 of the project was implemented successfully by the main contractor BOC/Linde, Murray Hill, in close collaboration with the two sub-contractors, Western Research Institute, Laramie, WY and Alstom Power Plant Laboratories, Windsor, CT. There was also close engagement with the DOE Program Manager, Tim Fout as appropriate, throughout the project.

Several project meetings were held during the Phase 1 implementation at appropriate locations based on the leading task under consideration. Quarterly project reports were submitted to DOE/NETL in a timely manner.

A final project review meeting was held in the Pittsburgh DOE/NETL office on September 25, 2008.

In addition to the Quarterly Project Reports, Task reports and this project final report, the following presentations were made by the project team members:

1. "Demonstration of a Novel, Low-Cost Oxygen Supply Process and its Integration with Oxy-Fuel Coal-Fired Boilers" was made in the technical session on "Clean Coal Burning Facilities", in the Sixth Annual Conference on Carbon Capture \& Sequestration held in Pittsburgh, PA, May 7, 10, 2007.

2. "Oxy-Combustion Versus Air-Blown Combustion of Coals" was made at the Clearwater Coal Conference in June 2007.

3. "Oxy-combustion versus air blown combustion of coal", was made at the AIChE Annual Meeting in Salt Lake City, UT on November 6, 2007.

A presentation on project status and plans was also made at the Carbon Sequestration Peer Review held by DOE/NETL in Pittsburgh, PA on September 19, 2007. 


\title{
Pilot Scale Demonstration of a Novel Low Cost Oxygen Supply Process and its Integration with Oxy-Fuel Coal Fired Boilers
}

\author{
Department of Energy - DE-FC26-06NT42478
}

\section{Task 1 Final Report}

Report Title: $\quad$ CAR Process Development Unit (PDU) Testing Program

Report Authors: Thomas F. Barton and Beau D. Braunberger

Western Research Institute, Advanced Technology Center, 350 North $9^{\text {th }}$ Street, Laramie, Wyoming 82072-3380

Date Prepared: $\quad$ September 29, 2008 


\section{Task 1 Report: CAR Process Development Unit (PDU) Testing Program}

\section{INSTALLATION AND OPERATION}

\section{$\underline{\text { CAR Process Development Unit Installation }}$}

The PDU unit of the CAR system was delivered to WRI in August of 2006. The unit was moved into place and all attachments were made for power, computer control, internet access, carbon dioxide, air, nitrogen, natural gas, and vent lines. Initial shakedown showed that additional airflow was required so a second compressor was installed.

\section{$\underline{\text { PDU Shakedown }}$}

Staff from BOC/Linde came to WRI to assist in the installation and shakedown of the PDU unit. The ceramic material for the absorption beds was reinstalled. All heaters, flow controllers, pressure control and safety systems were tested for safe operation. The logic control system (PLC) was turned on and communications between the control computer and the PLC were checked. Initial tests included beginning flow of air and carbon dioxide through the flow control systems and the absorption vessels. When flow was established the heaters were slowly brought up in temperature and the thermocouple systems checked for data collection. Within a short time, and after minor alterations and hardware adjustments, all systems were found to be within operational parameters. Eventually computer access on line was established so that BOC/Linde staff could monitor the unit remotely.

\section{$\underline{\text { PDU Testing }}$}

The oxygen is separated from the air stream using a perovskite ceramic material at high temperature $\left(800-900{ }^{\circ} \mathrm{C}\right)$. The unit contains two separate beds that are cycled to deliver the oxygen flow (one bed is adsorbing the oxygen while the other is desorbing). The oxygen is desorbed from the catalyst by a partial pressure swing using a purge gas containing low levels of oxygen; in standard runs $\mathrm{CO}_{2}$ was used for this purpose. Half cycle times are varied for most efficient operational parameters, but fall in the 30-second to 1-minute range. During typical operation, the process parameters are as follows:

\begin{tabular}{|l|l|}
\hline Process Parameter & Typical Range \\
\hline Inlet Air Flow & $45-70$ SCFM \\
\hline Inlet $\mathrm{CO}_{2}$ Flow & $40-50$ SCFM \\
\hline Air Heater Outlet Temperature & $700^{\circ} \mathrm{C}$ \\
\hline $\mathrm{CO}_{2}$ Heater Outlet Temperature & $575^{\circ} \mathrm{C}$ \\
\hline Methane Flow for Warm-Up & 1.5 SCFM per bed \\
\hline Methane Flow to Maintain Temperature & 0.5 SCFM per bed \\
\hline Cycle Time & $30-60$ seconds per side \\
\hline
\end{tabular}

Table 1: Typical Process Parameters 
The main features of the PDU are illustrated in Figures 1 and 2.

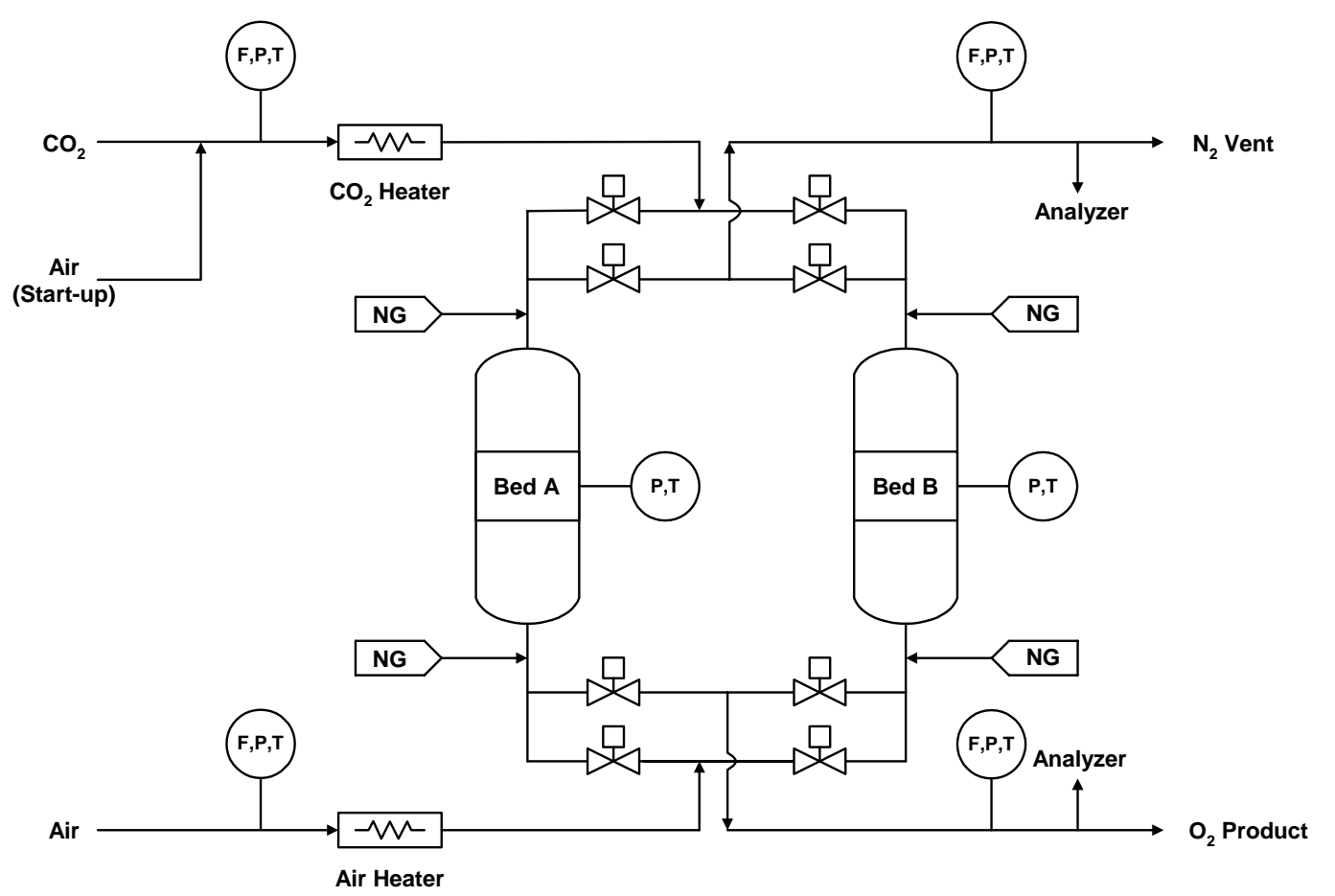

Figure 1: Schematic of CAR Process Development Unit (PDU)

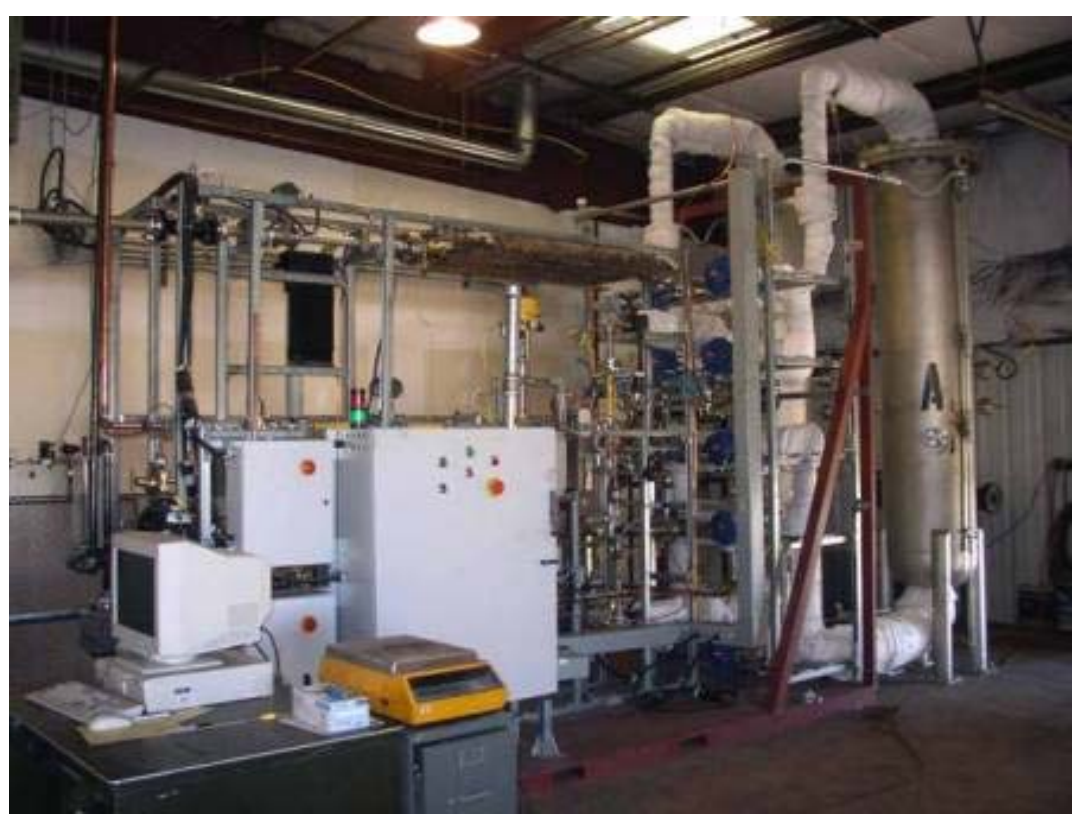

Figure 2: CAR Process Development Unit installed at WRI 
Multiple temperatures are monitored in the catalytic bed. These are spatially placed to give an accurate representation of the bulk temperatures in the ceramic bed. The thermocouple locations are illustrated in Figure 3 (these locations are used to show the temperature profiles during normal operation).

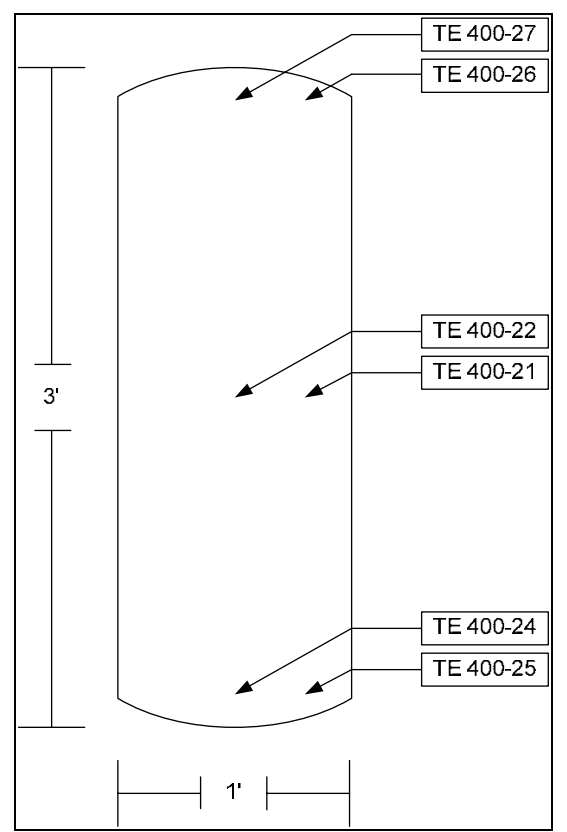

Figure 3: Ceramic Bed Thermocouple Location

The initial phase of startup involves heating the ceramic bed to an adequate temperature to burn a mixture of sub-LEL methane in air. This is achieved using an electric flowthrough air heater. A bulk temperature of about $450{ }^{\circ} \mathrm{C}$ must be reached in the beds to meet this requirement. Figure 4 shows a typical time-temperature profile for this phase of startup.

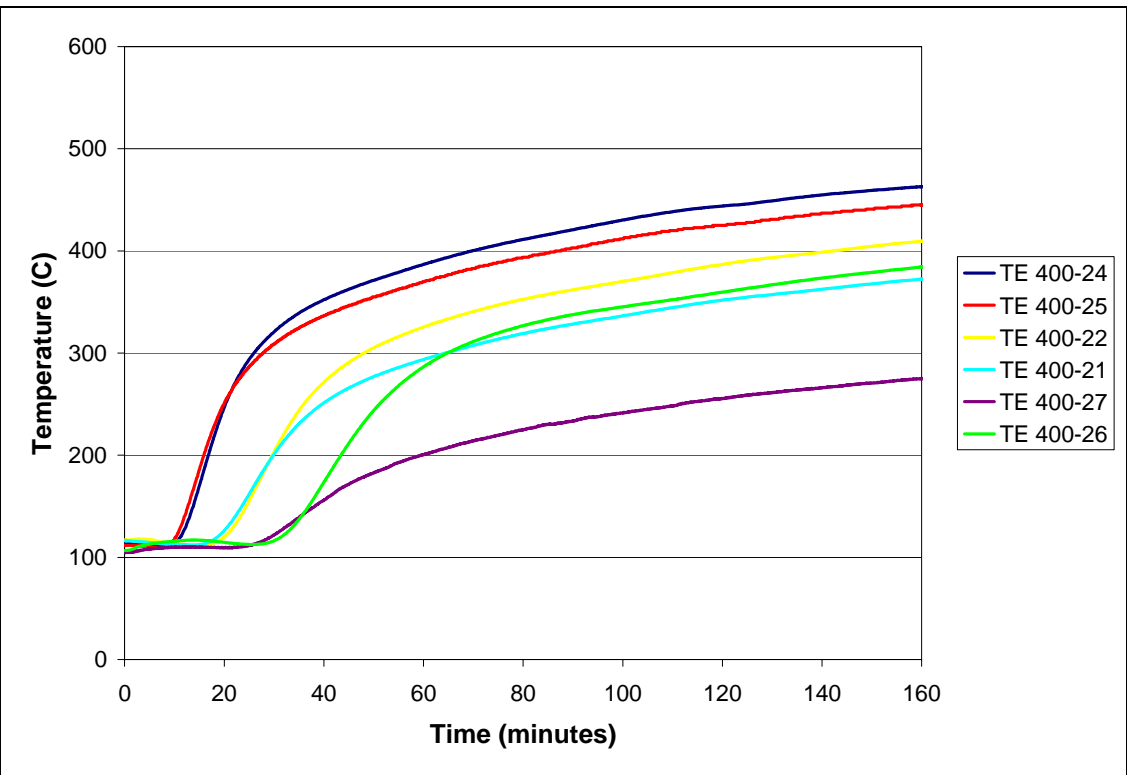

Figure 4: Pre-Methane Warm up Temperature Profile 
Once the ceramic bed reaches adequate temperatures, methane is introduced at low concentration (2-3\% by volume) to heat the bed up to operational temperatures.

Although this concentration of methane is less than that required for normal combustion, the bed material has some catalytic ability for combustion. Temperatures of $800-900{ }^{\circ} \mathrm{C}$ must be reached in the bed to maintain proper temperatures when cycling is started. Figure 5 shows a typical time-temperature profile for the ceramic bed under methane heating.

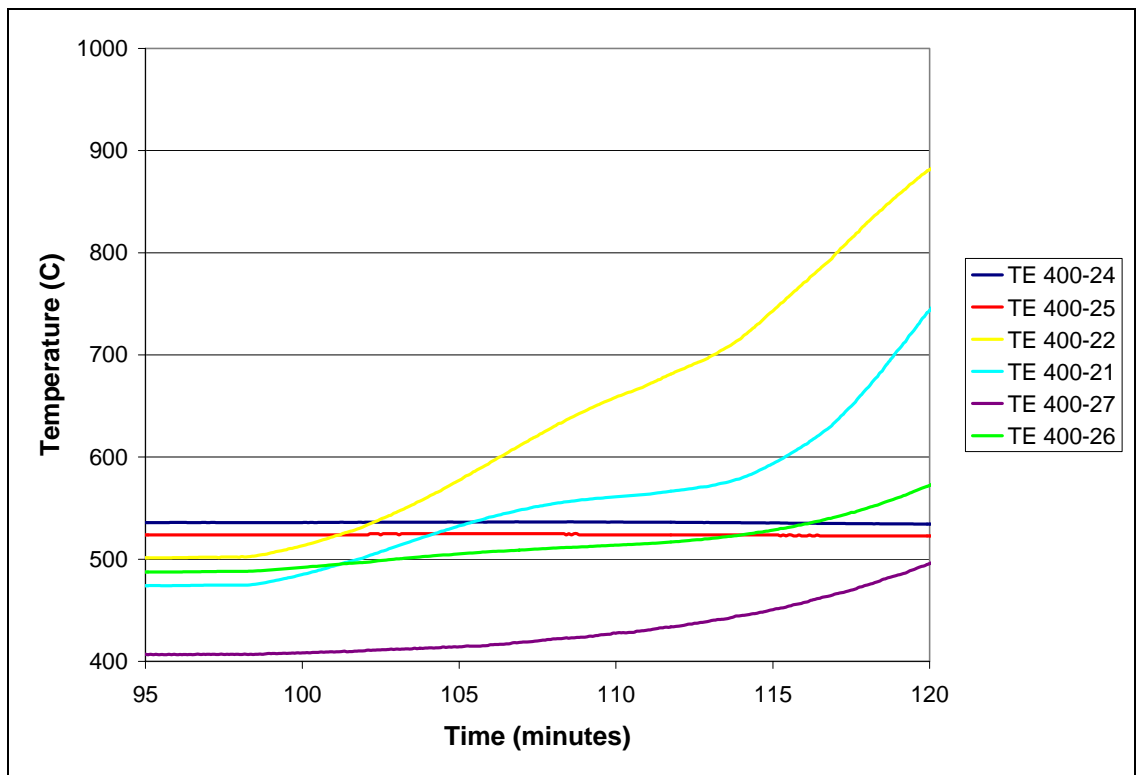

Figure 5: Methane Warm up Temperature Profile

After the ceramic bed reaches the proper temperatures, cycling is initiated. Air is introduced to one bed flowing from bottom-to-top, while $\mathrm{CO}_{2}$ is introduced to the other flowing top-to-bottom. This pattern is cycled between the beds with a half cycle time of 30 to 60 seconds. Methane flow is maintained, but the concentration is adjusted to hold the average bed temperature steady. Figure 6 shows a typical temperature profile for a cycling bed, while Figure 7 shows the system oxygen output normalized to the average value in the product stream. 


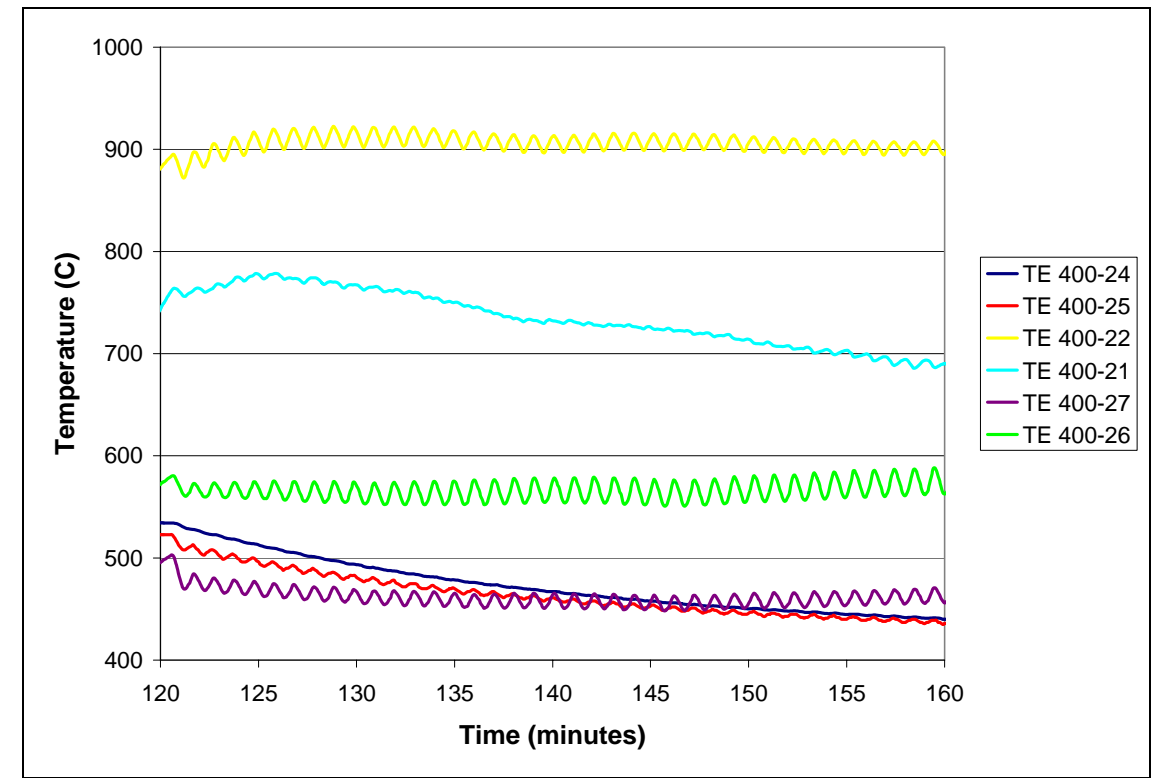

Figure 6: Cycling Bed Temperature Profile

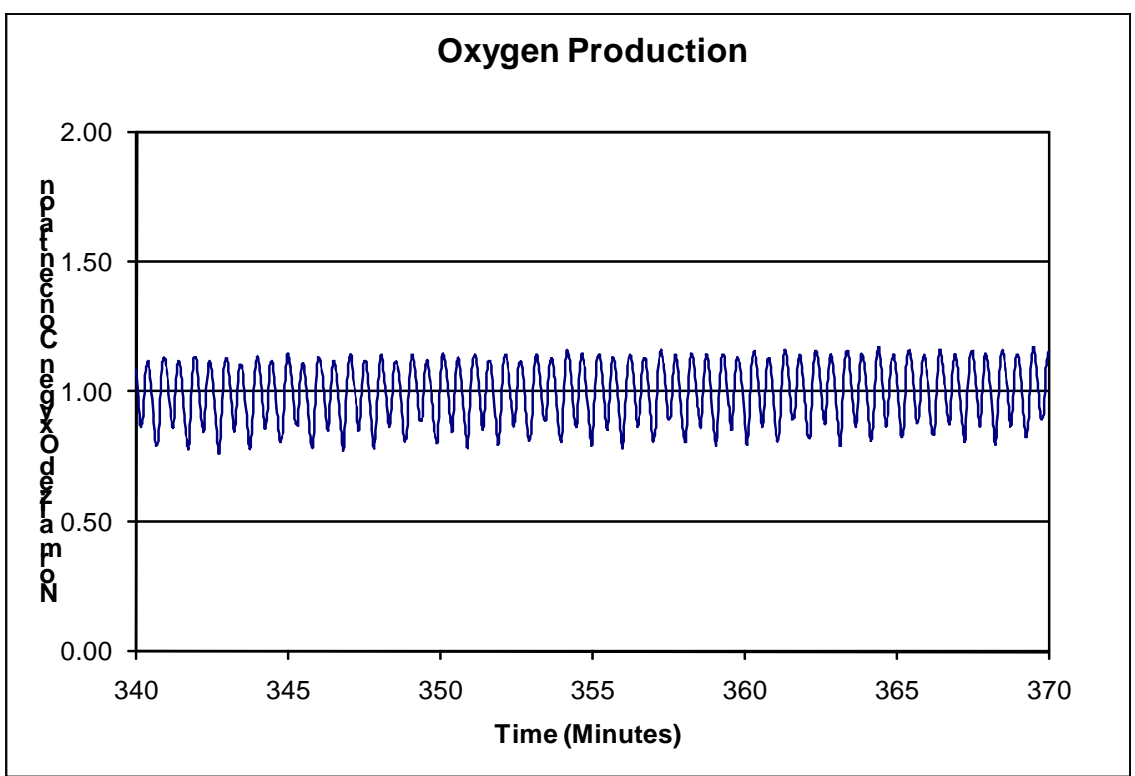

Figure 7: Cycling Bed Oxygen Production

Two bed cyclic steady state operation at high temperatures $\left(\sim 850^{\circ} \mathrm{C}\right)$ on the CAR PDU was achieved in early January 2007. Similar temperature profiles and oxygen production levels were achieved in both beds. This phase established the overall feasibility of the start-up, normal operation and shut down sequences of the system. The methane injection system to generate combustion heat in the system enabling the start-up sequence and to maintain the perovskite bed at high temperature by compensating for the heat loss from the system has also been demonstrated on a consistent basis. However, one of the key issues with the current mode of operation was the inability to achieve high temperatures uniformly throughout the perovskite bed. Uniform temperatures are critical in order to achieve good oxygen adsorption capability and achieve required productivity and product oxygen concentration. 
The focus of early investigations on the CAR PDU was heat balance throughout the beds, determining critical factors such as methane injection and flow rates of air and carbon dioxide.

During those experiments, work was conducted to gather mass balance data for oxygen in the system. Leak checks were made by flowing carbon dioxide through one side of the system and air through the other and recording flow-rates. Carbon dioxide concentration and oxygen concentrations were monitored to determine whether there are any leaks across the high temperature valves. Testing showed that leaks were less than $3 \%$ of total flows. By recording inlet flow rates and outlet flows and concentrations at temperature, determinations were made concerning the amount of oxygen being absorbed on each bed, and production rates of oxygen as $\mathrm{CO}_{2} / \mathrm{O}_{2}$ flows. The Nova gas analyzer was regularly calibrated and the concentrations recorded on the Nova were confirmed using separate GC injections. Variations in the mass balance oxygen data were a result of the frequent switching of flow directions accompanied by a lag between gas exiting from the beds and reaching the Nova analyzer. Oxygen concentrations also cycled during each switch of gas flow direction. Mass balances for oxygen were done on an instantaneous basis as well as an averaged basis for comparison. On line analysis and samples taken for gas chromatography were used to determine the best mass balance numbers for oxygen production. Dead volume within the system and leakage rates through valves were estimated for the mass balance calculations. Mass balance was achieved within $2 \%$ for the total gas flow, and less than $5 \%$ for individual gases.

\section{VERTICAL HEAT CONTROL}

Methane injection from the bottom of each bed during the air feed step was sufficient to bring a volume of the bed to operational temperatures between 800 and $900^{\circ} \mathrm{C}$. It was usually the top of each bed that reaches those temperatures first. During cycling, the hottest portion of the bed moves to the middle of the bed volume regardless of whether methane is injected from the top or bottom, though the time for the hot spot to move may be as much as an hour. Only under conditions where airflow from the bottom of the beds is nearly twice the carbon dioxide flow from the top will the heat return to the top of the bed. A conclusion from these experiments is that with the current PDU design, the thermal masses above and below the active portions of the beds were not able adequately to control the vertical temperature profiles in the PDU beds. 


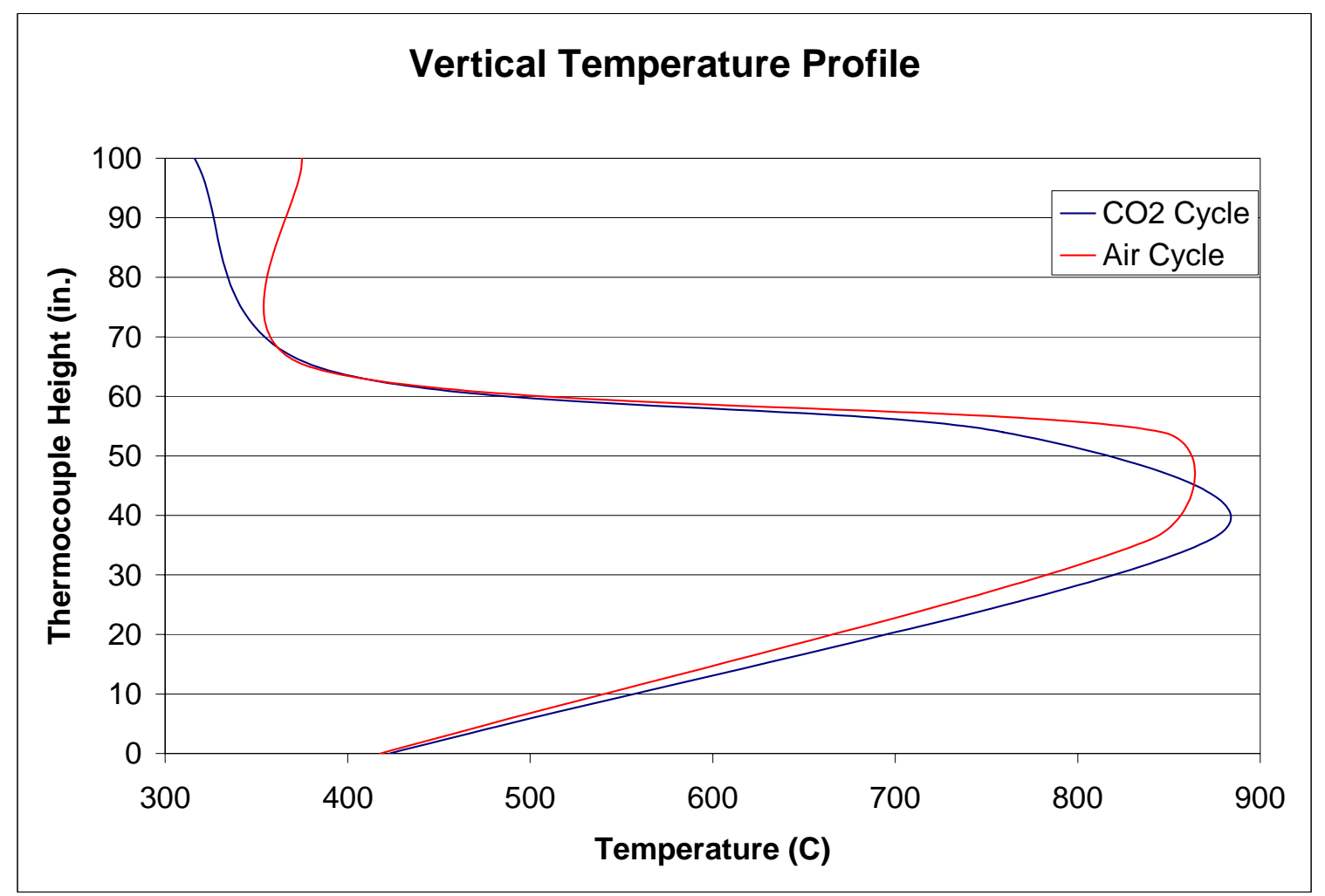

Figure 8: Vertical Temperature Profile in PDU

A number of experiments were conducted to show that it was possible to move the location of the hottest portion of the bed by un-balancing the inlet flows increasing $\mathrm{CO}_{2}$ flow and decrease the air flow to move heat down. This is illustrated in Figure 9. Some vertical heat control was also achieved through methane injection. Injection of methane from the top of the bed increases the temperature at the top more dramatically. The same is true for injection from the bottom.

Additional tests were conducted to improve the distribution of heat within the beds vertically during operation. Limitations imposed by the flow rate controls for air and carbon dioxide and methane injection rates and methane injection points prevented us from achieving more uniform temperatures throughout the entire vertical range.

The amount of active ceramic material in the bed was increased by a factor of 0.5 to improve overall oxygen production and assist in obtaining more uniform heat control. Some modest improvement was noted.

In a larger scale plant the vertical temperature profiles in the beds could be better controlled by manipulating the catalytic activity of the packing at different locations in the bed as well as by optimization of the upper and lower thermal masses relative to the perovskite mass for the given process flow rates. 


\section{Bed A Time-Temp Profile}

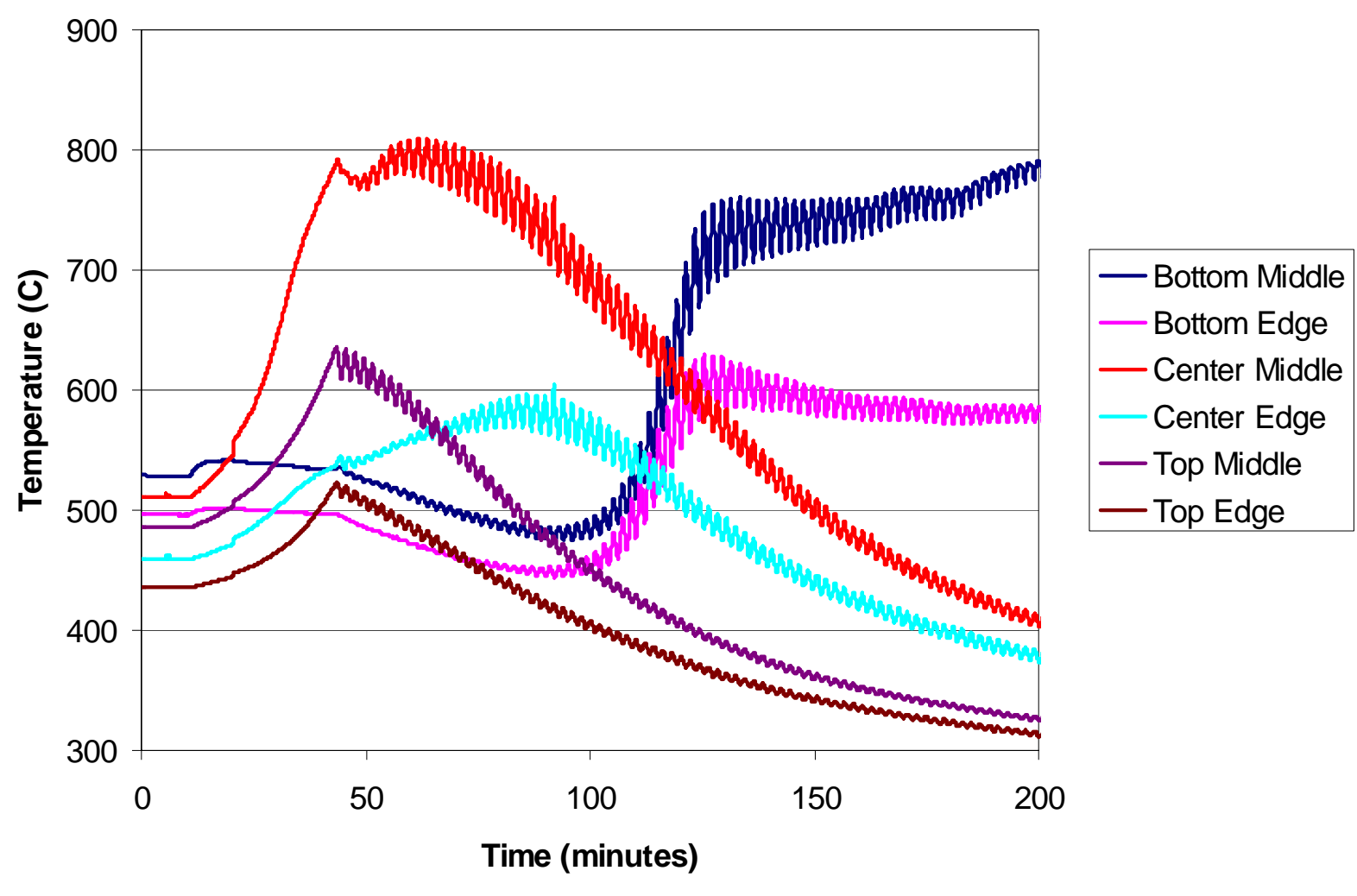

Figure 9: Movement of “Hot-Spot” by Adjustment of Gas Flow Rates

\section{RADIAL HEAT CONTROL}

Given the limitations by which the temperature profiles could be controlled in the vertical dimension, emphasis was then placed on radial heat control within the CAR PDU. The beds in the PDU are long and narrow compared to those that would be utilized in commercial designs. This led to substantial heat losses through the walls of the PDU beds. Loss of heat radially through the walls of the reactor vessels was quantified by completing a temperature distribution map of the outside walls of the unit. The skin temperature proved to be reasonably uniform but higher than original models predicted. Blankets of thermal insulation increased skin temperatures and modestly improved temperatures at the edge of the perovskite beds relative to the core temperatures. Improvements to the oxygen production noted during operation were marginal.

\section{EFFECTS OF CYCLE TIME}

A series of runs were undertaken to minimize the half cycle time with the objective of maximizing the productivity of the system whilst still maintaining stable operation. The part cycle time was successfully reduced from 60 seconds to 30 seconds and then to 20 
seconds. At 15 seconds part cycle time it was difficult to maintain system stability due to the time lag in actuating and stabilizing the methane flows.

\section{EFFECTS OF PROCESS TEMPERATURE}

Increasing the maximum bed temperature in the PDU from about $850^{\circ} \mathrm{C}$ to about $925^{\circ} \mathrm{C}$ did not give a significant performance improvement. Higher process temperatures had been observed to improve performance in the bench scale CAR experiments using the same sorbent materials.

\section{HIGHER PRESSURE}

A test with higher air feed pressure was successfully completed. Although this showed the expected higher performance of the perovskite sorbent with the greater oxygen partial pressure swing in the process, a high level of leakage through the high-temperature valves between the feed air and "product" streams made the results of limited validity.

\section{OXYFUEL COMBUSTION TESTS}

Whilst the necessary modifications were being made to integrate the CAR PDU with the WRI Combustion Reference Facility (CTF) a series of air fired tests and oxy-combustion tests were made in the CTF. These latter tests were performed utilizing oxidant streams comprising mixtures of 21 and $27 \% \mathrm{O}_{2}$ in $\mathrm{CO}_{2}$.

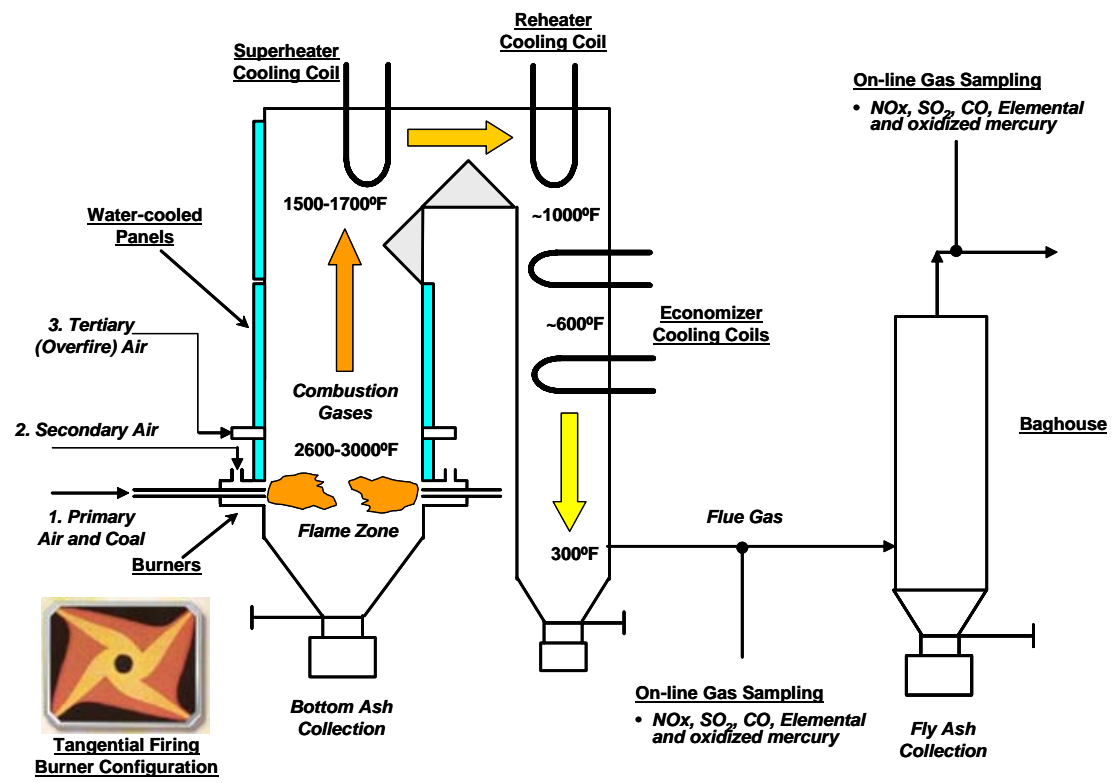

Figure 10: Schematic of Combustion Rest Facility (CTF)

Oxy-combustion versus air-fired tests were performed utilizing 3 different coals, with constant mass flow rates, constant burner stoichiometric ratios and with minimal air infiltration. Comparative temperature and heat transfer profiles, and, emission measurements were measured. 
Comparing oxy-combustion ( $27 \% \mathrm{O}_{2}$ in $\mathrm{CO}_{2}$ ) to air firing, high flue gas $\mathrm{CO}_{2}$ concentrations were observed with minimum $\mathrm{N}_{2}$ in-leak, lower NOx and Hg emissions but similar $\mathrm{SO}_{2}$ emissions, together with similar levels of unburned carbon in the fly ash, as well as similar temperature profiles and heat rejections.

These results were described in detail in a presentation entitled, "Oxy-combustion versus air blown combustion of coal", that was made by T. Barton of WRI at the AIChE Annual Meeting in Salt Lake City, UT on November 6, 2007.

\section{CAR PDU Integration with the Combustion Test Facility (CTF)}

Major equipment for the flue gas recirculation loop was designed, procured, and installed. The recirculation loop consisted of a refrigerated drier to reduce both the suction temperature to the recirculation compressor to an acceptable limit as set by the manufacture and the corrosiveness of the re-circulating flue gas. Additional features were added to protect the compressor from possible liquid carry over and from fly ash particles. This was accomplished through the addition of a flash drum and a particulate filter upstream of the compressor. The compressor utilized was an oil-free gas compressor with internal components designed to handle corrosive gases (e.g., stainless steel valves).

The CAR PDU and the WRI CTF were tested in integrated fashion in June 2008. A schematic of the PDU integrated with the CTF is shown in the following figure.

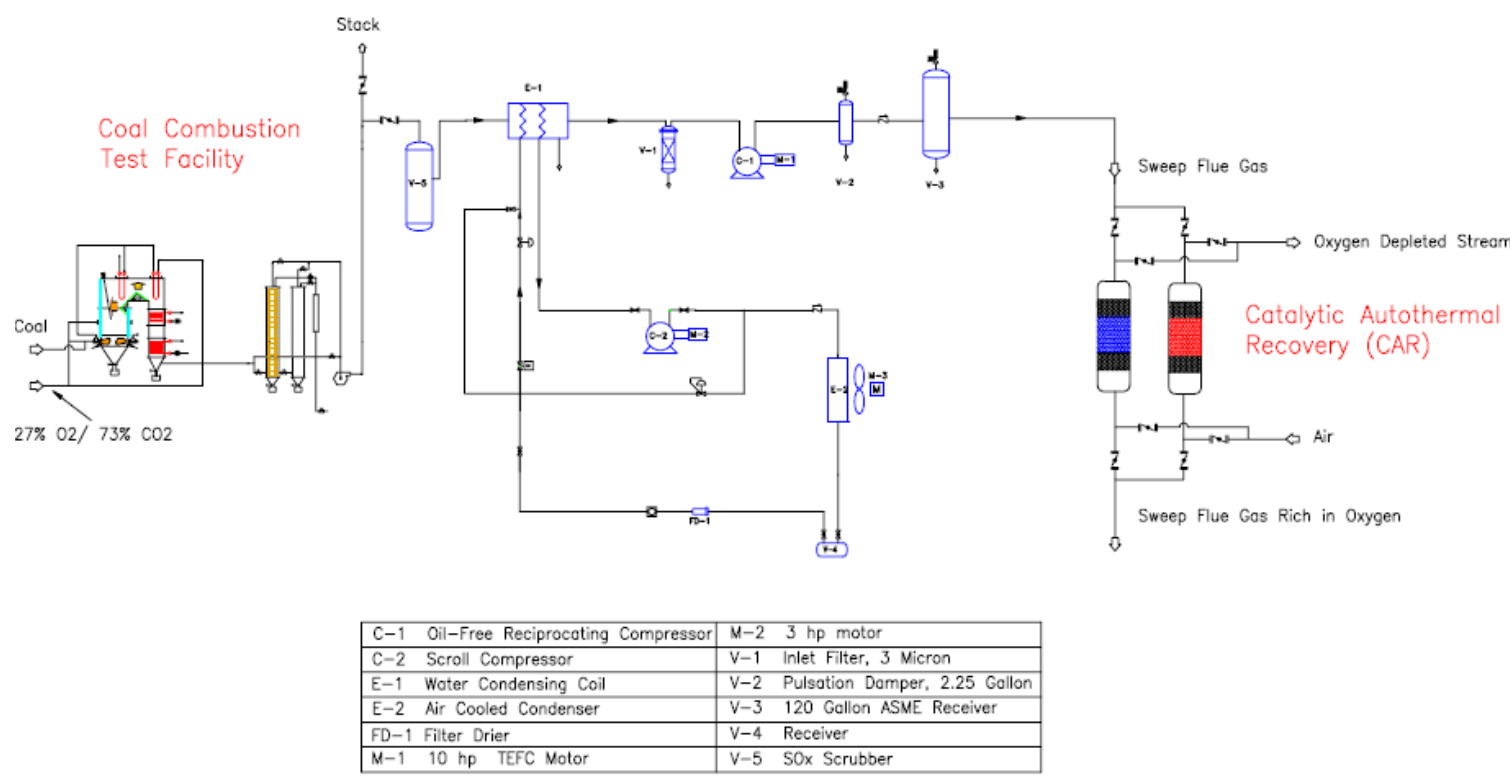

Figure 11: Integration of the CAR PDU with the WRI Combustion Test Facility

The CTF was operated on oxygen and $\mathrm{CO}_{2}$ provided by liquid tanks. The CAR PDU was operated on compressed air, while using the CTF flue gas for the sweep step of the cycle. The CAR beds were heated overnight using compressed air and the electric air heater. Once operation began, the beds were heated to temperature using natural gas as the fuel. The $\mathrm{CO}_{2}$ delivery system was operated only on flue gas for the duration of the test to 
conserve the cryogenic $\mathrm{CO}_{2}$ supply for the CTF operation. Since the CAR was being operated on flue gas, and there was a chance of sulfur contamination if the test ran too long, the cycling operation was limited to less than 3 hours.

Based on the following figures showing the time/temperature profiles for the catalyst beds, the bed temperatures were consistent with past testing. All composition data used for analysis was taken from the final portion of the testing time where the middles and tops of both beds are at operational temperature. This, too, was consistent with past CAR testing with a standard $\mathrm{CO}_{2}$ sweep. The air flow was operated at 61 SCFM while the flue gas sweep was 37 SCFM. These flows are lower than most previous tests. The flue gas flow rate was limited by the CTF combustion rates and flue gas delivery system. The cycle time was set at 30 seconds per half-cycle. This was the most common cycling time from previous testing.

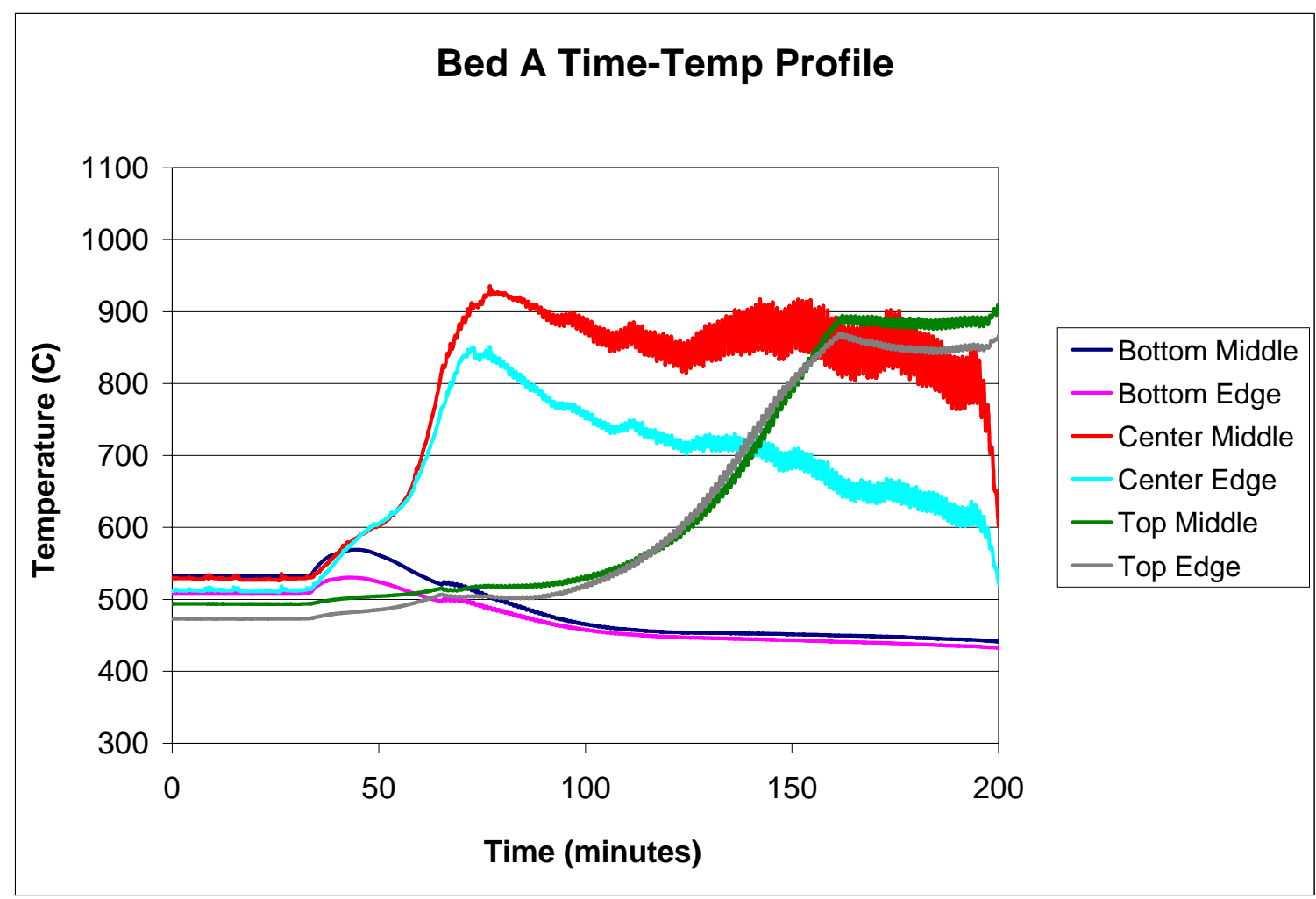

Figure 12: Temperature Profiles in CAR PDU Bed A during CTF Integrated Tests 


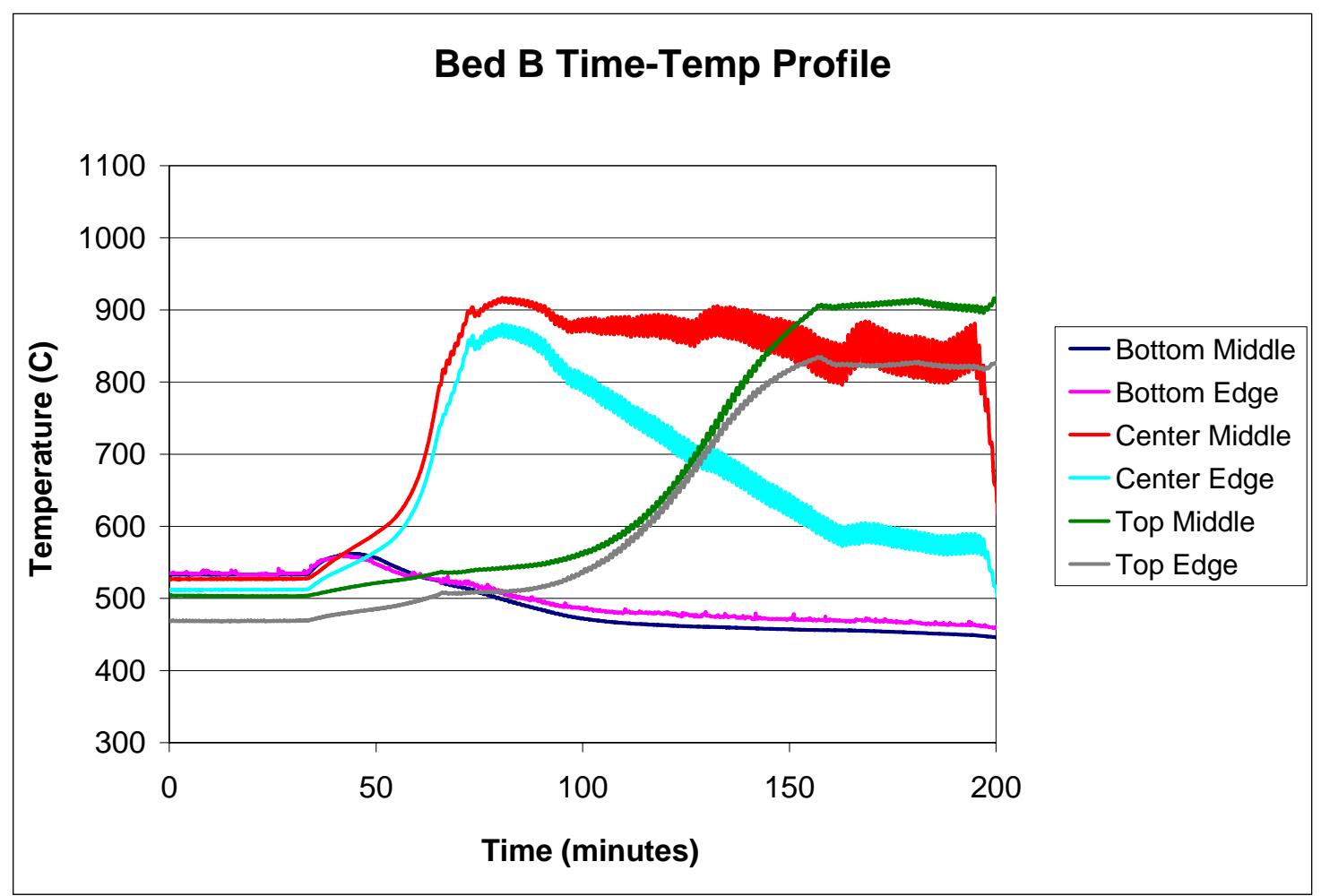

Figure 13: Temperature Profiles in CAR PDU Bed B during CTF Integrated Tests

A mass balance was prepared for the test using the same methods as previous tests. GC samples were taken from the flue gas inlet for composition data, and for the product and vent lines for NOVA accuracy verification. For the purpose of the mass balance, GC data was used for the flue gas inlet composition. NOVA data was used for the product and vent compositions. The GC data was within a couple percent of the NOVA data for all gases, showing that the NOVA data is reasonably accurate.

Based on linear extrapolation of previous mass balance data (higher flow rates were used in previous tests, but weren't possible with the flue gas delivery system) a perovskite produced oxygen volume of 3.5 SCFM was expected at the given flow rates of air and flue gas. After correction for valve leakage the gross oxygen production rate was in line with these expectations (c. 3.9 SCFM). The flue gas purge used had a typical oxygen concentration (c. 4\%). This introduced a limit to the lower oxygen partial pressure level possible in the process. After allowance for the oxygen in the purge stream the net oxygen produced by the perovskite was c. 2.5 SCFM.

In addition to the usual NOVA and GC data, the flue gas inlet and product streams were analyzed for trace gases $\left(\mathrm{CO}, \mathrm{NO}_{\mathrm{x}}\right.$, and $\left.\mathrm{SO}_{2}\right)$ using a Testo $350-\mathrm{XL}$ flue gas analyzer. This analysis was performed to determine the effect of the CAR perovskite on trace contaminant concentrations, and to verify that the unit was not exposed to any sulfur. On average, the flue gas feed contained about $9.8 \mathrm{ppm} \mathrm{CO}$, while the product stream contained $7.4 \mathrm{ppm}$. The $\mathrm{NO}_{\mathrm{x}}$ concentrations showed the opposite trend with the feed gas showing $178 \mathrm{ppm}$ and the product showing $195 \mathrm{ppm}$. Since the feed and product concentrations were taken at different times during the test, variations in the average concentrations being delivered from the CTF could have caused all of the variation. 


\title{
Technical Report
}

\begin{abstract}
Power Plant Laboratories
Research and Technology

2000 Day Hill Road

Windsor, CT 06095, USA

Tel.: (860) $285-4833$ or 2018

Fax: (860) 285-3473

Project Leaders: $\quad$ Gregory N. Liljedahl and Nsakala ya Nsakala

Project Name:

Pilot-Scale Demonstration of a Novel, Low-Cost Oxygen Supply Process and its Integration with Oxy-Fuel Coal-Fired Boilers

Document Title: $\quad$ Techno-Economic Analysis of the Retrofit of AEP Conesville Unit \#5 with $\mathrm{O}_{2}$ Firing via the Linde Ceramic Autothermal Recovery (CAR) Process
\end{abstract}

Document Ref. No.: $\quad$ PPL Report No. PPL-08-CT-15

Date of Issue: $\quad$ August 22, 2008

No. of pages: 143

Client:

Linde BOC Process Plants LLC

575 Mountain Avenue

Murray Hill NJ 07974

Author(s): $\quad$ Gregory N. Liljedahl and Nsakala ya Nsakala

Distribution:

Glen Jukkola, John Marion, Jean-Francois Leandri, Allen Pfeffer, Nancy Mohn, Ray Chamberland, Jean-Claude Semedard, Pierre Gauville

Keywords: $\quad$ Carbon Sequestration, $\mathrm{CO}_{2}$ Capture, Oxygen Firing, Ceramic Autothermal Recovery (CAR) Process, Coal, Retrofit, Cost of Electricity, and $\mathrm{CO}_{2}$ Mitigation Cost

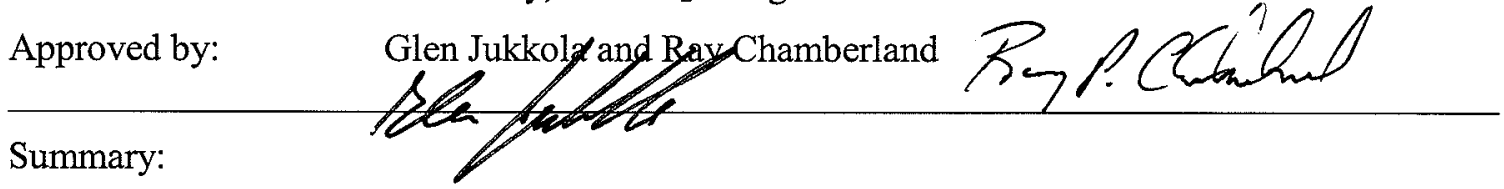

This report discusses the results obtained from a retrofit study of AEP Conesville Unit \#5 to oxygen firing for the purpose of capturing $\mathrm{CO}_{2}$ from the flue gas. The retrofit study integrates the existing boiler with an advanced oxygen supply system (Ceramic Autothermal Recovery "CAR") being developed by Linde. Various system configurations and parameters were investigated. These parameters were found to be important in evaluating plant performance, costs, and economics (i.e., plant thermal efficiency, plant retrofit costs, incremental cost of electricity, and $\mathrm{CO}_{2}$ mitigation cost) for this plant.

Information disclosed herein is furnished to the recipient solely for the use thereof as has been agreed upon with Alstom and all rights to such information are reserved by Alstom. The recipient of the information disclosed herein agrees, as a condition of its receipt of such information, that Alstom shall have no liability for any direct or indirect damages including special, punitive, incidental, or consequential damages caused by, or arising from, the recipient's use or non-use of the information. 
ADVANCED OXYGEN FIRING

LINDE CERAMIC AUTOTHERMAL RECOVERY PROCESS
$\mathrm{A} \mathrm{CO}_{2}$ CAPTURE RETROFIT STUDY OF AMERICAN ELECTRIC POWER'S 
TECHNO-ECONOMIC ANALYSIS

OF THE RETROFIT OF AEP CONESVILLE UNIT \#5 WITH $\mathrm{O}_{2}$ FIRING VIA THE LINDE CERAMIC AUTOTHERMAL RECOVERY (CAR) PROCESS

FINAL REPORT

SUBMITTED BY

ALSTOM POWER INC.

POWER PLANT LABORATORIES

2000 DAY HILL ROAD

WINDSOR, CT 06095

(860) 688-1911

Gregory N. Liljedahl, and Nsakala ya Nsakala

Project Co-Leaders

PREPARED FOR

LINDE BOC PROCESS PLANTS LLC

A MEMBER OF THE LINDE GROUP

575 MOUNTAIN AVENUE

MURRAY HILL NJ 07974

(CONTRACT NO. DE-FC 26-06 NT42748)

REPORT SUBMITTAL DATE: August 22, 2008

PROJECT PERFORMANCE PERIOD: 04/01/06 - 03/31/09

PPL REPORT NO. PPL-08-CT-15 


\section{DISCLAIMER}

This report was prepared as an account of work sponsored by an agency of the United Sates Government. Neither the United States Government nor any agency thereof, nor any of their employees makes any warranty, express or implied, or assumes any legal liability or responsibility for the accuracy, completeness, or usefulness of any information, apparatus, product, or process disclosed, or represents that its use would not infringe privately owned rights. This analysis is specific to American Electric Power's Conesville Unit \#5 and the results should not be taken out of context to generalize about $\mathrm{CO}_{2}$ retrofits or about new plants with $\mathrm{CO}_{2}$ control. Reference herein to any specific commercial product, process, or service by trade name, trademark, manufacturer, or otherwise does not necessarily constitute or imply its endorsement, recommendation, or favoring by the United States Government or any agency thereof. The views and opinions of authors expressed herein do not necessarily state or reflect those of the United States Government or any agency thereof.

Information disclosed herein is furnished to the recipient solely for the use thereof as has been agreed upon with Alstom and all rights to such information are reserved by Alstom. The recipient of the information disclosed herein agrees, as a condition of its receipt of such information, that Alstom shall have no liability for any direct or indirect damages including special, punitive, incidental, or consequential damages caused by, or arising from, the recipient's use or non-use of the information. 


\section{ACRONYMS AND ABBREVIATIONS}

\begin{tabular}{|c|c|}
\hline ABB & Asea Brown Boveri \\
\hline ABMA & American Boiler Makers Association \\
\hline ASU & Air Separation Unit \\
\hline AEP & American Electric Power \\
\hline bara & Bar absolute \\
\hline barg & Bar gauge \\
\hline BI & Boiler Island \\
\hline BOP & Balance of Plant \\
\hline Btu & British Thermal Unit \\
\hline Ср & Specific Heat \\
\hline CAR & Ceramic Autothermal Recovery \\
\hline CCS & Carbon Capture and Storage \\
\hline CERA & Cambridge Energy Research Associates \\
\hline CFD & Computational Fluid Dynamics \\
\hline cm. $\mathrm{H}_{2} \mathrm{O}$ & Centimeters of Water \\
\hline COE & Cost of Electricity \\
\hline DCGC & Direct Contact Gas Cooler \\
\hline DOE/NETL & Department of Energy/National Energy Technology Laboratory \\
\hline DTFS & Drop Tube Furnace System \\
\hline EOR & Enhanced Oil Recovery \\
\hline EPC & Engineered, Procured, and Constructed \\
\hline ESP & Electrostatic Precipitator \\
\hline FD & Forced Draft \\
\hline FGD & Flue Gas Desulfurization \\
\hline FGR & Flue gas recycle \\
\hline FOM & Fixed Operation \& Maintenance \\
\hline GHG & Greenhouse Gases \\
\hline gpm & Gallons per Minute \\
\hline GPU & Gas Processing Unit \\
\hline g & Grams \\
\hline $\mathrm{HHV}$ & Higher Heating Value \\
\hline $\mathrm{HP}$ & High Pressure \\
\hline hr & Hour \\
\hline ID & Induced Draft \\
\hline IHS & Information Handling Services Inc. \\
\hline in. $\mathrm{H}_{2} \mathrm{O}$ & Inches of Water \\
\hline in. Hga & Inches of Mercury, Absolute \\
\hline IP & Intermediate Pressure \\
\hline ISO & International Standards Organization \\
\hline $\mathrm{J}$ & Joules \\
\hline $\mathrm{kg}$ & Kilograms \\
\hline kWe & Kilowatts electric \\
\hline kWh & Kilowatt-hour \\
\hline $\mathrm{lbm}$ & Pound mass \\
\hline LDT & Let Down Turbine \\
\hline LHV & Lower Heating Value \\
\hline LP & Low Pressure \\
\hline LT & Low Temperature \\
\hline LTCS & Low temperature carbon steel \\
\hline MCR & Maximum Continuous Rating \\
\hline MEA & Monoethanolamine \\
\hline MJ & Mega joules \\
\hline MM-Btu & Million British Thermal Units \\
\hline MTP & Metal Temperature Program \\
\hline MWe & Megawatt Electric \\
\hline
\end{tabular}




$\begin{array}{ll}\text { OCDO } & \text { Ohio Coal Development Office } \\ \text { OSBL } & \text { Outside Boundary Limits } \\ \text { OXY-fuel } & \text { Oxygen firing } \\ \text { O\&M } & \text { Operation \& Maintenance } \\ \text { PA } & \text { Primary Air } \\ \text { PC } & \text { Pulverized Coal } \\ \text { PCCI } & \text { Power Capital Costs Index } \\ \text { PFD } & \text { Process Flow Diagram } \\ \text { PFWH } & \text { Parallel Feedwater Heater } \\ \text { ppm } & \text { Parts per million } \\ \text { psia } & \text { Pound per square inch, absolute } \\ \text { psig } & \text { Pound per square inch, gauge } \\ \text { RHBP } & \text { Reheat Boiler Program } \\ \text { s } & \text { Second } \\ \text { SA } & \text { Secondary Air } \\ \text { SCPC } & \text { Supercritical pulverized coal } \\ T_{\text {ad }} & \text { Adiabatic flame temperature } \\ \text { TGA } & \text { Thermo-gravimetric analysis } \\ \text { TPD } & \text { Ton Per Day } \\ \text { VOM } & \text { Variable Operation \& Maintenance }\end{array}$




\section{EXECUTIVE SUMMARY}

Fossil fuel fired electric power plants are among the largest and most concentrated producers of $\mathrm{CO}_{2}$ emissions. Recovery and sequestration of $\mathrm{CO}_{2}$ from the flue gas of such plants has been identified as one of the primary means for reducing anthropogenic $\mathrm{CO}_{2}$ emissions.

Among the more promising technologies under development for the recovery and sequestration of $\mathrm{CO}_{2}$ from coal fired power plants is oxygen firing. Oxygen firing uses high purity oxygen mixed with recirculated flue gas (mostly $\mathrm{CO}_{2}$ ) to provide a combustion oxidant for the fuel instead of air. The oxygen may be supplied by cryogenic air separation units, or in the future by more efficient processes such as oxygen transport membrane (OTM) or ceramic autothermal recovery (CAR). The oxygen-fired combustion process produces a flue gas stream consisting of mostly $\mathrm{CO}_{2}$ and $\mathrm{H}_{2} \mathrm{O}$ vapor and smaller amounts of other gasses $\left(\mathrm{O}_{2}, \mathrm{~N}_{2}, \mathrm{Ar}, \mathrm{SO}_{2}\right.$, etc.). Simple condensation of most of the water vapor yields a $\mathrm{CO}_{2}$-rich product stream, which can be compressed for sequestration or used for enhanced oil recovery (EOR).

This study builds on the results of previous work (Bozzuto, et al., 2001; Ramezan, Nsakala, Liljedahl, 2007) to help determine better approaches to capturing $\mathrm{CO}_{2}$ from existing coal-fired power plants. It also increases the available information on the impact of retrofitting $\mathrm{CO}_{2} \mathrm{capture}$ via oxygen firing to existing PC fired power plants. Alstom Power Inc.'s Power Plant Laboratories (Alstom) teamed with Linde BOC Process Plants LLC (Linde) to investigate the techno-economic feasibility of integrating an advanced oxygen production process (Ceramic Autothermal Recovery - CAR), being developed by Linde, with an existing pulverized coal fired power plant (AEP Conesville Unit \#5). The study scope consists of the evaluation of several oxygen fired $\mathrm{CO}_{2}$ capture cases, which use variations of the Linde CAR process for oxygen production. Additionally, an oxygen fired $\mathrm{CO}_{2}$ capture case using oxygen provided from a state of the art cryogenic type air separation unit (ASU) was also included. This case is provided primarily to benchmark the CAR systems relative to state of the art commercially available systems. An air fired Base Case without $\mathrm{CO}_{2}$ capture is also included to compare with the current operations for the plant.

\section{Study Cases}

The following list defines the study cases included in this report.

- Base Case: "business as usual” operation scenario for the existing plant (Conesville Unit \#5 air fired) without $\mathrm{CO}_{2}$ recovery.

- Case 1: Oxygen fired retrofit (cryogenic type ASU) of Conesville Unit \#5 adapted from the original study (Concept B from Bozzuto, et. al, 2001).

- Case 2: An update of the above Case 1 to a "state of the art" cryogenic ASU (95\% pure oxygen) and gas processing unit (GPU). Plant performance, retrofit costs and economics have been updated.

- Cases 3a, 3b, and 3c: Retrofit of Conesville Unit \#5 using the Ceramic Autothermal Recovery (CAR) oxygen production process with flue gas used as the sweep gas for the CAR process.

- Cases 4a and 4b: Retrofit of Conesville Unit \#5 using the Ceramic Autothermal Recovery (CAR) oxygen production process with steam used as a sweep gas for the CAR process.

The first two cases (Base Case and Case 1) are taken directly from the previous work (Bozzuto, et. al, 2001) and are provided only for comparison purposes. 
To provide a frame of reference, each of the cases is evaluated against a Base Case from the standpoints of performance and impacts on power generation cost. The Base Case represents the "business as usual" operation scenario for the existing plant (air fired) without $\mathrm{CO}_{2}$ recovery. The Base Case which is used for the current study is identical to the Base Case used in the previous studies (Bozzuto, et al., 2001; Ramezan, Nsakala, Liljedahl, 2007) from a plant performance standpoint. Fuel costs, operating and maintenance costs, and capacity factor for the Base Case have been updated based on AEP's latest recommendations (Ramezan, Nsakala, Liljedahl, 2007).

Case 1 which is the same as Concept B from the previous study (oxygen fired retrofit of Conesville \#5 - cryogenic type ASU-99\% pure oxygen) is provided for reference only. Retrofit costs for this case were escalated to present day and economics have also been updated to be comparable with the other cases of this study.

Case 2 represents an updated "state of the art" version of Case 1 described above. The primary changes made to Case 1 for the update include an improved "state of the art" ASU (95\% pure oxygen) and GPU, slight modifications to the oxygen distribution within the boiler, and updated investment costs and economics in order to be directly comparable with the current study results for the CAR Cases (i.e. Cases 3a, 3b, 3c, 4a, and 4b).

Cases 3a, 3b, and 3c represent the retrofit of Conesville Unit \#5 using the Ceramic Autothermal Recovery (CAR) oxygen production process with recirculated flue gas used as the sweep gas for the CAR process. These three cases represent different arrangements with respect to sweep gas preheat and air preheat as well as different assumptions regarding the oxygen holding capacity for the CAR bed material. Case 3a represents a case which uses packed bed heat exchangers that are integral with the CAR bed and located at both the inlet and outlet of the CAR beds. This case assumes an oxygen capacity of $0.5 \%$ of the weight of the CAR bed material. Case $\mathbf{3 b}$ is the same as Case 3a from a performance standpoint but assumes an oxygen capacity of $1.0 \%$ of the weight of the CAR bed material. This oxygen capacity increase decreases the number of CAR beds required and reduces the overall cost for the CAR system. Case 3c also assumes an oxygen capacity of $1.0 \%$ of the weight of the CAR bed material but instead of using integral packed bed heat exchangers, this case uses separate external heat exchangers for preheating the air and sweep gas. The external heat exchangers are significantly more expensive than the integral packed bed heat exchangers used in Cases 3a and 3b but terminal differences can be lowered which reduces the amount of natural gas required in the CAR system.

Cases 4a and $\mathbf{4 b}$ represent the retrofit of Conesville Unit \#5 using the Ceramic Autothermal Recovery (CAR) oxygen production process with steam used as a sweep gas for the CAR process. Similar to Case $3 \mathrm{~b}$, these cases both use packed bed heat exchangers that are integral with the CAR bed and assume an oxygen capacity of $1.0 \%$ of the weight of the CAR bed material. Case 4a uses an oxygen blower at the exit of the CAR process to supply the oxidant stream to the boiler. Because oxygen blowers are very expensive Linde recommended the investigation of Case 4b, which eliminates the use of the oxygen blower.

In the current study, significant quantities of heat rejected from the oxygen production systems and the $\mathrm{CO}_{2}$ capture/compression systems are integrated with the steam/water cycles. In the previous study (i.e., Case 1), heat integration was not used. 


\section{Plant Performance Results:}

Figures ES-1 and ES-2 compare the overall plant thermal efficiency (HHV basis) and thermal efficiency loss (relative to the Base Case) respectively. The CAR Cases 3a and 3b, which are identical from a plant performance perspective, show the best plant thermal efficiency (26.12\%). This represents an efficiency loss, as compared to the Base Case, of 8.89 percentage points. The CAR Case 3c shows slightly reduced performance with a thermal efficiency of $25.92 \%$ (i.e. an efficiency loss, as compared to the Base Case, of 9.09 percentage points).

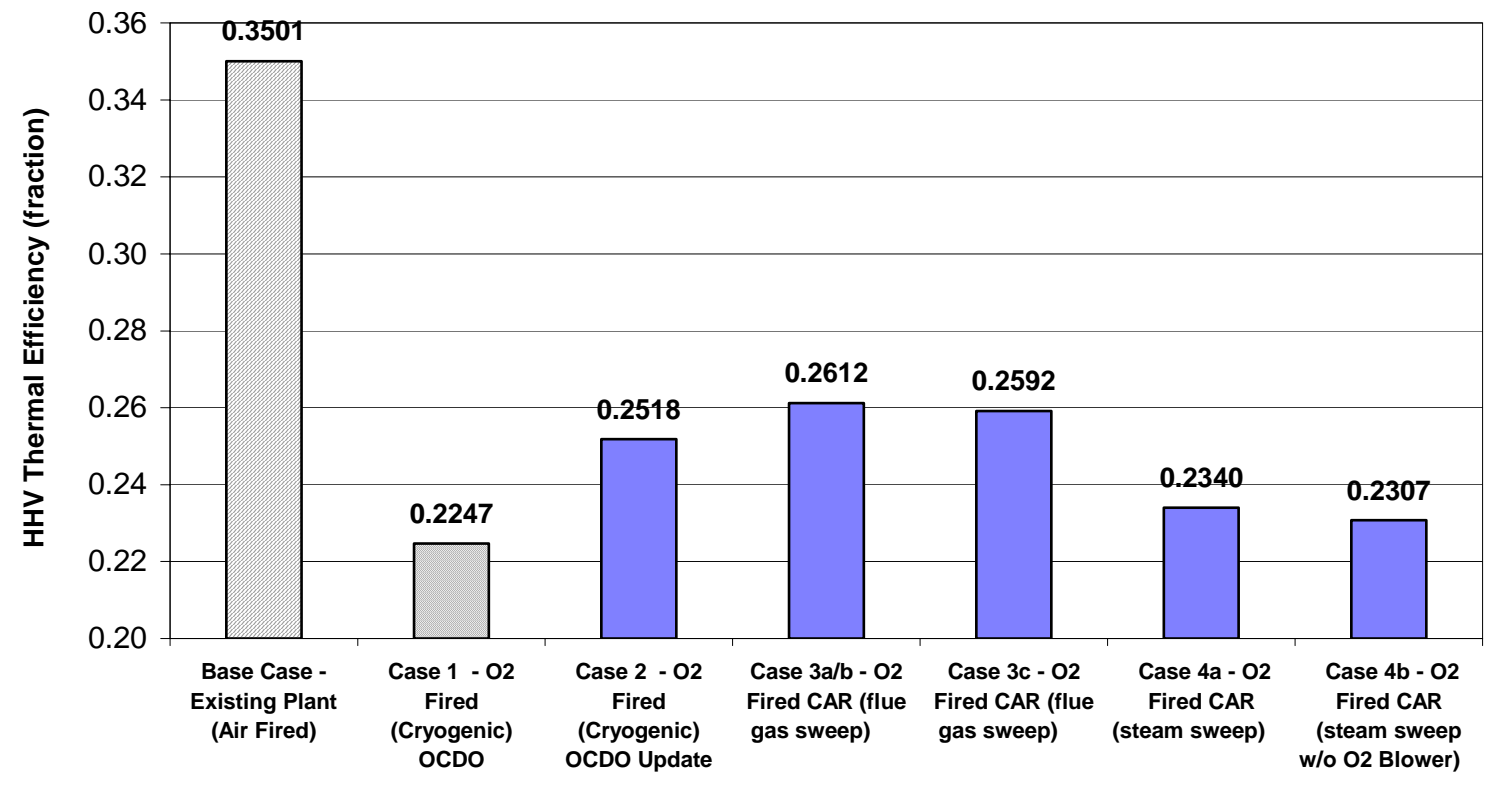

Figure ES-1: Plant Thermal Efficiency Comparison

The updated cryogenic ASU case (Case 2), which represents the benchmark case for comparison to the CAR cases, shows a thermal efficiency of $25.18 \%$, which represents an efficiency loss, as compared to the Base Case, of 9.83 percentage points. Case 1, which is from the original study (Bozzuto et al., 2001), shows a thermal efficiency of 22.47\%, which represents an efficiency loss, as compared to the Base Case, of 12.54 percentage points. The efficiency loss for the new cryogenic case (Case 2) has been reduced by 2.71 percentage points ( $>20 \%$ reduction in the plant thermal efficiency loss) due primarily to reduced power requirements for the ASU and GPU.

The CAR cases with steam as sweep gas (Case 4a and 4b) show significantly reduced performance with thermal efficiencies of $23.40 \%$ and $23.07 \%$ respectively (i.e., efficiency losses, as compared to the Base Case, of 11.61 and 11.94 percentage points respectively). 


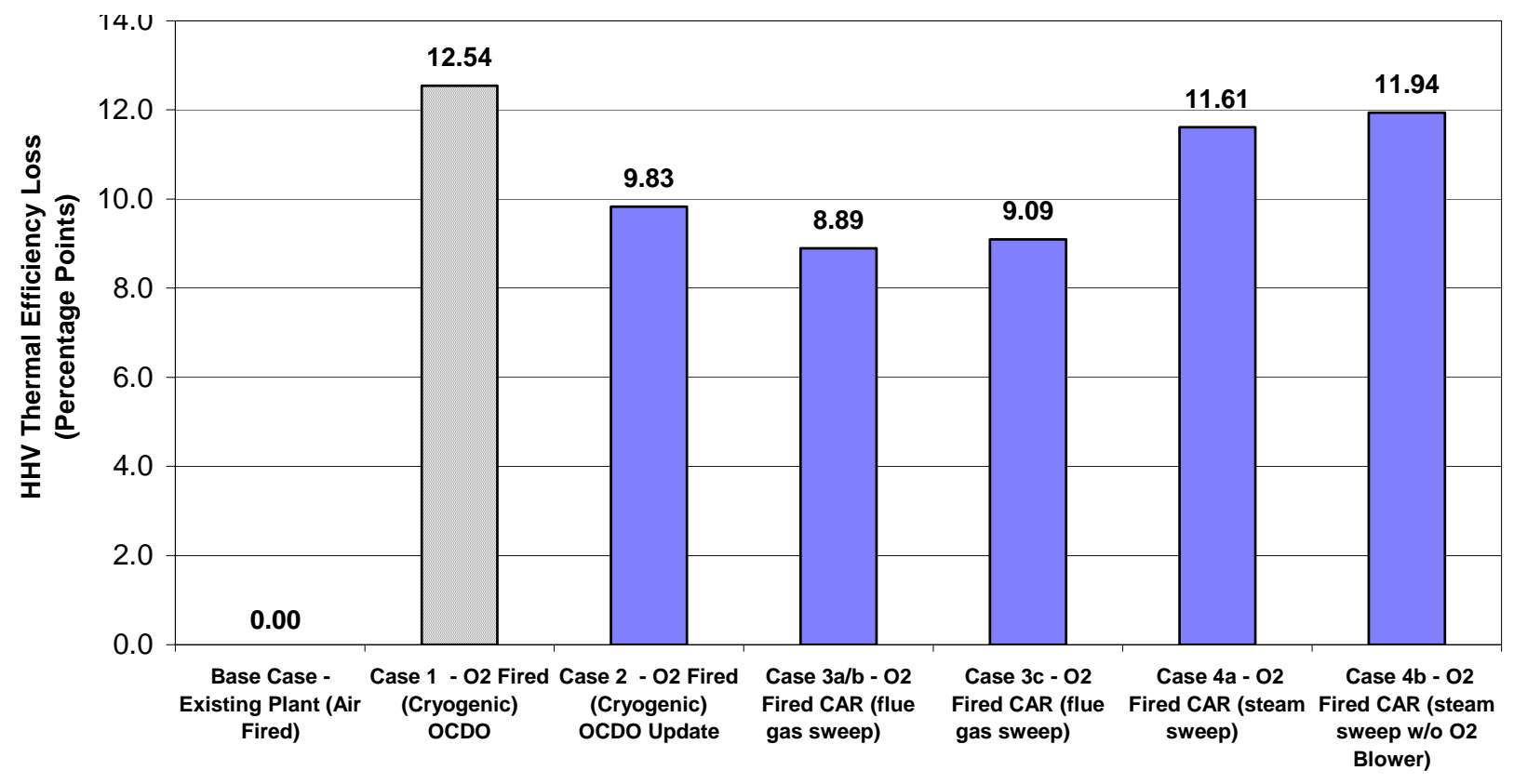

Figure ES-2: Plant Thermal Efficiency Loss Comparison (relative to Base Case)

Figure ES-3 shows a comparison of the specific oxygen production power requirements. As a benchmark, the "state of the art" cryogenic ASU case (Case 2) shows a specific oxygen production power requirement of about $223 \mathrm{kWh} /$ ton of delivered oxygen. By way of comparison the CAR cases 3a and 3b show a significant advantage in this parameter with a value of $115 \mathrm{kWh} / \mathrm{ton}$ of delivered oxygen (almost a 50\% reduction). CAR case 3c shows about $170 \mathrm{kWh} / \mathrm{ton}$ of delivered oxygen (a $24 \%$ reduction). The steam sweep cases (Cases $4 \mathrm{a}$ and $4 \mathrm{~b}$ ) show no advantage as compared to the cryogenic ASU case (Case 2) with oxygen production power requirements for these CAR cases about 15-18\% higher than for Case 2.

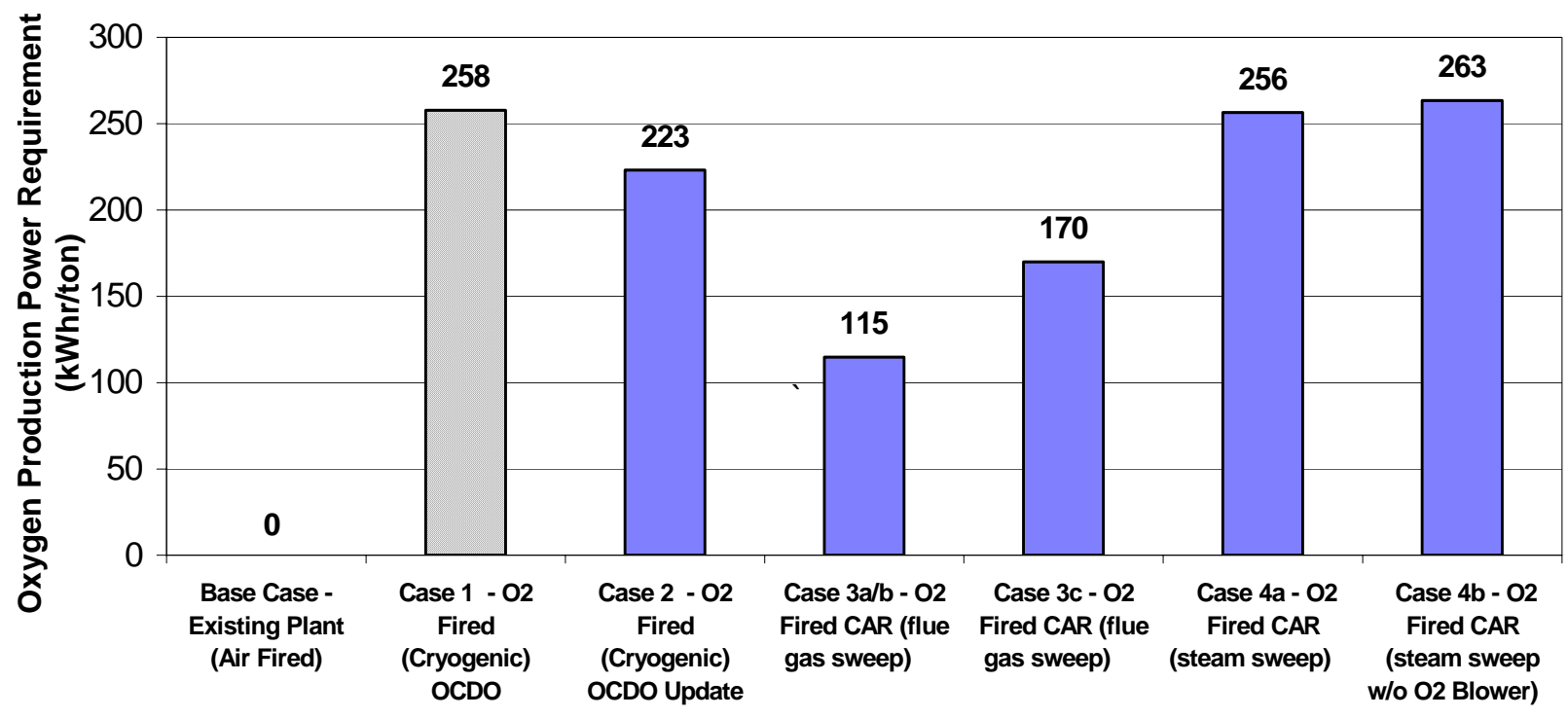

Figure ES-3: Oxygen Production Power Requirement Comparison 
The CAR systems investigated all require significant consumption rates of natural gas, which adversely impacts the economics as is shown later in the economic summary section. Figure ES-4 compares natural gas usage for the cases. The cryogenic cases (Cases 1 and 2) use a very small amount for desiccant regeneration (drying) in the gas processing unit. Cases $3 \mathrm{a}$ and $3 \mathrm{~b}$ use a significant quantity of natural gas in the CAR system (about $7.8 \%$ of the coal heat input). Case 3c was investigated in an effort to minimize the natural gas usage for the flue gas sweep option. Case 3c, which is the same as 3b except for the use of low terminal difference external heat exchangers (regenerators), is able to reduce the natural gas usage to about 3.6\% of the coal heat input. Cases $4 \mathrm{a}$ and $4 \mathrm{~b}$ (steam sweep) require a natural gas usage of about $3.0 \%$ of the coal heat input.

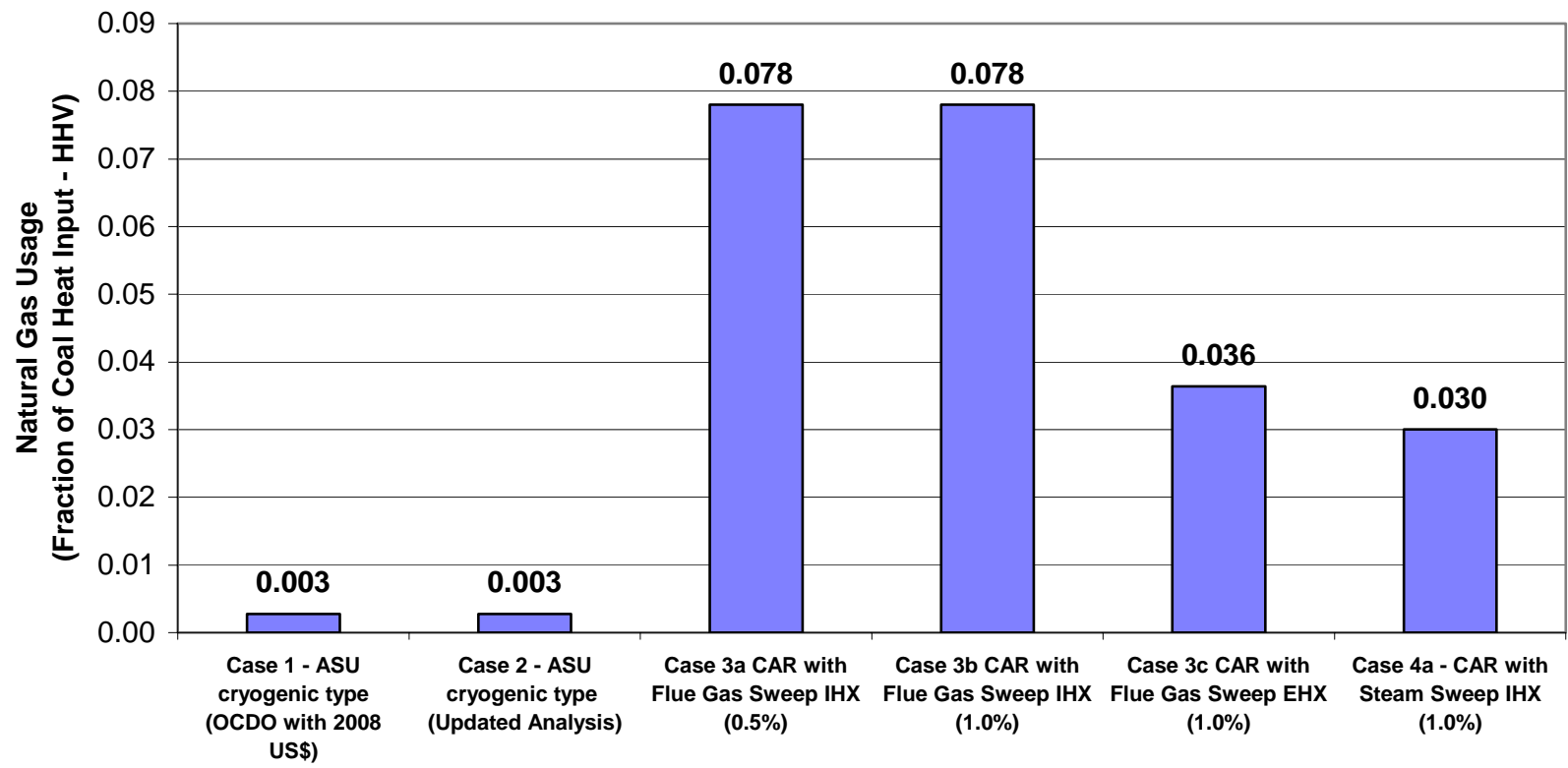

Figure ES-4: Natural Gas Usage

\section{Power Plant Retrofit Costs:}

Figure ES-5 shows a summary of the plant retrofit investment costs for all the cases investigated. Case $3 b$ (CAR flue gas sweep, integral heat exchangers, oxygen capacity of $1.0 \%$ ) was the lowest cost case investigated $(1,187 \$ / \mathrm{kWe})$. This case showed about a $20 \%$ lower specific retrofit investment cost (\$/kWe-net basis) than Case 2 (1,450 \$/kWe), the updated cryogenic ASU (i.e. the benchmark case). The other CAR cases (Cases 3b, 3c, and 4a) ranged from about 5\% - 10\% lower in cost than Case 2 . The cost for Case $4 \mathrm{~b}$ was not estimated due to the relatively poor performance described above and no expectation for the Case 4b CAR system costs to be lower than Case 3b.

Case 1, the cryogenic ASU case (99\% pure oxygen) from the original study (Bozzuto et al., 2001) that had the original costs simply escalated, was about 20\% higher than the updated cryogenic ASU case (Case 2). About half of the difference between Case 1 and Case 2 costs was due to the electrical output increase for Case 2 and half was due to the cost decrease for Case 2. 


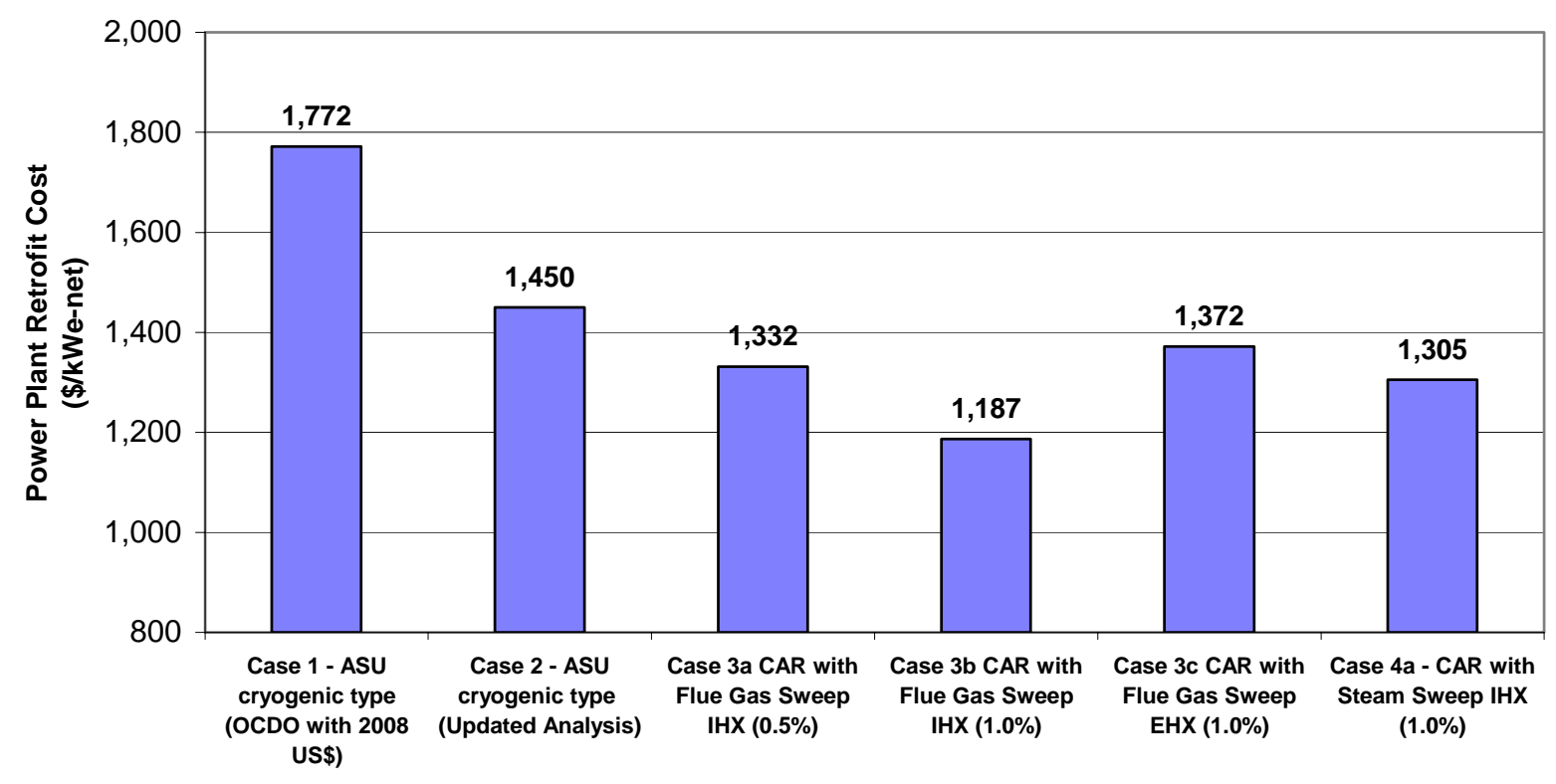

Figure ES-5: Power Plant Retrofit Cost Comparison

\section{Economic Analysis Results:}

Case 2, the updated cryogenic ASU case, represents the benchmark case for comparison with the CAR cases. As shown in Figure ES-6, the CAR Case 3b (flue gas sweep with integral heat exchange and $1.0 \%$ oxygen capacity) shows the best economics of all the cases studied. Case $3 \mathrm{~b}$ shows a marginal advantage in incremental COE of about 3\% as compared to Case 2. Were it not for the relatively large amount of natural gas usage for Case $3 b$ ( $\sim 7.8 \%$ of the coal heat input), the incremental COE for this case would have been significantly better.

Case 3c (flue gas sweep with external heat exchange and 1.0\% oxygen capacity), which uses significantly less natural gas than Case $3 b$ ( 3.6\% of the coal heat input) but has a higher investment cost associated with the external heat exchangers, shows incremental COE values about the same as for Case 2. Therefore, the use of the low terminal difference external heat exchangers to reduce natural gas consumption was proven not to be economical.

Case 3a, which was the same as Case $3 \mathrm{~b}$ except with $0.5 \%$ oxygen capacity shows an incremental COE that is about 3-4\% higher than the incremental COE for Case 2.

Case 4a (steam sweep with integral heat exchange and 1.0\% oxygen capacity) shows an incremental COE that is also about 3-4\% higher than the incremental COE for Case 2. The economics for Case $4 \mathrm{~b}$ were not calculated, as explained previously, due to the relatively poor performance for this case.

Not show in Figure ES-6 is Case 1 from the previous study because the graph is "zoomed in" to focus on the new cases from this study. As shown in the economics section later in this report, the Case 1 incremental COE values ranged from 4.95-5.24 $\mathbb{\$} / \mathrm{kWh}$ which is about 30 percent higher than Case 2. 
From a purely cap and trade perspective, the owner/operator of this plant would not contemplate any of these retrofit scenarios unless the cost of $\mathrm{CO}_{2}$ allowance exceeded $\sim \$ 40 /$ ton of $\mathrm{CO}_{2}$ emitted.
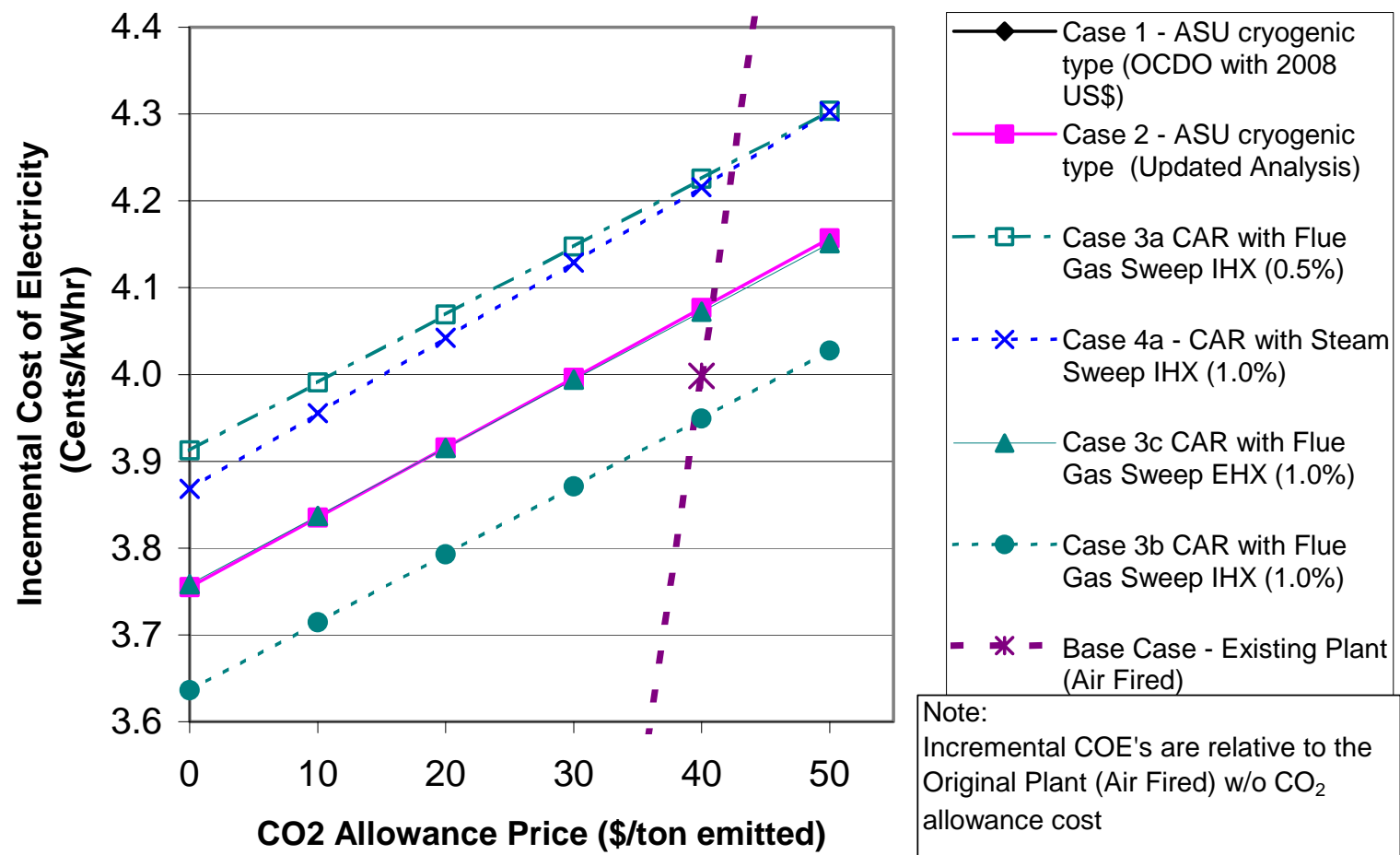

Figure ES-6: Incremental Cost of Electricity Comparison

\section{Conclusions:}

First, focusing just on the oxygen production process itself, the CAR system (Case 3b) showed a clear advantage over the cryogenic ASU system (Case 2) in both performance and cost. The specific power requirement for the CAR system was almost 50\% less than for the cryogenic ASU case (115 vs. $223 \mathrm{kWh} /$ ton of oxygen delivered, respectively). The specific oxygen production system cost for Case 3b was about $40 \%$ lower than the cryogenic ASU case ( 14,000 vs. $\sim 25,000$ $\$$ /ton/day of oxygen delivered, respectively). The oxygen production process comparison however only tells part of the story.

If we now focus on the complete power plant retrofit, Case $3 \mathrm{~b}$ (flue gas sweep, internal HX, 1.0\% oxygen capacity) was clearly the best configuration investigated for the CAR system from all measures of merit considered (i.e. plant performance, plant retrofit cost, and incremental cost of electricity). The plant performance analysis indicated a plant thermal efficiency loss for this case of 8.89 percentage points which was about one percentage point better than the cryogenic ASU benchmark case (Case 2). The plant retrofit cost for Case 3b was almost 20\% lower than the benchmark cryogenic ASU case (1,187 vs. 1,450 \$/kWe-net respectively). Although both performance and cost for the retrofit with the CAR system were substantially better than for the cryogenic ASU benchmark case, the incremental COE was only about 3\% lower for Case 3b than Case 2 due to the relatively large amount of natural gas usage for Case $3 \mathrm{~b}$ ( $\sim 7.8 \%$ of the coal heat input). Case 3c was investigated in an effort to minimize the natural gas usage ( $\sim 3.6 \%$ of the coal heat input). The increased capital costs associated with the external heat exchangers for this case 
caused the incremental COE to be about 3\% higher than for Case 3b (about the same as for Case 2).

From a purely cap and trade perspective, the owner/operator of this plant would not contemplate any of these retrofit scenarios unless the cost of $\mathrm{CO}_{2}$ allowance exceeded $\sim \$ 40 /$ ton of $\mathrm{CO}_{2}$ emitted.

CAR Process Development Unit Testing:

It should be pointed out that there were significant problems encountered during the CAR Process Development Unit testing which was done at the Western Research Institute's facility in Laramie, WY. The problems were primarily related to high heat losses from the unit and an intolerance of the perovskite material to sulfur in the sweep gas. The high heat losses caused higher than expected amounts of Methane usage, lower than expected bed temperatures, and low oxygen removal. With respect to the sulfur intolerance of the perovskite material, some of the materials tested were mechanically unstable while others were shown to decline in performance with the increase in $\mathrm{SO}_{2}$ loading. 
TABLE OF CONTENTS

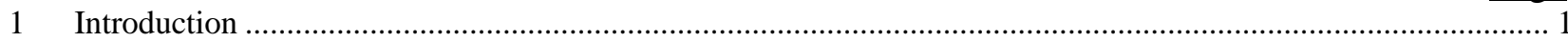

$1.1 \quad$ Motivation, Objectives, and Scope ………...................................................................................... 2

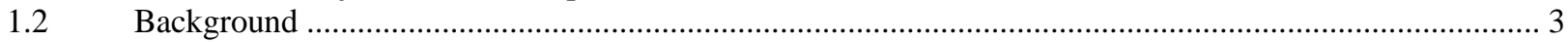

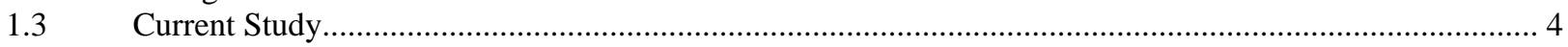

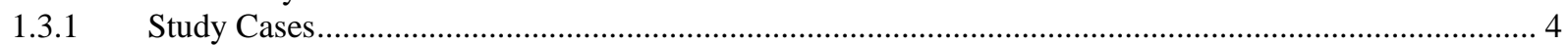

2 Design Basis for $\mathrm{CO}_{2}$ Capture Systems Retrofit Equipment and Basis For Performance Calculations .................. 7

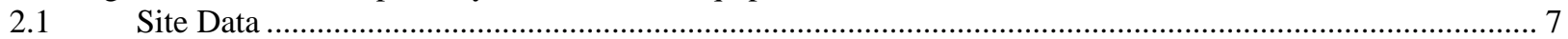

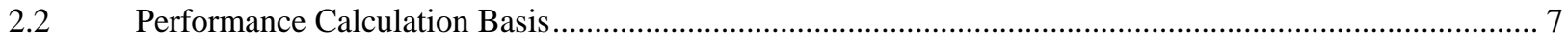

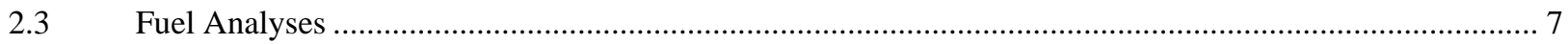

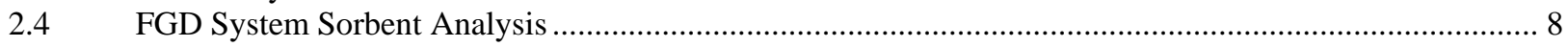

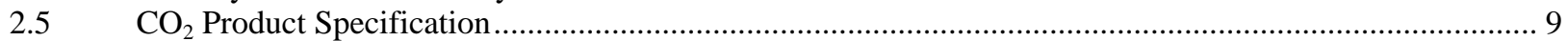

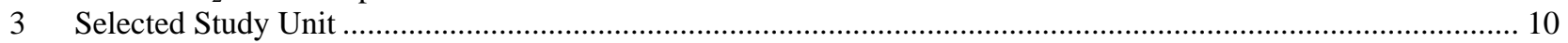

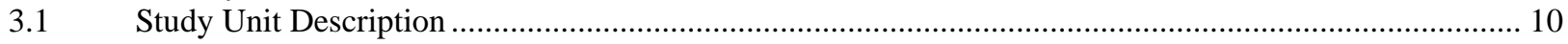

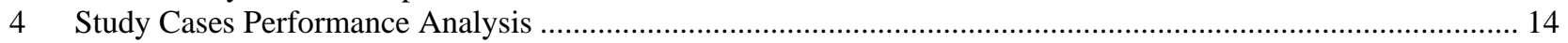

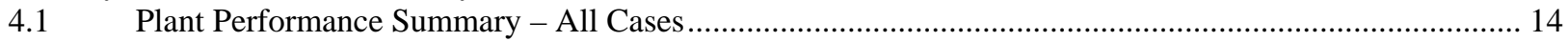

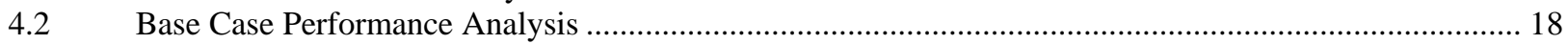

4.2.1 Calibration of the Boiler Computer Model - Base Case ................................................................ 18

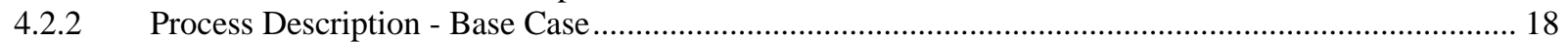

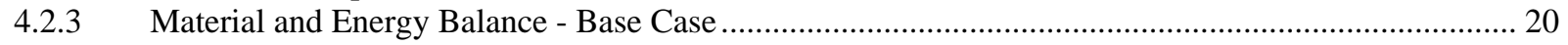

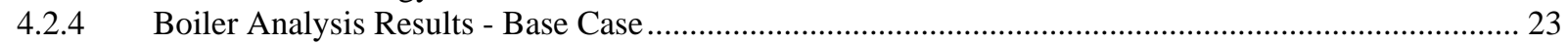

4.2.5 Steam Cycle Performance - Base Case ........................................................................................... 23

4.2.6 Flue Gas Desulfurization System Analysis - Base Case ................................................................ 27

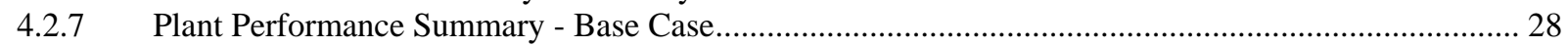

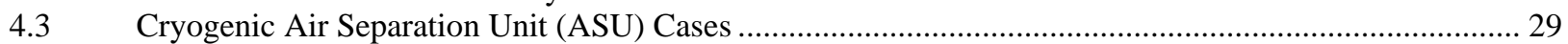

4.3.1 Case 1: Cryogenic ASU Case from Previous Study …….................................................................... 29

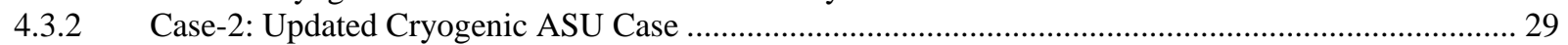

4.3.2.1 Process Description - Case 2 ..................................................................................................... 29

4.3.2.2 Material and Energy Balance - Case 2 …....................................................................................... 32

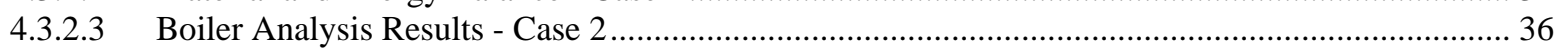

4.3.2.4 Steam Cycle Performance - Case 2 ............................................................................................. 36

4.3.2.5 Flue Gas Desulfurization System Analysis - Case 2 ............................................................. 37

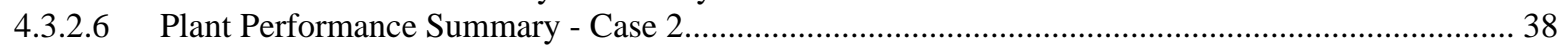

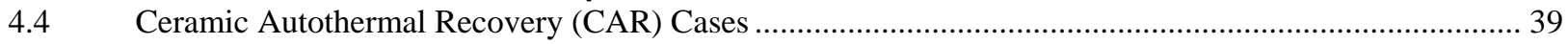

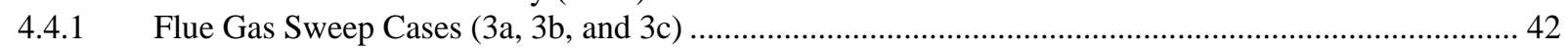

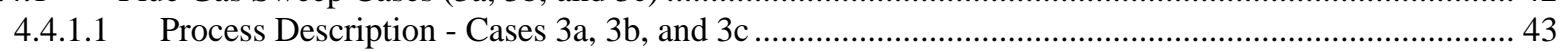

4.4.1.2 Material and Energy Balance - Cases 3a, 3b, and 3c .................................................................... 47

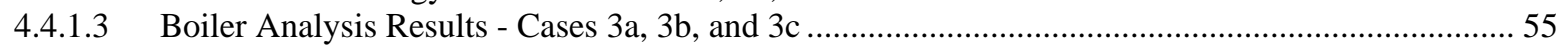

4.4.1.4 Modified FGD System Performance - Cases 3a, 3b, and 3c only ................................................... 55

4.4.1.5 Steam Cycle Performance - Cases 3a, 3b, and 3c ......................................................................... 56

4.4.1.6 Plant Performance Summary - Cases 3a, 3b, and 3c...................................................................... 58

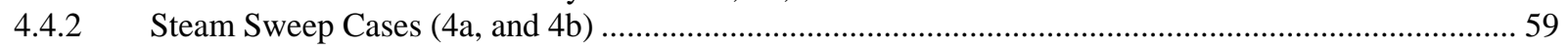

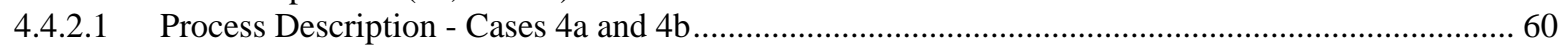

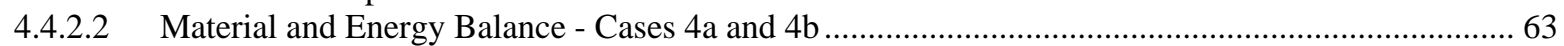

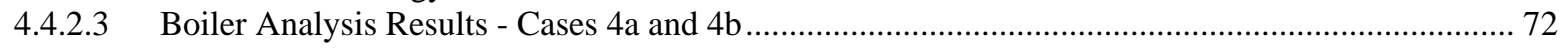

4.4.2.4 Steam Cycle Performance - Cases 4a and 4b ................................................................................. 72

4.4.2.5 Flue Gas Desulfurization System Analysis - Cases 4a and 4b ........................................................ 74

4.4.2.6 Plant Performance Summary - Cases 4a and 4b.............................................................................. 75

5 Plant Modifications Required for Oxygen Firing and $\mathrm{CO}_{2}$ Capture .................................................................. 76

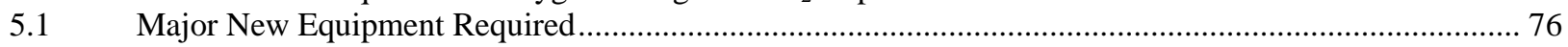

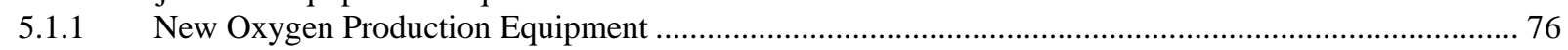

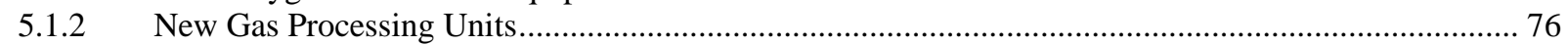

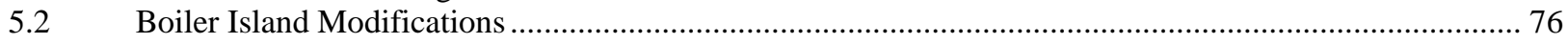

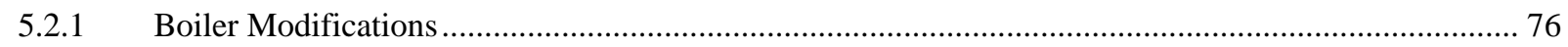




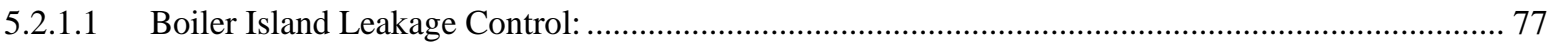

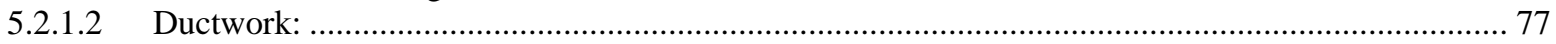

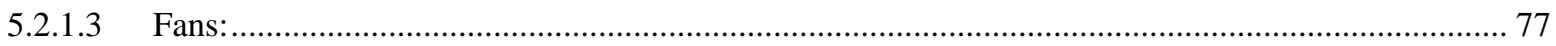

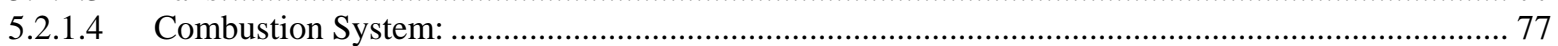

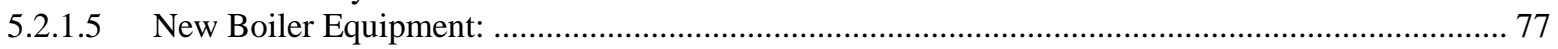

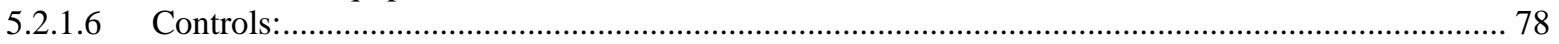

5.2.2 Flue Gas Desulfurization System Modifications (Cases 3a, 3b, and 3c only) ..................................... 78

5.2.2.1 Modified FGD System Process Description and Process Flow Diagram (Cases 3a, 3b, and 3c only) .

5.2.2.2 Modified FGD System Equipment Layout (Cases 3a, 3b, and 3c only)

5.2.2.3 Secondary FGD Absorber Effluent (Cases 3a, 3b, and 3c only) ................................................... 79

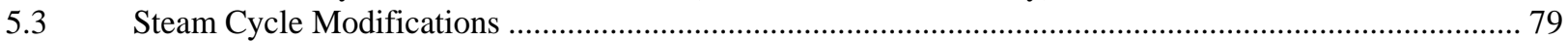

5.3.1 Cryogenic ASU Based Case 2 ……………...................................................................................... 80

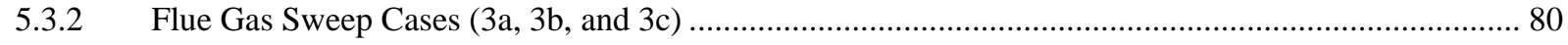

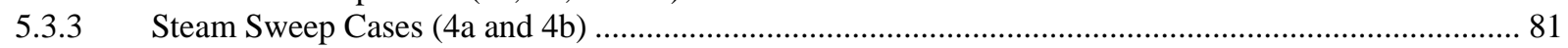

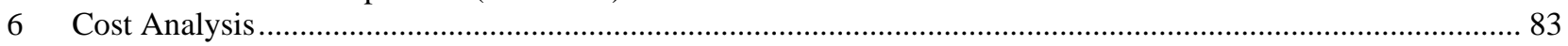

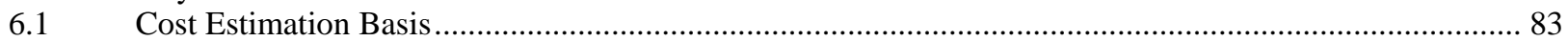

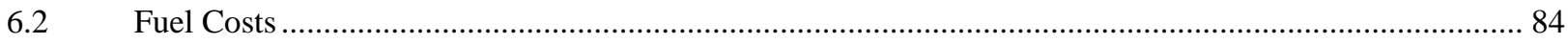

6.3 New Equipment and Plant Modification Costs..................................................................................... 85

6.3.1 Oxygen Production System Costs.......................................................................................................... 85

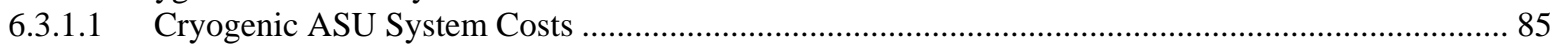

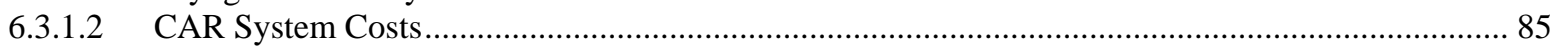

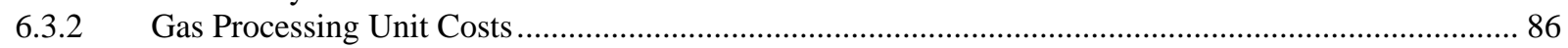

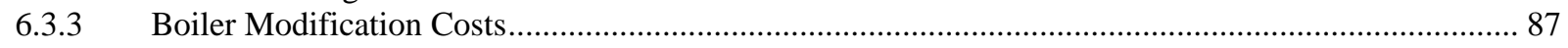

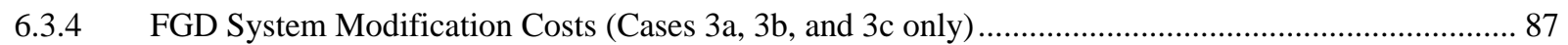

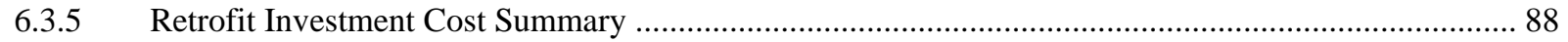

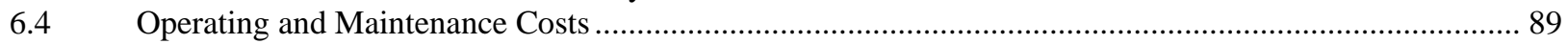

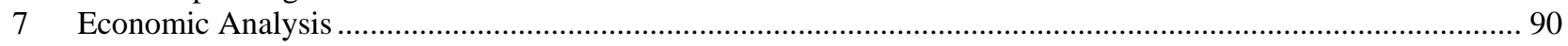

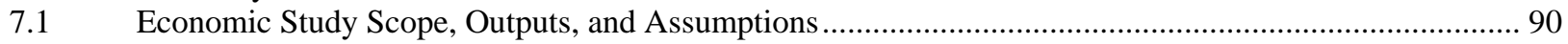

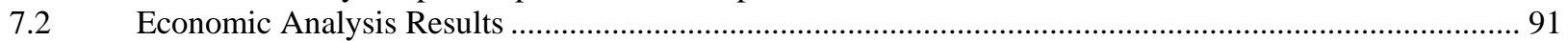

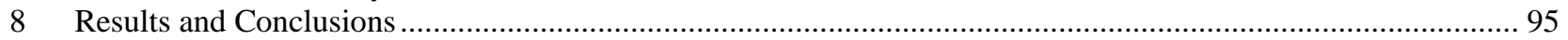

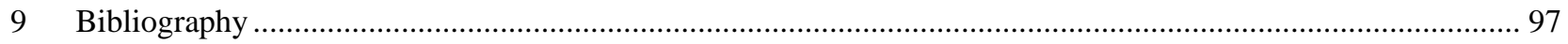

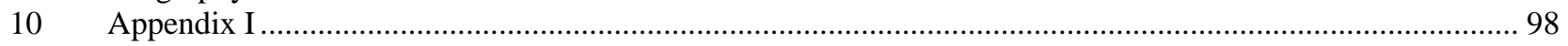

10.1 Concept B: $\mathrm{CO}_{2}$ Separation with Oxygen Firing and Flue Gas Recirculation........................................... 98

10.1.1 Overall System Description and Material and Energy Balance ........................................................ 98

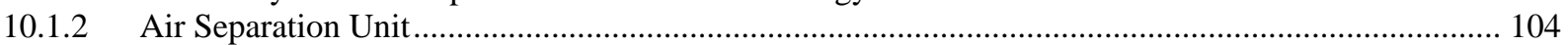

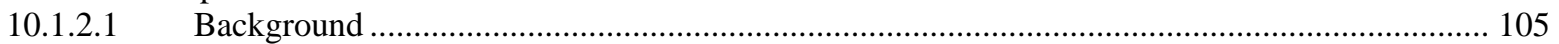

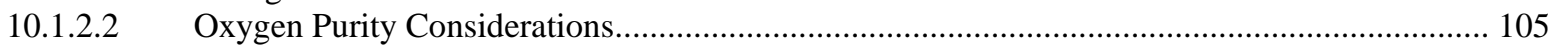

10.1.2.3 Major Vendors Experience........................................................................................................ 106

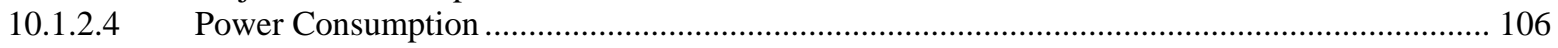

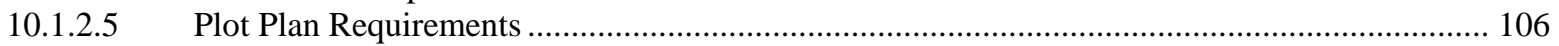

10.1.2.6 Investment and Operation and Maintenance Costs .................................................................... 107

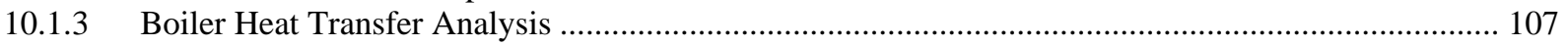

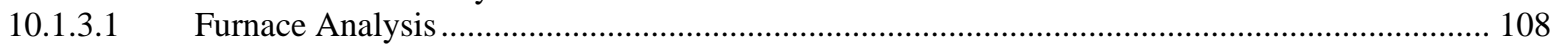

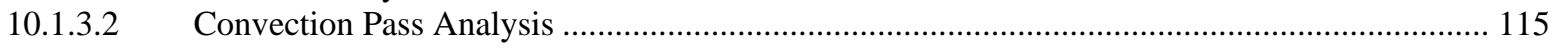

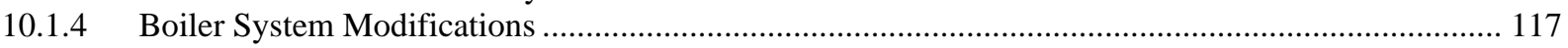

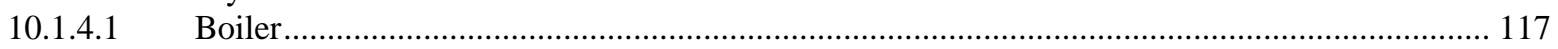

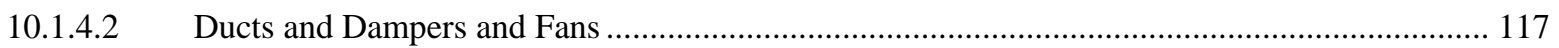

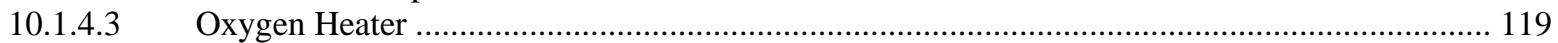

10.1.4.4 Parallel Low Pressure Feedwater Heater........................................................................... 120

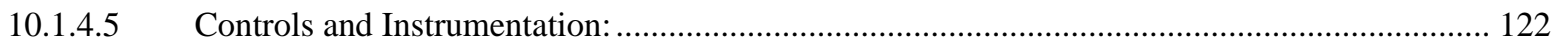

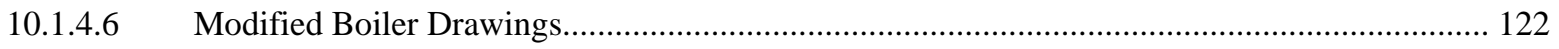

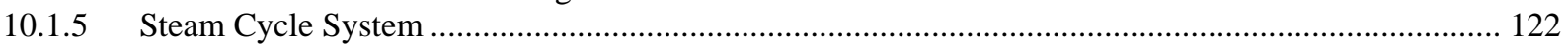

10.1.6 Flue Gas Desulfurization and Electrostatic Precipitator Systems Performance Issues ......................... 123

10.1.6.1 Flue Gas Desulfurization System Performance Issues ............................................................. 123 
10.1.6.2 Electrostatic Precipitator (ESP) System Performance Issues .............................................. 124

10.1.7 Carbon Dioxide Separation and Compression System ......................................................... 128

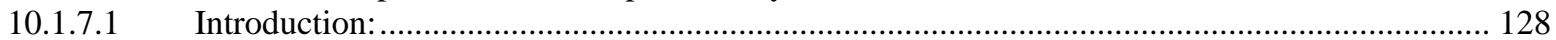

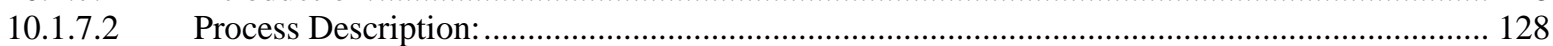

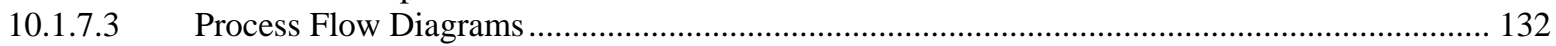

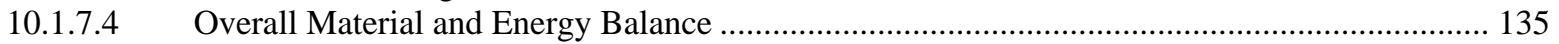

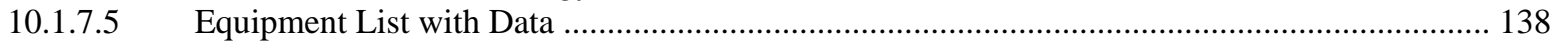

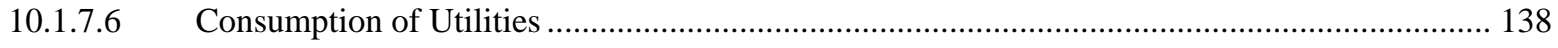

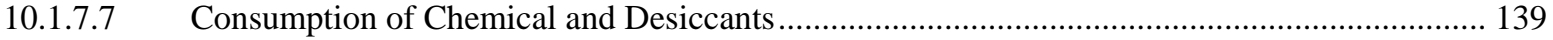

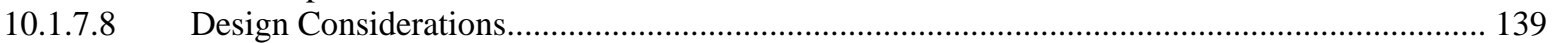

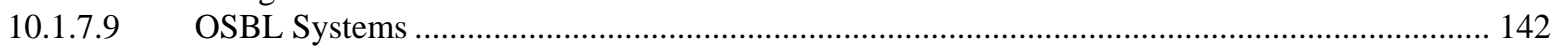

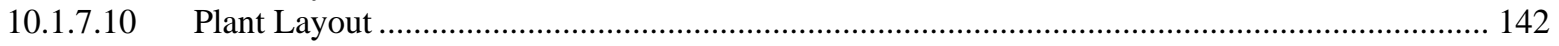




\section{LIST OF TABLES}

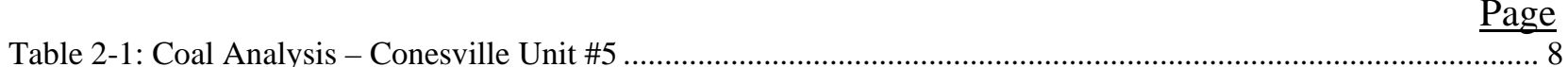

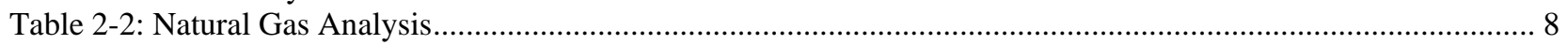

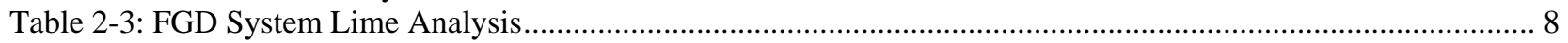

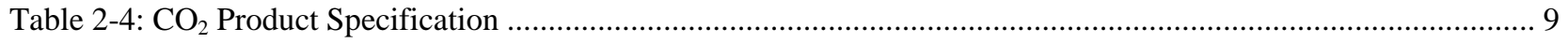

Table 4-1: Plant Performance Summary - All Cases ............................................................................................. 15

Table 4-2: Gas Side Material and Energy Balance (Base Case) ............................................................................... 21

Table 4-3: Boiler/Turbine Steam Flows and Conditions (Base Case) .................................................................... 23

Table 4-4: FGD System Analysis Assumptions (Base Case) .................................................................................... 28

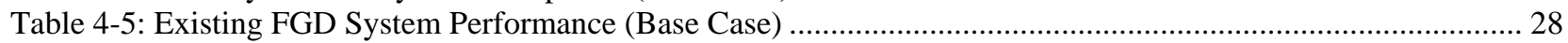

Table 4-6: Overall Plant Performance Summary (Base Case)...................................................................................... 29

Table 4-7: Boiler Island Material and Energy Balance - Case 2 ............................................................................... 33

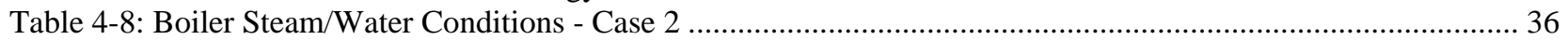

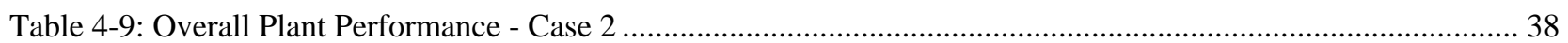

Table 4-10: Boiler Island Material and Energy Balance - Cases 3a and 3b.............................................................. 48

Table 4-11: Boiler Island Material and Energy Balance - Case 3c................................................................................ 51

Table 4-12: Boiler Steam/Water Conditions - Cases 3a and 3b................................................................................. 55

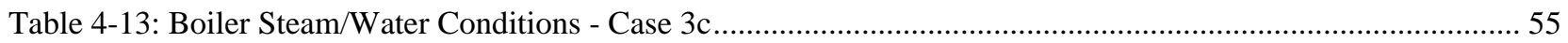

Table 4-14: Modified FGD System Assumptions (Cases 3a, 3b, and 3c) ……............................................................ 56

Table 4-15: Plant Performance Summary Cases 3a, 3b, and 3c ............................................................................... 59

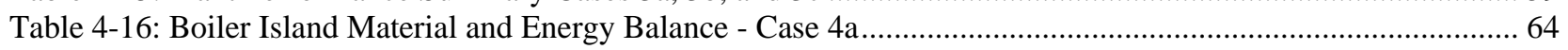

Table 4-17: Boiler Island Material and Energy Balance - Case 4b............................................................................... 68

Table 4-18: Boiler Steam/Water Conditions - Cases 4a and 4b............................................................................. 72

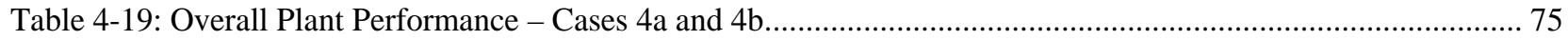

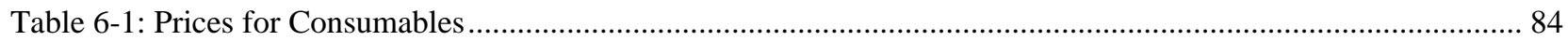

Table 6-2: CAR Oxygen Production System Investment Costs (EPC Basis) Cases 3a \& 3b........................................ 86

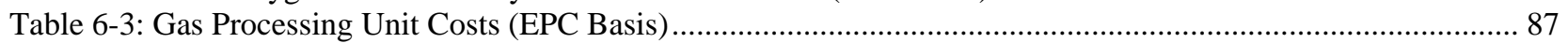

Table 6-4: Retrofit Investment Costs Summary - All Cases ........................................................................................ 88

Table 6-5: Annual Operating \& Maintenance Costs - Case 2 ..................................................................................... 89

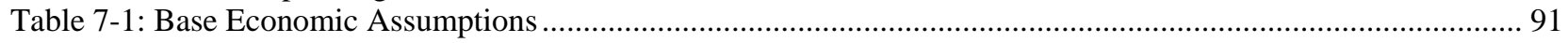

Table 7-2: Incremental Cost of Electricity Relative to Base Case............................................................................... 92

Table 7-3: $\mathrm{CO}_{2}$ Mitigation Costs Relative to Base Case .......................................................................................... 93

Table 10-1:Gas Side Material and Energy Balance for Concept B ............................................................................ 101

Table 10-2: Overall Plant Performance Summary for Concept B ............................................................................ 104

Table 10-3: Apparent Combustor Gas Emissivities................................................................................................... 110

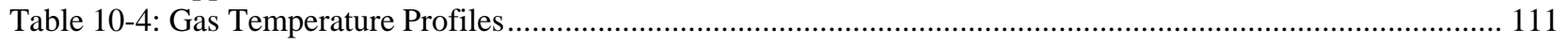

Table 10-5: Boiler/Turbine Steam Flows and Conditions for Concept B.................................................................. 117

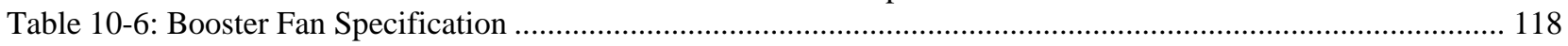

Table 10-7: Oxygen Heater Performance Requirements and Gas Analysis ............................................................ 119

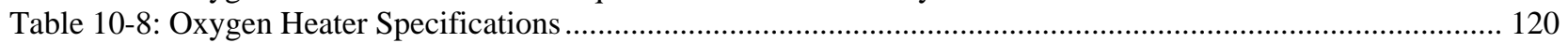

Table 10-9: Parallel Feedwater Heater Performance Requirements ............................................................................ 121

Table 10-10: Parallel Feedwater Heater Specification ............................................................................................ 121

Table 10-11: Parallel Feedwater Heater Header and Piping Specifications ............................................................. 121

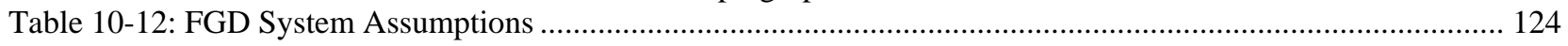

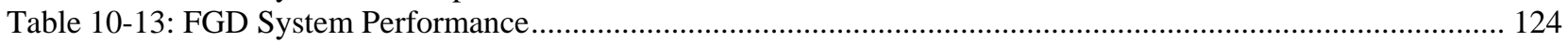

Table 10-14: Composition of Flue Gases Entering the Electrostatic Precipitator (ESP) ........................................... 127

Table 10-15: Material and Energy Balance for Flue Gas Cooling, $\mathrm{CO}_{2}$ Compression and Liquefaction..................... 136

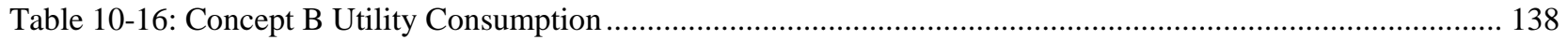

Table 10-17: Concept B Chemical and Desiccant Consumption.................................................................................. 139 


\section{LIST OF FIGURES}

Figure 1-1: Oxygen Fired $\mathrm{CO}_{2}$ Capture Retrofit Concept …......................................................................................

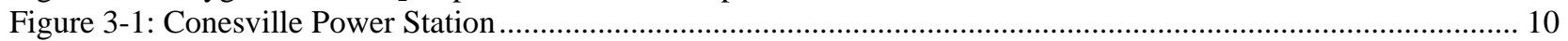

Figure 3-2: Study Unit Boiler (Existing Conesville Unit \#5 Steam Generator) …......................................................... 11

Figure 4-1: Selected Plant Performance Parameter Comparison - All Cases................................................................ 17

Figure 4-2: Simplified Gas Side Process Flow Diagram (Base Case) ……………………......................................... 19

Figure 4-3: Selected Conesville \#5 Turbine Heat Balance (basis for steam turbine modeling) .................................... 24

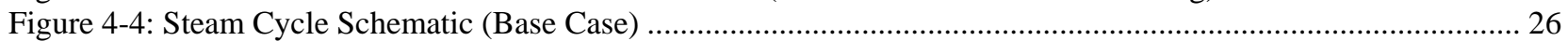

Figure 4-5: Steam Cycle T-S and Mollier Diagrams (Base Case) ............................................................................... 26

Figure 4-6: Existing Flue Gas Desulfurization System Process Flow Diagram (Base Case) ........................................ 27

Figure 4-7: Boiler Island Process Flow Diagram - Case 2 ............................................................................................ 31

Figure 4-8: Steam Cycle Schematic and Performance - Case 2............................................................................. 37

Figure 4-9: Steam Cycle T-S and Mollier Diagrams - Case 2 .................................................................................... 37

Figure 4-10: Bed Temperature Profiles of CAR Vessels with Regenerators................................................................. 39

Figure 4-11: CAR System Simplified Process Flow Diagram ......................................................................... 40

Figure 4-12: CAR Absorber Vessel Header Arrangement .................................................................................. 40

Figure 4-13: CAR Bed Cycle Steps and Blower Sequencing ..................................................................................... 41

Figure 4-14: Typical CAR System Block Diagram and Material and Energy Balance.................................................. 42

Figure 4-15: Conceptual Integration Concept for CAR Flue Gas Sweep Cases 3a and 3b ......................................... 45

Figure 4-16: Conceptual Integration Concept for CAR Flue Gas Sweep Case 3c........................................................ 46

Figure 4-17: Steam Cycle Schematic and Performance - Cases 3a and 3b........................................................... 57

Figure 4-18: Steam Cycle T-S and Mollier Diagrams - Cases 3a and 3b .................................................................. 57

Figure 4-19: Steam Cycle Schematic and Performance - Case 3c................................................................................. 58

Figure 4-20: Steam Cycle T-S and Mollier Diagrams - Case 3c ……........................................................................ 58

Figure 4-21: Conceptual Integration Concept for CAR Steam Sweep Cases 4a and 4b................................................. 62

Figure 4-22: Steam Cycle Schematic and Performance - Case 4a.............................................................................. 73

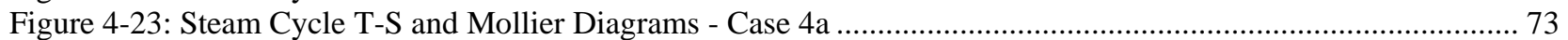

Figure 4-24: Steam Cycle Schematic and Performance - Case 4b (w/o O ${ }_{2}$ Blower) ..................................................... 74

Figure 4-25: Steam Cycle T-S and Mollier Diagrams - Case 4b ....................................................................... 74

Figure 5-1: Modified FGD System Simplified Process Flow Diagram (Cases 3a, 3b, and 3c).................................... 78

Figure 5-2: New Secondary $\mathrm{SO}_{2}$ Scrubber Location (Cases 3a, 3b, and 3c) ……................................................... 79

Figure 5-3: Modified Steam Cycle for Case 2 ...................................................................................................... 80

Figure 5-4: Modified Steam Cycle for Flue Gas Sweep Cases (3a, 3b, and 3c) …..................................................... 81

Figure 5-5: Modified Steam Cycle for Steam Sweep Cases (4a and 4b) ............................................................... 82

Figure 6-1: IHS/CERA Power Capital Costs Index................................................................................................. 83

Figure 6-2: Retrofit Investment Costs Summary - All Cases........................................................................................ 88

Figure 7-1: Incremental Cost of Electricity Relative to Base Case ……..................................................................... 92

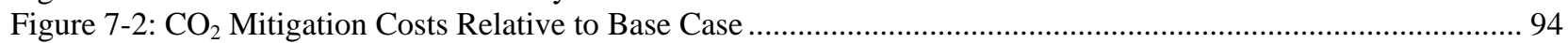

Figure 10-1: Simplified Gas Side Process Flow Diagram for $\mathrm{CO}_{2}$ Separation with Oxygen Firing ............................. 98

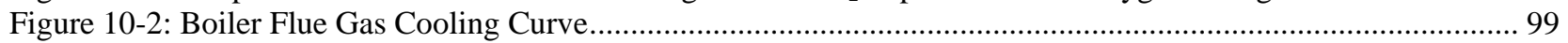

Figure 10-3: Process Flow Diagram of a BOC Improved Air Separation Unit ...................................................... 105

Figure 10-4: Variation of Radiative Heat Flux with Gas Temperature During Combustion in Air and $\mathrm{O}_{2} / \mathrm{CO}_{2} \mathrm{Mixtures}$

(from Thambimuthu, 1998) .......................................................................................................................... 109

Figure 10-5: Apparent Combustor Gas Emissivities as a Function of Axial Distance ................................................ 110

Figure 10-6: Centerline Gas Temperature Shift as a Function of Axial Distance (Case 2 - Case 1) ......................... 111

Figure 10-7:Calculated Adiabatic Flame Temperature as a Function of CO2/O2 Mole Ratio for Conesville Unit \#5 112

Figure 10-8: Specific Heats (Cp) of Nitrogen and Carbon Dioxide as a Function of Temperature............................ 112

Figure 10-9: Furnace Region Heat Flux Comparison.......................................................................................... 113

Figure 10-10: Convective Heat Transfer Rate Comparison....................................................................................... 115

Figure 10-11: Non-luminous Heat Transfer Rate Comparison................................................................................. 116

Figure 10-12: Total Heat Transfer Rate Comparison ............................................................................................ 116

Figure 10-13: Duct and Damper Diagram for Concept B................................................................................. 118

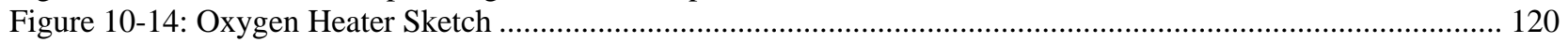

Figure 10-15: Parallel Feedwater Heater Arrangement ............................................................................................. 121 
Figure 10-16: Parallel Feedwater Heater Sketch

Figure 10-17: Modified Steam Cycle Diagram and Performance for Concept B .............................................. 123

Figure 10-18: Modified Steam Cycle Mollier Diagram for Concept B ....................................................... 123

Figure 10-19: Negative Corona Curves for Air-water Vapor Mixtures at 400F; Atmospheric Pressure; 3-in. Tube; 0.010 -in. Wire

Figure 10-20:Negative Corona Characteristics for Nitrogen-Oxygen Mixtures; 6-in Tube; 0.109-in Wire............... 126

Figure 10-21: Negative Corona Curves for Nitrogen-Sulfur Dioxide Mixtures; 6-in. Tube; 0.019-in. Wire............. 127

Figure 10-22: Process Flow Diagram for Concept B: Flue Gas Cooling

Figure 10-23: Process Flow Diagram for Concept B: $\mathrm{CO}_{2}$ Compression and Liquefaction.................................. 134

Figure 10-24: $\mathrm{CO}_{2}$ Recovery from Boiler Flue Gas (Combustion with 95\% Pure $\mathrm{O}_{2}$ and 5\% Air Infiltration) ........... 140

Figure 10-25: $\mathrm{CO}_{2}$ Recovery Boiler Flue Gas (Combustion with 99\% Pure $\mathrm{O}_{2}$ and 1\% Air Infiltration) 


\section{INTRODUCTION}

In discussions concerning greenhouse gas (GHG) emissions, $\mathrm{CO}_{2}$ is generally the gas that receives the most attention for its greenhouse effect. The greenhouse effect is the result of the presence of certain gases in the atmosphere, which reduce the loss of heat into space. Greenhouse gases are essential to maintaining the temperature of the earth in an acceptable range. A reduction in these gasses would result in a cooler earth and an increase would result in warming. There is growing concern that emission of greenhouse gases to the atmosphere at the current rate is resulting in climate change with undesired consequences. Greenhouse gases are produced by many natural and industrial processes, which currently result in $\mathrm{CO}_{2}$ levels of about $380 \mathrm{ppmv}$ in the atmosphere. This level is about 100 ppmv higher than during pre-industrial times. Although the greenhouse effect of $\mathrm{CO}_{2}$ is much less than equivalent amounts of several other greenhouse gases $\left(\mathrm{CH}_{4}, \mathrm{~N}_{2} \mathrm{O}\right.$, CFCs, etc. $), \mathrm{CO}_{2}$ is emitted in large amounts into the atmosphere and has a rather long atmospheric lifetime. When all these parameters are accounted for, $\mathrm{CO}_{2}$ is estimated to contribute approximately $60 \%$ of the greenhouse gas effect (Houghton, 1997).

Fossil fuel fired power plants are among the largest and most concentrated producers of $\mathrm{CO}_{2}$ emissions. Recovery and sequestration of $\mathrm{CO}_{2}$ from the flue gas of such plants has been identified as one of the primary means for reducing anthropogenic $\mathrm{CO}_{2}$ emissions. This has led to a comprehensive program to develop technologies to reduce $\mathrm{CO}_{2}$ emissions from coal-fired power plants. Hence, a portfolio of Clean Coal power generation technologies is on path to commercialization by technology providers in response to the need for near zero emissions and $\mathrm{CO}_{2}$ capture for sequestration or use.

New technologies, based upon both advanced combustion and gasification hold promise for economically achieving $\mathrm{CO}_{2}$ reductions through improved efficiencies. However, if the United States decides to embark on a $\mathrm{CO}_{2}$ emissions control program employing these new and cleaner technologies only, it may not be sufficient. It may also be necessary to reduce $\mathrm{CO}_{2}$ emissions from the existing fleet of power plants. Because existing fossil fuel fired power plants are among the largest point sources of $\mathrm{CO}_{2}$ emissions, it stands to reason that capturing $\mathrm{CO}_{2}$ from the flue gas of such plants would be an integral part of the overall $\mathrm{CO}_{2}$ control program.

Among the promising Clean Coal technologies under development to address $\mathrm{CO}_{2}$ emissions control is oxygen- (or Oxy-fuel) firing. Oxygen firing is a $\mathrm{CO}_{2}$ capture technology which uses oxygen mixed with recirculated flue gas (mostly $\left.\mathrm{CO}_{2}\right)$ to provide a combustion medium for the fuel instead of air. The oxygen may be supplied today by commercial cryogenic air separation units, or in the future by more efficient processes such as ceramic autothermal recovery (CAR) or oxygen transport membrane (OTM). The oxygen-fired combustion process produces a flue gas stream consisting of mostly $\mathrm{CO}_{2}$ and $\mathrm{H}_{2} \mathrm{O}$ vapor. Simple condensation of most of the water vapor yields a $\mathrm{CO}_{2}$-rich product stream, which can be simply compressed for sequestration or further processed into a high purity $\mathrm{CO}_{2}$ product for varied uses including enhanced oil recovery (EOR) or enhanced gas recovery (EGR).

This study builds on the results of previous work (Bozzuto, et al., 2001; Ramezan, Nsakala, Liljedahl, 2007) to help determine better approaches to capturing $\mathrm{CO}_{2}$ from existing coal-fired power plants and increases the available information on the impact of retrofitting $\mathrm{CO}_{2}$ capture via oxygen firing to existing PC fired power plants. More specifically, in this study Alstom Power Inc.'s Power Plant Laboratories (Alstom) teamed with Linde BOC Process Plants LLC (Linde) to 
investigate the techno-economic feasibility of integrating an advanced oxygen production process (Ceramic Autothermal Recovery - CAR), being developed by Linde, with an existing pulverized coal fired power plant (AEP's Conesville Unit \#5).

\subsection{Motivation, Objectives, and Scope}

The motivation for this study was to provide input to potential US electric utility actions to meet future potential $\mathrm{CO}_{2}$ mandates. If the US decides to reduce $\mathrm{CO}_{2}$ emissions consistent with the Kyoto protocol, action would need to be taken to address existing coal-based power plants. Although fuel switching from coal to gas is a possible scenario, it will not be a sufficient measure, and may not prove to be economically justified given the limited supply and the high and volatile price of natural gas. Our existing power infrastructure will clearly take several decades to be replaced. Therefore, some form of $\mathrm{CO}_{2}$ capture from existing coal-fired units will also be required. Demonstration of advanced low cost technologies is critical to carbon capture and storage (CCS) for both existing and new plants.

This study is designed to provide information to the public regarding some of the issues involved in reducing $\mathrm{CO}_{2}$ emissions in existing coal fired power plants, provides regulators with information to assess the impact of potential regulations, and provides data to plant owners/operators concerning oxygen fired $\mathrm{CO}_{2}$ capture technologies. All this will contribute to achieving necessary controls in the most economically feasible manner.

The objectives for this study are to evaluate the technical and economic impacts of removing $\mathrm{CO}_{2}$ from a typical existing US coal-fired electric power plant using oxygen firing and $\mathrm{CO}_{2}$ capture systems. The advanced oxygen production systems evaluated in this study use the Linde Ceramic Autothermal Recovery (CAR) process. Various configurations of the CAR process were investigated to identify the most economic arrangement. Commercial cryogenic based oxygen production systems are also evaluated in this study to help benchmark the advanced systems.

The study scope consists of the evaluation of several oxygen fired $\mathrm{CO}_{2}$ capture cases, which use variations of the Linde CAR process for oxygen production. Additionally, an oxygen fired $\mathrm{CO}_{2}$ capture case using oxygen provided from a state of the art cryogenic type air separation unit (ASU) was also included. This case represents an update of the cryogenic type ASU evaluation (Concept B) from the previous study (Bozzuto et al., 2001). A complete update is done including performance, costs and economics. This case is provided primarily to benchmark the CAR systems relative to state of the art commercially available systems. A Base Case without $\mathrm{CO}_{2}$ capture is also included for comparison purposes.

Technical and economic issues being evaluated include:

- Overall plant thermal efficiency

- Boiler performance and efficiency

- Boiler modifications

- Steam cycle output and efficiency

- Steam cycle modifications

- Plant $\mathrm{CO}_{2}$ emissions

- Flue Gas Desulfurization (FGD) system modifications and performance

- Retrofit investment cost

- Operating and maintenance (O\&M) costs 
- Cost of electricity (COE)

- $\mathrm{CO}_{2}$ mitigation costs

The primary impacts for all the $\mathrm{CO}_{2}$ capture cases included in this study are quantified in terms of plant electrical output reduction, thermal efficiency, $\mathrm{CO}_{2}$ emissions, retrofit investment costs, and the incremental cost of generating electricity resulting from the addition of the $\mathrm{CO}_{2}$ capture systems to the previously identified Base Case study unit.

\subsection{Background}

In a report titled, "Engineering Feasibility and Economics of $\mathrm{CO}_{2}$ Capture on an Existing CoalFired Power Plant,” (Bozzuto, et al., 2001), Alstom evaluated the impact of adding facilities to capture $>90 \%$ of the $\mathrm{CO}_{2}$ from American Electric Power's (AEP) Conesville, Ohio, Unit No. 5. This original analysis occurred during the 1999-2001-time period. Alstom teamed with American Electric Power (AEP), ABB Lummus Global Inc. (ABB), the US Department of Energy National Energy Technology Laboratory (NETL), and the Ohio Coal Development Office (OCDO) and conducted a comprehensive study evaluating the technical and economic feasibility of three alternate $\mathrm{CO}_{2}$ capture technologies as applied to an existing US coal-fired electric power plant. The power plant analyzed in this study was the Conesville Unit \#5, owned and operated by AEP of Columbus, Ohio. This unit is a nominal $450 \mathrm{MW}$, pulverized coal-fired, subcritical pressure steam plant.

One of the three $\mathrm{CO}_{2}$ capture concepts investigated in this earlier study was an oxygen-fired retrofit concept, which used a commercially available cryogenic type Air Separation Unit (ASU) and was referred to in the original study as Concept B. The basic concept of the overall system for Concept $\mathrm{B}$ is to replace air with oxygen for combustion in the furnace, thus directly producing a high $\mathrm{CO}_{2}$ content flue gas. In designing the Concept $\mathrm{B}$ system, emphasis was placed on utilizing as much as possible of the existing equipment, minimizing boiler island modifications, and providing operational flexibility to permit switching to the conventional mode of operation (air firing without $\mathrm{CO}_{2}$ capture) if desired. This process is depicted in Figure 1-1, a simplified schematic.

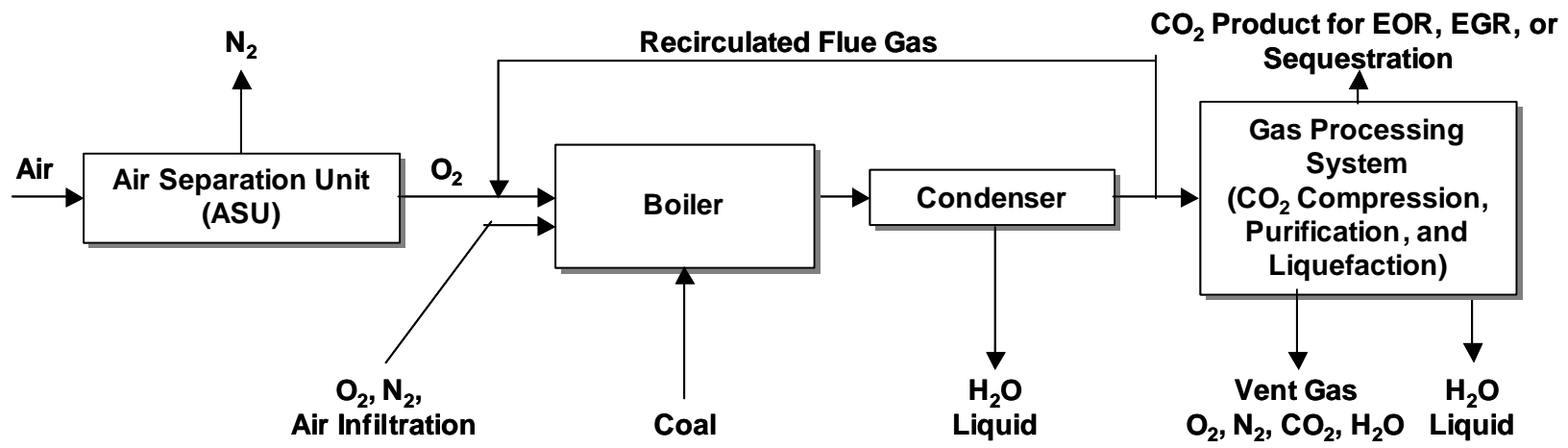

Figure 1-1: Oxygen Fired $\mathrm{CO}_{2}$ Capture Retrofit Concept

The proposed combustion system uses a mixture of nearly pure oxygen with recycled flue gas. Alternatively, the flue gas can be recycled back to the boiler upstream of the condenser. A 
conventional cryogenic ASU supplies the oxygen. The recycle flow rate is established by the need to maintain a thermal balance between the radiant and convective heat transfer surfaces of the existing steam generator. The quantity of the recirculated gas is approximately equal to the quantity of nitrogen contained in the combustion air that would have been supplied to the steam generator as part of the oxidant. Inherent in the flue gas recirculation process is the higher carbon dioxide and water vapor content in the flue gas. This increased concentration produces significant changes in the thermal and mechanical properties of the flue gas. These flue gas property differences cause significant differences in the heat transfer processes, which occur within the steam generator unit. Analyses were made to determine the impact of the heat transfer differences on boiler behaviour. Performance results were very encouraging and showed that with utilization of the proper amount of recirculated flue gas, the boiler could be operated with performance very similar to air firing and without the need for any pressure part changes to the existing boiler.

The results for Concept B were compared to a Base Case. The Base Case represents the "business as usual” operating scenario for the existing power plant (i.e. air firing) without $\mathrm{CO}_{2}$ capture. Investment costs (EPC basis, calculated in July 2001 \$US) required for adding the new ASU, adding the new $\mathrm{CO}_{2}$ capture/compression system, and for minor boiler island modifications to this existing unit were found to be very high ( $\sim 1,042 / \mathrm{kWe}-\mathrm{new}$ : where "new" refers to the new net output level of 273,347 kW). The impact on the cost of electricity was found to be an increase of about $4.4 \mathrm{f} / \mathrm{kWh}$ and the $\mathrm{CO}_{2}$ mitigation cost was $\$ 49 /$ ton of $\mathrm{CO}_{2}$.

Based on these results, further development and study was deemed necessary to find a better approach for capturing $\mathrm{CO}_{2}$ from existing PC fired power plants. This report represents one of the further studies on this topic.

\subsection{Current Study}

In the current study Alstom teamed with Linde to conduct a follow-up study. The current study was a conceptual level retrofit design study investigating state of the art and advanced oxygen combustion systems with $\mathrm{CO}_{2}$ capture as applied to the existing Conesville Unit \#5. The current study differs from the previous study (Bozzuto, et. al, 2001) in several ways.

- Only oxygen firing systems were considered in this study for $\mathrm{CO}_{2}$ capture. Amine and other $\mathrm{CO}_{2}$ capture systems analyzed in the previous studies were not considered in the current study.

- An advanced oxygen production system is investigated. The advanced system being developed by Linde is described as a Ceramic Autothermal Recovery (CAR) process. Several variations of this advanced oxygen production process were considered. In the previous study, the only oxygen-fired system analyzed used a commercially available cryogenic type air separation unit. A "state of the art" cryogenic type air separation unit based system was also analyzed in the current study and used as a benchmark for the advanced CAR cases.

- In the current study, significant quantities of heat rejected from the oxygen production systems and the $\mathrm{CO}_{2}$ capture/compression systems are integrated with the steam/water cycles. Previously, heat integration was not used.

\subsubsection{Study Cases}

The following list defines the cases included in the study presented in this report. 
- Base Case: "business as usual” operation scenario for the existing plant (air fired) without $\mathrm{CO}_{2}$ recovery.

- Case 1: Concept B oxygen fired retrofit (cryogenic type ASU) of Conesville Unit \#5 adapted from the original study (Bozzuto, et. al, 2001).

- Case 2: An update of the above Case 1 to a "state of the art" cryogenic ASU and gas processing unit (GPU). Plant performance, retrofit costs and economics have been updated.

- Cases 3a, 3b, and 3c: Retrofit of Conesville Unit \#5 using the Ceramic Autothermal Recovery (CAR) oxygen production process with flue gas used as the sweep gas for the CAR process.

- Cases 4a and 4b: Retrofit of Conesville Unit \#5 using the Ceramic Autothermal Recovery (CAR) oxygen production process with steam used as a sweep gas for the CAR process.

The first two cases (Base Case and Case 1) are taken directly from the previous work (Bozzuto, et. al, 2001) and are used only for comparison purposes.

To provide a frame of reference, each of the cases is evaluated against a Base Case from the standpoints of performance and impacts on power generation cost. The Base Case represents the "business as usual" operation scenario for the existing plant (air fired) without $\mathrm{CO}_{2}$ recovery. The Base Case which is used for the current study is identical to the Base Case used in the previous study from a plant performance standpoint. Fuel costs, operating and maintenance costs, and capacity factor for the Base Case have been updated based on AEP's latest recommendations (Ramezan, Nsakala, Liljedahl, 2007). All technical performance and cost results associated with these options are being evaluated in comparative manner.

Case 1 which is the same as Concept B from the previous study (oxygen fired retrofit of Conesville \#5 - cryogenic type ASU) is provided for reference only. Retrofit costs were escalated to present day and economics have been updated for this case to be comparable with the other cases of this study.

Case 2 represents an updated "state of the art" version of Case $\mathbf{1}$ described above. The primary changes made to Case 1 for the update include an improved state of the art ASU and GPU, slight modifications for oxygen distribution within the boiler, and updated investment costs and economics in order to be directly comparable with the current study results for the CAR Cases (i.e. Cases 3a, 3b, 3c, 4a, and 4b).

Cases 3a, 3b, and 3c represent the retrofit of Conesville Unit \#5 using the Ceramic Autothermal Recovery (CAR) oxygen production process with recirculated flue gas used as the sweep gas for the CAR process. These three cases represent different arrangements with respect to sweep gas preheat and air preheat as well as different assumptions regarding the oxygen holding capacity for the CAR bed material as described below. Case 3a represents a case which uses packed bed heat exchangers that are integral with the CAR bed and located at both the inlet and outlet of the CAR beds. This case assumes an oxygen capacity of $0.5 \%$ of the weight of the CAR bed material. Case $3 \mathrm{~b}$ is the same as Case 3a from a performance standpoint but assumes an oxygen capacity of 1.0\% of the weight of the CAR bed material. This oxygen capacity increase decreases the number of CAR beds required and reduces the overall cost for the CAR system. Case 3c also assumes an oxygen capacity of $1.0 \%$ of the weight of the CAR bed material but instead of using integral packed bed heat exchangers, this case uses separate external heat exchangers for preheating the air and sweep gas. The external heat exchangers are significantly more expensive than the integral 
packed bed heat exchangers used in Cases 3a and 3b but terminal differences can be lowered which reduces the amount of natural gas required in the CAR system.

Cases 4a and 4b: represent the retrofit of Conesville Unit \#5 using the Ceramic Autothermal Recovery (CAR) oxygen production process with steam used as a sweep gas for the CAR process. Case 4a represents a case that uses an oxygen blower at the exit of the CAR process to supply the oxidant stream to the boiler. Because oxygen blowers are very expensive Linde recommended the investigation of Case $4 \mathrm{~b}$, which eliminates the use of the oxygen blower.

Alstom managed and performed this techno-economic evaluation for Linde from its Power Plant Laboratories offices in Windsor, CT. Alstom Power is well established as a global leader in the design, manufacture, and service of power generation equipment, and in providing equipment and services for power plant environmental control systems. Linde is an international leader in process engineering, design, manufacture, and service of equipment for large-scale chemical plants for the production of industrial gases. As such, Linde is well positioned for the development of advanced oxygen supply systems sized for electric utility scale power plants. 


\section{DESIGN BASIS FOR $\mathrm{CO}_{2}$ CAPTURE SYSTEMS RETROFIT EQUIPMENT AND BASIS FOR PERFORMANCE CALCULATIONS}

This section describes many of the basic assumptions used for the design of equipment and in the calculation of performance for individual processes and the overall plant.

\subsection{Site Data}

Listed below is a brief summary of the site data used for equipment design in this conceptual level study:

- $\quad$ Plant is located in Conesville, Ohio, elevation 227 m (744 feet).

- Atmospheric pressure is $76 \mathrm{~cm}$ Hga (29.92 inches of $\mathrm{Hg}$ ).

- $\quad$ Dry bulb temperature maximum is $33^{\circ} \mathrm{C}\left(92^{\circ} \mathrm{F}\right)$ and minimum is $-1^{\circ} \mathrm{F}$.

- Wet bulb temperature for cooling tower design is $24^{\circ} \mathrm{C}\left(75^{\circ} \mathrm{F}\right)$.

- Average cooling tower water temperature is $27^{\circ} \mathrm{C}\left(80^{\circ} \mathrm{F}\right)$.

- Electric power is available from the existing facilities. Auxiliary power is provided through auxiliary transformers at 4,160-volt bus and is reduced down to 480 volts.

\subsection{Performance Calculation Basis}

Listed below is a brief summary of the basis used for plant performance calculations:

- For all plant performance calculations and material and energy balances the atmospheric conditions that were assumed are the ABMA standard conditions $\left(27^{\circ} \mathrm{C} / 80{ }^{\circ} \mathrm{F}, 1.014\right.$ bara/14.7 psia, $60 \%$ relative humidity)

- Condenser pressure used for all turbine heat balances is 0.084 bara (2.5 in. Hga).

- Pressure of product $\mathrm{CO}_{2}$ is 138 barg (2,000 psig).

\subsection{Fuel Analyses}

Table 2-1 shows the coal analysis used for this study and Table 2-2 shows the natural gas analysis. These analyses were used for all plant performance calculations. The coal analysis is representative of the coal that is currently being used by the study unit. Relatively small quantities of natural gas were used for desiccant regeneration in the $\mathrm{CO}_{2}$ drying package and larger amounts were used in the CAR systems. 
Table 2-1: Coal Analysis - Conesville Unit \#5

\begin{tabular}{|l|r|}
\hline Proximate Analysis, Wt.\% & \\
\hline Moisture & 10.1 \\
\hline Ash & 11.3 \\
\hline Volatile Matter & 32.7 \\
\hline Fixed Carbon & 45.9 \\
\hline Total & 100.0 \\
\hline & \\
\hline Ultimate Analysis, Wt.\% & \\
\hline Moisture & 10.1 \\
\hline Ash & 11.3 \\
\hline H & 4.3 \\
\hline C & 63.2 \\
\hline S & 2.7 \\
\hline $\mathrm{N}$ & 1.3 \\
\hline O & 7.1 \\
\hline Total & 100.0 \\
\hline & \\
\hline Higher Heating Value & 11,293 \\
\hline Btu/lbm & 26,266 \\
\hline kJ/kg & \\
\hline
\end{tabular}

Table 2-2: Natural Gas Analysis

\begin{tabular}{|c|c|c|}
\hline \multicolumn{2}{|l|}{ Component } & Vol. \% \\
\hline \multicolumn{2}{|l|}{ Methane } & 93.9 \\
\hline \multicolumn{2}{|l|}{ Ethane } & 3.2 \\
\hline \multicolumn{2}{|l|}{ Propane } & 0.7 \\
\hline \multicolumn{2}{|l|}{ n-Butane } & 0.4 \\
\hline \multicolumn{2}{|l|}{ Carbon Dioxide } & 1.0 \\
\hline \multicolumn{2}{|l|}{ Nitrogen } & 0.8 \\
\hline \multicolumn{2}{|l|}{ Total } & 100.0 \\
\hline & LHV & $\mathrm{HHV}$ \\
\hline $\mathrm{kJ} / \mathrm{kg}$ & 47805 & 53015 \\
\hline $\mathrm{kJ} / \mathrm{scm}$ & 35 & 39 \\
\hline Btu/lbm & 20552 & 22792 \\
\hline Btu/scf & 939 & 1040 \\
\hline
\end{tabular}

\subsection{FGD System Sorbent Analysis}

The sorbent used in the flue gas desulfurization (FGD) system for Conesville Unit \#5 is lime. The analysis of the lime used in this study is shown in Table 2-3 below.

Table 2-3: FGD System Lime Analysis

\begin{tabular}{|c|c|c|}
\hline Constituent & Units & Value \\
\hline $\mathrm{CaO}$ & $\mathrm{Wt} \%$ & 90 \\
\hline $\mathrm{MgO}$ & $\mathrm{Wt} \%$ & 5 \\
\hline Inerts & $\mathrm{Wt} \%$ & 5 \\
\hline
\end{tabular}




\section{$2.5 \quad \mathrm{CO}_{2}$ Product Specification}

The $\mathrm{CO}_{2}$ product specification is shown in Table 2-4 below. This specification was taken from a product specification developed for an enhanced oil recovery (EOR) application (Carney, 2008). A $\mathrm{CO}_{2}$ product pressure of 152 barg (2,200 psig) is used in all the cases that follow.

Table 2-4: $\mathrm{CO}_{2}$ Product Specification

\begin{tabular}{|c|c|c|}
\hline Parameter & Units & Value \\
\hline $\mathrm{CO}_{2}$ product utilization & N/A & Remote EOR \\
\hline Pipeline material & $\mathrm{N} / \mathrm{A}$ & Carbon steel \\
\hline Pressure & Barg (psig) & $152(2,200)$ \\
\hline $\mathrm{CO}_{2}, \min$ & vol\% & $95 \%$ \\
\hline $\mathrm{H}_{2} \mathrm{O}$ & vol\% & 0.015 \\
\hline $\mathrm{N}_{2}$, max & vol\% & $4 \%$ \\
\hline $\mathrm{O}_{2}, \max$ & ppmv & 40 \\
\hline Ar, max & ppmv & 10 \\
\hline $\mathrm{NH}_{3}$, max & ppmv & 10 \\
\hline $\mathrm{CO}, \max$ & ppmv & 10 \\
\hline Hydrocarbons, max & vol\% & $5 \%$ \\
\hline $\mathrm{H}_{2} \mathrm{~S}$, max & vol\% & $1.30 \%$ \\
\hline $\mathrm{CH}_{4}, \max$ & vol\% & $0.80 \%$ \\
\hline $\mathrm{H}_{2}$ & & uncertain \\
\hline $\mathrm{SO}_{2}$, max & ppmv & 40 \\
\hline NOx & & uncertain \\
\hline
\end{tabular}




\section{SELECTED STUDY UNIT}

This section provides a brief description of the selected Conesville \#5 study unit. The description provided in this section is the same as that provided previously in Bozzuto, et al., 2001, and in Ramezan, Nsakala, Liljedahl, 2007). It is shown here also, for convenience. The study unit is one of six existing coal fired steam plants located on the site as shown in Figure 3-1. American Electric Power (AEP) owns and operates these units except for Unit \#4, which is jointly owned by AEP, Cinergy, and Dayton Power and Light. The total electric generating capacity on this site is 2,080 MWe, although two of the older units (Units 1, and 2 shown on the left) have now been retired. The steam generated in Unit \#5 is utilized in a subcritical steam cycle for electric power generation. The nominal maximum electrical generation capacity of Conesville Unit \#5 is 430 MWe-net.

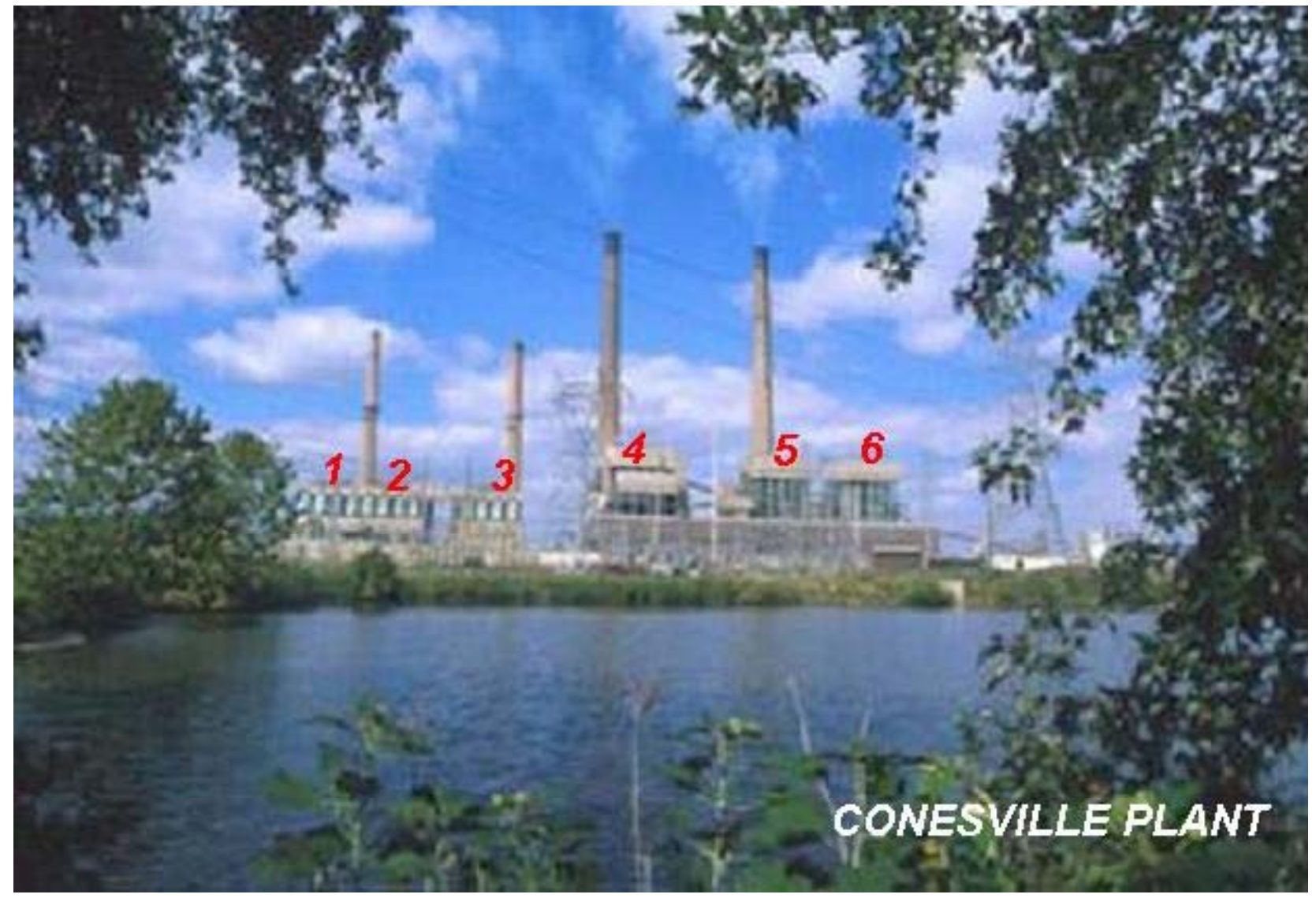

Figure 3-1: Conesville Power Station

\subsection{Study Unit Description}

The power plant analyzed in this study is American Electric Power's Conesville Unit \#5. This unit is a coal fired steam plant which generates a maximum output of $~ 430$ MWe-net using a subcritical pressure steam cycle. This plant has been in commercial operation since 1976. A general arrangement elevation drawing of the study unit steam generator is shown in Figure 3-2. 


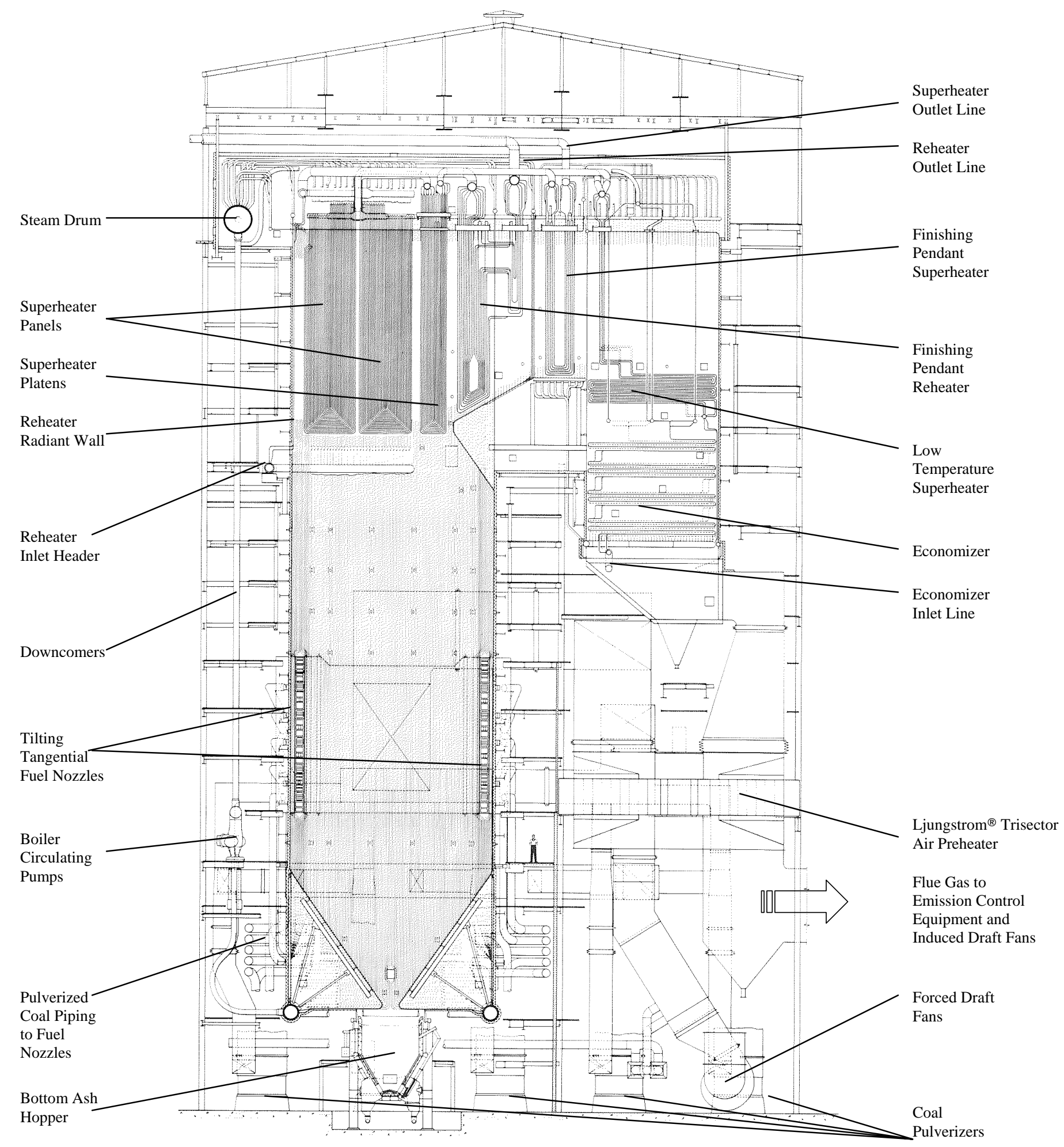

Figure 3-2: Study Unit Boiler (Existing Conesville Unit \#5 Steam Generator) 
The steam generator can be described as a tangentially coal fired, subcritical pressure, controlled circulation, and radiant reheat wall unit. The furnace is a single cell design utilizing five elevations of tilting tangential coal burners. The furnace is about $15.75 \mathrm{~m}(51.67 \mathrm{ft})$ wide, 13.51

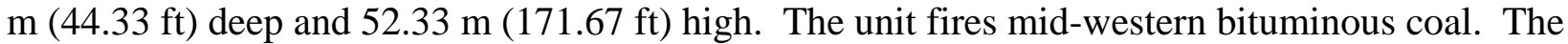
coal is supplied to the five burner elevations with five RP-903 coal pulverizers. The RP-903 bowl mill has a design base capacity of $15 \mathrm{~kg} / \mathrm{s}(119,000 \mathrm{lb} / \mathrm{hr})$ of coal. The coal has a Hardgrove Grindability Index of 55 and is pulverized to a fineness of $70 \%$ through 200 mesh. The unit is configured in a "Conventional Arch" type design and is representative in many ways of a large number of coal-fired units in use throughout the US today. The unit is designed to generate about $391 \mathrm{~kg} / \mathrm{s}\left(3.1 \times 10^{6} \mathrm{lbm} / \mathrm{hr}\right)$ of steam at nominal conditions of 175 bara (2,535 psia) and $538{ }^{\circ} \mathrm{C}$ $\left(1,000^{\circ} \mathrm{F}\right)$ with reheat steam also heated to $538^{\circ} \mathrm{C}\left(1,000^{\circ} \mathrm{F}\right)$. Outlet steam temperature control is provided with de-superheating spray and burner tilt. These represent the most common steam cycle operating conditions for the existing US fleet of utility scale power generation systems.

The superheater is divided into four major sections. Saturated steam leaving the steam drum first cools the roof and walls of the rear pass before supplying the low temperature superheater section. The low temperature superheater section is located in the rear pass of the unit and is a horizontal section with the outlet tubes in a vertical orientation adjacent to the finishing superheater section. Steam leaving the low temperature superheater section first flows through the de-superheater spray stations and then to the radiant superheat division panel section. The division panels are located in the upper furnace directly above the combustion zone of the lower furnace. Steam leaving the division panel section flows to the superheater platen section, which is a more closely spaced vertical section located between the panels and the finishing pendant reheater. Steam leaving the platens flows into the finishing superheater section which is also a pendant section located downstream of the pendant reheater, just before the gas turns downward to enter the low temperature superheater section in the rear pass of the unit. Steam leaving the finishing superheater is piped to the high-pressure turbine where it is expanded to reheat pressure and then returned to the reheat de-superheating spray station.

The reheater is divided into two sections, a low temperature radiant wall section followed by a spaced finishing pendent section. Steam is supplied to the reheater radiant wall from the desuperheating spray station, which is fed from the high-pressure turbine exhaust. The reheater radiant wall section is located in the upper furnace and covers the entire front wall and most of the two sidewalls of the upper furnace. The pendant finishing reheat section is located above the arch between the superheat platen and superheat finishing sections. Steam leaving the finishing reheater is returned to the intermediate pressure turbine where it continues its expansion through the intermediate and low-pressure turbines before being exhausted to the condenser.

The gases leaving the low temperature superheater section are then further cooled in an economizer section. The economizer is comprised of four banks of spiral-finned tubes $(0.79$ fins/cm; 2 fins/inch), which heats high-pressure boiler feedwater before it is supplied to the steam drum. The feedwater supplying the economizer is supplied from the final extraction feedwater heater.

Flue gas leaving the economizer section then enters the Ljungstrom ${ }^{\circledR}$ trisector regenerative air heater, which is used to heat both the primary and secondary air streams prior to combustion in the lower furnace. Particulate matter is removed from the cooled flue gas leaving the air heater in an 
electrostatic precipitator (ESP) and sulfur dioxide is removed in a lime based flue gas desulfurization (FGD) system. The induced draft fans are located between the ESP and the FGD. The cleaned flue gas leaving the FGD system is then exhausted to the atmosphere through the stack, which also serves twin Unit \#6. The induced draft and forced draft fans are controlled to operate the unit in a balanced draft mode with the furnace maintained at a slightly negative pressure, typically -1.25 mbar (-0.5 inwg).

The high pressure superheated steam leaving the finishing superheater is expanded through the high-pressure steam turbine, reheated in the two-stage reheater of the steam generator and returned to the intermediate pressure turbine. The steam continues its expansion through the intermediate pressure and low-pressure turbine sections where it expands to condenser pressure. The cold water for the condenser is supplied from mechanical draft cooling towers. The condensate pumps, which are motor driven, take the condensed water (condensate) from the condenser hot well and supply the condensate to the low-pressure heaters, which are followed by the deaerator. The steam cycle utilizes six regenerative feedwater heaters in series (three low-pressure heaters, a deaerator, and two high-pressure heaters) where the feedwater is preheated to about $256{ }^{\circ} \mathrm{C}$ (493 $\left.{ }^{\circ} \mathrm{F}\right)$. The feedwater preheating is provided by steam extracted from the turbine at six different locations. The boiler feed pump (BFP), which provides high-pressure feedwater to the highpressure heaters and then the boiler, is located downstream of the deaerator. The BFP is steam turbine driven with steam provided from the intermediate pressure turbine exhaust and expanded to condenser pressure. The preheated feedwater leaving the high-pressure heaters is supplied to the economizer of the steam generator unit. The turbine/generator produces about $463 \mathrm{MW}$ of electric power at Maximum Continuous Rating (MCR). 


\section{STUDY CASES PERFORMANCE ANALYSIS}

This section describes the performance of the eight selected study cases. First, a case-to-case comparison of overall plant performance is presented in Section 4.1. Next, detailed performance for each case is summarized for all major plant sections. The performance of each case includes a basic process description, a material and energy balance, boiler analysis results, steam cycle performance, flue gas desulfurization (FGD) system analysis, and an overall plant performance summary.

There is one "business as usual" air fired Base Case without $\mathrm{CO}_{2}$ capture, which can be used for comparison with the capture cases. The Base Case is copied directly from the original study (Bozzuto et al., 2001) and is also included here for convenience.

There are a total of seven oxygen-fired cases with $\mathrm{CO}_{2}$ capture. Two of the oxygen-fired cases (Case 1 and Case 2) utilize cryogenic type air separation units (ASU). Case 1 is adapted from the original study (Bozzuto et al., 2001) and is included here for comparison purposes. Case 2 is an update of Case 1 to include a state of the art cryogenic ASU and an updated gas processing unit (GPU). Plant performance, retrofit costs and economics have been updated also.

There are five cases that use variations of the CAR oxygen production process. The process variations were selected by Linde and Alstom in an effort to define the most economical configuration of the CAR system in this retrofit application. Three of the cases use flue gas as a sweep gas and two of the cases use steam for the sweep gas. Cases 3a, 3b, and 3c represent the retrofit of Conesville Unit \#5 using the Ceramic Autothermal Recovery (CAR) oxygen production process with flue gas used as the sweep gas for the CAR process. Cases $4 \mathrm{a}$ and $4 \mathrm{~b}$ represent the retrofit of Conesville Unit \#5 using the Ceramic Autothermal Recovery (CAR) oxygen production process with steam used as a sweep gas for the CAR process.

What follows in this section is first a performance summary and comparison of all the cases followed by a case-by-case detailed description of the performance analysis for each plant.

\subsection{Plant Performance Summary - All Cases}

Table 4-1 shows detailed overall plant performance summaries for all eight cases included in this study. Included in this table are various parameters for the boiler, the $\mathrm{CO}_{2}$ removal system, the steam cycle, an auxiliary power list, overall plant performance, and plant $\mathrm{CO}_{2}$ emissions. Figure 4-1 shows several comparison plots, which include all the cases, of selected key plant performance parameters from Table 4-1. 


\section{Table 4-1: Plant Performance Summary - All Cases}

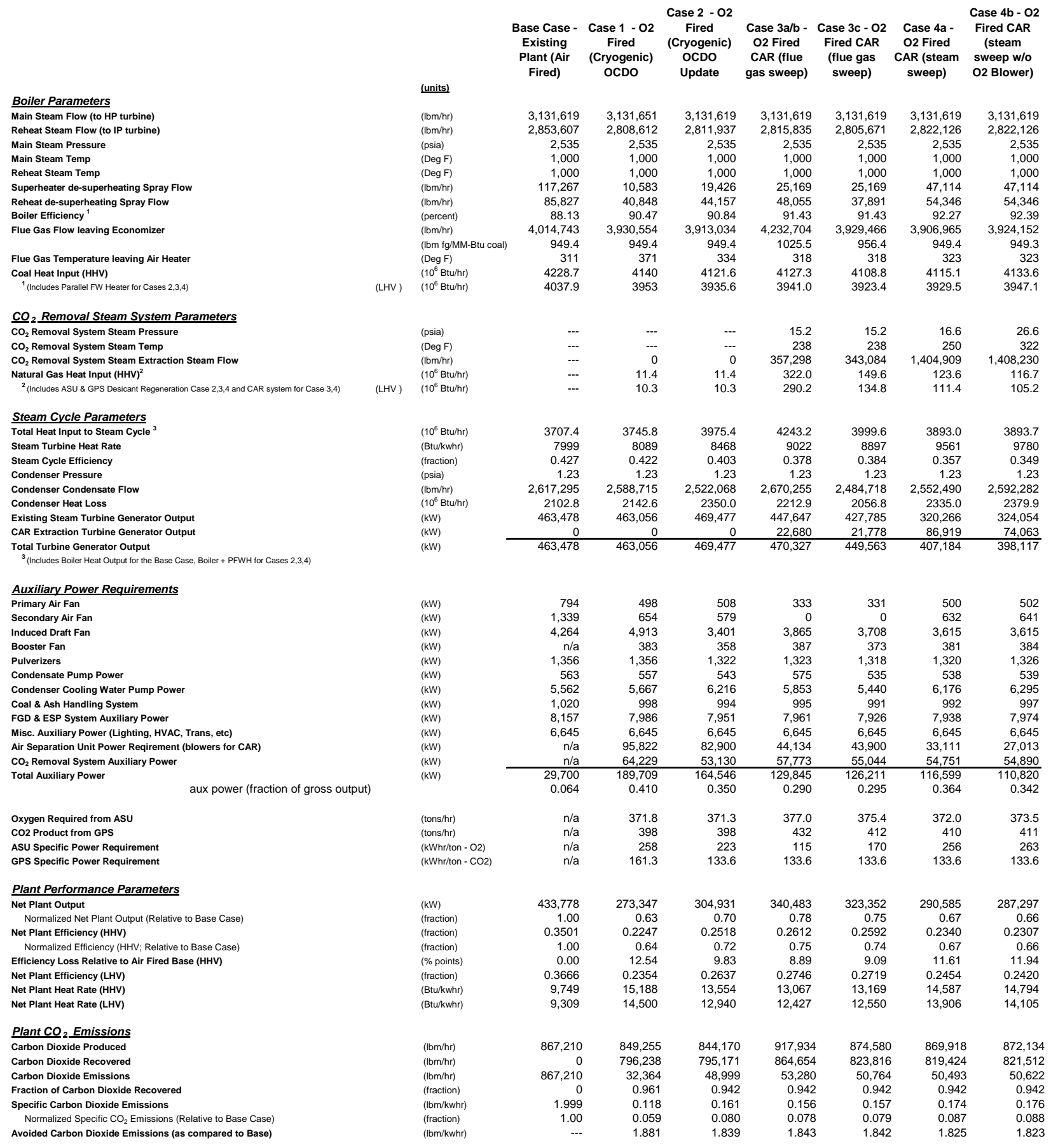

The upper two graphs of Figure 4-1 show $\mathrm{CO}_{2}$ emissions. All the capture options investigated capture $94-96 \%$ of the $\mathrm{CO}_{2}$ produced. On a normalized basis, the $\mathrm{CO}_{2}$ emissions range from 0.12 $0.18 \mathrm{lbm} / \mathrm{kWh}$. In general, there is not much difference among the individual cases with respect to $\mathrm{CO}_{2}$ emissions. 
The next two graphs of Figure 4-1 show the net electrical output from these plants. These graphs show that the CAR cases 3a and 3b produce the highest output with about $78 \%$ of the Base Case output, with Case 3c next highest at $75 \%$. By way of comparison the updated cryogenic ASU case (Case 2, which represents the benchmark case) produces about $70 \%$ of the Base Case output. The steam sweep cases (4a and 4b) were significantly lower with about $66-67 \%$ of the Base Case output and Case 1 was the lowest with about $63 \%$ of the Base Case output.

The next two graphs of Figure 4-1 are related to the overall plant thermal efficiency (HHV basis). The CAR cases 3a and 3b show the best thermal efficiency at 26.12\% which represents an efficiency loss, as compared to the Base Case, of 8.89 percentage points. The CAR case 3c shows similar performance with a thermal efficiency of 25.92\% (i.e. an efficiency loss, as compared to the Base Case, of 9.09 percentage points). By way of comparison the updated cryogenic ASU case (Case 2) shows a thermal efficiency of $25.18 \%$, which represents an efficiency loss, as compared to the Base Case, of 9.83 percentage points. The steam sweep cases (4a and $4 \mathrm{~b}$ ) were significantly lower with a thermal efficiency of 23.40-23.07\% respectively (i.e. an efficiency loss, as compared to the Base Case, of 11.61-11.94 percentage points)

The fourth graph down on the left-hand column of Figure 4-1 shows the specific oxygen production power requirements. As a benchmark, the updated cryogenic ASU case (Case 2) shows a specific oxygen production power requirement of about $223 \mathrm{kWh} /$ ton of delivered oxygen. By way of comparison the CAR cases 3a and 3b show a significant advantage in this parameter with a value of $115 \mathrm{kWh} /$ ton of delivered oxygen (almost a 50\% reduction) and CAR case 3c shows about $170 \mathrm{kWh} /$ ton of delivered oxygen (a 24\% reduction). The steam sweep cases (Cases $4 \mathrm{a}$ and 4b) show no advantage as compared to Case 2 with oxygen production power requirements for these CAR cases about 15-18\% higher than for Case 2.

The fourth graph down on the right-hand column of Figure 4-1 shows the impact of the low-level heat integration on the steam turbine heat rate. Although the low-level heat integration degrades the steam turbine heat rate, the net power output from the plant is increased as well as the overall plant thermal efficiency.

The final two graphs show natural gas usage for the systems. The cryogenic cases (Case 1 and 2) use a very small amount for desiccant regeneration (drying) in the gas processing unit. Cases 3a and 3b (flue gas sweep) use a significant quantity in the CAR system (about $7.8 \%$ of the coal heat input). Case 3c, which is the same as 3b except for the use of low terminal difference external heat exchangers (regenerators), is able to reduce the natural gas usage to about $3.6 \%$ of the coal heat input. Cases $4 \mathrm{a}$ and $4 \mathrm{~b}$ (steam sweep gas cases) require a natural gas usage of about $3.0 \%$ of the coal heat input. 

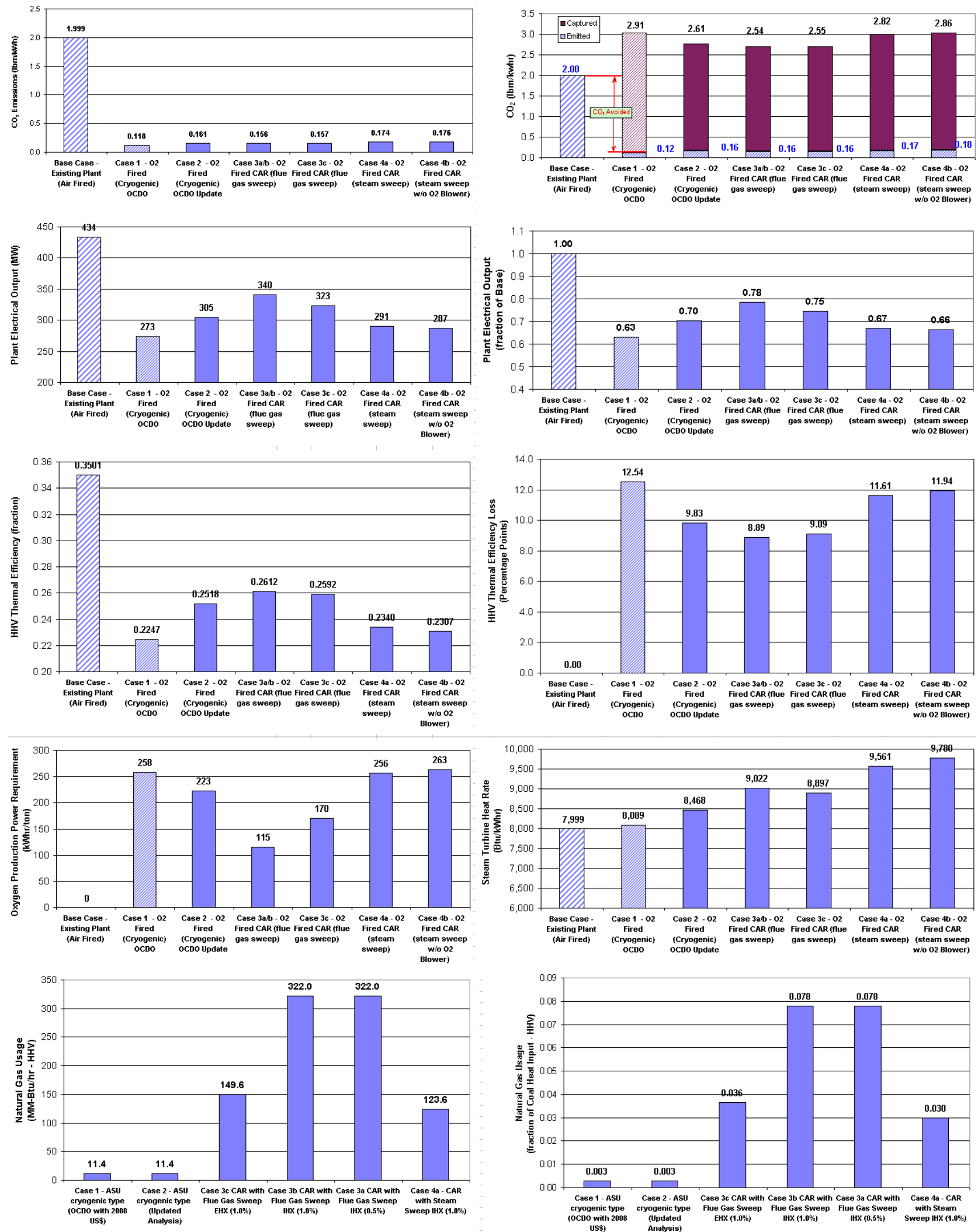

Figure 4-1: Selected Plant Performance Parameter Comparison - All Cases 


\subsection{Base Case Performance Analysis}

The Base Case performance analysis provided in this section is the same as that provided previously (Bozzuto, et al., 2001; Ramezan, Nsakala, Liljedahl, 2007). It is provided here also for completeness and convenience since this represents an important comparison case.

The Base Case can be described as the unmodified existing unit firing coal with air at full load and without capture of $\mathrm{CO}_{2}$ from the flue gas. This represents the "business as usual" operating scenario and is used as the basis of comparison for the $\mathrm{CO}_{2}$ removal options investigated in this study. The development of the Base Case was done as part of the original study (Bozzuto, et al., 2001) and was not repeated for the current study. The Base Case performance from the original study was used unchanged as the Base Case performance for the current study. A brief description of the Base Case development (extracted from the original study report) is provided in this section.

\subsubsection{Calibration of the Boiler Computer Model - Base Case}

The first step in the calculation of a Base Case was to set up a steady state performance computer model of the Conesville \#5 steam generator unit. This involves calculating or obtaining all the geometric information for the unit as required by the proprietary Reheat Boiler Program (RHBP). The RHBP provides an integrated, steady state performance model of the Boiler Island including, in addition to the steam generator unit, pulverizers, air heater, and steam temperature control logic. The RHBP is used to size components and/or predict performance of existing components. In this study, since the boiler island component sizes are known, the RHBP was used exclusively for calculating unit performance.

The next step in the heat transfer analysis of the Base Case was to calibrate the RHBP model of the unit. This involves obtaining test data (with air firing) for the existing unit and "adjusting” the performance model to match the test data. The required test data includes steam temperatures entering and leaving each major heat exchanger section in the unit, steam pressures, coal analysis, flue gas oxygen content, etc. The "adjustments or calibration factors" for the model are in the form of "surface effectiveness factors" and "fouling factors" for the various heat exchanger sections throughout the unit. Unfortunately, the test data used for calibration of this model was not totally complete and several assumptions were required in the calibration process. Although all the required data was not available, primarily due to existing instrumentation limitations, a satisfactory calibrated model was obtained.

Using the calibrated boiler model and providing it with new steam side inputs (mass flows, temperatures, and pressures) from the agreed upon MCR steam turbine material and energy balance, the model was run and performance was calculated for the Base Case. The performance for the overall power plant system is described in Section 4.2.7 with the boiler performance shown in Section 4.2.4 and the steam turbine performance in Section 4.2.5.

\subsubsection{Process Description - Base Case}

The simplified gas side process flow diagram (PFD) for the Base Case boiler island is shown in Figure 4-2 and the associated material and energy balance for this case is shown in Table 4-2. The stream numbers in the material and energy balance table correspond to the stream numbers shown in Figure 4-2. 


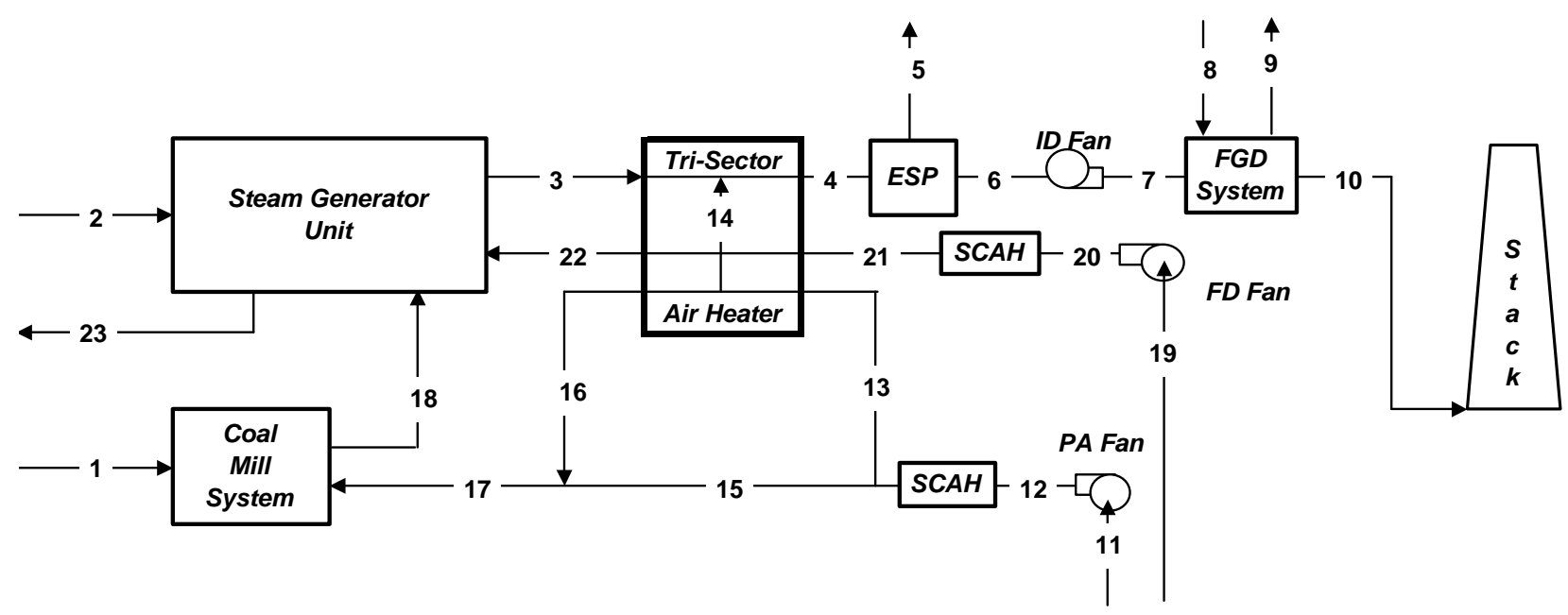

Figure 4-2: Simplified Gas Side Process Flow Diagram (Base Case)

Air for combustion of the coal is provided to the unit in two streams, primary and secondary air streams, which are raised to the proper pressure with the existing PA and FD fans. The primary and secondary air streams (Streams 11 and 19 respectively) are preheated separately in the existing Ljungstrom air heater. Steam coil air heaters are also provided in each stream for cold end protection of the main air heater in cold ambient conditions. The primary air stream, which represents about $24 \%$ of the total combustion air, feeds the coal mills. The mill outlet temperature (Stream 18) is controlled to the proper value with the existing control system through bypassing some of the cold primary air (Stream 15) around the air heater and mixing it with the hot primary air (Stream 16) leaving the air heater. The mixture forms the tempered primary air stream (Stream 17) entering the coal mills.

The coal-air mixture leaving the mills (Stream 18) is combusted in the furnace with the preheated secondary air (Stream 22). The furnace pressure is controlled with the draft system (FD, PA, and ID fans \& dampers) to run just slightly lower than atmospheric pressure. Because of this, a small quantity of infiltration air (Stream 2) leaks into the unit. Bottom ash (Stream 23), which typically amounts to about $20 \%$ of the ash contained in the coal, is removed through the furnace hopper located at the bottom of the furnace.

The flue gas and flyash mixture leaving the furnace (Stream 3) is cooled in the air heater. The fly ash is removed from the flue gas in the electrostatic precipitator (ESP). The flue gas leaving the ESP is raised to the proper pressure for discharge through the stack by the ID fans. The flue gas leaving the existing ID fans (Stream 7) enters the existing FGD system where $\mathrm{SO}_{2}$ is removed. The flue gas leaving the FGD system (Stream 10) flows to the stack, which is a common stack for Conesville Units \#5 and \#6, and is discharged to the atmosphere. 


\subsubsection{Material and Energy Balance - Base Case}

The material and energy balance for the Base Case is shown in Figure 4-2 below. The stream numbers correspond to Figure 4-2 shown above which shows the simplified boiler island PFD. 
Table 4-2: Gas Side Material and Energy Balance (Base Case)

\begin{tabular}{|c|c|c|c|c|c|c|c|c|c|c|c|c|c|c|}
\hline \begin{tabular}{|l|} 
Constituent \\
\end{tabular} & (Units) & 1 & 2 & 3 & 4 & 5 & 6 & 7 & 8 & 9 & 10 & 11 & 12 & 13 \\
\hline $\mathrm{O}_{2}$ & (lbm/hr) & 26586 & 42147 & 101097 & 144817 & & 144817 & 144817 & 5355 & & 144578 & 203237 & 203237 & 112918 \\
\hline $\mathrm{N}_{2}$ & $"$ & 4868 & 139626 & 2797385 & 2942220 & & 2942220 & 2942220 & & & 2942220 & 673283 & 673283 & 374075 \\
\hline $\mathrm{H}_{2} \mathrm{O}$ & $"$ & 37820 & 2357 & 228849 & 231294 & & 231294 & 231294 & 250709 & 45979 & 436024 & 11365 & 11365 & 6314 \\
\hline $\mathrm{CO}_{2}$ & $"$ & & & 867210 & 867210 & & 867210 & 867210 & & & 866156 & & & \\
\hline $\mathrm{SO}_{2}$ & $"$ & & & 20202 & 20202 & & 20202 & 20202 & & & 1063 & & & \\
\hline $\mathrm{H}_{2}$ & $"$ & 16102 & & & & & & & & & & & & \\
\hline Carbon & $"$ & 236655 & & & & & & & & & & & & \\
\hline Sulfur & $"$ & 10110 & & & & & & & & & & & & \\
\hline $\mathrm{Ca}$ & $"$ & & & & & & & & 12452 & & & & & \\
\hline Mg & $"$ & & & & & & & & 584 & & & & & \\
\hline MgO & $"$ & & & & & & & & & 484 & & & & \\
\hline $\mathrm{MgSO}_{3}$ & $"$ & & & & & & & & & 1293 & & & & \\
\hline $\mathrm{MgSO}_{4}$ & $"$ & & & & & & & & & 94 & & & & \\
\hline $\mathrm{CaSO}_{3}$ & $"$ & & & & & & & & & 35179 & & & & \\
\hline $\mathrm{CaSO}_{4}$ & $"$ & & & & & & & & & 2468 & & & & \\
\hline $\mathrm{CaCO}_{3}$ & $"$ & & & & & & & & & 2398 & & & & \\
\hline Ash / Inerts & $"$ & 42313 & & 33851 & 33851 & 33851 & & & 968 & 968 & & & & \\
\hline Total & (lbm/hr) & Raw Coal & $\begin{array}{l}\text { Leakage Air } \\
184130\end{array}$ & $\begin{array}{c}\text { Fluegas to } \mathrm{AH} \\
4014743\end{array}$ & $\begin{array}{r}\text { Fluegas to ESP } \\
4205743\end{array}$ & Flyash & $\begin{array}{c}\text { Fluegas to ID Fan } \\
4205743\end{array}$ & $\begin{array}{r}\text { Fluegas to FGD } \\
4205743\end{array}$ & Lime Slurry & FGD Disposal & $\begin{array}{r}\text { Fgas to CO2 Sep } \\
4390042\end{array}$ & $\begin{array}{r}\text { Pri Air to PA Fan } \\
887885\end{array}$ & $\begin{array}{r}\text { PA from PA Fan } \\
887885\end{array}$ & $\begin{array}{l}\text { Pri Air to } \mathrm{AH} \\
493308\end{array}$ \\
\hline Total Solids & $"$ & 374455 & & 33851 & 33851 & 33851 & & & 14003 & 42884 & & & & \\
\hline Total Flow & $"$ & 374455 & 184130 & 4048594 & 4239594 & 33851 & 4205743 & 4205743 & 270067 & 88863 & 4390042 & 887885 & 887885 & 493308 \\
\hline Temperature & (Deg F) & 80 & 80 & 706 & 311 & 311 & 311 & 325 & 80 & 136 & 136 & 80 & 92 & 92 \\
\hline Pressure & (Psia) & 14.7 & 14.7 & 14.6 & 14.3 & 14.7 & 14.2 & 15.0 & 14.7 & 14.7 & 14.7 & 14.7 & 15.6 & 15.6 \\
\hline $\mathbf{h}_{\text {sensible }} \|$ & (Btu/lbm) & 0.000 & 0.000 & 161.831 & 57.924 & 57.750 & 57.924 & 61.384 & 0.000 & 14.116 & 14.116 & 0.000 & 2.899 & 2.899 \\
\hline Chemical & $\left(10^{6} \mathrm{Btu} / \mathrm{hr}\right)$ & 4228.715 & & & & & & & & & & & & \\
\hline Sensible & $\left(10^{6} \mathrm{Btu} / \mathrm{hr}\right)$ & 0.000 & 0.000 & 655.007 & 245.567 & 1.955 & 243.612 & 258.166 & 0.000 & 3.314 & 63.916 & 0.000 & 2.574 & 1.430 \\
\hline Latent & $\left(10^{6} \mathrm{Btu} / \mathrm{hr}\right)$ & 0.000 & 2.475 & 240.291 & 242.858 & 0.000 & 242.858 & 242.858 & 0.000 & 0.000 & 464.020 & 11.933 & 11.933 & 6.630 \\
\hline Total Energy $^{(1)}$ & $\left(10^{6} \mathrm{Btu} / \mathrm{hr}\right)$ & 4228.715 & 2.475 & 895.298 & 488.425 & 1.955 & 486.470 & 501.024 & 0.000 & 3.314 & 527.936 & 11.933 & 14.507 & 8.060 \\
\hline
\end{tabular}




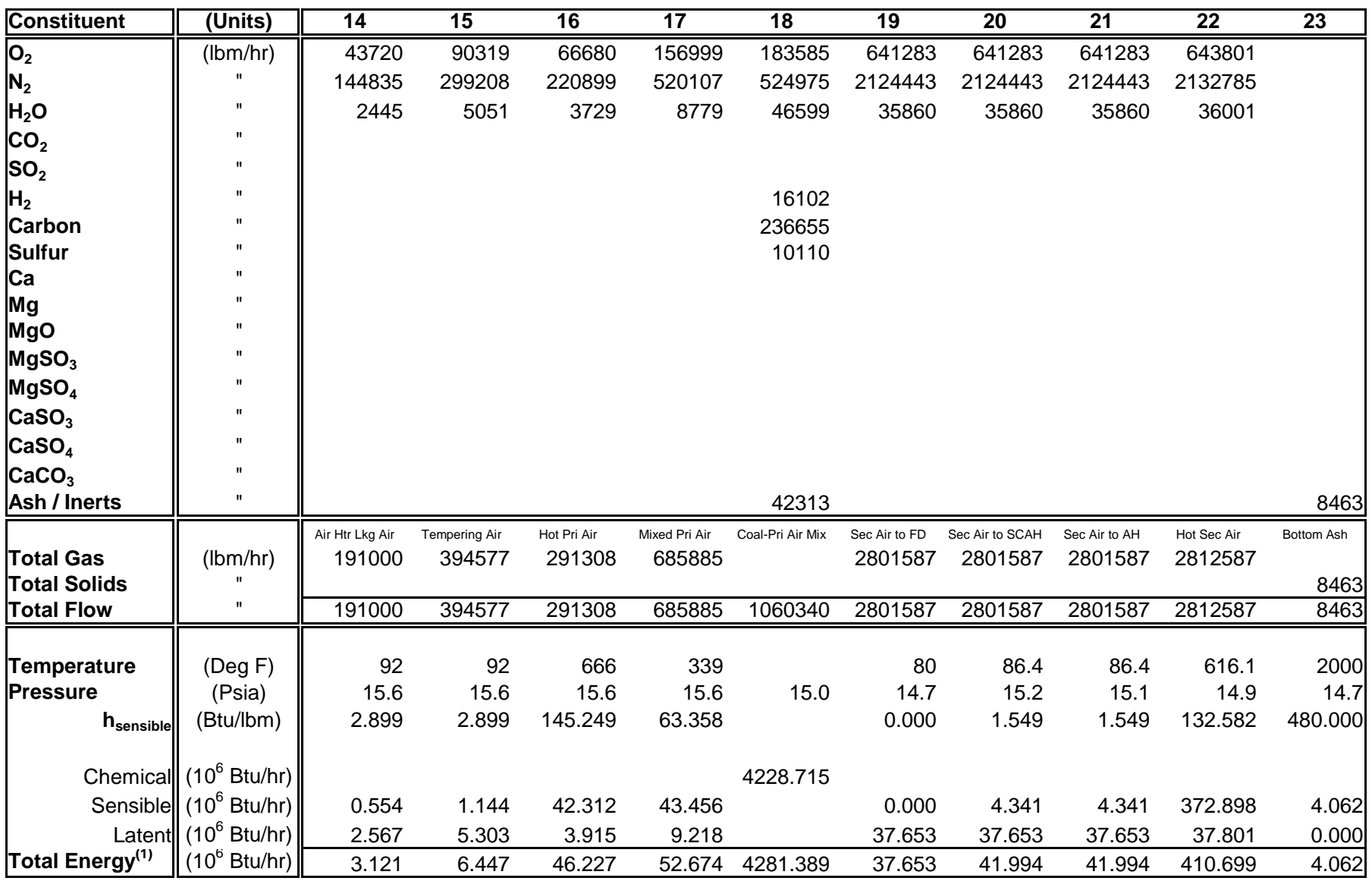

Notes:

(1) Energy Basis; Chemical based on Higher Heating Value (HHV); Sensible energy above 80F; Latent based on 1050 Btu/lbm of water vapor 


\subsubsection{Boiler Analysis Results - Base Case}

The main steam flow for this case and all other cases in this study is $395 \mathrm{~kg} / \mathrm{s}$ (3,131,619 lbm/hr). The cold reheat flow leaving the high-pressure turbine for this case and all other cases in this study is $348 \mathrm{~kg} / \mathrm{s}(2,765,058 \mathrm{lbm} / \mathrm{hr})$. The hot reheat flow (including de-superheating spray) returning to the intermediate pressure turbine for this case is $359 \mathrm{~kg} / \mathrm{s}(2,850,885 \mathrm{lbm} / \mathrm{hr})$. The overall steam conditions produced by the existing Conesville \#5 steam generator unit are shown in Table 4-3 below.

Table 4-3: Boiler/Turbine Steam Flows and Conditions (Base Case)

\begin{tabular}{|l|l|rrrrr|}
\hline \multicolumn{2}{|c|}{} & SHO & FWI & ECO & RHO & RHI \\
\hline Mass Flow & (lbm/hr) & 3131619 & 3131619 & 3017507 & 2850885 & 2850885 \\
Pressure & (psia) & 2535 & 3165 & 3070 & 590.8 & 656.5 \\
Temperature & (Deg F) & 1005 & 496.2 & 630 & 1005 & 607.7 \\
Enthalpy & (Btu/lbm) & 1459.7 & 483.2 & 652.8 & 1517.1 & 1290.4 \\
\hline
\end{tabular}

Notes:

SHO = Superheater Outlet; FWI = Feedwater Inlet; ECO = Economizer Outlet; RHO = Reheater Outlet; RHI = Reheater Inlet

To produce these conditions, the superheat circuit requires about 3.6 percent spray and the reheat circuit requires about 3.1 percent spray to maintain required steam outlet temperatures. The burner tilts are -10 degrees (the minimum value the customer uses). The boiler was fired with 15 percent excess air and the resulting boiler efficiency calculated for this case was 88.13 percent with an air heater exit gas temperature of $155^{\circ} \mathrm{C}\left(311^{\circ} \mathrm{F}\right)$.

\subsubsection{Steam Cycle Performance - Base Case}

The selected steam turbine energy and material balance for Conesville Unit \#5, which provides the basis for developing the steam turbine performance calculations presented in this study is shown below in Figure 4-3.

This turbine heat balance diagram, created by Black \& Veatch, is a valves wide open, 5 percent over pressure case utilizing a condenser pressure of 0.084 bara (2.5 in-Hga) and a steam extraction for air heating of $6.3 \mathrm{~kg} / \mathrm{s}(50,000 \mathrm{lbm} / \mathrm{hr})$. Following general guidelines it is assumed that this diagram reflects the design maximum allowable flow conditions of the existing turbine. 


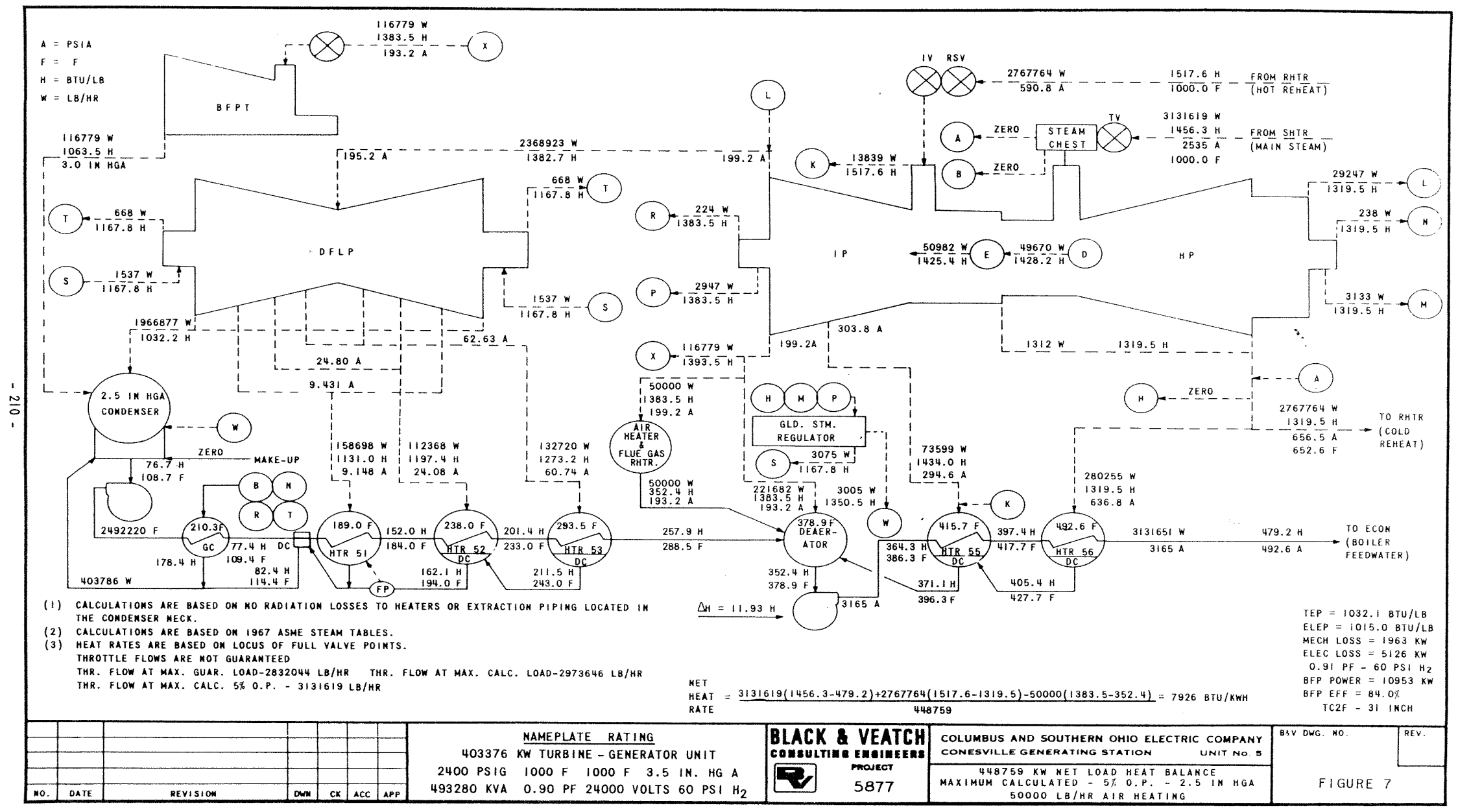

Figure 4-3: Selected Conesville \#5 Turbine Heat Balance (basis for steam turbine modeling) 
In order to reflect the key performance parameters of the selected unit "as designed", the Black \& Veatch heat balance diagram was re-modelled and the following adaptations were made:

- During normal operation no steam is required to feed the steam coil air heaters $(6.3 \mathrm{~kg} / \mathrm{s}$ or $50,000 \mathrm{lb} / \mathrm{hr}$ ). Therefore, this extraction flow is set to zero.

- Reheat de-superheater spray water flow rate of $11 \mathrm{~kg} / \mathrm{s}(85,827 \mathrm{lb} / \mathrm{hr})$ is to be used as calculated in associated boiler performance computer simulation runs.

The final steam cycle for the Base Case is shown schematically in Figure 4-4. Figure 4-5 shows the associated T-S and Mollier diagrams, which illustrate the process on temperature - entropy and enthalpy - entropy coordinates respectively. The high-pressure turbine expands about 391 $\mathrm{kg} / \mathrm{s}\left(3.1 \times 10^{6} \mathrm{lbm} / \mathrm{hr}\right)$ of steam at 175 bara $(2,535 \mathrm{psia})$ and $538{ }^{\circ} \mathrm{C}\left(1,000{ }^{\circ} \mathrm{F}\right)$. Reheat steam is returned to the intermediate pressure turbine at 41 bara (591 psia) and $538{ }^{\circ} \mathrm{C}\left(1,000{ }^{\circ} \mathrm{F}\right)$. These steam conditions (temperatures, pressures) represent the most common steam cycle operating conditions for existing utility scale power generation systems in use today in the US. The condenser pressure used for the Base Case and all other cases in this study was 0.084 bara (2.5 in Hga). The steam turbine performance analysis results show the generator produces an output of $463,478 \mathrm{kWe}$ and the steam turbine heat rate is about 8,440 kJ/kWh $(7,999 \mathrm{Btu} / \mathrm{kWh})$.

The key parameters describing the Base Case are listed below:

- $\quad$ Live steam pressure

- Live steam temperature

- Live steam flow

- Steam for air pre-heating

- RH de-superheating spray

- Backpressure

- Power output
$2,535 / 175$

$1,000 / 538$

$3,131,619$ / 395

$0 / 0$

$85,827 / 11$

$2.5 / 0.084$

463,478 psia / bara

${ }^{\circ} \mathrm{F} /{ }^{\circ} \mathrm{C}$

$\mathrm{lbm} / \mathrm{hr} / \mathrm{kg} / \mathrm{s}$

$\mathrm{lbm} / \mathrm{hr} / \mathrm{kg} / \mathrm{s}$

$\mathrm{lbm} / \mathrm{hr} / \mathrm{kg} / \mathrm{s}$

in-Hg abs / bara

$\mathrm{kW}$ 


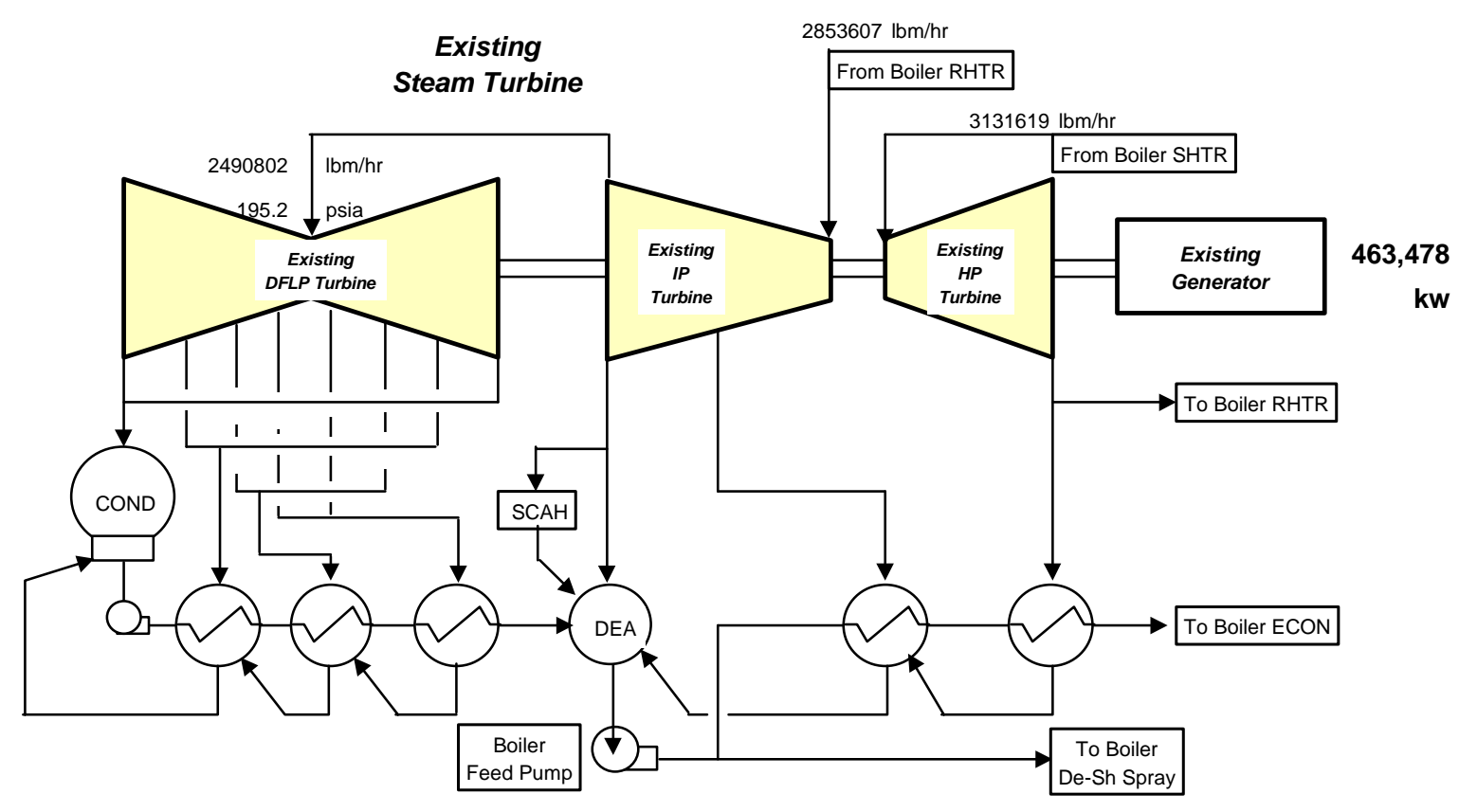

Steam Cycle Energy Balance

\begin{tabular}{|lrrr|}
\hline \hline Energy Outputs & $\left(10^{6} \mathrm{Btu} / \mathrm{hr}\right)$ & Energy Inputs & $\left(10^{6} \mathrm{Btu} / \mathrm{hr}\right)$ \\
Steam Turbine Power Output & 1606 & Boiler Heat Input & 3707 \\
Steam Coil Air Heater Output & 0 & Condensate Pump & 2 \\
Condenser Loss & 2103 & Total Energy Input & 3709 \\
\cline { 2 - 5 } \multicolumn{1}{r}{ Total Energy Output } & 3709 & In - Out & 0 \\
\hline
\end{tabular}

Turbine Heat Rate

7999

(Btu/kwhr)

Figure 4-4: Steam Cycle Schematic (Base Case)
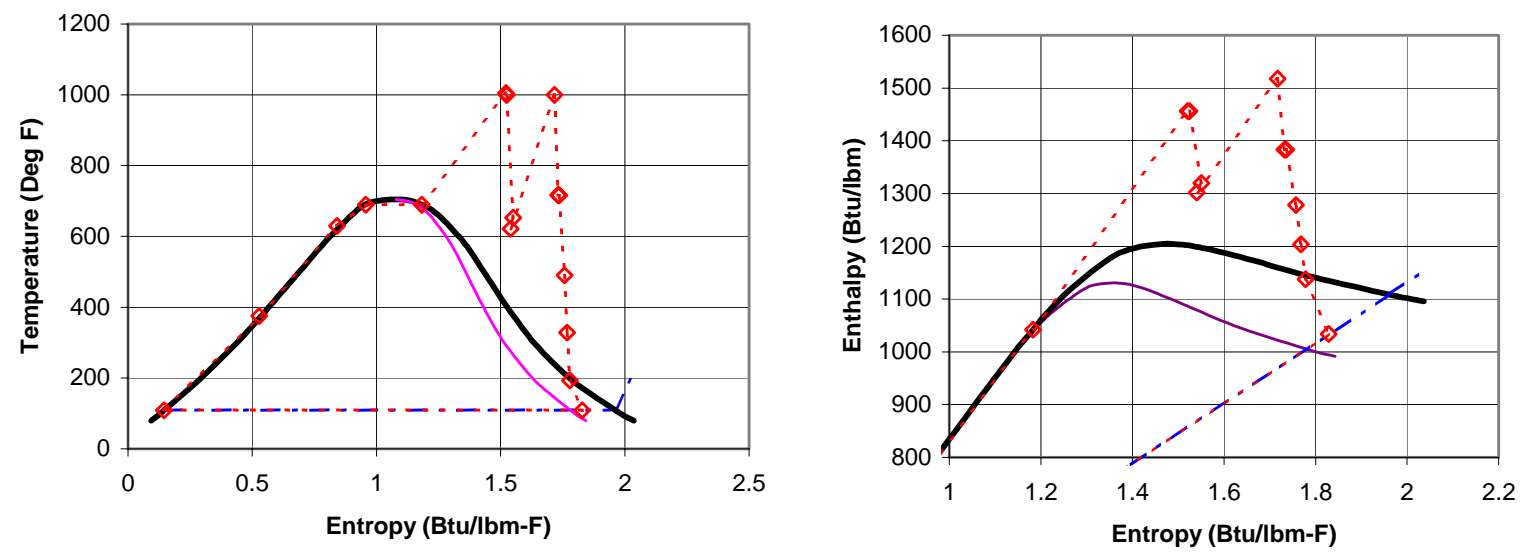

\begin{tabular}{ll}
\hline--- - Condenser Pressure & \\
$-10 \%$ Moisture & $--\diamond-$ Saturation Line \\
- Steam Cycle
\end{tabular}

\begin{tabular}{|ll|}
\hline - 10\% Moisture & - Saturation Line \\
--- Condenser Pressure & $-\diamond-$ - Steam Cycle
\end{tabular}

Figure 4-5: Steam Cycle T-S and Mollier Diagrams (Base Case) 


\subsubsection{Flue Gas Desulfurization System Analysis - Base Case}

Figure 4-6 shows the process flow diagram for the existing Flue Gas Desulfurization (FGD) system. The flue gas leaving the ID fan (Stream 7) is delivered to the absorber, which consists of a tray followed by a two-stage spray system. The incoming gas is saturated as it passes through the scrubbing slurry contained on the tray and through the two spray levels. The active component of the scrubbing slurry is calcium oxide (Stream 8a), which reacts with sulfur dioxide to form calcium bisulfite (Stream 9). The scrubbing slurry is circulated from the reagent feed tank that forms the base of the scrubber to the spray levels. The solids loading in the scrubbing slurry controls the blow down from the reaction tank to by-product disposal. The flue gas passes through chevron type mist eliminators that remove entrained liquid before exiting the scrubber (Stream 10). The water utilized in spray washing the mist eliminators also serves as make-up (Stream 8b).

Table 4-4 identifies the assumptions that were made in predicting the FGD performance. Table 4-5 shows the gas constituents at the existing absorber inlet and outlet locations. Results show a $\mathrm{CO}_{2} / \mathrm{SO}_{2}$ mole ratio of 63 and an $\mathrm{SO}_{2}$ removal efficiency of $94.9 \%$, corresponding to a value of $104 \mathrm{ppmv}$ at the outlet of the absorber.

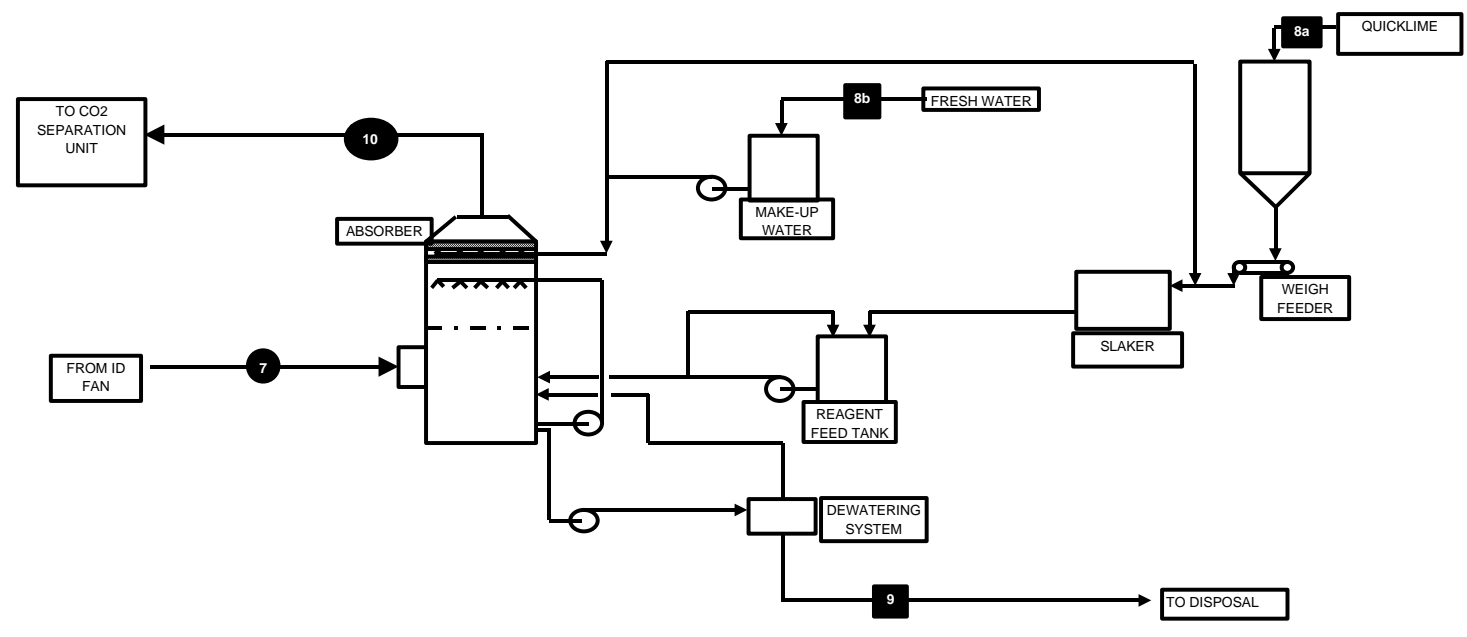

Figure 4-6: Existing Flue Gas Desulfurization System Process Flow Diagram (Base Case) 
Table 4-4: FGD System Analysis Assumptions (Base Case)

\begin{tabular}{|l|c|c|}
\hline Quantity & Unit & Existing Absorber \\
\hline $\mathrm{Ca} / \mathrm{S})$ & & \\
\hline Solids & Mol Ratio & 1.04 \\
\hline $\mathrm{CaO}$ & Wt.\% & 20 \\
\hline $\mathrm{MgO}$ & Wt.\% & 90 \\
\hline Inerts & Wt.\% & 5 \\
\hline Bypass Leakage & Wt.\% & 5 \\
\hline Liquid/Gas (L/G) Ratio & Wt. $\%$ & 2.5 \\
\hline $\mathrm{SO}_{2}$ Removal Efficiency & & 55 \\
\hline \multicolumn{1}{|c|}{ APC } & $\%$ & \\
\hline \multicolumn{1}{|c|}{ Absorber } & $\%$ & 94.8 \\
\hline
\end{tabular}

Table 4-5: Existing FGD System Performance (Base Case)

\begin{tabular}{|c|c|c|c|c|c|c|}
\hline \multirow[b]{3}{*}{ Species } & \multicolumn{6}{|c|}{ Base Case } \\
\hline & \multicolumn{3}{|c|}{ Existing Absorber Inlet } & \multicolumn{3}{|c|}{ Existina Absorber Outlet } \\
\hline & $\mathrm{Mol} / \mathrm{hr}$ & Vol.\% & Unit & $\mathrm{Mol} / \mathrm{hr}$ & Vol.\% & Unit \\
\hline $\mathrm{O}_{2}$ & 4,469 & 3.14 & Vol.\% & 4,461 & 2.91 & Vol.\% \\
\hline $\mathrm{N}_{2}$ & 105,018 & 73.74 & Vol.\% & 105,018 & 68.44 & Vol.\% \\
\hline $\mathrm{H}_{2} \mathrm{O}$ & 12,863 & 9.03 & Vol.\% & 24,228 & 15.79 & Vol.\% \\
\hline $\mathrm{CO}_{2}$ & 19,743 & 13.86 & Vol.\% & 19,720 & 12.85 & Vol. \% \\
\hline $\mathrm{SO}_{2}$ & 315 & 2,212 & vppm & 16 & 104 & vppm \\
\hline $\mathrm{SO}_{2}$ Removal Efficiency, \% & & & & & 94.9 & \\
\hline $\mathrm{CO}_{2} / \mathrm{SO}_{2}$ Mole Ratio & & 63 & & & & \\
\hline & & & & & & \\
\hline
\end{tabular}

\subsubsection{Plant Performance Summary - Base Case}

This system is described previously in Section 3.1 Overall plant performance is summarized in Table 4-6 below. Boiler efficiency (HHV basis) is calculated to be 88.13 percent. The net plant heat rate (HHV basis) is calculated to be $10,285 \mathrm{~kJ} / \mathrm{kWh}(9,749 \mathrm{Btu} / \mathrm{kWh})$ for this case as shown in Table 4-6. Auxiliary power is $29,700 \mathrm{kWe}$ and the net plant output is 433,778 kWe. Carbon dioxide emissions are $109 \mathrm{~kg} / \mathrm{s}(866,156 \mathrm{lbm} / \mathrm{hr})$ or about $907 \mathrm{~g} / \mathrm{kWh}(1.997 \mathrm{lbm} / \mathrm{kWh})$. 


\section{Table 4-6: Overall Plant Performance Summary (Base Case)}

\begin{tabular}{|c|c|c|}
\hline & (units) & $\begin{array}{c}\text { Original } \\
\text { Plant (Base) }\end{array}$ \\
\hline \multicolumn{3}{|l|}{ Euel Paramaters } \\
\hline Coal Heat Input (HHV) & $\left(10^{6} \mathrm{Btu} / \mathrm{hr}\right)$ & 4228.7 \\
\hline Natural Gas Heat Input (HHV) & $\left(10^{6} \mathrm{Btu} / \mathrm{hr}\right)$ & --- \\
\hline Total Fuel Heat Input (HHV) & $\left(10^{6} \mathrm{Btu} / \mathrm{hr}\right)$ & 4228.7 \\
\hline \multicolumn{3}{|l|}{ Steam Cycle Paramaters } \\
\hline Existing Steam Turbine Generator Output & $(\mathrm{kW})$ & 463478 \\
\hline CO2 Removal System Turbine Generator Output & $(\mathrm{kW})$ & 0 \\
\hline Total Turbine Generator Output & $(\mathrm{kW})$ & 463478 \\
\hline Total Auxiliary Power & $(\mathrm{kW})$ & 29700 \\
\hline Net Plant Output & $(\mathrm{kW})$ & 433778 \\
\hline \multicolumn{3}{|l|}{ Overall Plant Performance Paramaters } \\
\hline Net Plant Efficiency (HHV) & (fraction) & 0.3501 \\
\hline Net Plant Efficiency (LHV) & (fraction) & 0.3666 \\
\hline Normalized Efficiency (HHV; Relative to Base Case) & (fraction) & 1.0000 \\
\hline Net Plant Heat Rate (HHV) & (Btu/kwhr) & 9749 \\
\hline Net Plant Heat Rate (LHV) & (Btu/kwhr) & 9309 \\
\hline \multicolumn{3}{|l|}{ Overall Plant $\mathrm{CO}_{2}$ Emissions } \\
\hline Carbon Dioxide Emissions & (lbm/hr) & 866102 \\
\hline Specific Carbon Dioxide Emissions & (lbm/kwhr) & 1.997 \\
\hline Normalized Specific CO2 Emissions (Relative to Base Case) & (fraction) & 1.000 \\
\hline Avoided Carbon Dioxide Emissions (as compared to Base) & (lbm/kwhr) & --- \\
\hline Specific Carbon Dioxide Emissions & (kg/kwhr) & 0.906 \\
\hline Avoided Carbon Dioxide Emissions (as compared to Base) & (kg/kwhr) & --- \\
\hline
\end{tabular}

\subsection{Cryogenic Air Separation Unit (ASU) Cases}

\subsubsection{Case 1: Cryogenic ASU Case from Previous Study}

Case 1 is used for reference only and is described completely in Bozzuto et al, 2001. The plant performance description and analysis is provided for convenience in Appendix I (Section 10) of this report.

\subsubsection{Case-2: Updated Cryogenic ASU Case}

Case 2 represents an updated state of the art version of Case 1 described above. The primary changes made for the update include the use of an improved state of the art ASU and GPU, slight modifications for oxygen distribution within the boiler, and updated investment costs and economics (provided in Sections 6 and 7 respectively) in order to be directly comparable with the current study results for the CAR Cases (i.e. Cases 3a, 3b, 3c, 4a, and 4b). The ASU and GPU performance and cost data were based on information from a previous study (Carney, 2008).

\subsubsection{Process Description - Case 2}

Figure 4-7 shows the basic concept for integrating the cryogenic ASU system with the existing boiler island. The associated material and energy balance is shown in Table 4-7. 
The Flue gas leaving the existing ID fans (Stream 8) is cooled with a feedwater stream that is in parallel with the existing extraction feedwater heaters. The flue gas (Stream 9) then enters the existing FGD system where $\mathrm{SO}_{2}$ is removed. The flue gas leaving the FGD system (Stream 12) is further cooled to about $100 \mathrm{~F}$ in a direct contact gas cooler (DCGC) which minimizes the power requirements for the down stream fans and product gas compression system. The flue gas leaving the booster fan is split into two streams. Stream 15, which amounts to about 25 percent of the total flue gas, provides the product gas to the Gas Processing Unit (GPU) where $\mathrm{CO}_{2}$ compression, purification and liquefaction is completed. Stream 18, which represents about 75 percent of the total flue gas, provides recirculated flue gas to the boiler system.

The recirculated flue gas flow rate is established by the need to maintain a thermal balance between the radiant and convective heat transfer surfaces of the existing steam generator. This thermal balance is established such that allowable metal temperatures throughout the existing pressure parts (superheater, reheater sections, etc.) of the unit are not exceeded. The total quantity of the recirculated flue gas is approximately equal to the quantity of nitrogen contained in the air that is removed by the air separation unit (ASU).

The recirculated flue gas is split into primary and secondary streams, which are raised to the proper pressure with the existing PA and FD fans. At the fan outlets of the primary and secondary streams, oxygen from the new ASU is provided and mixed with the flue gas to obtain the desired oxygen level in these streams. The oxygen level in these streams must be limited in order to avoid material changes to the existing ductwork, air heater, and windbox. The remaining required combustion oxygen (Stream 3c) is preheated with some heat rejected by the gas processing Unit and then is supplied directly to the boiler windbox area of the boiler as shown.

The primary and secondary streams (Streams 21 and 29) are preheated in the existing Ljungstrom air heater. The primary air stream feeds the coal mills. The mill outlet temperature (Stream 26) is controlled to the proper value with the existing control system by bypassing some of the cold primary air (Stream 23) around the air heater and mixing it with the hot primary air (Stream 24). The coal-oxidant mixture leaving the mills (Stream 26) is combusted in the furnace with the preheated secondary oxidant (Stream 30) and the combustion oxygen from Stream 3c. The oxygen content in the flue gas stream leaving the furnace (Stream 4) is controlled to be the same value as it was in the air fired Base Case, about 3.2\% oxygen by volume. This corresponds to a stoichiometry of about 1.04 for this case.

The flue gas leaving the furnace (Stream 4) is cooled in the existing air heater, cleaned of particulate matter in the existing precipitator and raised in pressure by the existing ID fans, which completes the cycle. 


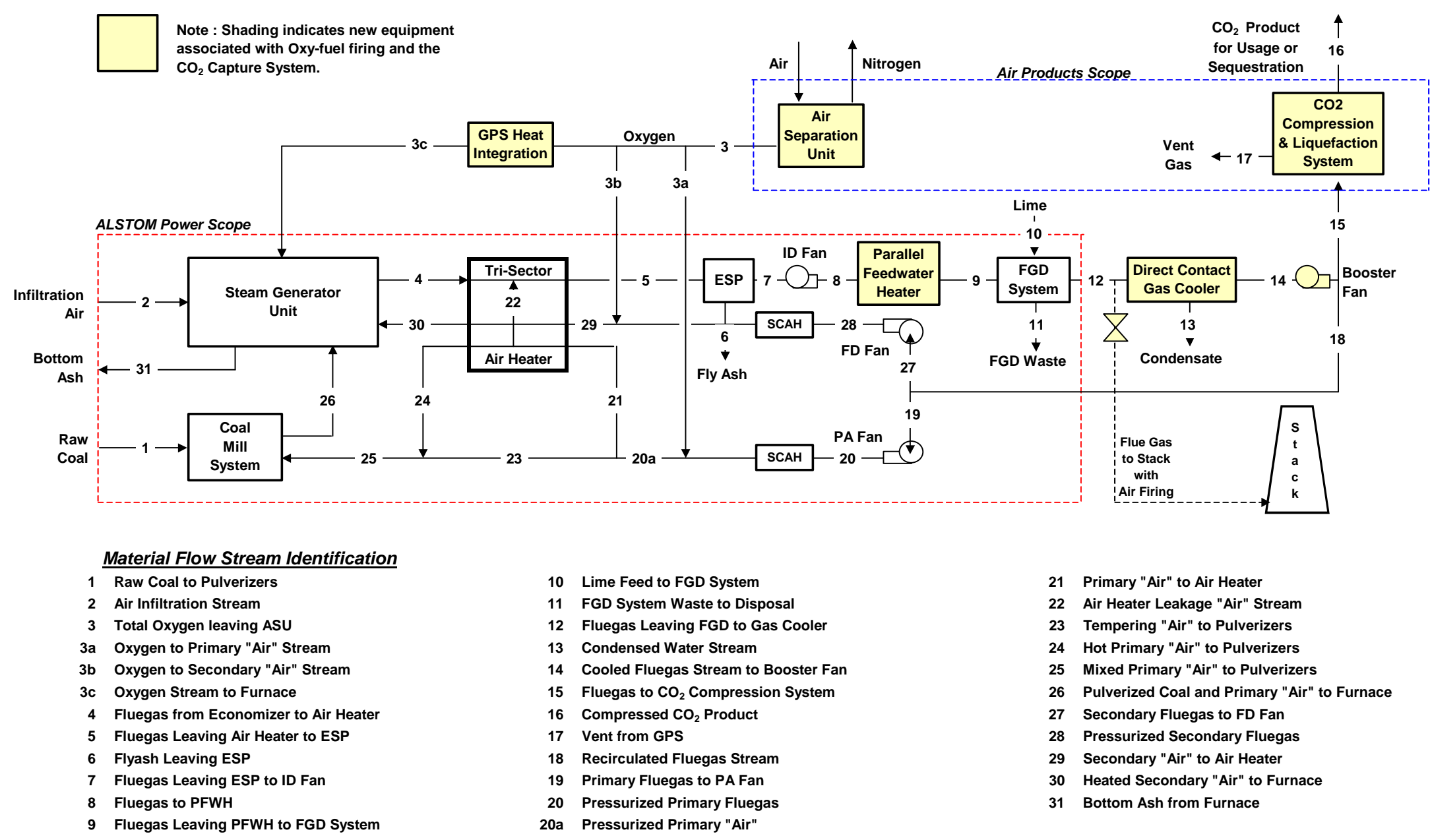

Figure 4-7: Boiler Island Process Flow Diagram - Case 2 


\subsubsection{Material and Energy Balance - Case 2}

The material and energy balance for Case 2 is shown in Table 4-7 below. The stream numbers correspond to Figure 4-7 shown above which shows the boiler island PFD and the basic concept for integrating the cryogenic ASU system with the existing boiler island. 
Table 4-7: Boiler Island Material and Energy Balance - Case 2

\begin{tabular}{|c|c|c|c|c|c|c|c|c|c|c|c|c|c|c|}
\hline Constituent & (Units) & 1 & 2 & 3 & $3 a$ & $3 \mathrm{~b}$ & $3 c$ & 4 & 5 & 5 & 6 & 7 & 8 & 9 \\
\hline$\overline{\mathrm{O}_{2}}$ & (Lbm/hr) & 25913 & 7541 & 746511 & 146973 & 406072 & 193466 & 98510 & 122857 & 122857 & & 122857 & 122857 & 122857 \\
\hline Ar & $"$ & & 428 & 19626 & 3864 & 10676 & 5086 & 77022 & 79959 & 79959 & & 79959 & 79959 & 79959 \\
\hline $\mathbf{N}_{2}$ & $"$ & 4745 & 24552 & 20636 & 4063 & 11225 & 5348 & 192558 & 199091 & 199091 & & 199091 & 199091 & 199091 \\
\hline $\mathrm{H}_{2} \mathrm{O}$ & $"$ & 36862 & 422 & & & & & 258378 & 261744 & 261744 & & 261744 & 261744 & 261744 \\
\hline $\mathrm{CO}_{2}$ & " & & & & & & & 3266155 & 3366941 & 3366941 & & 3366941 & 3366941 & 3366941 \\
\hline $\mathrm{SO}_{2}$ & $"$ & & & & & & & 20412 & 20442 & 20442 & & 20442 & 20442 & 20442 \\
\hline $\mathrm{H}_{2}$ & $"$ & 15694 & & & & & & & & & & & & \\
\hline Carbon & $"$ & 230660 & & & & & & & & & & & & \\
\hline Sulfur & $"$ & 9854 & & & & & & & & & & & & \\
\hline $\mathrm{CaO}$ & $"$ & & & & & & & & & & & & & \\
\hline MgO & $"$ & & & & & & & & & & & & & \\
\hline $\mathrm{CaSO}_{3}$ & $"$ & & & & & & & & & & & & & \\
\hline $\mathrm{CaSO}_{4}$ & $"$ & & & & & & & & & & & & & \\
\hline $\mathrm{MgSO}_{3}$ & " & & & & & & & & & & & & & \\
\hline $\mathrm{MgSO}_{4}$ & $"$ & & & & & & & & & & & & & \\
\hline $\begin{array}{l}\mathrm{CaCO}_{3} \\
\text { Ash / Inerts }\end{array}$ & $"$ & 41241 & & & & & & 32993 & 32993 & 32993 & 32993 & & & \\
\hline \multirow{4}{*}{\begin{tabular}{|l|} 
Total Gas \\
Total Solids \\
Total Flow \\
\end{tabular}} & \multirow{4}{*}{$\begin{array}{c}\text { (Lbm/hr) } \\
" \\
" \\
\end{array}$} & Raw Coal & Leakage Air & Oxygen from ASU & Primary 02 & Secondary O2 & Burner $\mathrm{O} 2$ & Fluegas to Air Htr & luegas to $\mathrm{O} 2 \mathrm{Htr}$ & Fluegas to ESP & Fly Ash & \multicolumn{3}{|c|}{ Fluegas to ID Fan Fluegas to PFWH Fluegas to FGD } \\
\hline & & & 32942 & 786772 & 154900 & 427972 & 203900 & 3913034 & 4051034 & 4051034 & & 4051034 & 4051034 & 4051034 \\
\hline & & 364968 & & & & & & 32993 & 32993 & 32993 & 32993 & & & \\
\hline & & 364968 & 32942 & 786772 & 154900 & 427972 & 203900 & 3946028 & 4084028 & 4084028 & 32993 & 4051034 & 4051034 & 4051034 \\
\hline Temperature & (Deg F) & 80 & 80 & 100 & 100 & 100 & 398 & 676 & 334 & 334 & 334 & 334 & 345 & 243 \\
\hline Pressure & (Psia) & 14.7 & 14.7 & 20.1 & 20.1 & 20.1 & 20.1 & 14.6 & 14.3 & 14.3 & 14.7 & 14.2 & 15.0 & 14.9 \\
\hline $\mathbf{h}_{\text {sensible }}$ & (Btu/lbm) & 0.000 & 0.000 & 4.368 & 4.368 & 4.368 & 71.307 & 148.611 & 59.009 & 59.009 & 63.500 & 59.009 & 61.846 & 37.003 \\
\hline Energy & & & & & & & & & & & & & & \\
\hline Chemical & $\left(10^{6} \mathrm{Btu} / \mathrm{hr}\right)$ & 4121.585 & & & & & & & & & & & & \\
\hline Sensible & $\left(10^{6} \mathrm{Btu} / \mathrm{hr}\right)$ & 0.000 & 0.000 & 3.437 & 0.677 & 1.870 & 14.539 & 586.439 & 241.141 & 241.141 & 2.095 & 239.046 & 250.539 & 149.901 \\
\hline Latent & $\left(10^{6} \mathrm{Btu} / \mathrm{hr}\right)$ & 0.000 & 0.443 & 0.000 & 0.000 & 0.000 & 0.000 & 271.297 & 274.832 & 274.832 & 0.000 & 274.832 & 274.832 & 274.832 \\
\hline Total Energy(1) & $\left(10^{6} \mathrm{Btu} / \mathrm{hr}\right)$ & 4121.585 & 0.443 & 3.437 & 0.677 & 1.870 & 14.539 & 857.737 & 515.972 & 515.972 & 2.095 & 513.877 & 525.371 & 424.733 \\
\hline
\end{tabular}

(1) Energy Basis; Chemical based on Higher Heating Value (HHV); Sensible energy above 80F; Latent based on 1,050 Btu/Lbm of water vapor 


\begin{tabular}{|c|c|c|c|c|c|c|c|c|c|c|c|c|}
\hline Constituent & (Units) & 10 & 11 & 12 & 13 & 14 & 15 & 16 & 17 & 18 & 19 & 20 \\
\hline $\mathrm{O}_{2}$ & (Lbm/hr) & & & 122614 & & 122614 & 30752 & & & 91862 & 26987 & 26987 \\
\hline $\mathrm{Ar}$ & $"$ & & & 79959 & & 79959 & 20054 & & & 59905 & 17599 & 17599 \\
\hline $\mathrm{N}_{2}$ & $"$ & & & 199091 & & 199091 & 49933 & & & 149158 & 43820 & 43820 \\
\hline $\mathrm{H}_{2} \mathrm{O}$ & $"$ & 158539 & 46699 & 373584 & 261177 & 112407 & 28192 & & & 84215 & 24740 & 24740 \\
\hline $\mathrm{CO}_{2}$ & $"$ & & & 3365870 & & 3365870 & 844170 & & & 2521700 & 740822 & 740822 \\
\hline $\mathrm{SO}_{2}$ & $"$ & & & 1004 & & 1004 & 252 & & & 752 & 221 & 221 \\
\hline $\mathrm{H}_{2}$ & $"$ & & & & & & & & & & & \\
\hline Carbon & $"$ & & & & & & & & & & & \\
\hline Sulfur & $"$ & & & & & & & & & & & \\
\hline $\mathrm{CaO}$ & $"$ & 17695 & & & & & & & & & & \\
\hline $\mathrm{MgO}$ & $"$ & 983 & 492 & & & & & & & & & \\
\hline $\mathrm{CaSO}_{3}$ & $"$ & & 33238 & & & & & & & & & \\
\hline $\mathrm{CaSO}_{4}$ & $"$ & & 1982 & & & & & & & & & \\
\hline $\mathrm{MgSO}_{3}$ & $"$ & & 1209 & & & & & & & & & \\
\hline $\mathrm{MgSO}_{4}$ & $"$ & & 73 & & & & & & & & & \\
\hline $\mathrm{CaCO}_{3}$ & $"$ & & 2435 & & & & & & & & & \\
\hline Ash / Inerts & " & 983 & 983 & & & & & & & & & \\
\hline \multirow{4}{*}{$\begin{array}{l}\text { Total Gas } \\
\text { Total Solids } \\
\text { Total Flow } \\
\end{array}$} & \multirow{4}{*}{$\begin{array}{c}\text { (Lbm/hr) } \\
" \\
" \\
\end{array}$} & Lime Slurry & FGD Byproduct & Fluegas to $\mathrm{Clr}$ & Condensate & $\begin{array}{l}\text { Fuegas to Bstr } \\
\text { Fan }\end{array}$ & $\begin{array}{l}\text { Tuegas to } \mathrm{CO}^{2} \\
\text { System }\end{array}$ & $\mathrm{CO} 2$ Product & Vent to Stack & Recirc Fluegas & PA Fan Inlet & PA Fan Outlet \\
\hline & & & & 4142122 & & 3880945 & 973352 & By AP & By AP & 2907593 & 854190 & 854190 \\
\hline & & 19661 & 40413 & & & & & & & & & \\
\hline & & 178200 & 87112 & 4142122 & 261177 & 3880945 & 973352 & & & 2907593 & 854190 & 854190 \\
\hline Temperature & $($ Deg F) & 80 & 144 & 144 & 100 & 100 & 101 & & & 101 & 101 & 110 \\
\hline Pressure & (Psia) & 14.7 & 14.7 & 14.6 & 14.7 & 14.6 & 14.7 & & & 14.7 & 14.7 & 15.6 \\
\hline $\mathbf{h}_{\text {sensible }}$ & (Btu/lbm) & 0.000 & 15.946 & 14.508 & 19.960 & 4.199 & 4.512 & & & 4.512 & 4.512 & 6.423 \\
\hline \multicolumn{13}{|l|}{ Energy } \\
\hline Chemical & $\left(10^{6} \mathrm{Btu} / \mathrm{hr}\right)$ & & & & & & & & & & & \\
\hline Sensible & $\left(10^{6} \mathrm{Btu} / \mathrm{hr}\right)$ & 0.000 & 3.618 & 60.092 & 5.213 & 16.297 & 4.391 & & & 13.118 & 3.854 & 5.486 \\
\hline Latent & $\left(10^{6} \mathrm{Btu} / \mathrm{hr}\right)$ & 0.000 & 0.000 & 392.263 & 0.000 & 118.027 & 29.601 & & & 88.425 & 25.978 & 25.978 \\
\hline Total Energy(1) & $\left(10^{6} \mathrm{Btu} / \mathrm{hr}\right)$ & 0.000 & 3.618 & 452.355 & 5.213 & 134.324 & 33.993 & & & 101.544 & 29.831 & 31.464 \\
\hline
\end{tabular}

Note:

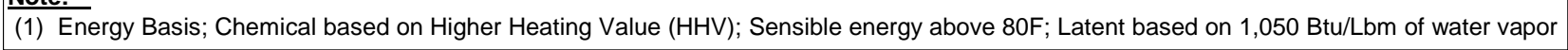




\begin{tabular}{|c|c|c|c|c|c|c|c|c|c|c|c|}
\hline Constituent & (Units) & 21 & 22 & 23 & 24 & 25 & 26 & 27 & 28 & 29 & 30 \\
\hline$\overline{\mathrm{O}_{2}}$ & (Lbm/hr) & 89756 & 24347 & 84205 & 70103 & 154308 & 180220 & 64875 & 64875 & 470947 & 466252 \\
\hline Ar & $"$ & 11074 & 2938 & 10389 & 8649 & 19038 & 19038 & 42306 & 42306 & 52982 & 52469 \\
\hline $\mathrm{N}_{2}$ & $"$ & 24705 & 6533 & 23177 & 19296 & 42473 & 47218 & 105339 & 105339 & 116564 & 115440 \\
\hline $\mathrm{H}_{2} \mathrm{O}$ & $"$ & 12765 & 3366 & 11976 & 9970 & 21945 & 58807 & 59474 & 59474 & 59474 & 58903 \\
\hline $\mathrm{CO}_{2}$ & $"$ & 382231 & 100786 & 358592 & 298538 & 657129 & 657129 & 1780878 & 1780878 & 1780878 & 1763785 \\
\hline $\mathrm{SO}_{2}$ & $"$ & 114 & 30 & 107 & 89 & 196 & 196 & 531 & 531 & 531 & 526 \\
\hline $\mathrm{H}_{2}$ & $"$ & & & & & & 15694 & & & & \\
\hline Carbon & " & & & & & & 230660 & & & & \\
\hline Sulfur & " & & & & & & 9854 & & & & \\
\hline $\mathrm{CaO}$ & $"$ & & & & & & & & & & \\
\hline MgO & " & & & & & & & & & & \\
\hline $\mathrm{CaSO}_{3}$ & $"$ & & & & & & & & & & \\
\hline $\mathrm{CaSO}_{4}$ & " & & & & & & & & & & \\
\hline $\mathrm{MgSO}_{3}$ & $"$ & & & & & & & & & & \\
\hline $\mathrm{MgSO}_{4}$ & $"$ & & & & & & & & & & \\
\hline $\begin{array}{l}\mathrm{CaCO}_{3} \\
\text { Ash / Inerts }\end{array}$ & " & & & & & & 41241 & & & & \\
\hline \multirow{3}{*}{$\begin{array}{l}\text { Total Gas } \\
\text { Total Solids } \\
\text { Total Flow } \\
\end{array}$} & \multirow{3}{*}{$\begin{array}{c}\text { (Lbm/hr) } \\
" \\
" \\
\end{array}$} & PA to Air Htr & AH leakage gas & Temp. Fluegas & Hot Pri Air & Mixed Pri Air & Coal-Pri Air Mix & Sec Air to FD & Sec Air to SCAH & Sec Air to AH & Sec Air to Furn \\
\hline & & 520645 & 138000 & 488445 & 406645 & 895090 & $\begin{array}{l}895090 \\
364968\end{array}$ & 2053403 & 2053403 & 2481376 & 2457376 \\
\hline & & 520645 & 138000 & 488445 & 406645 & 895090 & 1260058 & 2053403 & 2053403 & 2481376 & 2457376 \\
\hline Temperature & (Deg F) & 109 & 109 & 109 & 591 & 339 & & 101 & 106 & 105 & 617 \\
\hline Pressure & (Psia) & 15.6 & 15.6 & 15.6 & 15.6 & 15.6 & 15.0 & 14.7 & 15.1 & 15.1 & 14.9 \\
\hline $\mathbf{h}_{\text {sensible }}$ & (Btu/lbm) & 6.107 & 6.108 & 6.107 & 120.475 & 58.065 & & 4.512 & 5.418 & 5.237 & 127.161 \\
\hline \multicolumn{12}{|l|}{ Energy } \\
\hline Chemical & $\left(10^{6} \mathrm{Btu} / \mathrm{hr}\right)$ & & & & & & 4121.585 & & & & \\
\hline Sensible & $\left(10^{6} \mathrm{Btu} / \mathrm{hr}\right)$ & 3.180 & 0.843 & 2.983 & 48.991 & 51.974 & & 9.264 & 11.125 & 12.995 & 312.483 \\
\hline Latent & $\left(10^{6} \mathrm{Btu} / \mathrm{hr}\right)$ & 13.403 & 3.534 & 12.574 & 10.468 & 23.043 & & 62.448 & 62.448 & 62.448 & 61.848 \\
\hline Total Energy(1) & $\left(10^{6} \mathrm{Btu} / \mathrm{hr}\right)$ & 16.583 & 4.377 & 15.557 & 59.459 & 75.016 & 4196.602 & 71.712 & 73.573 & 75.443 & 374.331 \\
\hline
\end{tabular}




\subsubsection{Boiler Analysis Results - Case 2}

The main steam flow for this case and all other cases in this study is $395 \mathrm{~kg} / \mathrm{s}(3,131,619 \mathrm{lbm} / \mathrm{hr})$. The cold reheat flow leaving the high-pressure turbine for this case and all other cases in this study is $348 \mathrm{~kg} / \mathrm{s}(2,767,780 \mathrm{lbm} / \mathrm{hr})$. The hot reheat flow (including de-superheating spray) returning to the intermediate pressure turbine for this case is $354 \mathrm{~kg} / \mathrm{s}(2,811,937 \mathrm{lbm} / \mathrm{hr})$. The overall steam conditions produced by the existing Conesville \#5 steam generator unit are shown in Table 4-8 below.

Table 4-8: Boiler Steam/Water Conditions - Case 2

\begin{tabular}{|c|rrrrr|}
\hline & SHO & FWI & ECO & RHO & RHI \\
\hline Flow (lbm/hr) & $\mathbf{3 1 3 1 6 1 9}$ & 3131619 & $\mathbf{3 1 2 1 0 3 6}$ & 2811937 & 2811937 \\
Pressure (psia) & 2535 & 3165 & 3070 & $\mathbf{5 9 0 . 8}$ & $\mathbf{6 5 6 . 5}$ \\
Temperature (F) & 1000 & 493 & 612 & 1000 & 629 \\
Enthalpy (Btu/lbm) & 1456.3 & $\mathbf{4 7 9 . 2}$ & $\mathbf{6 2 5 . 7}$ & 1517.6 & 1304.5 \\
\hline
\end{tabular}

Notes:

SHO = Superheater Outlet; FWI = Feedwater Inlet; ECO = Economizer Outlet; RHO = Reheater Outlet; RHI $=$ Reheater Inlet

To produce these conditions, the superheat circuit requires about 0.6 percent spray and the reheat circuit requires about 1.6 percent spray to maintain required steam outlet temperatures. The burner tilts are -10 degrees (the minimum value the customer uses). The boiler was fired with about 4.3 percent excess oxygen ( 1.04 stoichiometry) and the resulting boiler efficiency calculated for this case was 88.40 percent with an air heater exit gas temperature of $168{ }^{\circ} \mathrm{C}$ (334 $\left.{ }^{\circ} \mathrm{F}\right)$. The boiler efficiency including the heat recovered from Stream 8 with the PFWH is calculated to be 90.84 percent.

\subsubsection{Steam Cycle Performance - Case 2}

The final steam cycle for Case 2 is shown schematically in Figure 4-8. Figure 4-9 shows the associated T-S and Mollier diagrams, which illustrate the process on temperature - entropy and enthalpy - entropy coordinates respectively. The high-pressure turbine expands about $391 \mathrm{~kg} / \mathrm{s}$ $\left(3.1 \times 10^{6} \mathrm{lbm} / \mathrm{hr}\right)$ of steam at 175 bara $(2,535 \mathrm{psia})$ and $538^{\circ} \mathrm{C}\left(1,000^{\circ} \mathrm{F}\right)$. Reheat steam is returned to the intermediate pressure turbine at 41 bara (591 psia) and $538{ }^{\circ} \mathrm{C}(1,000 \mathrm{~F})$. Lowlevel heat rejected from the flue gas, GPU, and ASU is recovered in the condensate stream as indicated. The condenser pressure used for the Case 2 and all other cases in this study was 6.35 $\mathrm{cm}$. Hga (2.5 in Hga). The steam turbine performance analysis results show the generator produces an output of 469,447 kWe, which is about 6 MWe more than the Base Case due to lowlevel heat recovery. The steam turbine heat rate is calculated to be about $8,935 \mathrm{~kJ} / \mathrm{kWh}(8,468$ $\mathrm{Btu} / \mathrm{kWh})$. 


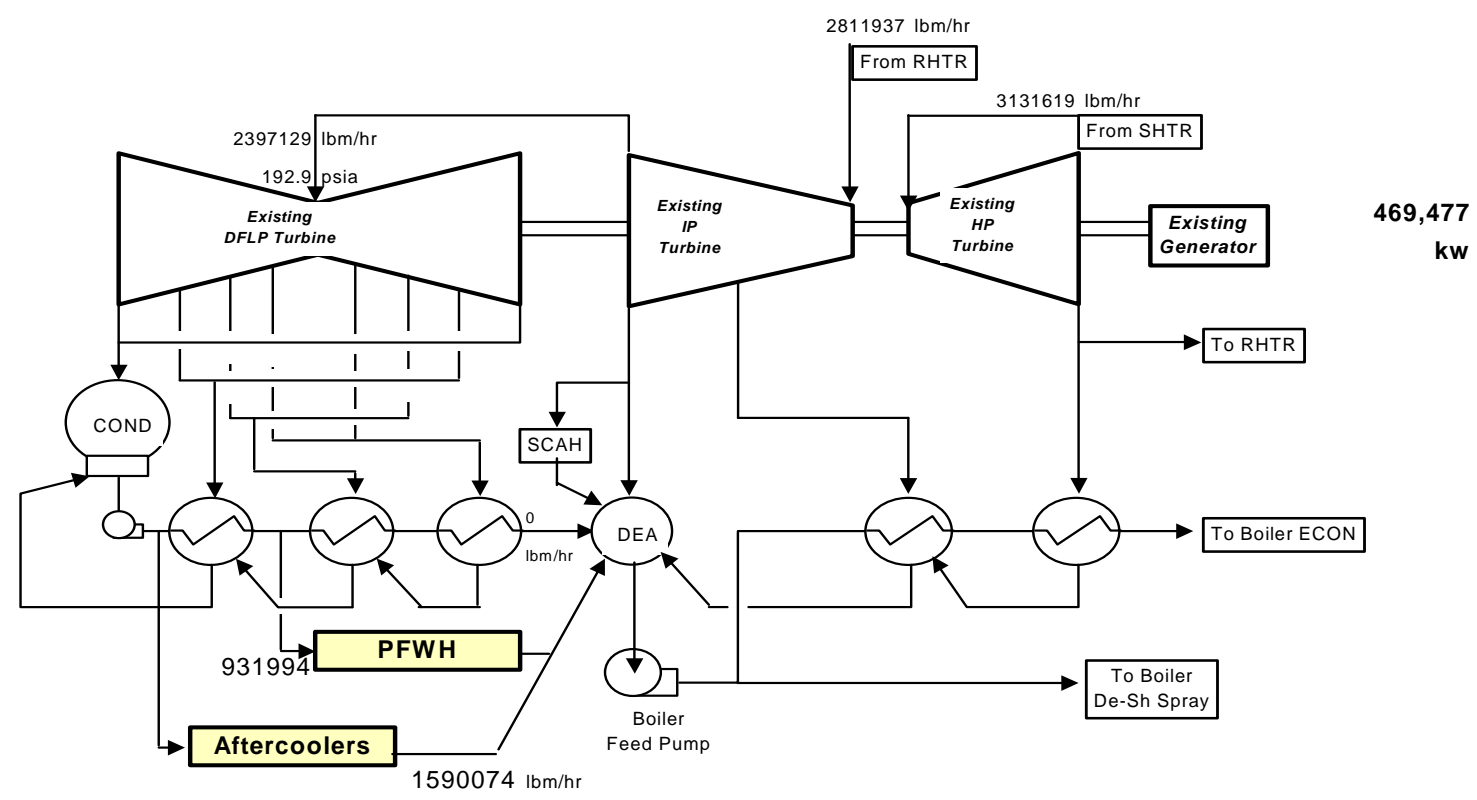

Steam Cycle Energy Balance

\begin{tabular}{|c|c|c|c|c|}
\hline Energy Outputs & $\left(10^{6} \mathrm{Btu} / \mathrm{hr}\right)$ & Energy Inputs & $\left(10^{6} \mathrm{Btu} / \mathrm{hr}\right)$ & Turbine Heat Rate \\
\hline Power Output (Existing Turbine) & 1627 & Boiler Heat Input & 3659 & 8468 \\
\hline Steam Coil Air Heater Output & 0 & PFWH Heat Input & 316 & (Btu/kwhr) \\
\hline Condenser Loss & 2350 & Condensate Pump & 2 & \\
\hline Total Energy Output & 3977 & $\begin{array}{r}\text { Total Energy Input } \\
\text { In - Out }\end{array}$ & $\begin{array}{r}3977 \\
0\end{array}$ & \\
\hline
\end{tabular}

Figure 4-8: Steam Cycle Schematic and Performance - Case 2
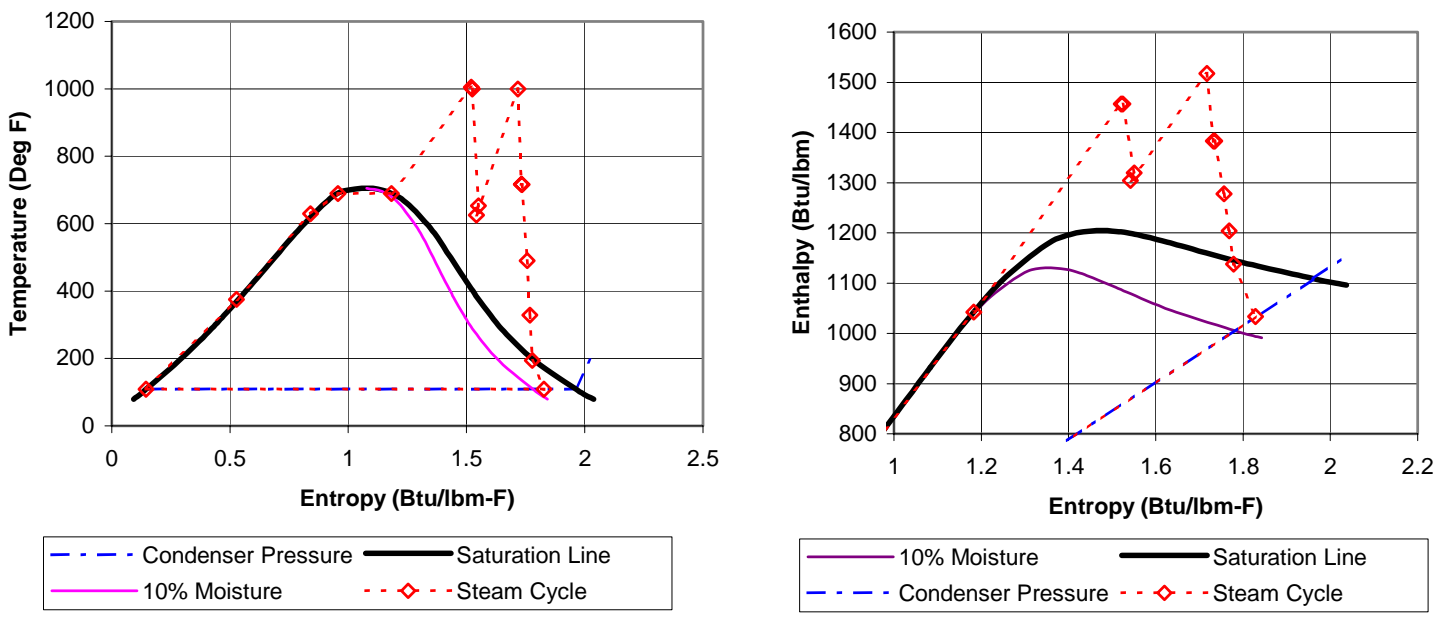

Figure 4-9: Steam Cycle T-S and Mollier Diagrams - Case 2

\subsubsection{Flue Gas Desulfurization System Analysis - Case 2}

The issues regarding the performance of the FGD system and the ESP with the high $\mathrm{CO}_{2}$ content flue gas are discussed in some detail in Appendix I - Section 10.1.6 and are not repeated here. The 
basic conclusions reached were that, under these circumstances, the flue gas desulfurization systems $\mathrm{SO}_{2}$ capture efficiency would decrease by approximately $2 \%$. Additionally, for the high $\mathrm{CO}_{2}$ content flue gas associated with oxygen firing no ESP performance degradation is expected.

\subsubsection{Plant Performance Summary - Case 2}

Overall plant performance, which accounts for the existing power plant equipment, the new ASU and the new GPU is summarized in Table 4-9 below. Boiler efficiency (HHV basis) is calculated to be 90.84 percent, including the heat recovery of the PFWH. The net plant heat rate (HHV basis) is calculated to be $14,299 \mathrm{~kJ} / \mathrm{kWh}(13,554 \mathrm{Btu} / \mathrm{kWh})$ for this case, as shown in Table 4-9, which corresponds to a plant thermal efficiency of about 25.18\% (HHV basis). This represents an efficiency loss of about 9.8 percentage points as compared to the Base Case. Auxiliary power is $164,546 \mathrm{kWe}$, which is about $35 \%$ of the gross output as compared to about $6.4 \%$ for the Base Case. The net plant output is $304,931 \mathrm{kWe}$, which is about $70 \%$ of the Base Case output. Carbon dioxide emissions are $6.2 \mathrm{~kg} / \mathrm{s}(48,999 \mathrm{lbm} / \mathrm{hr})$ or about $0.07 \mathrm{~kg} / \mathrm{kWh}(0.16 \mathrm{lbm} / \mathrm{kWh})$, which is about $8 \%$ of the Base Case value on a normalized basis (i.e. $\mathrm{kg} / \mathrm{kWh}$ or $\mathrm{lbm} / \mathrm{kWh}$ ).

\section{Table 4-9: Overall Plant Performance - Case 2}

Fuel Paramaters
Coal Heat Input (HHV)
Natural Gas Heat Input (HHV)
Total Fuel Heat Input (HHV)
Steam Cycle Paramaters
Existing Steam Turbine Generator Output
CAR Extraction Turbine Generator Output
Total Turbine Generator Output
Total Auxiliary Power
Net Plant Output
$\quad$ Normalized Net Plant Output (Relative to Base Case)

\section{Overall Plant Performance Paramaters}

Net Plant Efficiency (HHV)

Net Plant Efficiency (LHV)

Normalized Efficiency (HHV; Relative to Base Case)

Net Plant Heat Rate (HHV)

Net Plant Heat Rate (LHV)

Efficiency Loss Relative to Air Fired Base (HHV)

\section{Overall Plant $\mathrm{CO}_{2}$ Emissions}

Carbon Dioxide Produced

Carbon Dioxide Emissions

Specific Carbon Dioxide Emissions

Normalized Specific CO2 Emissions (Relative to Base Case)

Avoided Carbon Dioxide Emissions (as compared to Base)

Specific Carbon Dioxide Emissions

Avoided Carbon Dioxide Emissions (as compared to Base)

$\begin{array}{lc} & \begin{array}{c}\text { Case 2 - O2 } \\ \text { Fired } \\ \text { (Cryogenic) } \\ \text { OCDO } \\ \text { Update }\end{array} \\ (\text { units) } & 4121.6 \\ \left(10^{6} \mathrm{Btu} / \mathrm{hr}\right) & 11.4 \\ \left(10^{6} \mathrm{Btu} / \mathrm{hr}\right) & 4133.0 \\ \left(10^{6} \mathrm{Btu} / \mathrm{hr}\right) & \end{array}$

$(\mathrm{kW})$

$(\mathrm{kW})$

$(\mathrm{kW})$

$(\mathrm{kW})$

$(\mathrm{kW})$

(fraction)

469,477

0

469,477

164,546

304,931

0.70 


\subsection{Ceramic Autothermal Recovery (CAR) Cases}

Two sets of case studies were done for the CAR systems. These are categorized as follows:

1.) Flue gas sweep cases (Cases 3a, 3b, and 3c)

2.) Steam sweep cases (Cases $4 \mathrm{a}$, and $4 \mathrm{~b}$ ).

Figure 4-10 shows a schematic of the CAR beds with packed bed heat exchangers (regenerators) that are integral within the CAR vessels and located at both the inlet and outlet ends of the CAR vessels. Typical bed temperature profiles are also shown in the lower part of this figure.

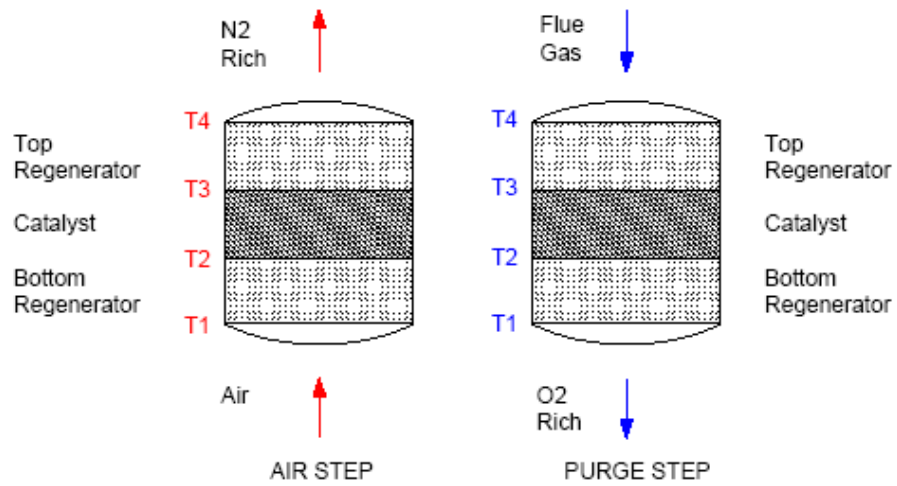

\begin{tabular}{c|c|c|c|c|c|c|c|}
\hline \multirow{2}{*}{ Case } & \multirow{2}{*}{ Step } & \multicolumn{4}{|c|}{ Gas Phase Temperatures, C (F) } & \multicolumn{2}{c}{ Catalyst Temp, C (F) } \\
\cline { 3 - 8 } & & T1 & T2 & T3 & T4 & Ts_in & Ts_final \\
\hline 1 & Air & $180(356)$ & $791(1456)$ & $821(1510)$ & $227(441)$ & $800(1472)$ & $821(1510)$ \\
\hline & Purge & $66(152)$ & $813(1495)$ & $849(1560)$ & $228(442)$ & $821(1510)$ & $800(1472)$ \\
\hline
\end{tabular}

Figure 4-10: Bed Temperature Profiles of CAR Vessels with Regenerators

The basic process flow diagram of a CAR system with multiple beds (10 beds) is shown in Figure 4-11. Air is supplied at the required pressure with the four air blowers shown on the left side of the diagram. The air is preheated in the air/nitrogen heat exchangers also shown on the left side of the diagram. The right side of the diagram shows the sweep gas stream (flue gas) entering the sweep gas blowers and the oxygen rich stream leaving the product buffer tanks ready to supply the boiler. Also shown on the right side of the diagram is a stream of low-pressure steam, which is used to "rinse" the vessels between cycles. 


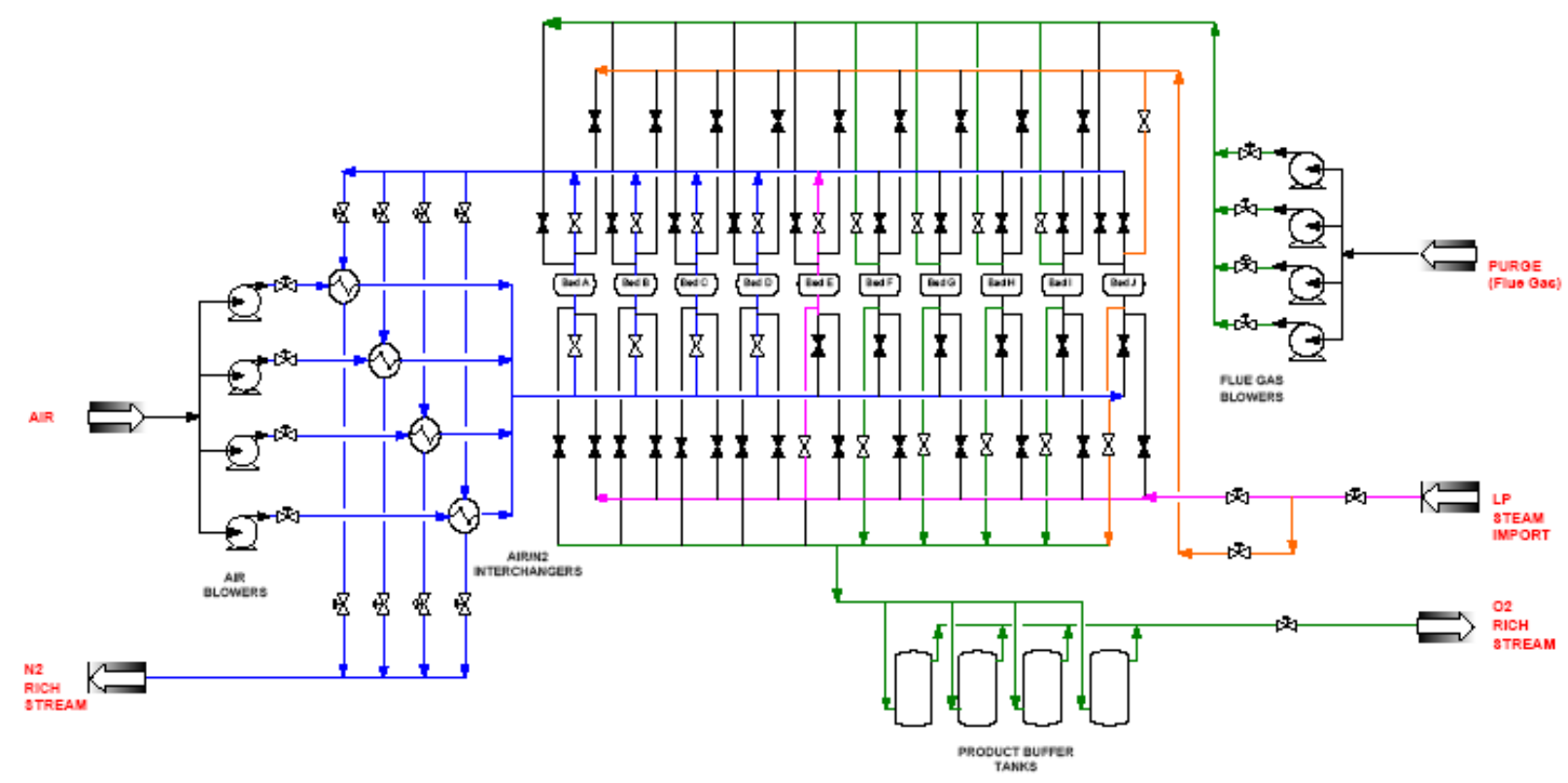

Figure 4-11: CAR System Simplified Process Flow Diagram

The CAR absorber vessel header arrangement (using flue gas as the sweep gas) for each bed is shown in Figure 4-12. As shown there are a total of eight inlet and outlet pipes for each vessel and a total of forty valves required per bed.

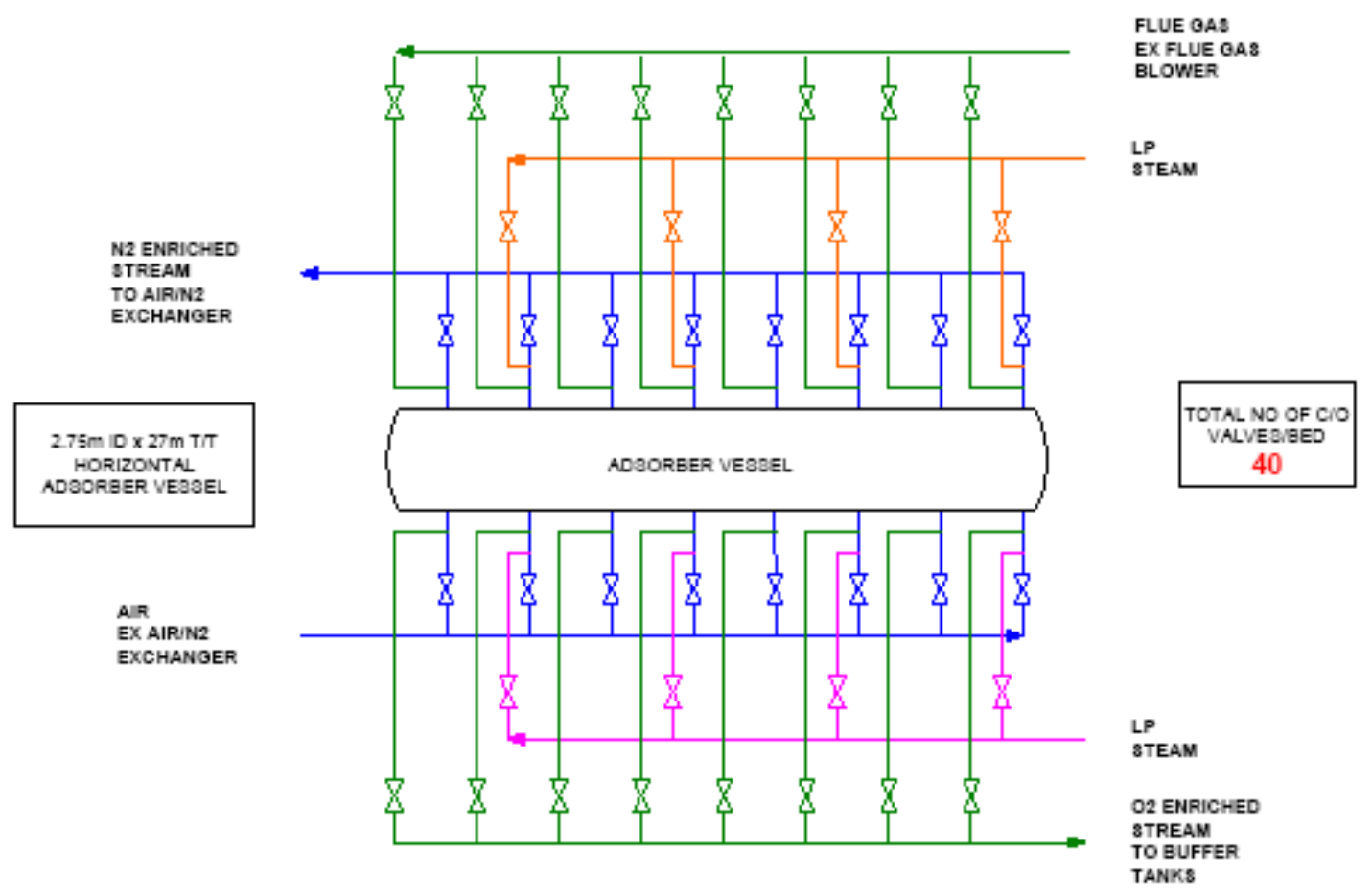

Figure 4-12: CAR Absorber Vessel Header Arrangement 
The cycle steps for the ten beds and the sequencing of the blowers are shown in Figure 4-13. The upper diagram shows how the air, steam rinse (STR), and sweep gas (purge) steps are sequenced for the system. The lower diagram indicates the sequencing of the air and flue gas blowers.

\begin{tabular}{|c|c|c|c|c|c|c|c|c|c|c|}
\hline & $b$ & & & 24 & 30 & & & & 54 & 60 \\
\hline 1 & \multicolumn{4}{|c|}{ AIR } & STR & \multicolumn{4}{|c|}{ PURGE } & STR \\
\hline 2 & \multicolumn{4}{|c|}{ PURGE } & STR & \multicolumn{4}{|c|}{ AIR } & STR \\
\hline 3 & STR & \multicolumn{4}{|c|}{ AIR } & STR & \multicolumn{4}{|c|}{ PURGE } \\
\hline 4 & STR & \multicolumn{4}{|c|}{ PURGE } & STR & \multicolumn{4}{|c|}{ AIR } \\
\hline 5 & & STR & \multicolumn{4}{|c|}{ A.IR } & STR & \multicolumn{3}{|c|}{ PURGE } \\
\hline 6 & & STR & \multicolumn{4}{|c|}{ PURGE } & STR & \multicolumn{3}{|c|}{ AIR } \\
\hline 7 & \multicolumn{2}{|c|}{ PURGE } & STR & \multicolumn{4}{|c|}{ AIR } & STR & \multicolumn{2}{|c|}{ PURGE } \\
\hline 8 & \multicolumn{2}{|c|}{ AIR } & STR & \multicolumn{4}{|c|}{ PURGE } & STR & \multicolumn{2}{|c|}{ AIR } \\
\hline 9 & \multicolumn{3}{|c|}{ PURGE } & STR & \multicolumn{4}{|c|}{ AlR } & STR & \\
\hline 10 & \multicolumn{3}{|c|}{ AIR } & STR & \multicolumn{4}{|c|}{ PURGE } & STR & \\
\hline
\end{tabular}
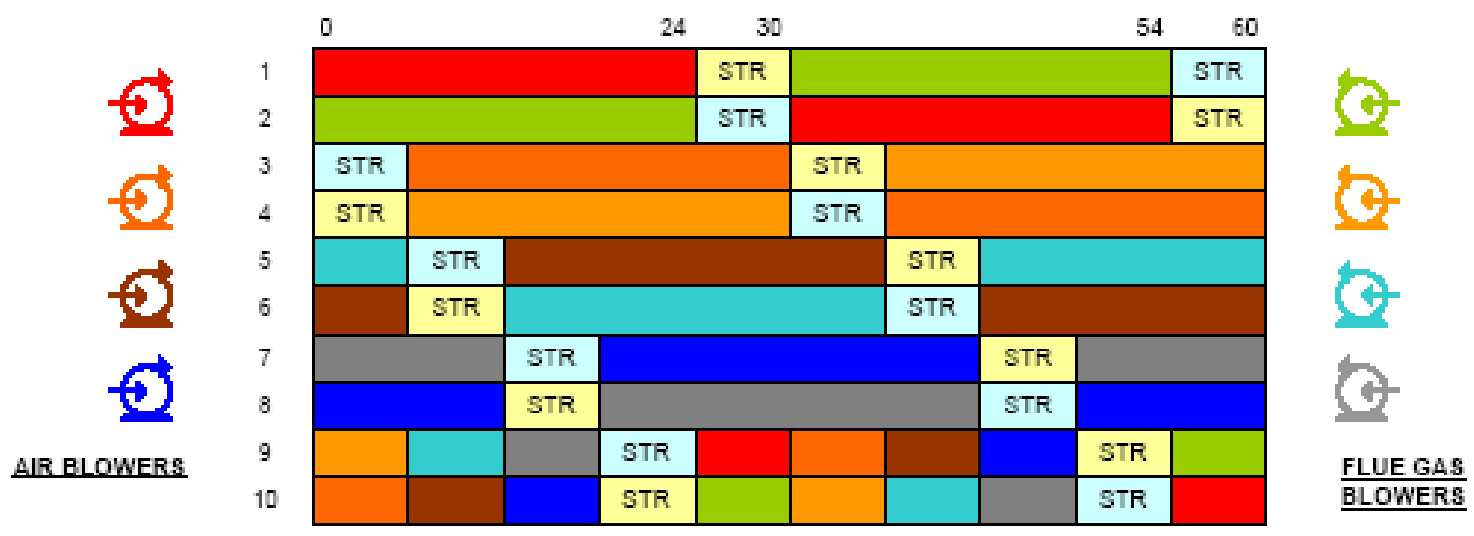

Figure 4-13: CAR Bed Cycle Steps and Blower Sequencing

A typical block flow diagram and material and energy balance for the CAR system using flue gas as a sweep gas is shown in Figure 4-14. Key parameters used for this simulation such as the ratios of Air/Purge, Steam/Air, and Steam/Purge are shown on the lower right side of the figure. The net oxygen recovery, nitrogen rejection and carbon dioxide recovery are also indicated on the lower right side of the figure as well as the fuel parameters. 


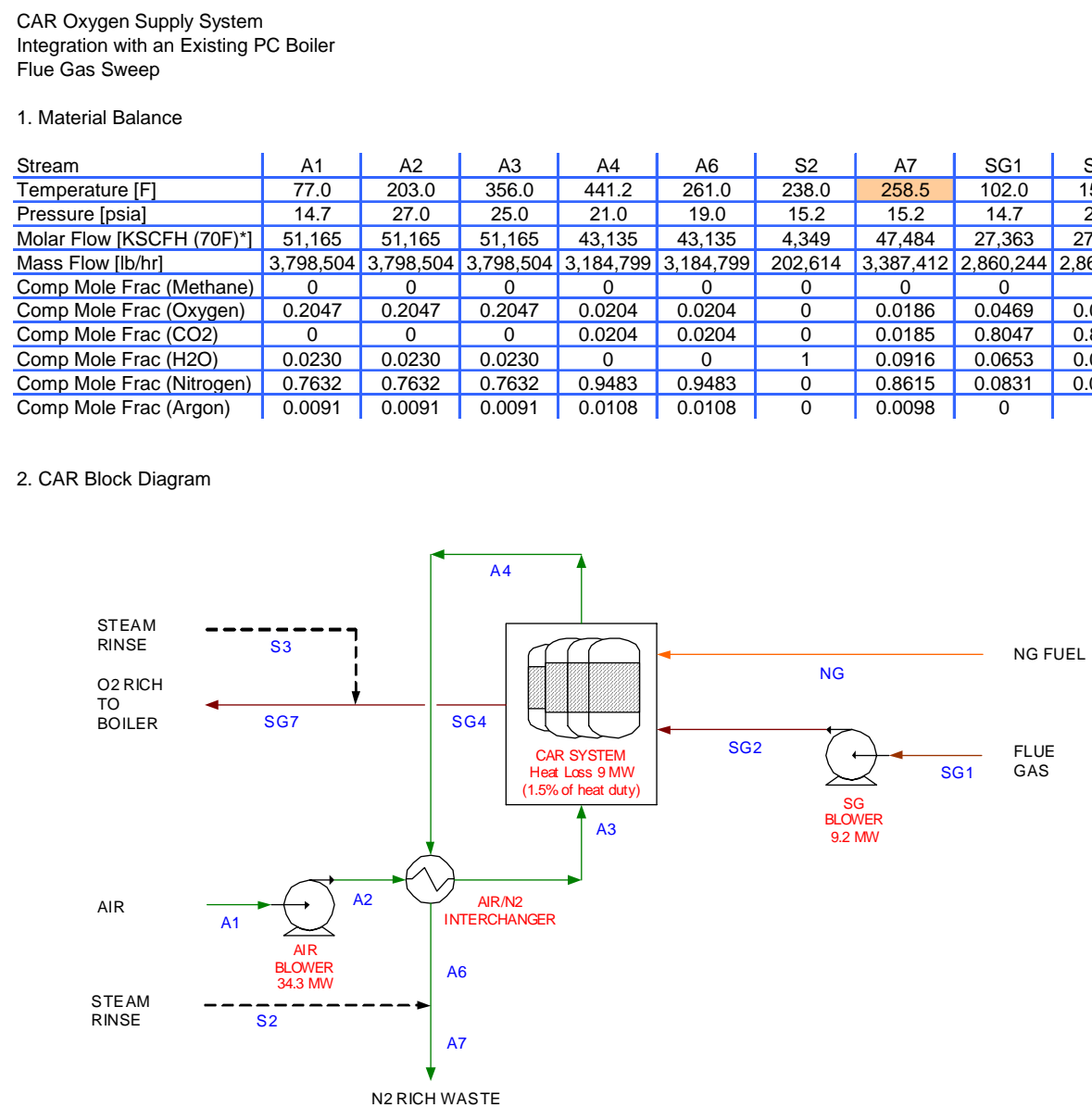

$\begin{array}{lc}\text { Key Parameters } & \\ \text { Air/Purge (A1/SG1) } & 1.87 \\ \text { Steam/Air (S2/A1) } & 0.085 \\ \text { Steam/Purge (S3/SG1) } & 0.12 \\ & \\ & \\ \text { Net O2 Recovery, mol \% } & 86.3 \% \\ \text { Net N2 Rejection, mol \% } & 99.0 \% \\ \text { CO2 Recovered, mol\% } & 97.3 \% \\ & \\ & \\ \text { Fuel, kscfh } & 279 \\ \text { HHV, Btu/scf } & 990 \\ \text { Fuel Heat Input, MMBtu/hr } & 276\end{array}$

Figure 4-14: Typical CAR System Block Diagram and Material and Energy Balance

\subsubsection{Flue Gas Sweep Cases (3a, 3b, and 3c)}

Cases 3a, 3b, and 3c represent the retrofit of Conesville Unit \#5 using the Ceramic Autothermal Recovery (CAR) oxygen production process with recirculated flue gas used as the sweep gas for the CAR process. These three cases represent different arrangements with respect to sweep gas preheat and air preheat, within the CAR system, as well as different assumptions regarding the oxygen holding capacity for the CAR bed material as described below.

Case 3a represents a case which uses packed bed heat exchangers (regenerators) that are integral within the CAR vessels and located at both the inlet and outlet ends of the CAR vessels as depicted in Figure 4-10 shown previously. Case 3a also assumes an oxygen capacity of 0.5\% of the weight of the CAR bed material. 
Case $3 b$ is exactly the same as Case 3a from a performance standpoint but assumes an oxygen capacity of $1.0 \%$ of the weight of the CAR bed material. This capacity increase results in the requirement for fewer CAR beds and a resulting cost reduction for the CAR system.

Case 3c also assumes an oxygen capacity of $1.0 \%$ of the weight of the CAR bed material but instead of using integral packed bed heat exchangers (regenerators) as shown in Figure 4-10, this case uses separate external heat exchangers for preheating the air and sweep gas. The external heat exchangers are significantly more expensive than the integral packed bed heat exchangers used in Cases 3a and 3b but terminal differences can be lowered which reduces the amount of natural gas consumed in the CAR system. Therefore, the performance of this system is different than for Cases $3 \mathrm{a}$ and $3 \mathrm{~b}$.

\subsubsection{Process Description - Cases 3a, 3b, and 3c}

This basic process description applies to Cases 3a, 3b, and 3c.

Figure 4-15 (for Cases 3a and 3b) and Figure 4-16 (for Case 3c) show the basic concepts considered for integrating the CAR system, using flue gas as the sweep medium, with the existing boiler island. Flue gas leaving the existing ID fans (Stream 7) is cooled with feedwater in parallel with the extraction feedwater heaters and then enters the existing FGD system where $\mathrm{SO}_{2}$ is removed. The existing FGD system is modified with the addition of a secondary scrubber to remove $\mathrm{SO}_{2}$ down to a level of $<10 \mathrm{ppmv}$ as required by the CAR system. Section 5.2.2 describes the modifications to the FGD system to accomplish this. The flue gas leaving the FGD system (Stream 11) is further cooled to about $100 \mathrm{~F}$ in a direct contact gas cooler which minimizes the power requirements for the downstream fans and product gas compression system. The flue gas leaving the booster fan is split into two streams (Stream 14 and Stream SG1). Stream 14, which represents about 26 percent of the total, provides the product gas feed stream to the Gas Processing Unit. Stream SG1, which represents about 74 percent of the total, provides sweep gas to the CAR system and as such represents the recycle portion of the flue gas.

The sweep gas is raised to the proper pressure with the sweep gas blowers. The sweep gas is then preheated before it enters the CAR bed where it picks up the oxygen from the bed material. The oxidant stream leaving the CAR bed (Stream SG3 for cases 3a and 3b and Stream SG4 for case 3c) is cooled and then divided into primary "air" and secondary "air" streams (Streams 17 and 25 respectively), which feed the boiler.

Air is delivered to the CAR system at the required pressure with the air blower. The air is then preheated before entering the CAR beds where most of the oxygen contained in the air is retained by the bed material. The oxygen-depleted stream leaving the CAR beds (Stream A4), which is comprised of mostly nitrogen, is cooled and then discharged through the existing stack. Streams S1, S2, and S3 are steam streams, which are used to purge the beds between the intermittent air and flue gas sweep cycles.

The oxidant stream leaving the CAR system (Stream SG5 for Cases 3a and 3b and Stream SG7 for Case 3c) is split into two streams, which form the primary and secondary oxidant streams. The primary and secondary oxidant streams are preheated in the existing Ljungstrom air heater in the same manner as with air firing. The primary oxidant stream is raised to the proper pressure with the existing PA fans and then feeds the coal mills. The mill outlet temperature is controlled to the 
proper value in the normal fashion with the existing control system by bypassing some of the cold primary air (Stream 21) around the air heater. The tempered primary oxidant stream (Stream 23) is then supplied to the coal mills. The coal-oxidant mixture leaving the mills (Stream 24) is combusted in the furnace along with the preheated secondary oxidant (Stream 26). The oxygen content in the flue gas stream leaving the furnace (Stream 3) is controlled to be the same value as it was in the air fired Base Case, about 3.2\% oxygen by volume. This corresponds to a stoichiometry of about 1.05 for these CAR cases. The flue gas leaving the furnace (Stream 3) is cooled in the air heater, cleaned of particulate matter in the precipitator and raised in pressure by the ID fan, which completes the cycle. 


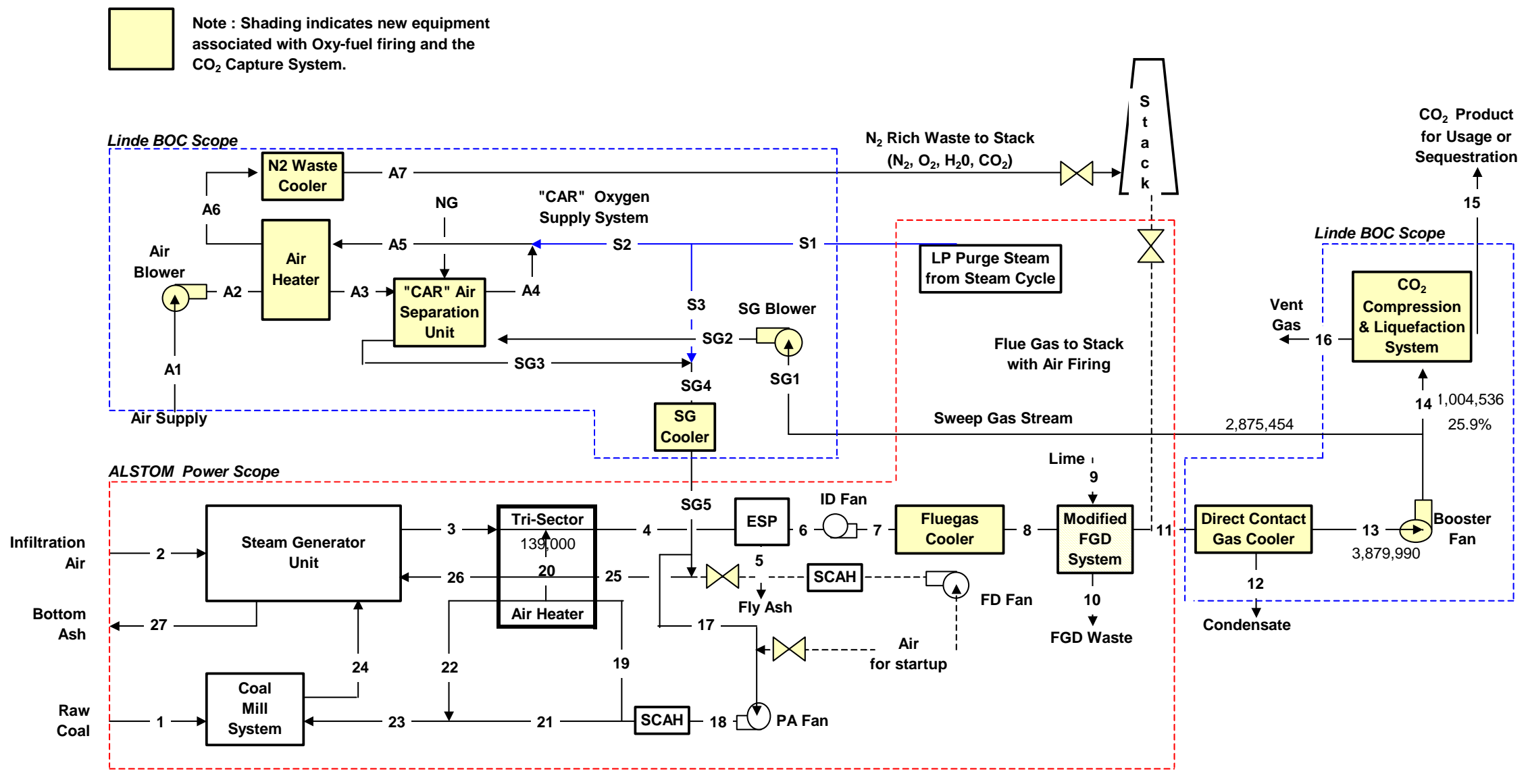

Figure 4-15: Conceptual Integration Concept for CAR Flue Gas Sweep Cases 3a and 3b 


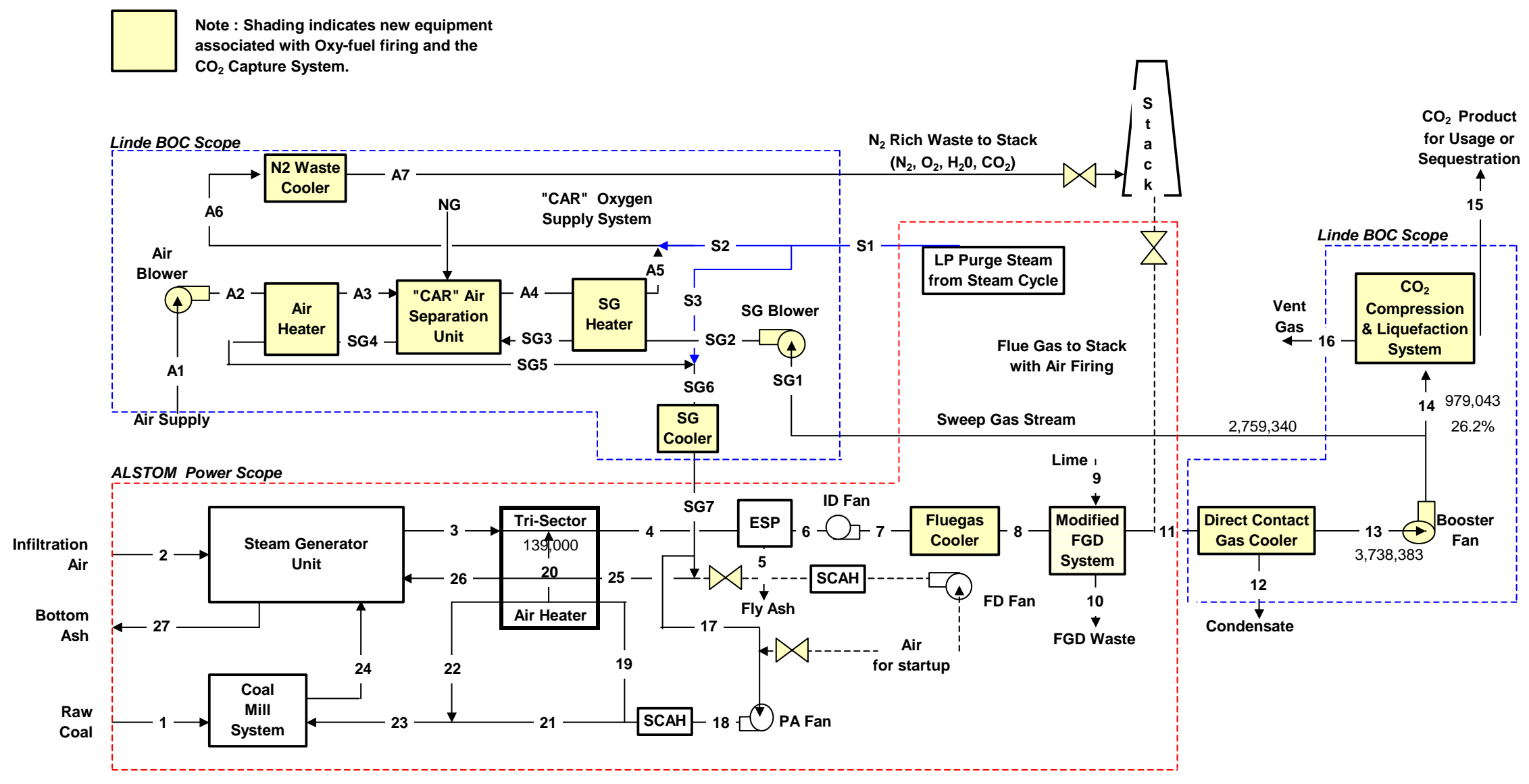

Figure 4-16: Conceptual Integration Concept for CAR Flue Gas Sweep Case 3c 


\subsubsection{Material and Energy Balance - Cases 3a, 3b, and 3c}

The material and energy balance for Cases 3a and 3b is shown in Table 4-10 below. The stream numbers correspond to Figure 4-15 shown above which shows the boiler island PFD and the basic concept for integrating the CAR flue gas sweep system with the existing boiler island.

Similarly, the material and energy balance for Case 3c is shown in Table 4-11 below. The stream numbers correspond to Figure 4-16 shown above. 
Table 4-10: Boiler Island Material and Energy Balance - Cases 3a and 3b

\begin{tabular}{|c|c|c|c|c|c|c|c|c|c|c|c|c|c|c|c|}
\hline Constituent & (Units) & 1 & 2 & 3 & 4 & 5 & 6 & 7 & 8 & 9 & 10 & 11 & 12 & 13 & 14 \\
\hline $\mathrm{O}_{2}$ & (Lbm/hr) & 25948 & 7241 & 112251 & 143081 & & 143081 & 143081 & 143081 & & & 142835 & & 142835 & 36980 \\
\hline $\mathrm{N}_{2}$ & " & 4751 & 23986 & 215530 & 222476 & & 222476 & 222476 & 222476 & & & 222476 & & 222476 & 57599 \\
\hline $\mathrm{H}_{2} \mathrm{O}$ & $"$ & 36912 & 405 & 434041 & 443572 & & 443572 & 443572 & 443572 & 160690 & 47333 & 556929 & 445038 & 111891 & 28970 \\
\hline $\mathrm{CO}_{2}$ & $"$ & & & 3312122 & 3403814 & & 3403814 & 3403814 & 3403814 & & & 3402729 & & 3402729 & 880971 \\
\hline $\mathrm{SO}_{2}$ & $"$ & & & 19759 & 19760 & & 19760 & 19760 & 19760 & & & 59 & & 59 & 15 \\
\hline $\mathrm{H}_{2}$ & $"$ & 15715 & & & & & & & & & & & & & \\
\hline Carbon & $"$ & 230977 & & & & & & & & & & & & & \\
\hline Sulfur & $"$ & 9868 & & & & & & & & & & & & & \\
\hline $\mathrm{CaO}$ & " & & & & & & & & & 17935 & & & & & \\
\hline $\mathrm{MgO}$ & $"$ & & & & & & & & & 996 & 498 & & & & \\
\hline $\mathrm{CaSO}_{3}$ & $"$ & & & & & & & & & & 33689 & & & & \\
\hline $\mathrm{CaSO}_{4}$ & $"$ & & & & & & & & & & 2009 & & & & \\
\hline $\mathrm{MgSO}_{3}$ & $"$ & & & & & & & & & & 1226 & & & & \\
\hline $\mathrm{MgSO}_{4}$ & $"$ & & & & & & & & & & 74 & & & & \\
\hline $\mathrm{CaCO}_{3}$ & $"$ & & & & & & & & & & 2468 & & & & \\
\hline Ash / Inerts & $"$ & 41298 & & 33039 & 33039 & 33039 & & & & 996 & 996 & & & & \\
\hline & & $\begin{array}{l}\text { Raw Coal } \\
\end{array}$ & $\begin{array}{l}\text { Leakage Air } \\
\end{array}$ & Fluegas to Air Htr F & Fluegas to $\mathrm{O} 2 \mathrm{Htr}$ & Fly Ash & $\begin{array}{l}\text { Fluegas to ID Fan F } \\
\end{array}$ & Fluegas to PFWH & $\begin{array}{l}\text { Fluegas to FGD } \\
\end{array}$ & $\begin{array}{ll}\text { Lime Slury } \\
\end{array}$ & "FGD Byproduct & "Fluegas to $\mathrm{Cl}$ & "Condensate & Eluegas to Bstr Far. & 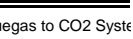 \\
\hline Total Gas & (Lbm/hr) & 0 & 31632 & 4093704 & 4232704 & 0 & 4232704 & 4232704 & 4232704 & 0 & 0 & 4325028 & 0 & 3879990 & 1004536 \\
\hline Total Solids & $"$ & 365470 & 0 & 33039 & 33039 & 33039 & 0 & 0 & 0 & 19928 & 40961 & 0 & 0 & 0 & 0 \\
\hline Total Flow & $"$ & 365470 & 31632 & 4126742 & 4265742 & 33039 & 4232704 & 4232704 & 4232704 & 180618 & 88293 & 4325028 & 445038 & 3879990 & 1004536 \\
\hline Temperature & (Deg F) & 80 & 80 & 677 & 318 & 318 & 318 & 330 & 160 & 80 & 144 & 144 & 100 & 100 & 102 \\
\hline Pressure & (Psia) & 14.7 & 14.7 & 14.6 & 14.3 & 14.7 & 14.2 & 15.0 & 14.9 & 14.7 & 14.7 & 14.6 & 14.7 & 14.6 & 14.7 \\
\hline $\mathbf{h}_{\text {sensible }}$ & Btu/lbm & 0.000 & 0.000 & 155.602 & 57.785 & 59.500 & 57.785 & 60.902 & 18.684 & 0.000 & 15.946 & 15.210 & 19.960 & 4.238 & 4.578 \\
\hline Chemical & $\left(10^{6} \mathrm{Btu} / \mathrm{hr}\right)$ & 4127.256 & 0.000 & 0.000 & 0.000 & 0.000 & 0.000 & 0.000 & 0.000 & 0.000 & 0.000 & 0.000 & 0.000 & 0.000 & 0.000 \\
\hline Sensible & $\left(10^{6} \mathrm{Btu} / \mathrm{hr}\right)$ & 0.000 & 0.000 & 641.921 & 246.552 & 1.966 & 244.586 & 257.778 & 79.085 & 0.000 & 0.653 & 65.783 & 8.883 & 16.444 & 4.599 \\
\hline Latent & $\left(10^{6} \mathrm{Btu} / \mathrm{hr}\right)$ & 0.000 & 0.425 & 455.743 & 465.750 & 0.000 & 465.750 & 465.750 & 465.750 & 0.000 & 0.000 & 584.775 & 0.000 & 117.486 & 30.418 \\
\hline Total Energy $^{(1)}$ & $\left(10^{6} \mathrm{Btu} / \mathrm{hr}\right)$ & 4127.256 & 0.425 & 1097.664 & 712.302 & 1.966 & 710.336 & 723.528 & 544.835 & 0.000 & 0.653 & 650.558 & 8.883 & 133.929 & 35.017 \\
\hline
\end{tabular}




\begin{tabular}{|c|c|c|c|c|c|c|c|c|c|c|c|c|c|c|c|}
\hline Constituent & (Units) & 15 & 16 & 17 & 18 & 19 & 20 & 21 & 22 & 23 & 24 & 25 & 26 & 27 & A1 \\
\hline$\overline{\mathrm{O}_{2}}$ & $\overline{(\mathrm{Lbm} / \mathrm{hr})}$ & & & 173542 & 173542 & 93054 & 30830 & 80488 & 67991 & 148478 & 174427 & 2686350 & 680583 & & 871226 \\
\hline $\mathrm{N}_{2}$ & $"$ & & & 39100 & 39100 & 20966 & 6946 & 18134 & 15319 & 33453 & 38204 & 154639 & 153340 & & 2886197 \\
\hline $\mathrm{H}_{2} \mathrm{O}$ & $"$ & & & 53646 & 53646 & 28765 & 9530 & 24881 & 21018 & 45899 & 82811 & 212169 & 210386 & & 48719 \\
\hline $\mathrm{CO}_{2}$ & $"$ & & & 516132 & 516132 & 276753 & 91692 & 239379 & 202212 & 441591 & 441591 & 2041279 & 2024128 & & \\
\hline $\mathrm{SO}_{2}$ & $"$ & & & 9 & 9 & 5 & 2 & 4 & 3 & 8 & 8 & 35 & 34 & & \\
\hline & $"$ & & & & & & & & & & 15715 & & & & \\
\hline Carbon & $"$ & & & & & & & & & & 230977 & & & & \\
\hline Sulfur & $"$ & & & & & & & & & & 9868 & & & & \\
\hline $\mathrm{CaO}$ & " & & & & & & & & & & & & & & \\
\hline $\begin{array}{l}\mathrm{MgO} \\
\mathrm{CaSO}_{3}\end{array}$ & $"$ & & & & & & & & & & & & & & \\
\hline $\begin{array}{l}\mathrm{CaSO}_{3} \\
\mathrm{CaSO}_{4}\end{array}$ & $"$ & & & & & & & & & & & & & & \\
\hline $\mathrm{MgSO}_{3}$ & " & & & & & & & & & & & & & & \\
\hline $\mathrm{MgSO}_{4}$ & $"$ & & & & & & & & & & & & & & \\
\hline $\begin{array}{l}\mathrm{CaCO}_{3} \\
\text { Ash / Inerts }\end{array}$ & $"$ & & & & & & & & & & 41298 & & & 8260 & \\
\hline & & & & PA Fan Inlet & PA Fan Outlet & PA to Air Htr & AH leakage gas & Temp. Fluegas & Hot Pri Air & Mixed Pri Air & $\begin{array}{l}\text { Coal-Pri Air Mix } \\
\end{array}$ & (Sec Air to AH & Sec Air to Furn & Bottom Ash & \\
\hline Total Gas & (Lbm/hr) & & & 782429 & 782429 & 419543 & 139000 & 362886 & 306543 & 669429 & 669429 & 3094471 & 3068471 & 0 & 3806142 \\
\hline Total Solids & $"$ & & & 0 & 0 & 0 & 0 & 0 & 0 & 0 & 365470 & 0 & 0 & 8260 & \\
\hline Total Flow & $"$ & & & 782429 & 782429 & 419543 & 139000 & 362886 & 306543 & 669429 & 1034899 & 3094471 & 3068471 & 8260 & 3806142 \\
\hline Temperature & (Deg F) & & & 120 & 126 & 126 & 126 & 126 & 572 & 339 & 0 & 120 & 593 & 2000 & 80 \\
\hline Pressure & (Psia) & & & 15.1 & 15.6 & 15.6 & 15.6 & 15.6 & 15.6 & 15.6 & 15.0 & 15.1 & 14.9 & 14.7 & 14.7 \\
\hline $\mathbf{h}_{\text {sensible }}$ & Btu/lbm & & & 9.028 & 10.408 & 10.408 & 10.408 & 10.408 & 121.647 & 61.346 & 0.000 & 9.028 & 127.223 & 480.000 & 0.000 \\
\hline Chemical & $\left(10^{6} \mathrm{Btu} / \mathrm{hr}\right)$ & & & 0.000 & 0.000 & 0.000 & 0.000 & 0.000 & 0.000 & 0.000 & 4127.256 & 0.000 & 0.000 & 0.000 & 0.000 \\
\hline Sensible & $\left(10^{6} \mathrm{Btu} / \mathrm{hr}\right)$ & & & 7.064 & 8.144 & 4.367 & 1.447 & 3.777 & 37.290 & 41.067 & 0.000 & 27.936 & 390.381 & 3.965 & 0.000 \\
\hline Latent & $\left(10^{6} \mathrm{Btu} / \mathrm{hr}\right)$ & & & 56.329 & 56.329 & 30.204 & 10.007 & 26.125 & 22.069 & 48.194 & 0.000 & 222.777 & 220.905 & 0.000 & 51.155 \\
\hline Total Energy $^{(I)}$ & $\left(10^{\circ} \mathrm{Btu} / \mathrm{hr}\right)$ & & & 63.392 & 64.472 & 34.570 & 11.454 & 29.902 & 59.359 & 89.261 & 4216.516 & 250.713 & 611.287 & 3.965 & 51.155 \\
\hline
\end{tabular}

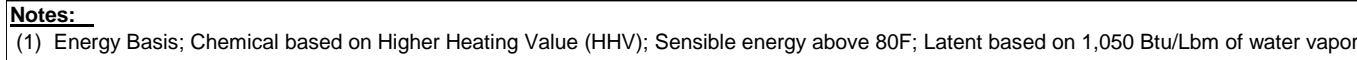




\begin{tabular}{|c|c|c|c|c|c|c|c|c|c|c|c|c|c|c|c|c|}
\hline \begin{tabular}{|c|} 
Constituent \\
\end{tabular} & (Units) & A2 & A3 & NG & A4 & A5 & A6 & A7 & S1 & S2 & S3 & SG1 & SG2 & SG3 & SG4 & SG5 \\
\hline$\overline{\mathrm{O}_{2}}$ & (Lbm/hr) & 871226 & 871226 & & 65342 & 655342 & 65342 & 65342 & & & & 105855 & 105855 & 859892 & 859892 & 859892 \\
\hline $\mathrm{N}_{2}$ & $"$ & 2886197 & 2886197 & & 2857335 & 2857335 & 2857335 & 2857335 & & & & 164877 & 164877 & 193739 & 193739 & 193739 \\
\hline $\mathrm{H}_{2} \mathrm{O}$ & $"$ & 48719 & 48719 & & 48719 & 252312 & 252312 & 252312 & 357298 & 203594 & 153704 & 82921 & 82921 & 112111 & 265815 & 265815 \\
\hline $\mathrm{CO}_{2}$ & " & & & & & & & & & & & 2521758 & 2521758 & 2557411 & 2557411 & 2557411 \\
\hline $\mathrm{SO}_{2}$ & " & & & & & & & & & & & 43 & 43 & 43 & 43 & 43 \\
\hline $\mathrm{H}_{2}$ & " & & & 3266 & & & & & & & & & & & & \\
\hline Carbon & $"$ & & & 9729 & & & & & & & & & & & & \\
\hline $\begin{array}{l}\text { Sulfur } \\
\mathrm{CaO}\end{array}$ & $"$ & & & & & & & & & & & & & & & \\
\hline $\mathrm{MgO}$ & $"$ & & & & & & & & & & & & & & & \\
\hline $\mathrm{CaSO}_{3}$ & " & & & & & & & & & & & & & & & \\
\hline $\mathrm{CaSO}_{4}$ & " & & & & & & & & & & & & & & & \\
\hline $\mathrm{MgSO}_{3}$ & " & & & & & & & & & & & & & & & \\
\hline $\mathrm{MgSO}_{4}$ & " & & & & & & & & & & & & & & & \\
\hline $\begin{array}{l}\mathrm{CaCO}_{3} \\
\text { Ash / Inerts }\end{array}$ & $"$ & & & & & & & & & & & & & & & \\
\hline Total Gas & (Lbm/hr) & 3806142 & 3806142 & 12996 & 2971396 & 3174990 & 3174990 & 3174990 & 357298 & 203594 & 153704 & 2875454 & 2875454 & 3723196 & 3876900 & 3876900 \\
\hline Total Flow & $"$ & 3806142 & 3806142 & 12996 & 2971396 & 3174990 & 3174990 & 3174990 & 357298 & 203594 & 153704 & 2875454 & 2875454 & 3723196 & 3876900 & 3876900 \\
\hline Temperature & (Deg F) & 208 & 356 & 80 & 441 & 419 & 254 & 120 & 238 & 238 & 238 & 102 & 153 & 442 & 427 & 120 \\
\hline Pressure & (Psia) & 27.0 & 24.1 & 0.0 & 15.1 & 15.1 & 14.9 & 14.7 & 15.2 & 15.2 & 15.2 & 14.7 & 20.0 & 15.4 & 15.2 & 15.1 \\
\hline $\mathbf{h}_{\text {sensible }}$ & Btu/lbm & 31.116 & 67.579 & $\begin{array}{r}0.000 \\
23896\end{array}$ & 90.535 & 89.266 & 45.555 & 10.483 & 70.740 & 70.740 & 70.740 & 4.578 & 15.775 & 84.190 & 83.657 & 9.028 \\
\hline Chemical & $\left(10^{6} \mathrm{Btu} / \mathrm{hr}\right)$ & 0.000 & 0.000 & 310.547 & 0.000 & 0.000 & 0.000 & 0.000 & 0.000 & 0.000 & 0.000 & 0.000 & 0.000 & 0.000 & 0.000 & 0.000 \\
\hline Sensible & $\left(10^{6} \mathrm{Btu} / \mathrm{hr}\right)$ & 118.432 & 257.213 & 0.000 & 269.016 & 283.418 & 144.637 & 33.285 & 25.275 & 14.402 & 10.873 & 13.165 & 45.361 & 313.458 & 324.330 & 35.000 \\
\hline Latent & $\left(10^{6} \mathrm{Btu} / \mathrm{hr}\right)$ & 51.155 & 51.155 & 0.000 & 51.155 & 264.928 & 264.928 & 264.928 & 375.163 & 213.773 & 161.389 & 87.067 & 87.067 & 117.717 & 279.106 & 279.106 \\
\hline Total Energy $^{(1)}$ & $\left(10^{6} \mathrm{Btu} / \mathrm{hr}\right)$ & 169.587 & 308.368 & 310.547 & 320.170 & 548.346 & 409.565 & 298.213 & 400.438 & 228.176 & 172.262 & 100.232 & 132.429 & 431.174 & 603.436 & 314.106 \\
\hline
\end{tabular}


Table 4-11: Boiler Island Material and Energy Balance - Case 3c

\begin{tabular}{|c|c|c|c|c|c|c|c|c|c|c|c|c|c|c|c|}
\hline Constituent & (Units) & 1 & 2 & 3 & 4 & 5 & 6 & 7 & 8 & 9 & 10 & 11 & 12 & 13 & 14 \\
\hline $\mathrm{O}_{2}$ & (Lbm/hr) & 25832 & 7208 & 109155 & 141143 & & 141143 & 141143 & 141143 & & & 140898 & & 140898 & 36900 \\
\hline $\mathrm{N}_{2}$ & $"$ & 4730 & 23879 & 208085 & 215063 & & 215063 & 215063 & 215063 & & & 215063 & & 215063 & 56323 \\
\hline $\mathrm{H}_{2} \mathrm{O}$ & $"$ & 36747 & 403 & 408581 & 417586 & & 417586 & 417586 & 417586 & 159971 & 47121 & 530436 & 421994 & 108441 & 28400 \\
\hline $\mathrm{CO}_{2}$ & $"$ & & & 3183975 & 3275003 & & 3275003 & 3275003 & 3275003 & & & 3273923 & & 3273923 & 857406 \\
\hline $\mathrm{SO}_{2}$ & $"$ & & & 19670 & 19671 & & 19671 & 19671 & 19671 & & & 58 & & 58 & 15 \\
\hline $\mathrm{H}_{2}$ & $"$ & 15645 & & & & & & & & & & & & & \\
\hline Carbon & " & 229944 & & & & & & & & & & & & & \\
\hline Sulfur & $"$ & 9824 & & & & & & & & & & & & & \\
\hline CaO & " & & & & & & & & & 17855 & & & & & \\
\hline MgO & $"$ & & & & & & & & & 992 & 496 & & & & \\
\hline $\mathrm{CaSO}_{3}$ & $"$ & & & & & & & & & & 33538 & & & & \\
\hline $\mathrm{CaSO}_{4}$ & " & & & & & & & & & & 2000 & & & & \\
\hline $\mathrm{MgSO}_{3}$ & $"$ & & & & & & & & & & 1220 & & & & \\
\hline $\mathrm{MgSO}_{4}$ & $"$ & & & & & & & & & & 74 & & & & \\
\hline $\mathrm{CaCO}_{3}$ & $"$ & & & & & & & & & & 2457 & & & & \\
\hline Ash / Inerts & $"$ & 41113 & & 32891 & 32891 & 32891 & & & & 992 & 992 & & & & \\
\hline & & Raw Coal & Leakage Air & Fluegas to Air Htr & Iluegas to $\mathrm{O} 2 \mathrm{Htr}$ & Fly Ash & Fluegas to ID Fan & Iluegas to PFWH & Fluegas to FGD & Lime Slurry & FGD Byproduct & Fluegas to $\mathrm{Cl}$ & Condensate & =luegas to Bstr Far & as to $\mathrm{CO} 2 \mathrm{Sys}$ \\
\hline Total Gas & (Lbm/hr) & & 31490 & 3929466 & 4068466 & 0 & 4068466 & 4068466 & 4068466 & 0 & 0 & 4160377 & 0 & 3738383 & 979043 \\
\hline Total S & $"$ & 363835 & 0 & 32891 & 32891 & 32891 & 0 & 0 & 0 & 19839 & 40778 & 0 & 0 & 0 & \\
\hline Total Flow & " & 363835 & 31490 & 3962357 & 4101357 & 32891 & 4068466 & 4068466 & 4068466 & 179809 & 87898 & 4160377 & 421994 & 3738383 & 979043 \\
\hline Temperature & (Deg F) & 80 & 80 & 676 & 318 & 318 & 318 & 330 & 200 & 80 & 144 & 144 & 100 & 100 & 102 \\
\hline Pressure & (Psia) & 14.7 & 14.7 & 14.6 & 14.3 & 14.7 & 14.2 & 15.0 & 14.9 & 14.7 & 14.7 & 14.6 & 14.7 & 14.6 & 14.7 \\
\hline $\mathbf{h}_{\text {sensible }}$ & Btu/lbm & 0.000 & 0.000 & 155.033 & 57.667 & 59.500 & 57.667 & 60.778 & 28.259 & 0.000 & 15.946 & 15.192 & 19.960 & 4.239 & 4.580 \\
\hline Chemical & $\left(10^{6} \mathrm{Btu} / \mathrm{hr}\right)$ & 4108.787 & 0.000 & 0.000 & 0.000 & 0.000 & 0.000 & 0.000 & 0.000 & 0.000 & 0.000 & 0.000 & 0.000 & 0.000 & 0.000 \\
\hline Sensible & $\left(10^{6} \mathrm{Btu} / \mathrm{hr}\right)$ & 0.000 & 0.000 & 614.099 & 236.572 & 1.957 & 234.615 & 247.271 & 114.971 & 0.000 & 0.650 & 63.204 & 8.423 & 15.848 & 4.484 \\
\hline Latent & $\left(10^{6} \mathrm{Btu} / \mathrm{hr}\right)$ & 0.000 & 0.423 & 429.010 & 438.465 & 0.000 & 438.465 & 438.465 & 438.465 & 0.000 & 0.000 & 556.958 & 0.000 & 113.864 & 29.820 \\
\hline Total Energy ${ }^{(1)}$ & $\left(10^{\circ} \mathrm{Btu} / \mathrm{hr}\right)$ & 4108.787 & 0.423 & 1043.109 & 675.037 & 1.957 & 673.080 & 685.736 & 553.437 & 0.000 & 0.650 & 620.162 & 8.423 & 129.712 & 34.303 \\
\hline
\end{tabular}

(1) Energy Basis; Chemical based on Higher Heating Value (HHV); Sensible energy above 80F; Latent based on 1,050 Btu/Lbm of water vapor 


\begin{tabular}{|c|c|c|c|c|c|c|c|c|c|c|c|c|c|c|}
\hline Constituent & (Units) & 15 & 16 & 17 & 18 & 19 & 20 & 21 & 22 & 23 & 24 & 25 & 26 & 27 \\
\hline $\mathrm{O}_{2}$ & (Lbm/hr) & & & 179368 & 179368 & 96407 & 31987 & 82961 & 70403 & 153363 & 179196 & 675378 & 669395 & \\
\hline$N_{2}$ & $"$ & & & 39127 & 39127 & 21030 & 6978 & 18097 & 15358 & 33455 & 38185 & 147327 & 146022 & \\
\hline $\mathrm{H}_{2} \mathrm{O}$ & $"$ & & & 50495 & 50495 & 27140 & 9005 & 23355 & 19819 & 43174 & 79922 & 190130 & 188445 & \\
\hline $\mathrm{CO}_{2}$ & $"$ & & & 510434 & 510434 & 274349 & 91028 & 236086 & 200348 & 436433 & 436433 & 1921953 & 1904926 & \\
\hline $\mathrm{SO}_{2}$ & " & & & 9 & 9 & 5 & 2 & 4 & 4 & 8 & 8 & 34 & 33 & \\
\hline $\mathrm{H}_{2}$ & " & & & & & & & & & & 15645 & & & \\
\hline Carbon & $"$ & & & & & & & & & & 229944 & & & \\
\hline Sulfur & " & & & & & & & & & & 9824 & & & \\
\hline $\mathrm{CaO}$ & " & & & & & & & & & & & & & \\
\hline $\mathrm{MgO}$ & " & & & & & & & & & & & & & \\
\hline $\mathrm{CaSO}_{3}$ & $"$ & & & & & & & & & & & & & \\
\hline $\mathrm{CaSO}_{4}$ & $"$ & & & & & & & & & & & & & \\
\hline $\mathrm{MgSO}_{3}$ & $"$ & & & & & & & & & & & & & \\
\hline $\mathrm{MgSO}_{4}$ & $"$ & & & & & & & & & & & & & \\
\hline $\begin{array}{l}\mathrm{CaCO}_{3} \\
\text { Ash / Inerts }\end{array}$ & " & & & & & & & & & & 41113 & & & 8223 \\
\hline Total Gas & (Lbm/hr) & \begin{tabular}{|l|} 
CO2 Product \\
By Linde
\end{tabular} & $\begin{array}{l}\text { Vent to Stack } \\
\text { By Linde }\end{array}$ & $\begin{array}{l}\text { PA Fan Inlet } \\
779433\end{array}$ & $\begin{array}{l}\text { PA Fan Outlet } \\
779433\end{array}$ & $\begin{array}{l}\text { PA to Air Htr } \\
418931\end{array}$ & $\begin{array}{r}\text { AH leakage gas } \\
139000\end{array}$ & $\begin{array}{c}\text { Temp. Fluegas } \\
360503\end{array}$ & $\begin{array}{l}\text { Hot Pri Air } \\
305931\end{array}$ & $\begin{array}{c}\text { Mixed Pri Air } \\
666433\end{array}$ & $\begin{array}{r}\text { Coal-Pri Air Mix } \\
666433\end{array}$ & $\begin{array}{l}\text { Sec Air to AH } \\
2934822\end{array}$ & $\begin{array}{l}\text { Sec Air to Furn } \\
2908822\end{array}$ & $\begin{array}{l}\text { Bottom Ash } \\
0\end{array}$ \\
\hline Total Solids & $"$ & & & 0 & 0 & 0 & 0 & 0 & 0 & 0 & 363835 & 0 & 0 & 8223 \\
\hline Total Flow & " & & & 779433 & 779433 & 418931 & 139000 & 360503 & 305931 & 666433 & 1030268 & 2934822 & 2908822 & 8223 \\
\hline Temperature & (Deg F) & & & 120 & 126 & 126 & 126 & 126 & 571 & 339 & 0 & 120 & 596 & 2000 \\
\hline Pressure & (Psia) & & & 15.1 & 15.6 & 15.6 & 15.6 & 15.6 & 15.6 & 15.6 & 15.0 & 15.1 & 14.9 & 14.7 \\
\hline $\mathbf{h}_{\text {sensible }}$ & Btu/lbm & & & 8.998 & 10.374 & 10.374 & 10.374 & 10.374 & 120.950 & 61.135 & 0.000 & 8.998 & 127.638 & 480.000 \\
\hline Chemical & $\left(10^{6} \mathrm{Btu} / \mathrm{hr}\right)$ & & & 0.000 & 0.000 & 0.000 & 0.000 & 0.000 & 0.000 & 0.000 & 4108.787 & 0.000 & 0.000 & 0.000 \\
\hline Sensible & $\left(10^{6} \mathrm{Btu} / \mathrm{hr}\right)$ & & & 7.013 & 8.086 & 4.346 & 1.442 & 3.740 & 37.002 & 40.742 & 0.000 & 26.406 & 371.277 & 3.947 \\
\hline Latent & $\left(10^{6} \mathrm{Btu} / \mathrm{hr}\right)$ & & & 53.020 & 53.020 & 28.497 & 9.455 & 24.523 & 20.810 & 45.333 & 0.000 & 199.636 & 197.868 & 0.000 \\
\hline Total Energy $^{(1)}$ & $\left(10^{6} \mathrm{Btu} / \mathrm{hr}\right)$ & & & 60.033 & 61.105 & 32.843 & 10.897 & 28.262 & 57.813 & 86.075 & 4194.862 & 226.043 & 569.144 & 3.947 \\
\hline
\end{tabular}

Notes:

(1) Energy Basis; Chemical based on Higher Heating Value (HHV); Sensible energy above 80F; Latent based on 1,050 Btu/Lbm of water vapor 


\begin{tabular}{|c|c|c|c|c|c|c|c|c|c|c|c|c|c|c|c|}
\hline Constituent & (Units) & A1 & A2 & A3 & NG & A4 & A5 & A6 & A7 & S1 & S2 & S3 & SG1 & SG2 & SG3 \\
\hline $\mathrm{O}_{2}$ & (Lbm/hr) & 836569 & 836569 & 836569 & & 62743 & 62743 & 62743 & 62743 & & & & 103998 & 103998 & 103998 \\
\hline$N_{2}$ & $"$ & 2771385 & 2771385 & 2771385 & & 2743671 & 2743671 & 2743671 & 2743671 & & & & 158740 & 158740 & 158740 \\
\hline $\mathrm{H}_{2} \mathrm{O}$ & $"$ & 46781 & 46781 & 46781 & & 46781 & 46781 & 242275 & 242275 & 343084 & 195495 & 147590 & 80042 & 80042 & 80042 \\
\hline $\mathrm{CO}_{2}$ & $"$ & & & & & & & & & & & & 2416517 & 2416517 & 2416517 \\
\hline
\end{tabular}

1454

$\begin{array}{lll}43 & 43 & 43\end{array}$

$\mathrm{H}_{2}$

Carbon

Sulfur

CaO

MgO

$\mathrm{CaSO}_{3}$

$\mathrm{CaSO}_{4}$

$\mathrm{MgSO}_{3}$

$\mathrm{MgSO}_{4}$

$\mathrm{CaCO}_{3}$

Ash I Inerts

\begin{tabular}{|c|c|c|c|c|c|c|c|c|c|c|c|c|c|c|c|}
\hline \begin{tabular}{|l} 
Total Gas \\
Total Solids
\end{tabular} & $\begin{array}{c}(\mathrm{Lbm} / \mathrm{hr}) \\
"\end{array}$ & $\begin{array}{r}3654734 \\
0\end{array}$ & $\begin{array}{r}3654734 \\
0\end{array}$ & & $\begin{array}{r}5785 \\
0\end{array}$ & $\begin{array}{r}2853195 \\
0\end{array}$ & $\begin{array}{r}2853195 \\
0\end{array}$ & $\begin{array}{r}3048689 \\
0\end{array}$ & $\begin{array}{r}3048689 \\
0\end{array}$ & $\begin{array}{r}343084 \\
0\end{array}$ & $\begin{array}{r}195495 \\
0\end{array}$ & $\begin{array}{r}147590 \\
0\end{array}$ & $\begin{array}{r}2759340 \\
0\end{array}$ & $\begin{array}{r}2759340 \\
0\end{array}$ & $\begin{array}{r}2759340 \\
0\end{array}$ \\
\hline Total Flow & $"$ & 3654734 & 3654734 & 3654734 & 5785 & 2853195 & 2853195 & 3048689 & 3048689 & 343084 & 195495 & 147590 & 2759340 & 2759340 & 2759340 \\
\hline Temperature & (Deg F) & 80 & 208 & 1410 & 80 & 1501 & 165 & 173 & 120 & 238 & 238 & 238 & 102 & 162 & 1494 \\
\hline Pressure & (Psia) & 14.7 & 27.0 & 24.1 & 0.0 & 15.1 & 15.1 & 14.9 & 14.7 & 15.2 & 15.2 & 15.2 & 14.7 & 21.0 & 15.4 \\
\hline $\mathbf{h}_{\text {sensible }}$ & Btu/lbm & 0.000 & 31.116 & 342.907 & $\begin{array}{r}0.000 \\
23896\end{array}$ & 373.931 & 21.321 & 24.490 & 10.483 & 70.740 & 70.740 & 70.740 & 4.580 & 17.666 & 382.270 \\
\hline Chemical & $\left(10^{6} \mathrm{Btu} / \mathrm{hr}\right)$ & 0.000 & 0.000 & 0.000 & 138.232 & 0.000 & 0.000 & 0.000 & 0.000 & 0.000 & 0.000 & 0.000 & 0.000 & 0.000 & 0.000 \\
\hline Sensible & $\left(10^{6} \mathrm{Btu} / \mathrm{hr}\right)$ & 0.000 & 113.721 & 1253.233 & 0.000 & 1066.899 & 60.832 & 74.661 & 31.961 & 24.270 & 13.829 & 10.440 & 12.637 & 48.747 & 1054.814 \\
\hline Latent & $\left(10^{6} \mathrm{Btu} / \mathrm{hr}\right)$ & 49.120 & 49.120 & 49.120 & 0.000 & 49.120 & 49.120 & 254.389 & 254.389 & 360.239 & 205.270 & 154.969 & 84.044 & 84.044 & 84.044 \\
\hline Total Energy $^{(1)}$ & $\left(10^{\circ} \mathrm{Btu} / \mathrm{hr}\right)$ & 49.120 & 162.841 & 1302.353 & 138.232 & 1116.018 & 109.951 & 329.050 & 286.350 & 384.508 & 219.099 & 165.410 & 96.681 & 132.791 & 1138.858 \\
\hline
\end{tabular}

Notes:

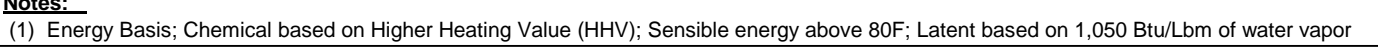




\begin{tabular}{|l||c||rrrr}
\hline Constituent & (Units) & \multicolumn{1}{c|}{ SG4 } & \multicolumn{1}{c|}{ SG5 } & \multicolumn{1}{c}{ SG6 } & \multicolumn{1}{c}{ SG7 } \\
\hline \hline $\mathrm{O}_{2}$ & $(\mathrm{Lbm} / \mathrm{hr})$ & 854746 & 854746 & 854746 & 854746 \\
$\mathrm{~N}_{\mathbf{2}}$ & $"$ & 186454 & 186454 & 186454 & 186454 \\
$\mathrm{H}_{2} \mathrm{O}$ & $"$ & 93035 & 93035 & 240625 & 240625 \\
$\mathrm{CO}_{2}$ & $"$ & 2432387 & 2432387 & 2432387 & 2432387 \\
$\mathrm{SO}_{2}$ & $"$ & & & & \\
\hline
\end{tabular}

\begin{tabular}{|l||r|rrrr}
$\mathrm{SO}_{2}$ & $"$ & 2432387 & 2432387 & 2432387 & 2432387 \\
& $"$ & 43 & 43 & 43 & 43
\end{tabular}

Carbon

Sulfur

$\mathrm{CaO}$

$\mathrm{MgO}$

$\mathrm{CaSO}_{3}$

$\mathrm{CaSO}_{4}$

$\mathrm{MgSO}_{3}$

$\mathrm{MgSO}_{4}$

$\mathrm{CaCO}_{3}$

Ash I Inerts

\begin{tabular}{|c|c|c|c|c|c|}
\hline Ash / Inerts & " & & & & \\
\hline \begin{tabular}{|l} 
Total Gas \\
Total Solids \\
Total Flow
\end{tabular} & $\begin{array}{c}\text { (Lbm/hr) } \\
" \\
"\end{array}$ & $\begin{array}{r}3566665 \\
0 \\
3566665\end{array}$ & $\begin{array}{r}3566665 \\
0 \\
3566665\end{array}$ & $\begin{array}{r}3714255 \\
0 \\
3714255\end{array}$ & $\begin{array}{r}3714255 \\
0 \\
3714255\end{array}$ \\
\hline Temperature & (Deg F) & 1490 & 322 & 316 & 120 \\
\hline Pressure & (Psia) & 15.4 & 15.4 & 15.2 & 15.1 \\
\hline $\mathbf{h}_{\text {sensible }}$ & $\mathrm{Btu} / \mathrm{lbm}$ & 374.305 & 54.816 & 55.448 & 8.998 \\
\hline Chemical & $\left(10^{6} \mathrm{Btu} / \mathrm{hr}\right)$ & 0.000 & 0.000 & 0.000 & 0.000 \\
\hline Sensible & $\left(10^{6} \mathrm{Btu} / \mathrm{hr}\right)$ & 1335.021 & 195.509 & 205.949 & 33.419 \\
\hline Latent & (10 $\left.10^{6} \mathrm{Btu} / \mathrm{hr}\right)$ & 97.687 & 97.687 & 252.656 & 252.656 \\
\hline
\end{tabular}

\begin{tabular}{l||l|rrrr}
\hline Total Energy $^{(1)}$ & $\left(10^{\circ} \mathrm{Btu} / \mathrm{hr}\right)$ & 1432.708 & 293.196 & 458.605 & 286.075 \\
\hline
\end{tabular}

Notes:

(1) Energy Basis; Chemical based on Higher Heating Value (HHV); Sensible energy above 80F; Latent based on 1,050 Btu/Lbm of water vapor 


\subsubsection{Boiler Analysis Results - Cases 3a, 3b, and 3c}

The main steam flow for Cases 3a, 3b and 3c and all other cases in this study is $395 \mathrm{~kg} / \mathrm{s}$ $(3,131,619 \mathrm{lbm} / \mathrm{hr})$. The cold reheat flow leaving the high-pressure turbine for Cases 3a, 3b and 3c and all other cases in this study is $348 \mathrm{~kg} / \mathrm{s}(2,767,780 \mathrm{lbm} / \mathrm{hr})$. The hot reheat flow (including de-superheating spray) returning to the intermediate pressure turbine is $354 \mathrm{~kg} / \mathrm{s}(2,815,852$ $\mathrm{lbm} / \mathrm{hr}$ ) for Cases 3a and 3b and is $354 \mathrm{~kg} / \mathrm{s}(2,805,671 \mathrm{lbm} / \mathrm{hr})$ for Case 3c. The overall steam conditions produced by the existing Conesville \#5 steam generator unit are shown in Table 4-12 for Cases 3a and 3b and in Table 4-13 for Case 3c below.

Table 4-12: Boiler Steam/Water Conditions - Cases 3a and 3b

\begin{tabular}{|c|rrrrr|}
\hline & SHO & FWI & ECO & RHO & RHI \\
\hline Flow (Ibm/hr) & 3131619 & 3131619 & 3121036 & 2815852 & 2815852 \\
Pressure (psia) & 2535 & 3165 & 3070 & 590.8 & 656.5 \\
Temperature (F) & 1000 & 493 & 612 & 1000 & 627 \\
Enthalpy (Btu/lbm) & 1456.3 & 479.2 & 625.7 & 1517.6 & 1303.2 \\
\hline
\end{tabular}

Table 4-13: Boiler Steam/Water Conditions - Case 3c

\begin{tabular}{|c|rrrrr|}
\hline & SHO & FWI & ECO & RHO & RHI \\
\hline Flow (lbm/hr) & 3131619 & 3131619 & 3121036 & 2805671 & 2805671 \\
Pressure (psia) & 2535 & 3165 & 3070 & 590.8 & 656.5 \\
Temperature (F) & 1000 & 493 & 612 & 1000 & 632 \\
Enthalpy (Btu/lbm) & 1456.3 & 479.2 & 625.7 & 1517.6 & 1306.6 \\
\hline
\end{tabular}

Notes:

$\underline{\mathrm{SHO}}=$ Superheater Outlet; FWI = Feedwater Inlet; ECO = Economizer Outlet; RHO = Reheater Outlet; RHI $=$ Reheater Inlet

To produce these conditions for Cases $3 \mathrm{a}$ and $3 \mathrm{~b}$, the superheat circuit requires about 0.8 percent spray and the reheat circuit requires about 1.7 percent spray to maintain required steam outlet temperatures. The burner tilts are -10 degrees (the minimum value the customer uses). The boiler was fired with about 5.2 percent excess oxygen and the resulting boiler efficiency calculated for this case was 88.76 percent with an air heater exit gas temperature of $159^{\circ} \mathrm{C}\left(318^{\circ} \mathrm{F}\right)$. The boiler efficiency including the heat recovered from Stream 7 using the $\mathrm{PFWH}$ is calculated to be 91.43 percent.

To produce these conditions for Case 3c, the superheat circuit requires about 0.1 percent spray and the reheat circuit requires about 1.4 percent spray to maintain required steam outlet temperatures. The burner tilts are -10 degrees (the minimum value the customer uses). The boiler was fired with about 5.2 percent excess oxygen and the resulting boiler efficiency calculated for this case was 88.95 percent with an air heater exit gas temperature of $159^{\circ} \mathrm{C}\left(318^{\circ} \mathrm{F}\right)$. The boiler efficiency including the heat recovered from Stream 7 using the PFWH is calculated to be 91.43 percent.

\subsubsection{Modified FGD System Performance - Cases 3a, 3b, and 3c only}

The issues regarding the performance of the existing FGD system and the ESP with the high $\mathrm{CO}_{2}$ content flue gas are discussed in some detail in Appendix I - Section 10.1.6 and are not repeated 
here. The basic conclusions reached were that, under these circumstances, the flue gas desulfurization systems $\mathrm{SO}_{2}$ capture efficiency would decrease by approximately $2 \%$. Additionally, for the high $\mathrm{CO}_{2}$ content flue gas associated with oxygen firing no ESP performance degradation is expected

Table 4-14 identifies the assumptions that were made in predicting the modified FGD system performance.

Table 4-14: Modified FGD System Assumptions (Cases 3a, 3b, and 3c)

\begin{tabular}{|l|c|c|c|}
\hline Quantity & Unit & Existing Absorber & Secondary Absorber \\
\hline $\mathrm{Ca} / \mathrm{S}$ & & & \\
\hline Solids & Mol Ratio & 1.04 & 1.04 \\
\hline $\mathrm{CaO}$ & Wt.\% & 20 & 20 \\
\hline $\mathrm{MgO}$ & Wt.\% & 90 & 90 \\
\hline Inerts & Wt.\% & 5 & 5 \\
\hline By-pass Leakage & Wt.\% & 5 & 5 \\
\hline Liquid/Gas (L/G) Ratio & Wt.\% & 2.5 & 0 \\
\hline $\mathrm{SO}_{2}$ Removal Efficiency & gpm/1000 acfm & 75 & 45 \\
\hline APC & & & 93.0 \\
\hline Absorber & $\%$ & 94.8 & 93.0 \\
\hline
\end{tabular}

\subsubsection{Steam Cycle Performance - Cases 3a, 3b, and 3c}

The final steam cycle for Cases $3 a$ and $3 b$ is shown schematically in Figure 4-17. Figure 4-18 shows the associated T-S and Mollier diagrams, which illustrates the process on temperature entropy and enthalpy - entropy coordinates respectively. The high-pressure turbine expands about $391 \mathrm{~kg} / \mathrm{s}\left(3.1 \times 10^{6} \mathrm{lbm} / \mathrm{hr}\right)$ of steam at 175 bara $(2,535 \mathrm{psia})$ and $538{ }^{\circ} \mathrm{C}\left(1,000^{\circ} \mathrm{F}\right)$. Reheat steam is returned to the intermediate pressure turbine at 41 bara (591 psia) and $538{ }^{\circ} \mathrm{C}(1,000 \mathrm{~F})$. Lowlevel heat rejected from the flue gas, GPU, and CAR system is recovered in the condensate stream as indicated. The condenser pressure used for the Cases 3a and 3b and all other cases in this study was $6.35 \mathrm{~cm}$. Hga (2.5 in Hga). The steam turbine performance analysis results show the generators produces an output of $470,327 \mathrm{kWe}$. The steam turbine heat rate is calculated to be about 9,520 kJ/kWh $(9,022 \mathrm{Btu} / \mathrm{kWh})$. 


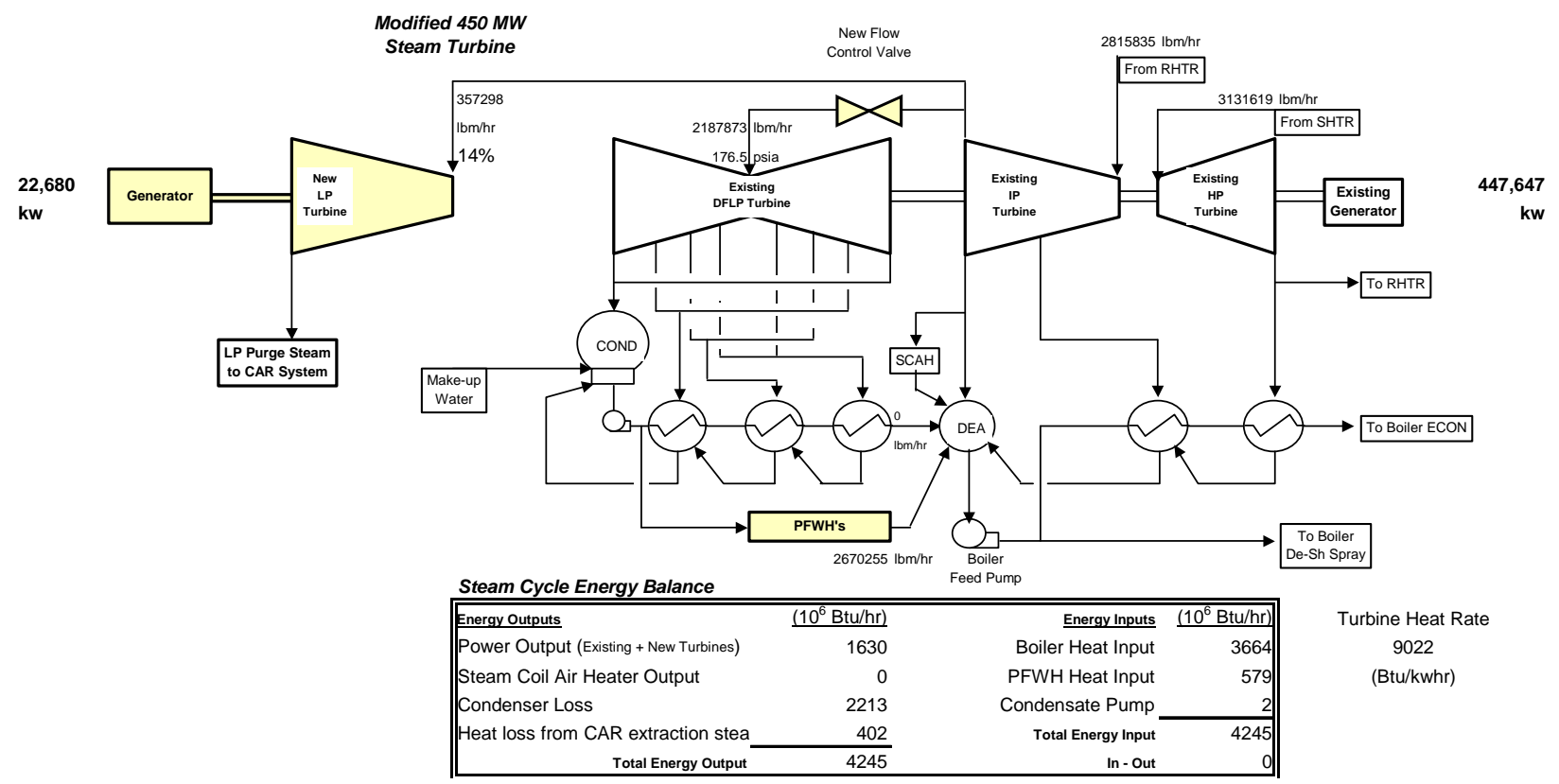

Figure 4-17: Steam Cycle Schematic and Performance - Cases 3a and 3b
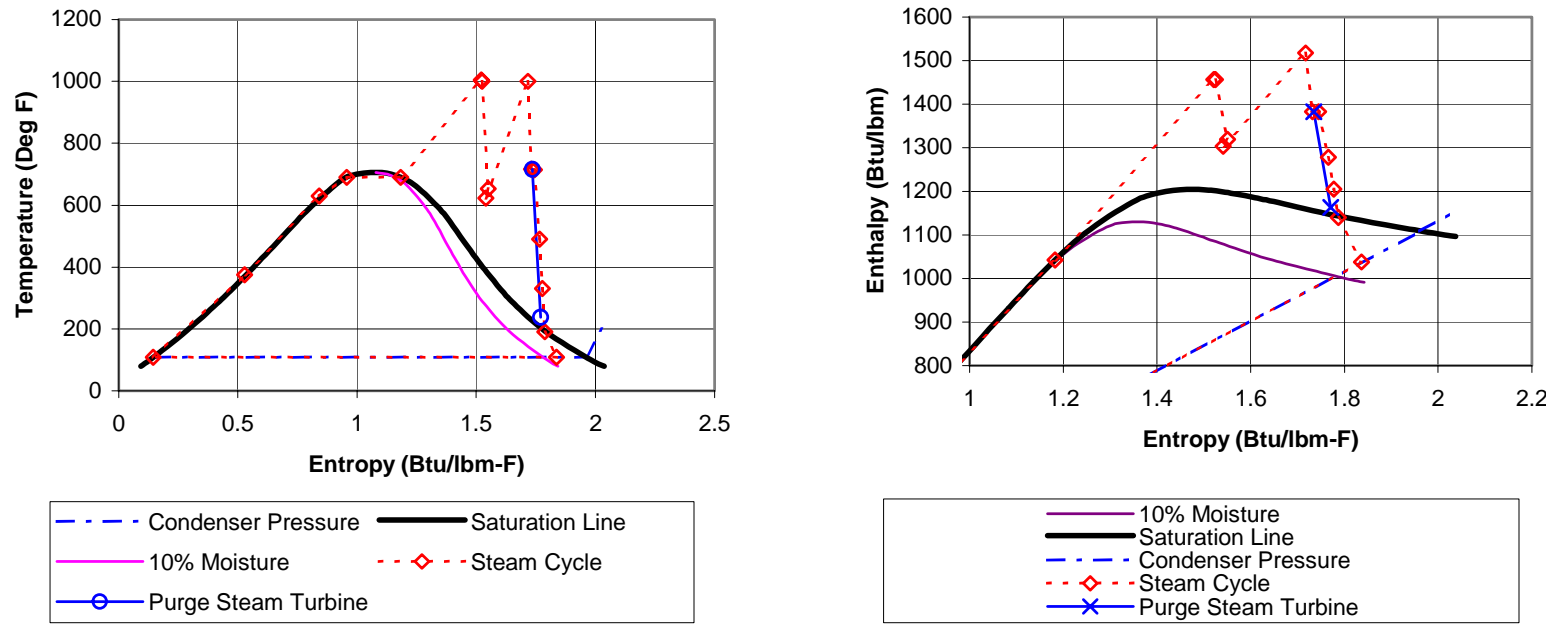

Figure 4-18: Steam Cycle T-S and Mollier Diagrams - Cases 3a and 3b

The final steam cycle for Case 3c is shown schematically in Figure 4-19. Figure 4-20 shows the associated T-S and Mollier diagrams, which illustrates the process on temperature - entropy and enthalpy - entropy coordinates respectively. The high-pressure turbine expands about $391 \mathrm{~kg} / \mathrm{s}$ $\left(3.1 \times 10^{6} \mathrm{lbm} / \mathrm{hr}\right)$ of steam at 175 bara $(2,535 \mathrm{psia})$ and $538^{\circ} \mathrm{C}\left(1,000^{\circ} \mathrm{F}\right)$. Reheat steam is returned to the intermediate pressure turbine at 41 bara (591 psia) and $538{ }^{\circ} \mathrm{C}(1,000 \mathrm{~F})$. Lowlevel heat rejected from the flue gas, GPU, and CAR system is recovered in the condensate stream as indicated. The condenser pressure used for the Case 3c and all other cases in this study was 6.35 
cm. Hga (2.5 in Hga). The steam turbine performance analysis results show the generators produces an output of 449,563 $\mathrm{kWe}$. The steam turbine heat rate is calculated to be about 9,388 $\mathrm{kJ} / \mathrm{kWh}(8,897 \mathrm{Btu} / \mathrm{kWh})$.

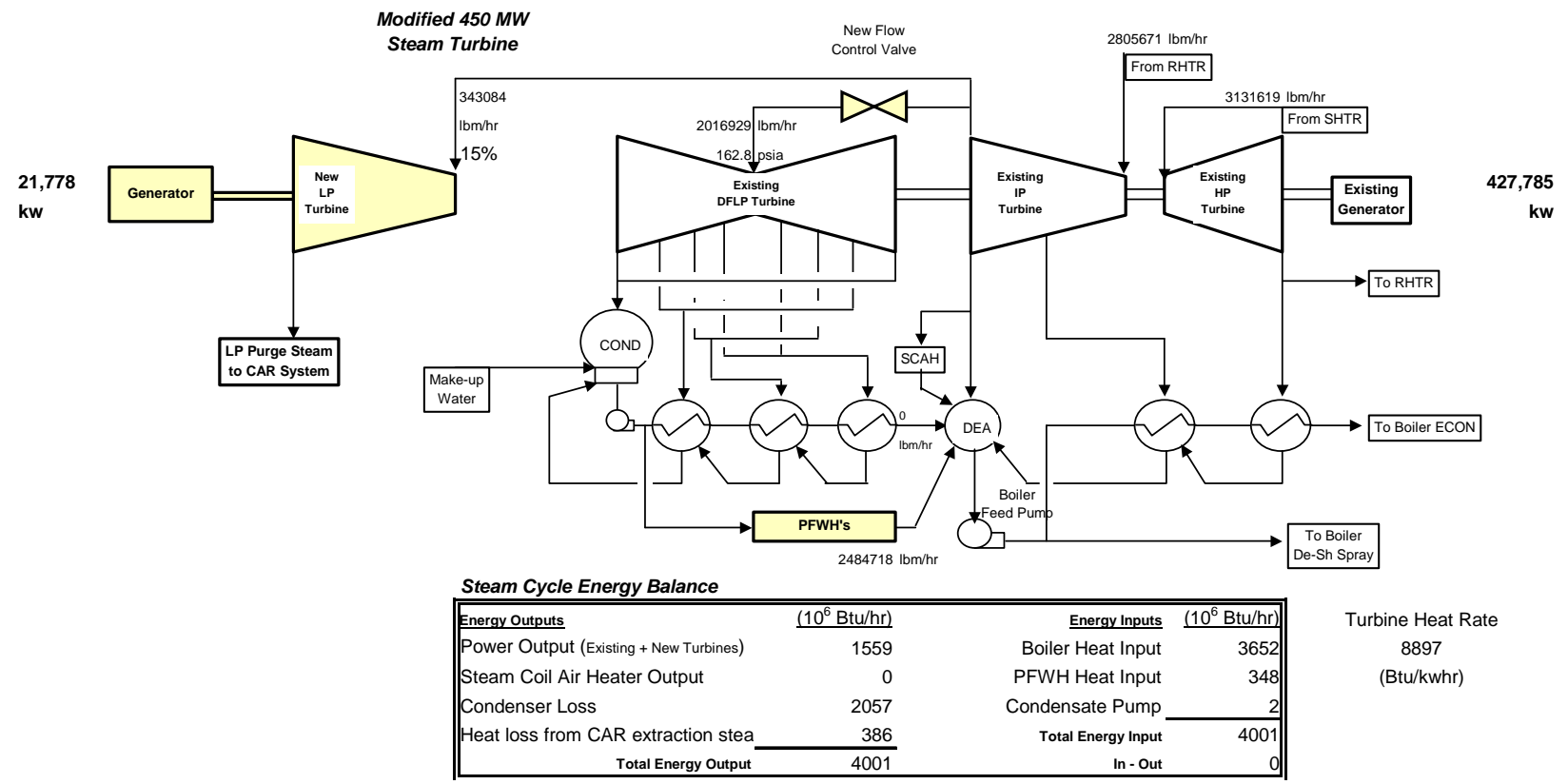

Figure 4-19: Steam Cycle Schematic and Performance - Case 3c
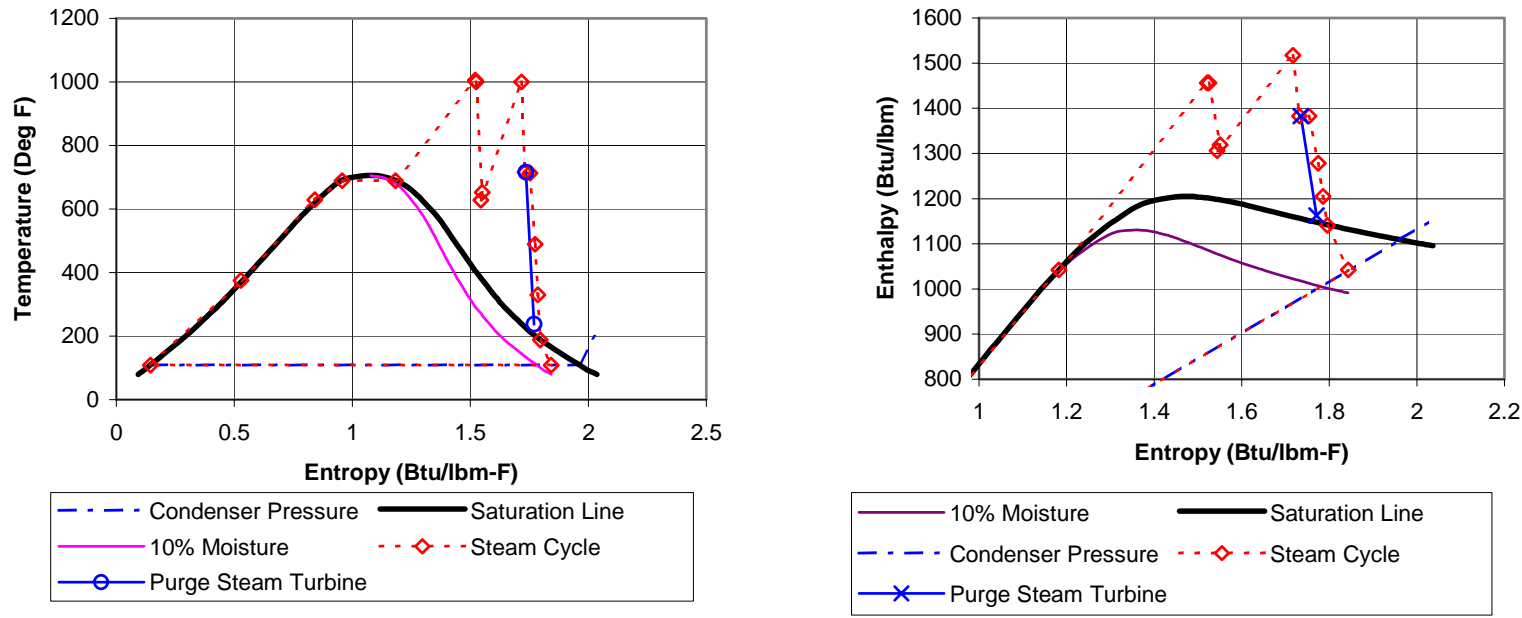

Figure 4-20: Steam Cycle T-S and Mollier Diagrams - Case 3c

\subsubsection{Plant Performance Summary - Cases 3a, 3b, and 3c}

Overall plant performance for these three cases is summarized in Table 4-15. The performance for Cases $3 \mathrm{a}$ and $3 \mathrm{~b}$ is identical as shown in the first column. Boiler efficiency is calculated to be 91.43 percent for all three cases. The total fuel heat input is $4,449.2 \times 10^{6} \mathrm{Btu} / \mathrm{hr}$ for Cases $3 \mathrm{a}$ and 
3b and is 4,258.4 $\times 10^{6} \mathrm{Btu} / \mathrm{hr}$ for Case 3c (less natural gas is fired in the CAR system for Case 3c as was explained previously). The net plant heat rate is calculated to be $13,067 \mathrm{Btu} / \mathrm{kWh}$ for Cases 3a and 3b and 13,169 Btu/kWh for Case 3c. Auxiliary power is $129,845 \mathrm{kWe}$ (about $28.0 \%$ of gross output) for Cases 3a and 3b and 126,211 kWe (also about 28.0\% of gross output) for Case 3c. The net plant output is 340,483 kWe for Cases 3a and 3b and 323,352 kWe for Case 3c. Carbon dioxide emissions are 53,280 lbm/hr or about $0.156 \mathrm{lbm} / \mathrm{kWh}$ for Cases 3a and 3b. Carbon dioxide emissions are 50,764 lbm/hr or about $0.157 \mathrm{lbm} / \mathrm{kWh}$ for Case 3c.

\section{Table 4-15: Plant Performance Summary Cases 3a, 3b, and 3c}

\begin{tabular}{|c|c|c|c|}
\hline & (units) & $\begin{array}{c}\text { Case } 3 a / b \text { - } \\
\text { O2 Fired } \\
\text { CAR (flue } \\
\text { gas sweep) }\end{array}$ & $\begin{array}{c}\text { Case 3c - O2 } \\
\text { Fired CAR } \\
\text { (flue gas } \\
\text { sweep) }\end{array}$ \\
\hline \multicolumn{4}{|l|}{ Fuel Paramaters } \\
\hline$\overline{\text { Coal Heat Input (HHV) }}$ & $\left(10^{6} \mathrm{Btu} / \mathrm{hr}\right)$ & 4127.3 & 4108.8 \\
\hline Natural Gas Heat Input (HHV) & $\left(10^{6} \mathrm{Btu} / \mathrm{hr}\right)$ & 322.0 & 149.6 \\
\hline Total Fuel Heat Input (HHV) & $\left(10^{6} \mathrm{Btu} / \mathrm{hr}\right)$ & 4449.2 & 4258.4 \\
\hline \multicolumn{4}{|l|}{ Steam Cycle Paramaters } \\
\hline Existing Steam Turbine Generator Output & $(\mathrm{kW})$ & 447,647 & 427,785 \\
\hline CAR Extraction Turbine Generator Output & $(\mathrm{kW})$ & 22680 & 21778 \\
\hline Total Turbine Generator Output & $(\mathrm{kW})$ & 470,327 & 449,563 \\
\hline Total Auxiliary Power & $(\mathrm{kW})$ & 129,845 & 126,211 \\
\hline Net Plant Output & $(\mathrm{kW})$ & 340,483 & 323,352 \\
\hline Normalized Net Plant Output (Relative to Base Case) & (fraction) & 0.78 & 0.75 \\
\hline \multicolumn{4}{|l|}{ Overall Plant Performance Paramaters } \\
\hline Net Plant Efficiency (HHV) & (fraction) & 0.2612 & 0.2592 \\
\hline Normalized Efficiency (HHV; Relative to Base Case) & (fraction) & 0.7460 & 0.7402 \\
\hline Net Plant Heat Rate (HHV) & (Btu/kwhr) & 13067 & 13169 \\
\hline Efficiency Loss Relative to Air Fired Base (HHV) & (\% points) & 8.89 & 9.09 \\
\hline \multicolumn{4}{|l|}{ 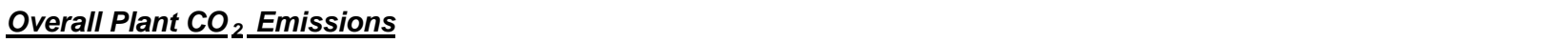 } \\
\hline Carbon Dioxide Produced & $(\mathrm{lbm} / \mathrm{hr})$ & 917,934 & 874,580 \\
\hline Carbon Dioxide Emissions & $(\mathrm{lbm} / \mathrm{hr})$ & 53,280 & 50,764 \\
\hline Specific Carbon Dioxide Emissions & (lbm/kwhr) & 0.156 & 0.157 \\
\hline Normalized Specific CO2 Emissions (Relative to Base Case) & (fraction) & 0.078 & 0.079 \\
\hline Avoided Carbon Dioxide Emissions (as compared to Base) & (lbm/kwhr) & 1.843 & 1.842 \\
\hline Specific Carbon Dioxide Emissions & (kg/kwhr) & 0.071 & 0.071 \\
\hline Avoided Carbon Dioxide Emissions (as compared to Base) & (kg/kwhr) & 0.837 & 0.836 \\
\hline
\end{tabular}

\subsubsection{Steam Sweep Cases (4a, and 4b)}

Cases 4a and 4b represent the retrofit of Conesville Unit \#5 using the Ceramic Autothermal Recovery (CAR) oxygen production process with steam used as a sweep gas for the CAR process. The basic process flow diagram for the CAR system would look very similar to Figure 4-11 shown previously except the sweep gas (purge) source would be low-pressure steam instead of flue gas. Also, the flue gas blowers would not be needed. Case 4a represents a case that uses oxygen blowers to pressurize the cooled oxidant stream leaving the CAR system to the proper 
pressure for the boiler. Because oxygen blowers are relatively expensive Linde recommended the investigation of Case 4b, which eliminates the use of the oxygen blowers.

\subsubsection{Process Description - Cases 4a and 4b}

This process description applies to Cases $4 \mathrm{a}$ and $4 \mathrm{~b}$.

Figure 4-21 shows the basic concept considered for integrating the CAR system, using steam as the sweep medium, with the existing boiler island. This diagram applies to Case 4a however the only difference for Case $4 \mathrm{~b}$ would be the elimination of the oxygen blower and the operation of the CAR steam condenser at a higher pressure to make up for the oxygen blower removal.

Flue gas leaving the existing ID fans (Stream 7) is cooled with feedwater in parallel with the extraction feedwater heaters and then enters the existing FGD system where $\mathrm{SO}_{2}$ is removed. Unlike the flue gas sweep cases, the existing FGD system for the steam sweep cases does not need to be modified to provide additional $\mathrm{SO}_{2}$ removal. The flue gas leaving the FGD system (Stream 11 ) is further cooled to about $100 \mathrm{~F}$ in a direct contact gas cooler which minimizes the power requirements for the down stream fans and product gas compression system. The flue gas leaving the booster fan is split into two streams (Stream 14 and Stream 17). Stream 14, which represents about 25 percent of the total, provides the product gas feed stream to the Gas Processing Unit. Stream 17, which represents about 75 percent of the total, provides recirculated flue gas to the boiler to maintain temperatures in an acceptable range for the existing boiler pressure part materials.

Air is delivered to the CAR system at the required pressure with the air blower. The air is then preheated before entering the CAR beds where most of the oxygen contained in the air is retained by the bed material. The oxygen-depleted stream leaving the CAR beds (Stream A4), which is comprised of mostly nitrogen is cooled and then discharged through the existing stack. Stream S3 is a low-pressure steam stream, which is used to purge the beds between the intermittent air and steam sweep cycles.

The steam sweep gas (Stream S1) is extracted from the existing turbine from the IP/LP crossover pipe and is reduced to the proper pressure by expansion through a new let down turbine. The sweep gas is then preheated before it enters the CAR bed (Stream S2) where it picks up the oxygen from the bed material. The oxygen/steam mixture leaving the CAR bed (Stream O1) is cooled and most of the steam is condensed. The condensate (Stream C1) is preheated with heat provided from the oxygen steam mixture leaving the CAR system and is returned to the steam cycle (Stream C3). The oxidant stream leaving the condenser (Stream O4) is raised to the proper pressure with the oxygen blower and then supplied to the boiler (Stream O5). The oxidant stream leaving the CAR system (Stream O5) is shown as a single stream for simplicity. In reality this stream would be split into three streams as was explained for Case 2 (refer to Figure 4-7).

The recycled flue gas (Stream 17) is divided into primary "air" and secondary "air" streams (Streams 19 and 27 respectively), which feed the boiler. The primary and secondary streams are preheated in the existing Ljungstrom air heater in the same manner as with air firing. The primary stream is raised to the proper pressure with the existing PA fans and then feeds the coal mills. The mill outlet temperature is controlled to the proper value in the normal fashion with the existing control system by bypassing some of the cold primary air (Stream 22) around the air heater. The tempered primary oxidant stream (Stream 24) is then supplied to the coal mills. The coal-gas mixture leaving the mills (Stream 25) is combusted in the furnace along with the preheated 
secondary oxidant (Stream 29). The oxygen content in the flue gas stream leaving the furnace (Stream 3) is controlled to be the same value as it was in the air fired Base Case, about 3.2\% oxygen by volume. This corresponds to a stoichiometry of about 1.05 for these CAR cases. The flue gas leaving the furnace (Stream 3) is cooled in the air heater, cleaned of particulate matter in the electrostatic precipitator (ESP) and raised in pressure by the ID fan, which completes the cycle. 


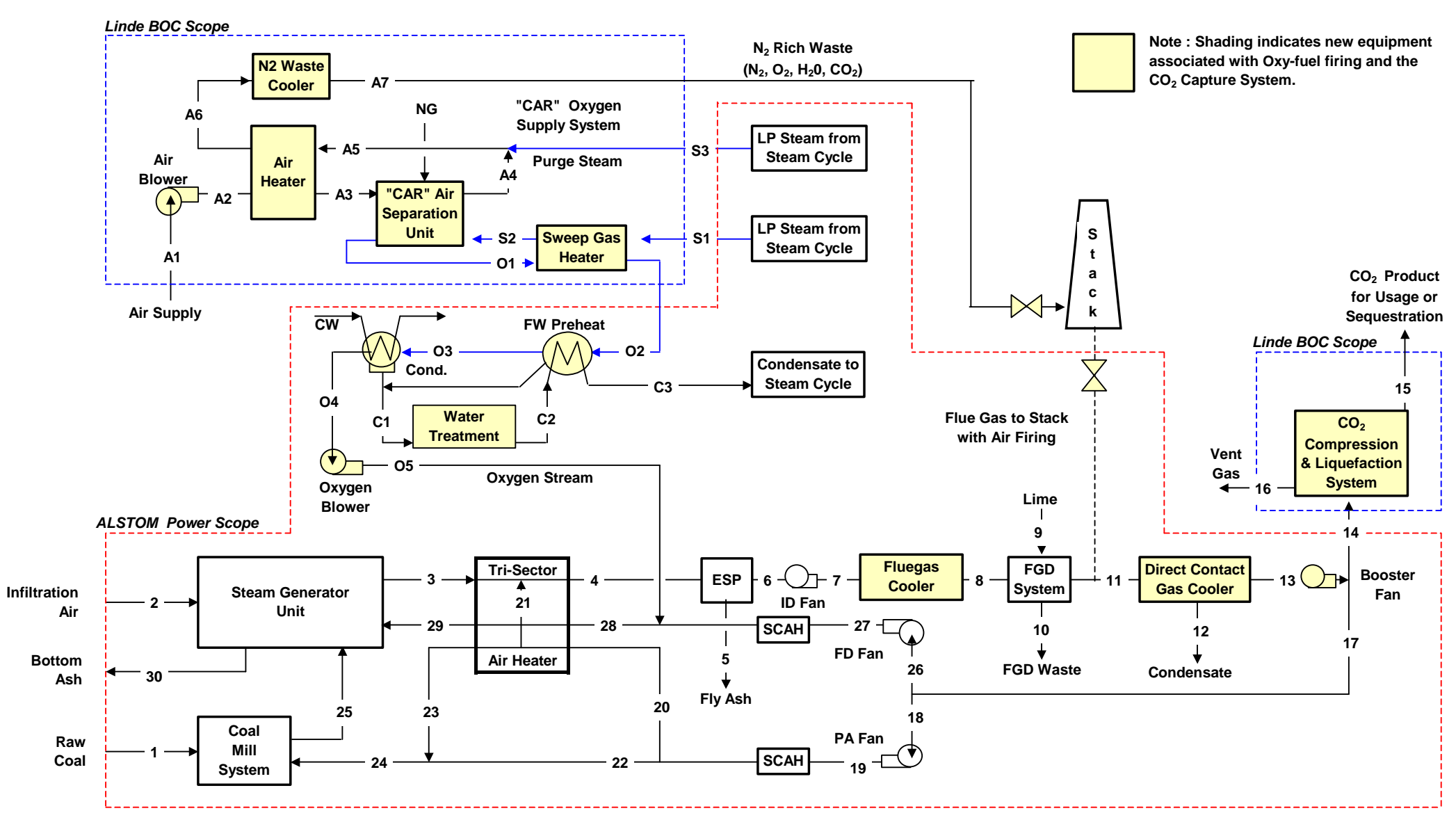

Figure 4-21: Conceptual Integration Concept for CAR Steam Sweep Cases 4a and 4b 


\subsubsection{Material and Energy Balance - Cases 4a and 4b}

The material and energy balance for Case $4 \mathrm{a}$ is shown in Table 4-16 below. The stream numbers correspond to Figure 4-21 shown above which shows the boiler island PFD and the basic concept for integrating the CAR flue gas sweep system with the existing boiler island.

Similarly, the material and energy balance for Case $4 \mathrm{~b}$ is shown in Table 4-17 below. The stream numbers correspond to Figure 4-21 shown above. 
Table 4-16: Boiler Island Material and Energy Balance - Case 4a

\begin{tabular}{|c|c|c|c|c|c|c|c|c|c|c|c|c|c|c|c|}
\hline Constituent & (Units) & 1 & 2 & 3 & 4 & 5 & 6 & 7 & 8 & 9 & 10 & 11 & 12 & 13 & 14 \\
\hline $\mathrm{O}_{2}$ & $\overline{(\mathrm{Lbm} / \mathrm{hr})}$ & 25872 & 7219 & 102864 & 114905 & & 114905 & 114905 & 114905 & & & 114663 & & 114663 & 29017 \\
\hline $\mathrm{N}_{2}$ & $"$ & 4737 & 23916 & 213423 & 221166 & & 221166 & 221166 & 221166 & & & 221166 & & 221166 & 55968 \\
\hline $\mathrm{H}_{2} \mathrm{O}$ & $"$ & 36804 & 404 & 301690 & 305929 & & 305929 & 305929 & 305929 & 158374 & 46650 & 417653 & 306595 & 111058 & 28135 \\
\hline $\mathrm{CO}_{2}$ & $"$ & & & 3268650 & 3382594 & & 3382594 & 3382594 & 3382594 & & & 3381524 & & 3381524 & 855731 \\
\hline $\mathrm{SO}_{2}$ & $"$ & & & 20339 & 20371 & & 20371 & 20371 & 20371 & & & 953 & & 953 & 241 \\
\hline $\mathrm{H}_{2}$ & $"$ & 15669 & & & & & & & & & & & & & \\
\hline Carbon & $"$ & 230299 & & & & & & & & & & & & & \\
\hline Sulfur & $"$ & 9839 & & & & & & & & & & & & & \\
\hline $\mathrm{CaO}$ & " & & & & & & & & & 17677 & & & & & \\
\hline MgO & $"$ & & & & & & & & & 982 & 491 & & & & \\
\hline $\mathrm{CaSO}_{3}$ & $"$ & & & & & & & & & & 33203 & & & & \\
\hline $\mathrm{CaSO}_{4}$ & $"$ & & & & & & & & & & 1980 & & & & \\
\hline $\mathrm{MgSO}_{3}$ & $"$ & & & & & & & & & & 1208 & & & & \\
\hline $\mathrm{MgSO}_{4}$ & $"$ & & & & & & & & & & 73 & & & & \\
\hline $\mathrm{CaCO}_{3}$ & $"$ & & & & & & & & & & 2433 & & & & \\
\hline Ash / Inerts & $"$ & 41177 & & 32942 & 32942 & 32942 & & & & 982 & 982 & & & & \\
\hline \multirow{4}{*}{\begin{tabular}{|l} 
Total Gas \\
Total Solids \\
Total Flow \\
\end{tabular}} & \multirow{4}{*}{$\begin{array}{c}\text { (Lbm/hr) } \\
" \\
" \\
\end{array}$} & Raw Coal & Leakage Air & Fluegas to Air $\mathrm{Htr}$ & Fluegas to $\mathrm{O} 2 \mathrm{Htr}$ & Fly Ash & Fluegas to ID Fan F & Eluegas to PFWH & Fluegas to FGD & Lime Slury & FGD Byproduct & Fluegas to $\mathrm{Clr}$ & Condensate & \multirow{2}{*}{\multicolumn{2}{|c|}{ =luegas to Bstr Farregas to CO2 Sys }} \\
\hline & & 0 & 31539 & 3906965 & 4044965 & 0 & 4044965 & 4044965 & 4044965 & 0 & 0 & 4135959 & 0 & & \\
\hline & & 364398 & 0 & 32942 & 32942 & 32942 & & & & & & & & & \\
\hline & & 364398 & 31539 & 3939907 & 4077907 & 32942 & 4044965 & 4044965 & 4044965 & 178015 & 87021 & 4135959 & 306595 & 3829364 & 969092 \\
\hline & & $\overline{0}$ & $\overline{0}$ & $\overline{0}$ & $\overline{0}$ & $\overline{0}$ & $\overline{00}$ & $\overline{00}$ & $\overline{0}$ & $\overline{0}$ & $\overline{0}$ & $\overline{0}$ & $\overline{0}$ & 0 & $\overline{0}$ \\
\hline Temperature & (Deg F) & 80 & 80 & 676 & 323 & 323 & 323 & 335 & 181 & 80 & 144 & 144 & 100 & 100 & 102 \\
\hline Pressure & (Psia) & 14.7 & 14.7 & 14.6 & 14.3 & 14.7 & 14.2 & 15.0 & 14.9 & 14.7 & 14.7 & 14.6 & 14.7 & 14.6 & 14.7 \\
\hline $\mathbf{h}_{\text {sensible }}$ & Btu/lbm & 0.000 & 0.000 & 151.478 & 57.412 & 60.750 & 57.412 & 60.463 & 23.106 & 0.000 & 15.946 & 14.784 & 19.960 & 4.236 & 4.576 \\
\hline Chemical & $\left(10^{6} \mathrm{Btu} / \mathrm{hr}\right)$ & 4115.144 & 0.000 & 0.000 & 0.000 & 0.000 & 0.000 & 0.000 & 0.000 & 0.000 & 0.000 & 0.000 & 0.000 & 0.000 & 0.000 \\
\hline Sensible & (10 $\left(10^{6} \mathrm{Btu} / \mathrm{hr}\right)$ & 0.000 & 0.000 & 596.730 & 234.232 & 2.001 & 232.231 & 244.569 & 93.463 & 0.000 & 0.644 & 61.147 & 6.120 & 16.223 & 4.435 \\
\hline Latent & (10 $\left.10^{6} \mathrm{Btu} / \mathrm{hr}\right)$ & 0.000 & 0.424 & 316.774 & 321.226 & 0.000 & 321.226 & 321.226 & 321.226 & 0.000 & 0.000 & 438.535 & 0.000 & 116.611 & 29.541 \\
\hline Total Energy ${ }^{(1)}$ & $\left(10^{\circ} \mathrm{Btu} / \mathrm{hr}\right)$ & 4115.144 & 0.424 & 913.504 & 555.458 & 2.001 & 553.456 & 565.795 & 414.689 & 0.000 & 0.644 & 499.682 & 6.120 & 132.834 & 33.976 \\
\hline
\end{tabular}




\begin{tabular}{|c|c|c|c|c|c|c|c|c|c|c|c|c|c|c|c|c|}
\hline Constituent & (Units) & 15 & 16 & 17 & 18 & 19 & 20 & 21 & 22 & 23 & 24 & 25 & 26 & 27 & 28 & 29 \\
\hline $\mathrm{O}_{2}$ & (Lbm/hr) & & & 85646 & 23370 & 23370 & 12724 & 12041 & 10646 & 9340 & 19986 & 45858 & 62276 & 62276 & 806243 & 797585 \\
\hline $\mathrm{N}_{2}$ & " & & & 165198 & 45076 & 45076 & 24542 & 7744 & 20534 & 18016 & 38550 & 43287 & 120121 & 120121 & 147437 & 146219 \\
\hline $\mathrm{H}_{2} \mathrm{O}$ & $"$ & & & 82923 & 22627 & 22627 & 12319 & 4240 & 10307 & 9043 & 19351 & 56155 & 60296 & 60296 & 106068 & 105104 \\
\hline $\mathrm{CO}_{2}$ & " & & & 2525794 & 689197 & 689197 & 375241 & 113944 & 313956 & 275455 & 589411 & 589411 & 1836596 & 1836596 & 1849477 & 1835319 \\
\hline $\mathrm{SO}_{2}$ & " & & & 712 & 194 & 194 & 106 & 32 & 89 & 78 & 166 & 166 & 518 & 518 & 518 & 514 \\
\hline & $"$ & & & & & & & & & & & 15669 & & & & \\
\hline Carbon & $"$ & & & & & & & & & & & 230299 & & & & \\
\hline $\begin{array}{l}\text { Sulfur } \\
\text { CaO }\end{array}$ & $"$ & & & & & & & & & & & 9839 & & & & \\
\hline MgO & " & & & & & & & & & & & & & & & \\
\hline $\mathrm{CaSO}_{3}$ & $"$ & & & & & & & & & & & & & & & \\
\hline $\mathrm{CaSO}_{4}$ & " & & & & & & & & & & & & & & & \\
\hline $\mathrm{MgSO}_{3}$ & " & & & & & & & & & & & & & & & \\
\hline $\mathrm{MgSO}_{4}$ & " & & & & & & & & & & & & & & & \\
\hline $\mathrm{CaCO}_{3}$ & $"$ & & & & & & & & & & & & & & & \\
\hline & & & & & & & & & & & & 41177 & & & & \\
\hline \multirow{3}{*}{\begin{tabular}{|l} 
Total Gas \\
Total Solids \\
Total Flow
\end{tabular}} & $(\mathrm{hm} / \mathrm{hr})$ & & & Recirc Fluegas & PA Fan Inlet & PA Fan Outlet & PA to Air Htr & AH leakage gas & Temp. Fluegas & Hot Pri Air & Mixed Pri Air & Coal-Pri Air Mix & Sec Air to FD & Sec Air to SCAH & Sec Air to AH & $\begin{array}{r}\text { Sec Air to Furn } \\
2884741\end{array}$ \\
\hline & (டолиा & & & & & & & & & & & & & & & \\
\hline & " & & & 2860272 & 780464 & 780464 & 424933 & 138000 & 355532 & 311933 & 667464 & 1031862 & 2079808 & 2079808 & 2909741 & 2884741 \\
\hline \multirow{4}{*}{ 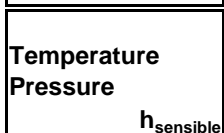 } & & & & 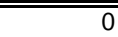 & $\overline{0}$ & 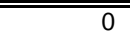 & $\overline{0}$ & $\overline{0}$ & $\overline{0}$ & $\overline{0}$ & $\overline{0}$ & $\overline{0}$ & $\overline{0}$ & $\overline{0}$ & $\overline{0}$ & $\begin{array}{ll} & 0\end{array}$ \\
\hline & (Deg F) & & & 102 & 102 & 111 & 111 & 111 & 111 & 574 & 339 & 0 & 102 & 106 & 130 & 599 \\
\hline & (Psia) & & & 14.7 & 14.7 & 15.6 & 15.6 & 15.6 & 15.6 & 15.6 & 15.6 & 15.0 & 14.7 & 15.1 & 15.1 & 14.9 \\
\hline & Btu/lbm & & & 4.576 & 4.576 & 6.654 & 6.654 & 6.697 & 6.654 & 117.975 & 58.679 & 0.000 & 4.576 & 5.561 & 11.021 & 125.000 \\
\hline Chemicall & $\left(10^{6} \mathrm{Btu} / \mathrm{hr}\right)$ & & & 0.000 & 0.000 & 0.000 & 0.000 & 0.000 & 0.000 & 0.000 & 0.000 & 4115.144 & 0.000 & 0.000 & 0.000 & 0.000 \\
\hline Sensible & $\left(10^{6} \mathrm{Btu} / \mathrm{hr}\right)$ & & & 13.088 & 3.571 & 5.193 & 2.828 & 0.924 & 2.366 & 36.800 & 39.166 & 0.000 & 9.517 & 11.566 & 32.067 & 360.592 \\
\hline Latent & $\left(10^{6} \mathrm{Btu} / \mathrm{hr}\right)$ & & & 87.069 & 23.758 & 23.758 & 12.935 & 4.452 & 10.823 & 9.496 & 20.318 & 0.000 & 63.311 & 63.311 & 111.371 & 110.359 \\
\hline Total Energy $^{(1)}$ & $\left(10^{6} \mathrm{Btu} / \mathrm{hr}\right)$ & & & 100.158 & 27.329 & 28.951 & 15.763 & 5.376 & 13.189 & 46.296 & 59.484 & 4174.629 & 72.828 & 74.877 & 143.438 & 470.952 \\
\hline
\end{tabular}




\begin{tabular}{|c|c|c|c|c|c|c|c|c|c|c|c|c|c|c|c|c|}
\hline Constituent & (Units) & A1 & A2 & A3 & NG & A4 & A5 & A6 & A7 & S1 & S2 & S3 & 01 & $\mathrm{O2}$ & Dew Pt. & 03 \\
\hline $\mathrm{O}_{2}$ & (Lbm/hr) & 824538 & 824538 & 824538 & & 61840 & "61840 & "61840 & "61840 & 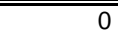 & 0 & 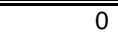 & 743966 & 743966 & 743966 & 743966 \\
\hline $\mathrm{N}_{2}$ & $"$ & 2731528 & 2731528 & 2731528 & & 2704213 & 2704213 & 2704213 & 2704213 & 0 & 0 & 0 & 27315 & 27315 & 27315 & 27315 \\
\hline $\mathrm{H}_{2} \mathrm{O}$ & $"$ & 46108 & 46108 & 46108 & & 46108 & 238791 & 238791 & 238791 & 1212226 & 1212226 & 192683 & 1222771 & 1222771 & 1222771 & 1149559 \\
\hline $\mathrm{CO}_{2}$ & $"$ & 0 & 0 & 0 & & & & & & & & & 12881 & 12881 & 12881 & 12881 \\
\hline $\mathrm{SO}_{2}$ & " & 0 & 0 & 0 & & & & & & & & & & & & \\
\hline $\mathrm{H}_{2}$ & " & 0 & 0 & 0 & 1180 & & & & & & & & & & & \\
\hline Carbon & " & 0 & 0 & 0 & 3515 & & & & & & & & & & & \\
\hline Sulfur & $"$ & 0 & 0 & 0 & & & & & & & & & & & & \\
\hline $\mathrm{CaO}$ & $"$ & 0 & 0 & 0 & & & & & & & & & & & & \\
\hline MgO & " & 0 & 0 & 0 & & & & & & & & & & & & \\
\hline $\mathrm{CaSO}_{3}$ & " & 0 & 0 & 0 & & & & & & & & & & & & \\
\hline $\mathrm{CaSO}_{4}$ & $"$ & 0 & 0 & 0 & & & & & & & & & & & & \\
\hline $\mathrm{MgSO}_{3}$ & $"$ & 0 & 0 & 0 & & & & & & & & & & & & \\
\hline $\mathrm{MgSO}_{4}$ & " & 0 & 0 & 0 & & & & & & & & & & & & \\
\hline $\mathrm{CaCO}_{3}$ & $"$ & 0 & 0 & 0 & & & & & & & & & & & & \\
\hline Ash / Inerts & $"$ & 0 & 0 & 0 & & & & & & & & & & & & \\
\hline \multirow{3}{*}{\begin{tabular}{|l} 
Total Gas \\
Total Solids \\
Total Flow \\
\end{tabular}} & & Air Supply & Blower air & CAR Air & Natural Gas & CAR Waste & CAR Waste to $H R$ & AR Waste to HR:A & $R$ Waste to Stac & Sweep Steam & Hot Sweep Steam & Purge Steam & 2 Stream from CA & $\mathrm{O} 2$ Stream to $\mathrm{HR}$ & & 22 stream to Conc \\
\hline & $\begin{array}{c}(\mathrm{Lbm} / \mathrm{hr}) \\
"\end{array}$ & 3602174 & 3602174 & 3602174 & 4695 & 2812161 & 3004845 & 3004845 & 3004845 & 1212226 & 1212226 & 192683 & 2006933 & 2006933 & 2006933 & 1933721 \\
\hline & $"$ & 3602174 & 3602174 & 3602174 & 4695 & 2812161 & 3004845 & 3004845 & 3004845 & 1212226 & 1212226 & 192683 & 2006933 & 2006933 & 2006933 & 1933721 \\
\hline \multirow{3}{*}{$\begin{array}{l}\text { Temperature } \\
\text { Pressure }\end{array}$} & & 0 & $\overline{0}$ & 0 & 0 & $\overline{0}$ & 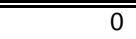 & 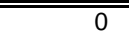 & 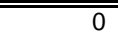 & 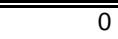 & 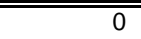 & 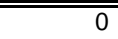 & 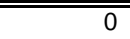 & 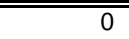 & 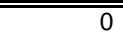 & 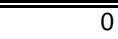 \\
\hline & (Deg F) & 80 & 185 & 478 & 80 & 572 & 536 & 210 & 120 & 250 & 547 & 250 & 572 & 352 & 180 & 178 \\
\hline & (Psia) & 14.7 & 24.4 & 24.1 & 0.0 & 15.1 & 15.1 & 14.9 & 14.7 & 16.6 & 16.4 & 16.6 & 10.2 & 10.1 & 10.1 & 10.0 \\
\hline $\mathbf{h}_{\text {sensible }}$ & Btu/lbm & 0.000 & 25.534 & 97.865 & $\begin{array}{r}0.000 \\
23896\end{array}$ & 123.790 & 120.751 & 34.040 & 10.483 & 76.388 & 214.095 & 76.388 & 181.900 & 98.722 & 35.684 & 34.890 \\
\hline Chemical & $\left(10^{6} \mathrm{Btu} / \mathrm{hr}\right)$ & 0.000 & 0.000 & 0.000 & 112.193 & 0.000 & 0.000 & 0.000 & 0.000 & 0.000 & 0.000 & 0.000 & 0.000 & 0.000 & 0.000 & 0.000 \\
\hline Sensible & $\left(10^{6} \mathrm{Btu} / \mathrm{hr}\right)$ & 0.000 & 91.978 & 352.528 & 0.000 & 348.118 & 362.837 & 102.286 & 31.501 & 92.599 & 259.532 & 14.719 & 365.062 & 198.129 & 71.616 & 67.468 \\
\hline Latent & $\left(10^{6} \mathrm{Btu} / \mathrm{hr}\right)$ & 48.413 & 48.413 & 48.413 & 0.000 & 48.413 & 250.731 & 250.731 & 250.731 & 1272.837 & 1272.837 & 202.317 & 1283.910 & 1283.910 & 1283.910 & 1207.037 \\
\hline Total Energy $^{(1)}$ & $\left(10^{6} \mathrm{Btu} / \mathrm{hr}\right)$ & 48.413 & 140.391 & 400.942 & 112.193 & 396.531 & 613.567 & 353.017 & 282.232 & 1365.436 & 1532.369 & 217.036 & 1648.971 & 1482.039 & 1355.526 & 1274.505 \\
\hline
\end{tabular}




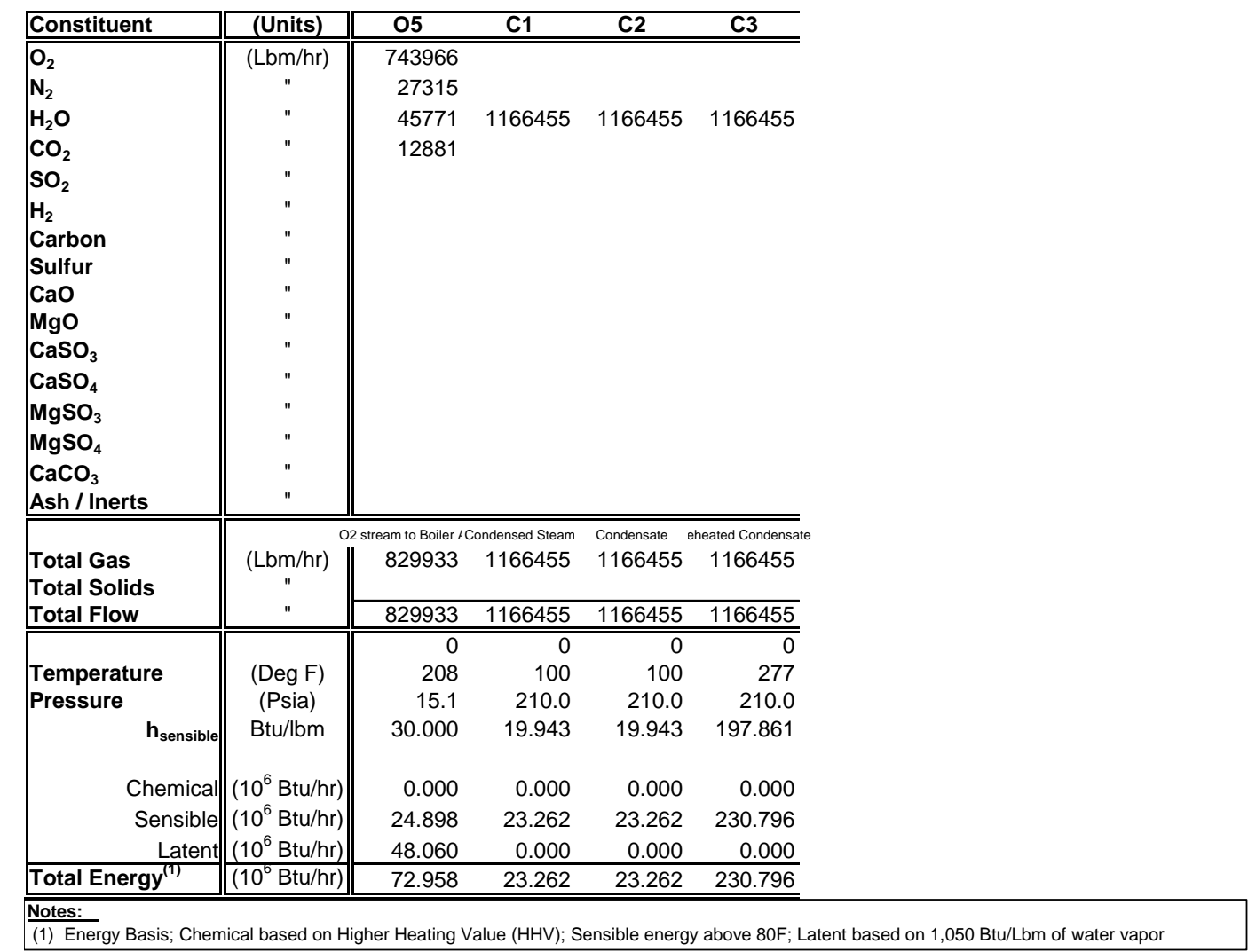


Table 4-17: Boiler Island Material and Energy Balance - Case 4b

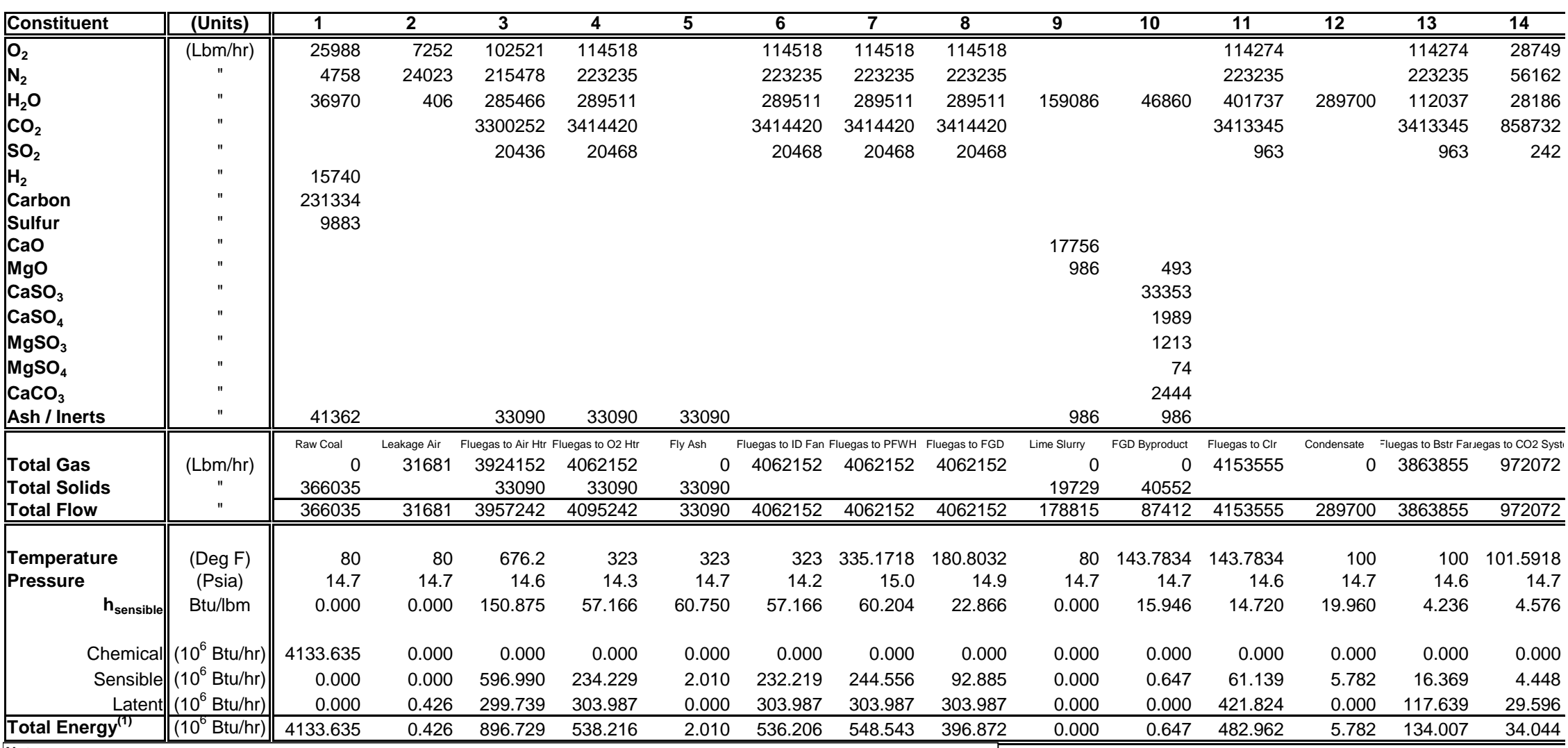

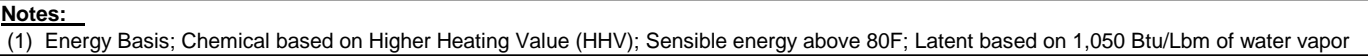




\begin{tabular}{|c|c|c|c|c|c|c|c|c|c|c|c|c|c|c|c|}
\hline Constituent & (Units) & 15 & 16 & 17 & 18 & 19 & 20 & 21 & 22 & 23 & 24 & 25 & 26 & 27 & 28 \\
\hline$\overline{\mathrm{O}_{2}}$ & $\overline{(\mathrm{Lbm} / \mathrm{hr})}$ & & & 85525 & 23171 & 23171 & 12609 & 11997 & 10562 & 9267 & 19829 & 445818 & 62354 & 62354 & 809265 \\
\hline $\mathrm{N}_{2}$ & " & & & 167074 & 45265 & 45265 & 24631 & 7758 & 20633 & 18103 & 38736 & 43495 & 121809 & 121809 & 149189 \\
\hline $\mathrm{H}_{2} \mathrm{O}$ & " & & & 83851 & 22717 & 22717 & 12362 & 4046 & 10355 & 9085 & 19441 & 56410 & 61133 & 61133 & 88763 \\
\hline $\mathrm{CO}_{2}$ & " & & & 2554613 & 692115 & 692115 & 376624 & 114168 & 315491 & 276799 & 592290 & 592290 & 1862498 & 1862498 & 1874593 \\
\hline $\mathrm{SO}_{2}$ & " & & & 721 & 195 & 195 & 106 & 32 & 89 & 78 & 167 & 167 & 526 & 526 & 526 \\
\hline $\mathrm{H}_{2}$ & " & & & & & & & & & & & 15740 & & & \\
\hline Carbon & " & & & & & & & & & & & 231334 & & & \\
\hline Sulfur & $"$ & & & & & & & & & & & 9883 & & & \\
\hline $\mathrm{CaO}$ & $"$ & & & & & & & & & & & & & & \\
\hline MgO & " & & & & & & & & & & & & & & \\
\hline $\mathrm{CaSO}_{3}$ & " & & & & & & & & & & & & & & \\
\hline $\mathrm{CaSO}_{4}$ & " & & & & & & & & & & & & & & \\
\hline $\mathrm{MgSO}_{3}$ & $"$ & & & & & & & & & & & & & & \\
\hline $\mathrm{MgSO}_{4}$ & " & & & & & & & & & & & & & & \\
\hline $\begin{array}{l}\mathrm{CaCO}_{3} \\
\text { Ash / Inerts }\end{array}$ & $"$ & & & & & & & & & & & 41362 & & & \\
\hline \multirow{3}{*}{\begin{tabular}{|l} 
Total Gas \\
Total Solids \\
Total Flow \\
\end{tabular}} & \multirow{3}{*}{$\begin{array}{c}\text { (Lbm/hr) } \\
" \\
" \\
\end{array}$} & 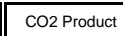 & Vent to Stack & Recirc Fluegas & PA Fan Inlet & PA Fan Outtet & PA to Air Htr & AH leakage gas & Temp. Fluegas & Hot Pri Air & Mixed Pri Air & Coal-Pri Air Mix & Sec Air to FD & Sec Air to SCAH & Sec Air to AH \\
\hline & & |By Linde & By Linde & 2891783 & 783463 & 783463 & 426332 & 138000 & 357131 & 313332 & 670463 & $\begin{array}{l}670463 \\
366035\end{array}$ & 2108320 & 2108320 & 2922335 \\
\hline & & & & 2891783 & 783463 & 783463 & 426332 & 138000 & 357131 & 313332 & 670463 & 1036499 & 2108320 & 2108320 & 2922335 \\
\hline Temperature & $(\operatorname{Deg} F)$ & & & 101.5918 & 101.5918 & 111.3008 & 111.3008 & 111.3008 & 111.3008 & 574 & 338.9 & 0 & 101.5918 & 106.2015 & 104.3889 \\
\hline Pressure & (Psia) & & & 14.7 & 14.7 & 15.6 & 15.6 & 15.6 & 15.6 & 15.6 & 15.6 & 15.0 & 14.7 & 15.1 & 15.1 \\
\hline $\mathbf{h}_{\text {sensible }}$ & Btu/lbm & & & 4.576 & 4.576 & 6.654 & 6.654 & 6.686 & 6.654 & 117.976 & 58.679 & 0.000 & 4.576 & 5.561 & 5.284 \\
\hline Chemical & $\left(10^{6} \mathrm{Btu} / \mathrm{hr}\right)$ & & & 0.000 & 0.000 & 0.000 & 0.000 & 0.000 & 0.000 & 0.000 & 0.000 & 4133.635 & 0.000 & 0.000 & 0.000 \\
\hline Sensible & $\left(10^{6} \mathrm{Btu} / \mathrm{hr}\right)$ & & & 13.232 & 3.585 & 5.213 & 2.837 & 0.923 & 2.376 & 36.966 & 39.342 & 0.000 & 9.647 & 11.724 & 15.441 \\
\hline Latent & $\left(10^{6} \mathrm{Btu} / \mathrm{hr}\right)$ & & & 88.043 & 23.853 & 23.853 & 12.980 & 4.248 & 10.873 & 9.540 & 20.413 & 0.000 & 64.190 & 64.190 & 93.201 \\
\hline Total Energy $^{(1)}$ & $\left(10^{6} \mathrm{Btu} / \mathrm{hr}\right)$ & & & 101.275 & 27.438 & 29.066 & 15.817 & 5.171 & 13.250 & 46.505 & 59.755 & 4193.390 & 73.837 & 75.914 & 108.642 \\
\hline
\end{tabular}

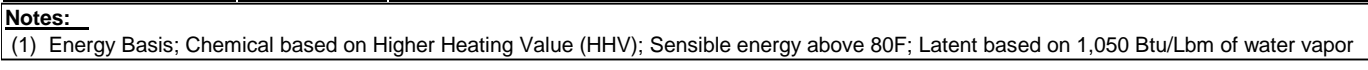




\begin{tabular}{|c|c|c|c|c|c|c|c|c|c|c|c|c|c|c|c|}
\hline Constituent & (Units) & 29 & 30 & A1 & A2 & A3 & NG & A4 & A5 & A6 & A7 & S1 & S2 & S3 & 01 \\
\hline$\overline{\overline{\mathrm{O}_{2}}}$ & 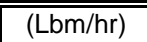 & 800611 & & 826486 & 826486 & 826486 & & $\bar{~} 61986$ & "61986 & "61986 & "61986 & & & & $\overline{7446911}$ \\
\hline $\mathrm{N}_{2}$ & $"$ & 147959 & & 2737985 & 2737985 & 2737985 & & 2710605 & 2710605 & 2710605 & 2710605 & & & & 27380 \\
\hline $\mathrm{H}_{2} \mathrm{O}$ & $"$ & 87994 & & 46217 & 46217 & 46217 & & 46217 & 239356 & 239356 & 239356 & 1215091 & 1215091 & 193139 & 1224993 \\
\hline $\mathrm{CO}_{2}$ & $"$ & 1860250 & & & & & & & & & & & & & 12095 \\
\hline $\mathrm{SO}_{2}$ & $"$ & 522 & & & & & & & & & & & & & \\
\hline $\mathrm{H}_{2}$ & $"$ & & & & & & 1108 & & & & & & & & \\
\hline Carbon & $"$ & & & & & & 3301 & & & & & & & & \\
\hline Sulfur & $"$ & & & & & & & & & & & & & & \\
\hline $\mathrm{CaO}$ & $"$ & & & & & & & & & & & & & & \\
\hline MgO & $"$ & & & & & & & & & & & & & & \\
\hline $\mathrm{CaSO}_{3}$ & " & & & & & & & & & & & & & & \\
\hline $\mathrm{CaSO}_{4}$ & " & & & & & & & & & & & & & & \\
\hline $\mathrm{MgSO}_{3}$ & $"$ & & & & & & & & & & & & & & \\
\hline $\mathrm{MgSO}_{4}$ & $"$ & & & & & & & & & & & & & & \\
\hline $\begin{array}{l}\mathrm{CaCO}_{3} \\
\text { Ash / Inerts }\end{array}$ & " & & 8272 & & & & & & & & & & & & \\
\hline \multirow{3}{*}{$\begin{array}{l}\text { Total Gas } \\
\text { Total Solids } \\
\text { Total Flow } \\
\end{array}$} & \multirow{3}{*}{$\begin{array}{c}\text { (Lbm/hr) } \\
" \\
" \\
\end{array}$} & Sec Air to Furn & Bottom Ash & Air Supply & Blower air & CAR Air & $\begin{array}{l}\text { Natural Gas } \\
\end{array}$ & CAR Waste & $\begin{array}{l}\text { CAR Waste to HR } \\
\end{array}$ & CAR Waste to HR: & R Waste to Stac & Sweep Steam & Hot Sweep Steam & Purge Steam & $\overline{12 \text { Stream from } C A}$ \\
\hline & & 2897335 & $\begin{array}{r}0 \\
8272\end{array}$ & 3610688 & 3610688 & 3610688 & 4409 & 2818808 & 3011947 & 3011947 & 3011947 & 1215091 & 1215091 & 193139 & 2011380 \\
\hline & & 2897335 & 8272 & 3610688 & 3610688 & 3610688 & 4409 & 2818808 & 3011947 & 3011947 & 3011947 & 1215091 & 1215091 & 193139 & 2011380 \\
\hline \multirow{3}{*}{$\begin{array}{l}\text { Temperature } \\
\text { Pressure } \\
\qquad \mathbf{h}_{\text {sensible }}\end{array}$} & (Deg F) & 577.5987 & 2000 & 80 & 184.7614 & 484.9657 & 80 & 572 & 544.1584 & 209.7614 & 120 & 321.9341 & 547 & 321.9341 & 572 \\
\hline & (Psia) & 14.9 & 14.7 & 14.7 & 24.4 & 24.1 & 0.0 & 15.1 & 15.1 & 14.9 & 14.7 & 26.6 & 26.2 & 26.6 & 16.4 \\
\hline & $\mathrm{Btu} / \mathrm{lbm}$ & 118.755 & 480.000 & 0.000 & 25.534 & 99.609 & $\begin{array}{r}0.000 \\
23896\end{array}$ & 123.790 & 122.841 & 34.040 & 10.483 & 108.976 & 214.095 & 108.976 & 181.872 \\
\hline Chemical & $\left(10^{6} \mathrm{Btu} / \mathrm{hr}\right)$ & 0.000 & 0.000 & 0.000 & 0.000 & 0.000 & 105.351 & 0.000 & 0.000 & 0.000 & 0.000 & 0.000 & 0.000 & 0.000 & 0.000 \\
\hline Sensible & $\left(10^{6} \mathrm{Btu} / \mathrm{hr}\right)$ & 344.074 & 3.971 & 0.000 & 92.195 & 359.657 & 0.000 & 348.941 & 369.989 & 102.528 & 31.575 & 132.416 & 260.145 & 21.047 & 365.814 \\
\hline Latent & $\left(10^{6} \mathrm{Btu} / \mathrm{hr}\right)$ & 92.393 & 0.000 & 48.528 & 48.528 & 48.528 & 0.000 & 48.528 & 251.323 & 251.323 & 251.323 & 1275.846 & 1275.846 & 202.796 & 1286.243 \\
\hline Total Energy $^{(1)}$ & $\left(10^{\circ} \mathrm{Btu} / \mathrm{hr}\right)$ & 436.467 & 3.971 & 48.528 & 140.723 & 408.185 & 105.351 & 397.469 & 621.313 & 353.851 & 282.899 & 1408.261 & 1535.991 & 223.843 & 1652.058 \\
\hline
\end{tabular}

Notes:

(1) Energy Basis; Chemical based on Higher Heating Value (HHV); Sensible energy above 80F; Latent based on 1,050 Btu/Lbm of water vapor 


\begin{tabular}{|c|c|c|c|c|c|c|c|c|c|}
\hline Constituent & (Units) & 02 & $\begin{array}{l}\text { Dew Pt. } \\
\end{array}$ & 03 & 04 & 05 & C1 & $\mathrm{C2}$ & $\mathrm{C} 3$ \\
\hline $\mathrm{O}_{2}$ & (Lbm/hr) & 746911 & 746911 & 746911 & 746911 & 746911 & & & \\
\hline $\mathrm{N}_{2}$ & " & 27380 & 27380 & 27380 & 27380 & 27380 & & & \\
\hline $\mathrm{H}_{2} \mathrm{O}$ & " & 1224993 & 1224993 & 1127666 & 27629 & 27629 & 1187462 & 1187462 & 1187462 \\
\hline $\mathrm{CO}_{2}$ & " & 12095 & 12095 & 12095 & 12095 & 12095 & & & \\
\hline
\end{tabular}

Carbon

Sulfur

CaO

MgO

$\mathrm{CaSO}_{3}$

$\mathrm{CaSO}_{4}$

$\mathrm{MgSO}_{3}$

$\mathrm{MgSO}_{4}$

$\mathrm{CaCO}_{3}$

Ash / Inerts

\begin{tabular}{|c|c|c|c|c|c|c|c|c|c|}
\hline \multirow{3}{*}{$\begin{array}{l}\text { Total Gas } \\
\text { Total Solids } \\
\text { Total Flow } \\
\end{array}$} & \multirow{3}{*}{$\begin{array}{c}(\mathrm{Lbm} / \mathrm{hr}) \\
" \\
" \\
\end{array}$} & O2 Stream to HR & & \multicolumn{4}{|c|}{ 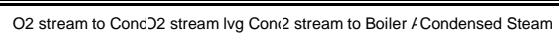 } & \multicolumn{2}{|c|}{$\begin{array}{ll}\text { Condensate eheated Condensa } \\
\end{array}$} \\
\hline & & 2011380 & 2011380 & 1914053 & 814016 & 814016 & 1187462 & 1187462 & 1187462 \\
\hline & & 2011380 & 2011380 & 1914053 & 814016 & 814016 & 1187462 & 1187462 & 1187462 \\
\hline Temperature & (Deg F) & 404.5532 & 201.5296 & 199.8386 & 100 & 100 & 100 & 100 & 316.1541 \\
\hline Pressure & (Psia) & 16.2 & 16.2 & 16.0 & 15.1 & 15.1 & 210.0 & 210.0 & 210.0 \\
\hline $\mathbf{h}_{\text {sensible }}$ & $\mathrm{Btu} / \mathrm{lbm}$ & 118.369 & 43.629 & 42.484 & 4.566 & 4.566 & 19.943 & 19.943 & 238.023 \\
\hline Chemical & $\left(10^{6} \mathrm{Btu} / \mathrm{hr}\right)$ & 0.000 & 0.000 & 0.000 & 0.000 & 0.000 & 0.000 & 0.000 & 0.000 \\
\hline Sensible & $\left(10^{6} \mathrm{Btu} / \mathrm{hr}\right)$ & 238.085 & 87.755 & 81.316 & 3.717 & 3.717 & 23.681 & 23.681 & 282.643 \\
\hline Latent & (10 $\mathrm{Btu} / \mathrm{hr})$ & 1286.243 & 1286.243 & 1184.050 & 29.011 & 29.011 & 0.000 & 0.000 & 0.000 \\
\hline otal Energy ${ }^{(1)}$ & $\left(10^{6} \mathrm{Btu} / \mathrm{hr}\right)$ & 1524.328 & 1373.998 & 1265.366 & 32.728 & 32.728 & 23.681 & 23.681 & 282.643 \\
\hline
\end{tabular}

Notes:

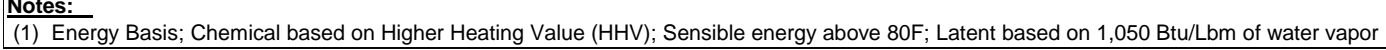




\subsubsection{Boiler Analysis Results - Cases 4a and 4b}

The main steam flow for Cases 4a and 4b and all other cases in this study is $395 \mathrm{~kg} / \mathrm{s}(3,131,619$ $\mathrm{lbm} / \mathrm{hr}$ ). The cold reheat flow leaving the high-pressure turbine for Cases $4 \mathrm{a}$ and $4 \mathrm{~b}$ and all other cases in this study is $348 \mathrm{~kg} / \mathrm{s}(2,767,780 \mathrm{lbm} / \mathrm{hr})$. The hot reheat flow (including de-superheating spray) returning to the intermediate pressure turbine is $354 \mathrm{~kg} / \mathrm{s}(2,822,053 \mathrm{lbm} / \mathrm{hr})$ for Cases $4 \mathrm{a}$ and 4b. The overall steam conditions produced by the existing Conesville \#5 steam generator unit are shown in Table 4-12 for Cases 4a and 4b below.

Table 4-18: Boiler Steam/Water Conditions - Cases 4a and 4b

\begin{tabular}{|c|rrrrr|}
\hline & SHO & FWI & ECO & RHO & RHI \\
\hline Flow (Ibm/hr) & 3131619 & 3131619 & 3121036 & 2822053 & 2822053 \\
Pressure (psia) & 2535 & 3165 & 3070 & 590.8 & 656.5 \\
Temperature (F) & 1000 & 493 & 612 & 1000 & 624 \\
Enthalpy (Btu/lbm) & 1456.3 & 479.2 & 625.7 & 1517.6 & 1301.1 \\
\hline
\end{tabular}

Notes:

SHO = Superheater Outlet; FWI = Feedwater Inlet; ECO = Economizer Outlet; RHO = Reheater Outlet; RHI = Reheater Inlet

To produce these conditions for Cases $4 \mathrm{a}$ and $4 \mathrm{~b}$, the superheat circuit requires about 1.5 percent spray and the reheat circuit requires about 1.9 percent spray to maintain required steam outlet temperatures. The burner tilts are -10 degrees (the minimum value the customer uses). The boiler was fired with about 4.0 percent excess oxygen and the resulting boiler efficiency calculated for this case was 88.73 percent with an air heater exit gas temperature of $162{ }^{\circ} \mathrm{C}\left(323^{\circ} \mathrm{F}\right)$. The boiler efficiency including the heat recovered from Stream 7 using the PFWH is calculated to be 92.39 percent.

\subsubsection{Steam Cycle Performance - Cases 4a and 4b}

The final steam cycle for Case 4a is shown schematically in Figure 4-22. Figure 4-23 shows the associated T-S and Mollier diagrams, which illustrates the process on temperature - entropy and enthalpy - entropy coordinates respectively. The high-pressure turbine expands about $391 \mathrm{~kg} / \mathrm{s}$ $\left(3.1 \times 10^{6} \mathrm{lbm} / \mathrm{hr}\right)$ of steam at 175 bara $(2,535 \mathrm{psia})$ and $538^{\circ} \mathrm{C}\left(1,000^{\circ} \mathrm{F}\right)$. Reheat steam is returned to the intermediate pressure turbine at 41 bara (591 psia) and $538{ }^{\circ} \mathrm{C}(1,000 \mathrm{~F})$. Lowlevel heat rejected from the flue gas, GPU, and CAR system is recovered in the condensate stream as indicated. The condenser pressure used for the Case 2 and all other cases in this study was 6.35 $\mathrm{cm}$. Hga (2.5 in Hga). The steam turbine performance analysis results show the generators produce an output of 407,184 $\mathrm{kWe}$. The steam turbine heat rate is calculated to be about $10,088 \mathrm{~kJ} / \mathrm{kWh}(9,561 \mathrm{Btu} / \mathrm{kWh})$. 


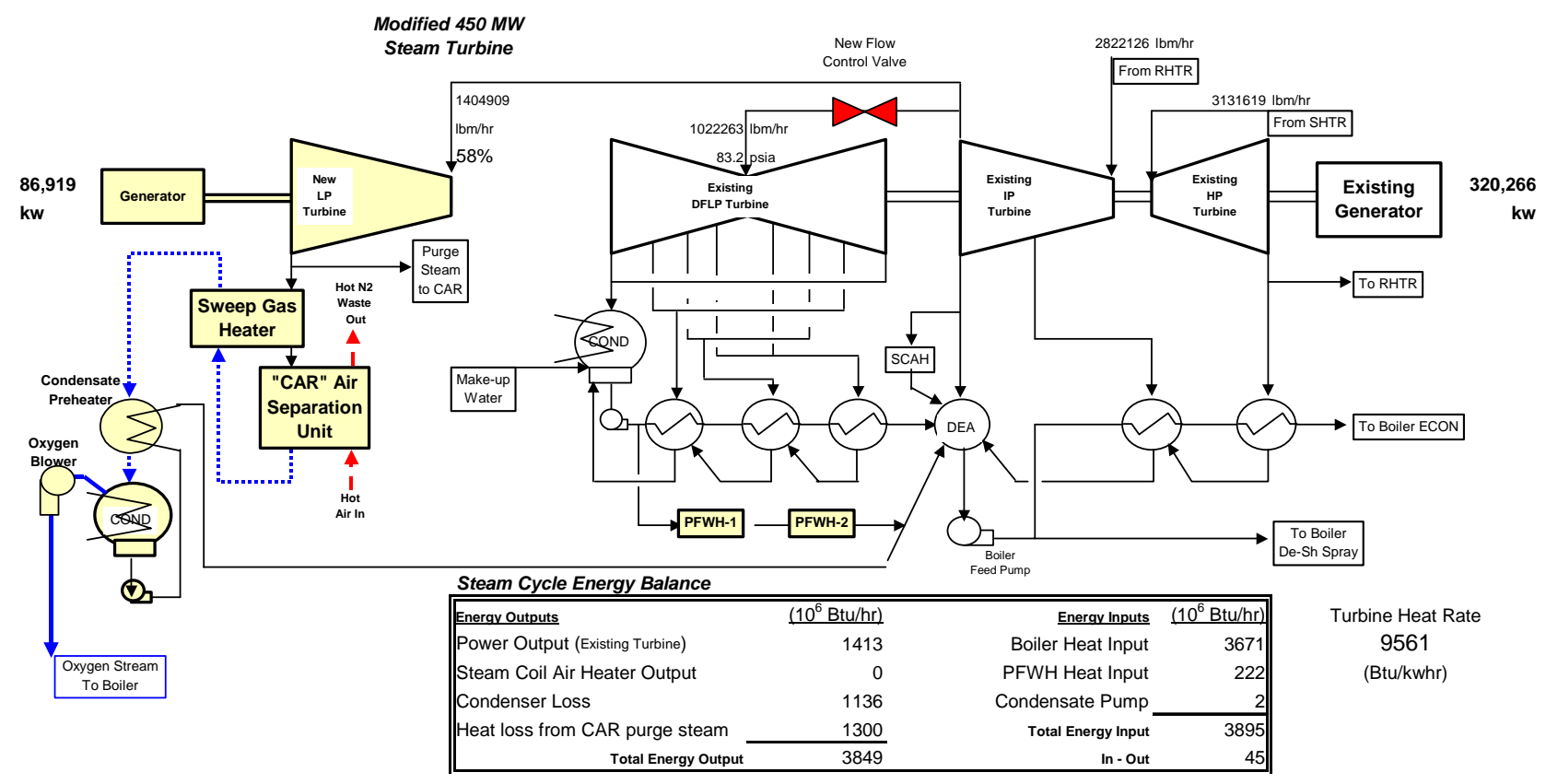

Figure 4-22: Steam Cycle Schematic and Performance - Case 4a
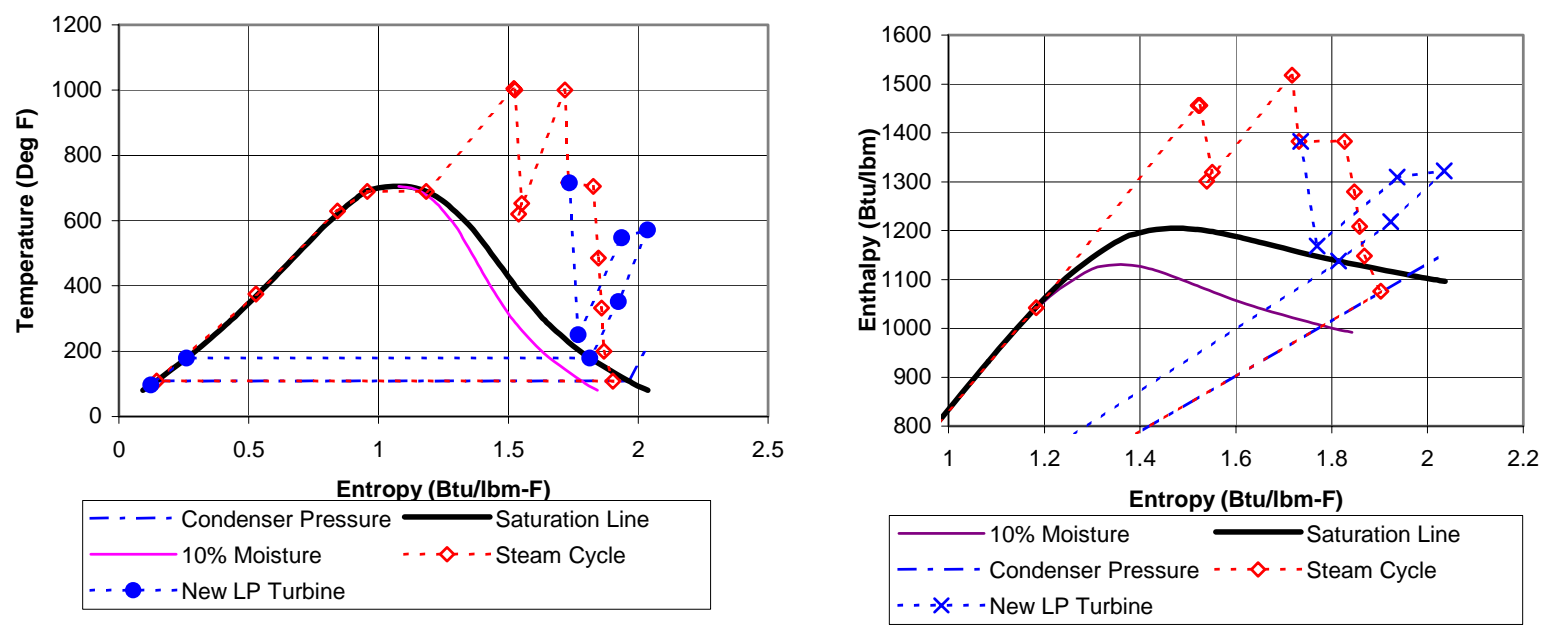

Figure 4-23: Steam Cycle T-S and Mollier Diagrams - Case 4a

The final steam cycle for Case $4 \mathrm{~b}$ is shown schematically in Figure 4-24. Figure 4-25 shows the associated T-S and Mollier diagrams, which illustrates the process on temperature - entropy and enthalpy - entropy coordinates respectively. The high-pressure turbine expands about $391 \mathrm{~kg} / \mathrm{s}$ $\left(3.1 \times 10^{6} \mathrm{lbm} / \mathrm{hr}\right)$ of steam at 175 bara $(2,535 \mathrm{psia})$ and $538^{\circ} \mathrm{C}\left(1,000^{\circ} \mathrm{F}\right)$. Reheat steam is returned to the intermediate pressure turbine at 41 bara (591 psia) and $538{ }^{\circ} \mathrm{C}(1,000 \mathrm{~F})$. Lowlevel heat rejected from the flue gas, GPU, and CAR system is recovered in the condensate stream 
as indicated. The condenser pressure used for the Case $4 \mathrm{~b}$ and all other cases in this study was $6.35 \mathrm{~cm}$. Hga (2.5 in Hga). The steam turbine performance analysis results show the generator produces an output of $398,117 \mathrm{kWe}$. The steam turbine heat rate is calculated to be about 10,319 $\mathrm{kJ} / \mathrm{kWh}(9,780 \mathrm{Btu} / \mathrm{kWh})$.

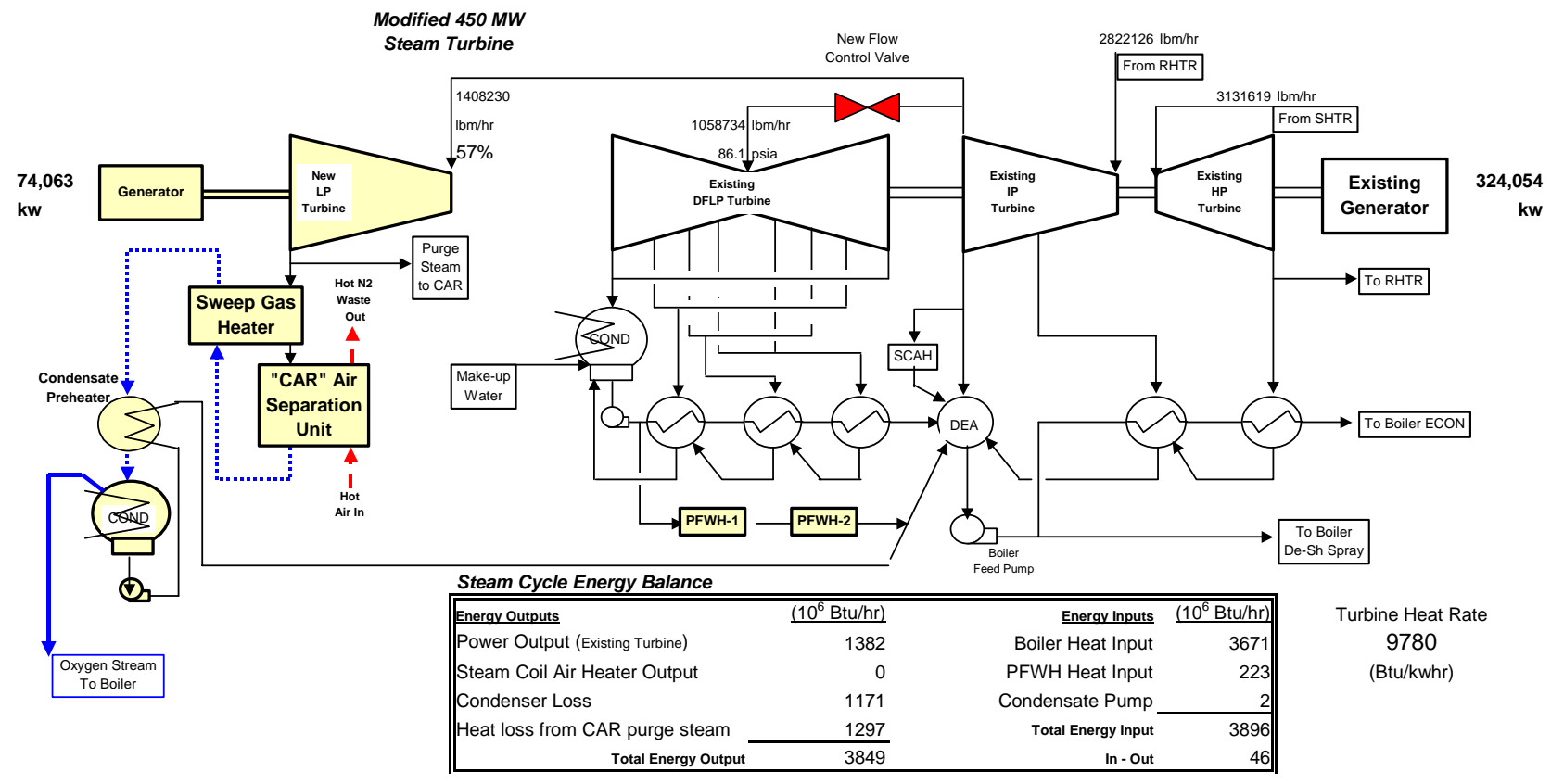

Figure 4-24: Steam Cycle Schematic and Performance - Case 4b (w/o $\mathrm{O}_{2}$ Blower)
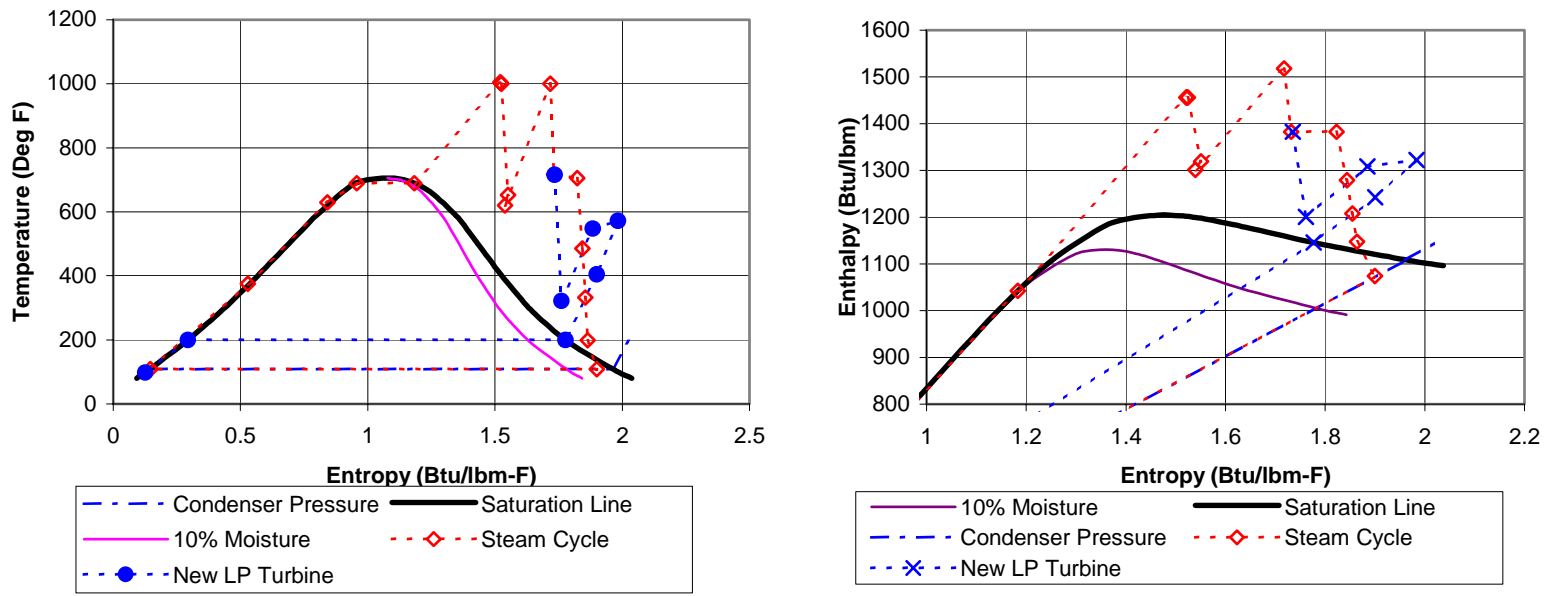

Figure 4-25: Steam Cycle T-S and Mollier Diagrams - Case 4b

\subsubsection{Flue Gas Desulfurization System Analysis - Cases 4a and 4b}

The issues regarding the performance of the FGD system and the ESP with the high $\mathrm{CO}_{2}$ content flue gas are discussed in some detail in Appendix I - Section 10.1.6 and are not repeated here. The basic conclusions reached were that, under these circumstances, the flue gas desulfurization 
systems $\mathrm{SO}_{2}$ capture efficiency would decrease by approximately $2 \%$. Additionally, for the high $\mathrm{CO}_{2}$ content flue gas associated with oxygen firing no ESP performance degradation is expected.

\subsubsection{Plant Performance Summary - Cases 4a and 4b}

Overall plant performance for these two cases is summarized in Table 4-19. Boiler efficiency is calculated to be 92.27 and 92.39 percent for cases $4 \mathrm{a}$ and $4 \mathrm{~b}$ respectively. The total fuel heat input is $4,238.7 \times 10^{6} \mathrm{Btu} / \mathrm{hr}$ for Case $4 \mathrm{a}$ and is $4,250.4 \times 10^{6} \mathrm{Btu} / \mathrm{hr}$ for Case $4 \mathrm{~b}$. The net plant heat rate (HHV basis) is calculated to be $14,587 \mathrm{Btu} / \mathrm{kWh}$ for Cases $4 \mathrm{a}$ and $14,794 \mathrm{Btu} / \mathrm{kWh}$ for Case $4 \mathrm{~b}$. Auxiliary power is $116,559 \mathrm{kWe}$ or about $29.0 \%$ of gross output for Cases $4 \mathrm{a}$ and $110,820 \mathrm{kWe}$ or about $28.0 \%$ of gross output for Case $4 \mathrm{~b}$. The net plant output is $290,585 \mathrm{kWe}$ for Case $4 \mathrm{a}$ and 287,297 kWe for Case 4b. Carbon dioxide emissions are 50,493 lbm/hr or about $0.174 \mathrm{lbm} / \mathrm{kWh}$ for Case 4a. Carbon dioxide emissions are 50,622 lbm/hr or about $0.176 \mathrm{lbm} / \mathrm{kWh}$ for Case 4b.

Table 4-19: Overall Plant Performance - Cases 4a and 4b

\begin{tabular}{|c|c|c|c|}
\hline & (units) & $\begin{array}{l}\text { Case 4a - } \\
\text { O2 Fired } \\
\text { CAR (steam } \\
\text { sweep) }\end{array}$ & $\begin{array}{c}\text { Case 4b - O2 } \\
\text { Fired CAR } \\
\text { (steam } \\
\text { sweep wlo } \\
\text { O2 Blower) }\end{array}$ \\
\hline \multicolumn{4}{|l|}{ Fuel Paramaters } \\
\hline$\overline{\text { Coal Heat Input (HHV) }}$ & $\left(10^{6} \mathrm{Btu} / \mathrm{hr}\right)$ & 4115.1 & 4133.6 \\
\hline Natural Gas Heat Input (HHV) & $\left(10^{6} \mathrm{Btu} / \mathrm{hr}\right)$ & 123.6 & 116.7 \\
\hline Total Fuel Heat Input (HHV) & $\left(10^{6} \mathrm{Btu} / \mathrm{hr}\right)$ & 4238.7 & 4250.4 \\
\hline \multicolumn{4}{|l|}{ Steam Cycle Paramaters } \\
\hline 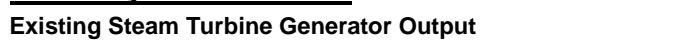 & $(\mathrm{kW})$ & 320,266 & 324,054 \\
\hline CAR Extraction Turbine Generator Output & $(\mathrm{kW})$ & 86919 & 74063 \\
\hline Total Turbine Generator Output & $(\mathrm{kW})$ & 407,184 & 398,117 \\
\hline Total Auxiliary Power & $(\mathrm{kW})$ & 116,599 & 110,820 \\
\hline Net Plant Output & $(\mathrm{kW})$ & 290,585 & 287,297 \\
\hline Normalized Net Plant Output (Relative to Base Case) & (fraction) & 0.67 & 0.66 \\
\hline \multicolumn{4}{|l|}{ Overall Plant Performance Paramaters } \\
\hline Net Plant Efficiency (HHV) & (fraction) & 0.2340 & 0.2307 \\
\hline Normalized Efficiency (HHV; Relative to Base Case) & (fraction) & 0.6683 & 0.6589 \\
\hline Net Plant Heat Rate (HHV) & (Btu/kwhr) & 14587 & 14794 \\
\hline Efficiency Loss Relative to Air Fired Base (HHV) & (\% points) & 11.61 & 11.94 \\
\hline \multicolumn{4}{|l|}{ 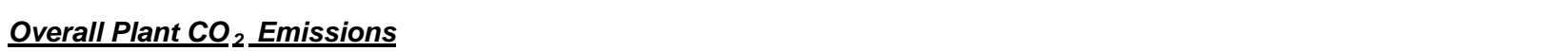 } \\
\hline Carbon Dioxide Produced & $(\mathrm{lbm} / \mathrm{hr})$ & 869,918 & 872,134 \\
\hline Carbon Dioxide Emissions & $(\mathrm{lbm} / \mathrm{hr})$ & 50,493 & 50,622 \\
\hline Specific Carbon Dioxide Emissions & $(\mathrm{lbm} / \mathrm{kwhr})$ & 0.174 & 0.176 \\
\hline Normalized Specific CO2 Emissions (Relative to Base Case) & (fraction) & 0.087 & 0.088 \\
\hline Avoided Carbon Dioxide Emissions (as compared to Base) & (lbm/kwhr) & 1.825 & 1.823 \\
\hline Specific Carbon Dioxide Emissions & (kg/kwhr) & 0.079 & 0.080 \\
\hline Avoided Carbon Dioxide Emissions (as compared to Base) & (kg/kwhr) & 0.829 & 0.828 \\
\hline
\end{tabular}




\section{PLANT MODIFICATIONS REQUIRED FOR OXYGEN FIRING AND $\mathrm{CO}_{2}$ CAPTURE}

This section describes plant modifications to the study unit, which are required to accommodate oxygen firing and $\mathrm{CO}_{2}$ capture in this unit. The modifications described in this section are those required for the new cases only (Cases 2, 3a, 3b, 3c, 4a, and 4b). Modifications for the original Case 1 (Bozzuto et al., 2001) are included in Appendix I, Section 10.1. The modifications to the existing plant equipment for these new cases are further classified as Major New Equipment, Boiler Island modifications, and Steam Cycle modifications.

\subsection{Major New Equipment Required}

Two major new systems are required for all these retrofit cases. The first system required is the new oxygen production equipment, which is used to supply oxygen to the boiler for coal combustion instead of air. The second system required is the gas processing unit, which is used to compress, dry, purify, and liquefy the $\mathrm{CO}_{2}$ product such that it complies with the $\mathrm{CO}_{2}$ product specification prior to sequestration.

\subsubsection{New Oxygen Production Equipment}

The addition of the oxygen production equipment represents one of the major modifications to the existing power plant. For Case 2, a cryogenic type air separation unit (ASU) was used (two identical parallel trains). For Cases 3a, 3b, 3c, 4a, and 4b, advanced Ceramic Autothermal Recovery (CAR) oxygen production systems were used.

\subsubsection{New Gas Processing Units}

The addition of the Gas Processing Unit (GPU) represents the second of the major modifications to the existing power plant. This equipment is required for all the study cases, which include $\mathrm{CO}_{2}$ capture (2, 3a, 3b, 3c, 4a, and 4b).

\subsection{Boiler Island Modifications}

This section describes boiler island modifications for the study unit, which are required to accommodate oxygen firing in this unit. The specific modifications to the boiler island shown in this section are further classified with respect to the individual case for which the described modification would apply since the required modifications differ somewhat from case to case.

\subsubsection{Boiler Modifications}

For this project the boiler scope is defined as everything on the gas side upstream of the FGD System. Therefore, it includes equipment such as the Conesville \#5 steam generator, pulverizers, fans, ductwork, electrostatic precipitator (ESP), air heater, coal and ash handling systems, etc. Purposely not included in the boiler scope definition is the FGD system. The FGD system modifications are identified separately in Section 5.2.2.

Listed below are the basic modifications required for the Conesville \#5 boiler unit to support firing with oxygen for the purpose of $\mathrm{CO}_{2}$ capture. Some of these items apply to one case or another as indicated. 


\subsubsection{Boiler Island Leakage Control:}

For all the oxygen-fired cases studied, the boiler island should be inspected for potential air leaks into the system and should be sealed to minimize any air infiltration. Special attention should be given to all penetrations including seal boxes for convective surfaces, sootblowers, wall blowers, expansion joints, ductwork, fuel piping, fans and windbox. Additionally, a new seal gas system utilizing a relatively small quantity of recirculated flue gas, as the seal gas will be provided.

\subsubsection{Ductwork:}

For Case 2 (cryogenic ASU), an oxygen supply duct from the new ASU to the existing boiler will provide oxygen to three locations: [1. to the outlet of the primary air (PA) fans, 2. to the outlet of the forced draft (FD) fans, 3. directly to the boiler windbox]. Oxygen injection grids and mixers are provided in the primary and secondary air ducts for this case to assure uniform mixing of the oxygen with the recirculated flue gas. Similarly, new ductwork and dampers are also required for the recirculated flue gas stream that feeds the existing FD and PA fans. Cases $4 \mathrm{a}$ and $4 \mathrm{~b}$ require these ductwork modifications also.

For the flue gas sweep CAR Cases (3a, 3b, and 3c), ductwork providing recirculated flue gas to the CAR system for use as sweep gas is provided. For all the CAR Cases (3a, 3b, and 3c) ductwork supplying the oxidant stream from the CAR system to both the primary and secondary circuit on the cold side of the existing air heater is provided.

For all oxygen-fired cases, new flue gas ductwork is required to install the Parallel Feedwater Heaters. The existing ductwork from each of the two Induced Draft fan outlets to each of the Scrubber inlets must be removed and replaced with new ductwork that accommodates the new Parallel Feedwater Heaters (PFWH's). For all oxygen-fired cases, ducts/pipes/dampers/valves are required for the new seal gas system.

\subsubsection{Fans:}

The existing PA, FD and ID fans have been checked and are adequate for all cases and therefore do not need replacement. Note that for the flue gas sweep cases (3a, 3b, and 3c) the FD fans are not used during oxygen firing. Although not included in the Alstom scope, a new booster fan is added after the direct contact gas cooler (DCGC) to accommodate the additional draft losses associated with the new PFWH and DCGC.

\subsubsection{Combustion System:}

For Case 2, modifications are made in the windbox area of the boiler such that a relatively small fraction of the total oxygen supplied can be injected directly into the furnace. Windbox modifications for the CAR cases are not required.

\subsubsection{New Boiler Equipment:}

For all oxygen-fired cases, two new Parallel Feedwater Heaters (PFWH's) are provided at the exit of the two existing ID Fans to improve boiler efficiency and steam turbine generator output. The heaters are installed in a feedwater stream in parallel with the first two existing extraction lowpressure feedwater heaters (FWH \#1 and FWH \#2). Additionally, for all oxygen-fired cases a direct contact flue gas cooler (DCGC) and a booster fan are added in the flue gas stream after the FGD system. The DCGC is added to further cool the flue gas in order to minimize down stream power requirements (i.e. fans and product gas compression). The booster fan is required to take 
care of the additional draft losses for the new PFWH, DCGC (all cases), and secondary scrubber (Cases 3a, 3b, and 3c).

\subsubsection{Controls:}

For all oxygen-fired cases, additional controls and instrumentation will be required for the new components and systems described above. The transition between air firing and oxygen firing needs careful consideration.

\subsubsection{Flue Gas Desulfurization System Modifications (Cases 3a, 3b, and 3c only)}

The FGD system does not require modification for the cryogenic ASU Case 2, or for the CAR cases which utilize steam as the sweep gas (Cases $4 a$, and $4 b$ ).

The FGD system for all three cases with flue gas sweep (Cases 3a, 3b, and 3c) is modified with the addition of a secondary absorber to reduce the $\mathrm{SO}_{2}$ content to $10 \mathrm{ppmv}$ or less as required by the CAR system downstream, which uses recirculated flue gas as the sweep gas.

\subsubsection{Modified FGD System Process Description and Process Flow Diagram (Cases 3a, 3b, and 3c only)}

The principle of operation of the FGD system is briefly described in the previous study (Bozzuto, et al, 2001) and is not repeated here. In the flue gas sweep cases, however, the entire flue gas stream leaving the existing FGD system absorber is supplied to the new secondary absorber. Additional piping and ductwork is required as shown in Figure 5-1, which provides a simplified process flow diagram for the modified FGD system.

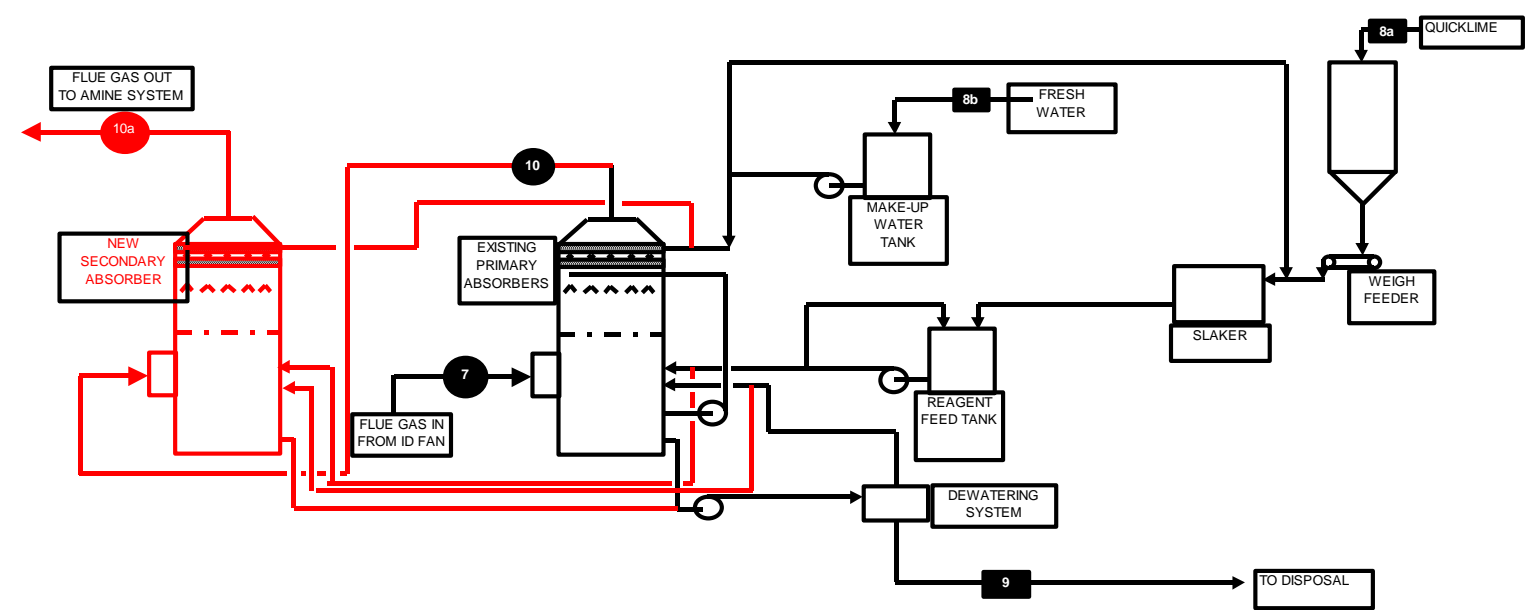

Figure 5-1: Modified FGD System Simplified Process Flow Diagram (Cases 3a, 3b, and 3c)

\subsubsection{Modified FGD System Equipment Layout (Cases 3a, 3b, and 3c only)}

Figure 5-2 shows the location of the new secondary $\mathrm{SO}_{2}$ absorber. The new secondary absorber is a single vessel, which is $12.8 \mathrm{~m} \mathrm{(42} \mathrm{ft)} \mathrm{in} \mathrm{diameter,} \mathrm{and} \mathrm{is} \mathrm{located} \mathrm{just} \mathrm{to} \mathrm{the} \mathrm{north} \mathrm{and} \mathrm{adjacent} \mathrm{to}$ the existing Conesville Unit \#5 lime preparation and scrubber equipment building (i.e. label \#53 shown in green in the lower right part of Figure 5-2). This location minimizes the length of ductwork running from the existing FGD system to the new secondary $\mathrm{SO}_{2}$ absorber. The blue lines indicate minor alterations, which must be made to the access roads located in this area. 


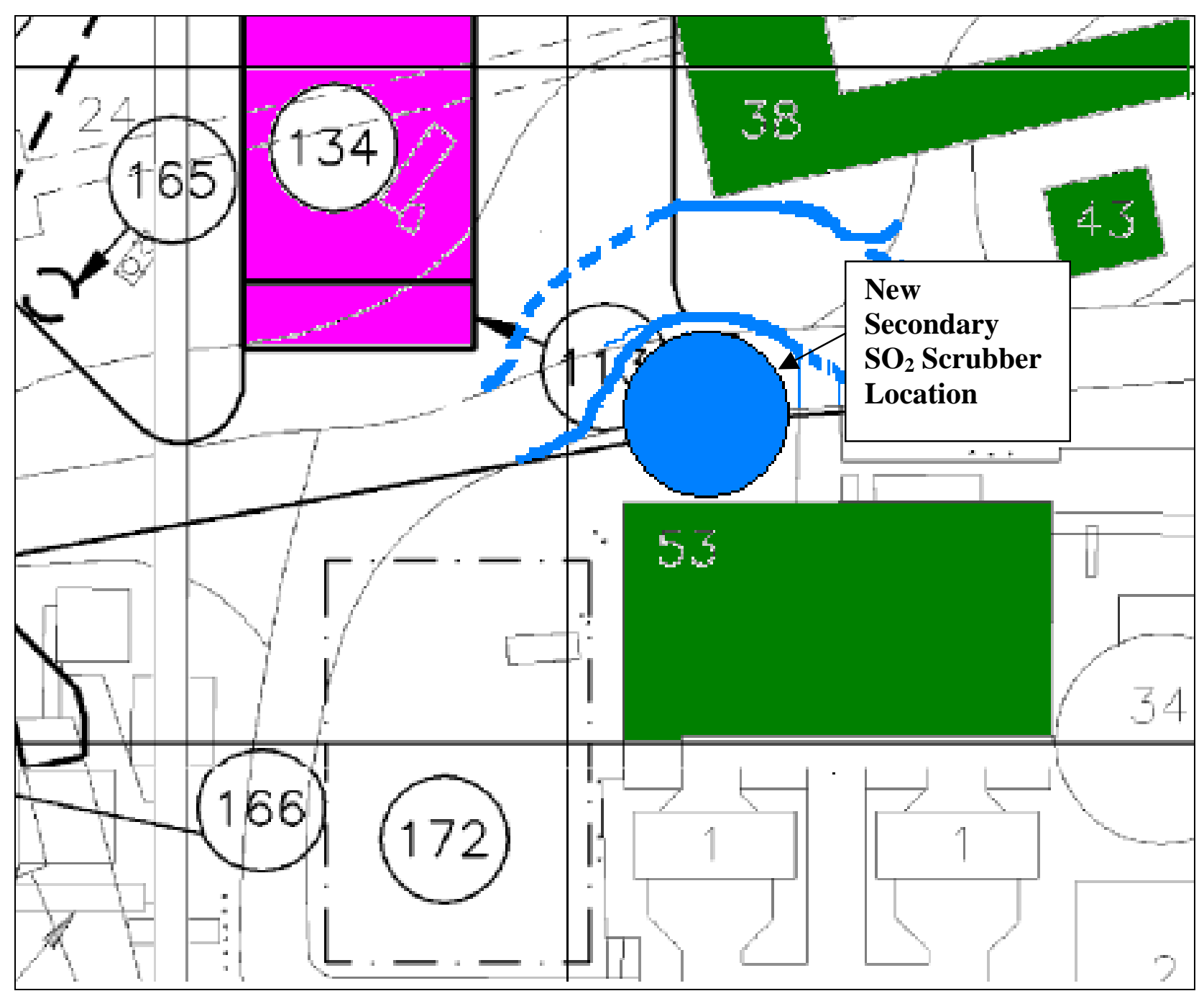

Figure 5-2: New Secondary $\mathrm{SO}_{2}$ Scrubber Location (Cases 3a, 3b, and 3c)

\subsubsection{Secondary FGD Absorber Effluent (Cases 3a, 3b, and 3c only)}

The existing Conesville Unit \#5 uses lime in its flue gas desulfurizer (FGD) system. In the cost estimate of this plant, it has been assumed that the existing plant disposal facilities can accommodate the relatively small additional load from the new secondary regenerator.

\subsection{Steam Cycle Modifications}

This section describes modifications required to the steam cycles for the oxygen fired retrofit cases. 


\subsubsection{Cryogenic ASU Based Case 2}

The cryogenic ASU cases require relatively minor steam cycle modifications as shown in Figure 5-3. For Case 2, condensate is used to recover low-level heat rejected from various sources throughout the plant (ASU system, boiler flue gas, and gas processing unit).

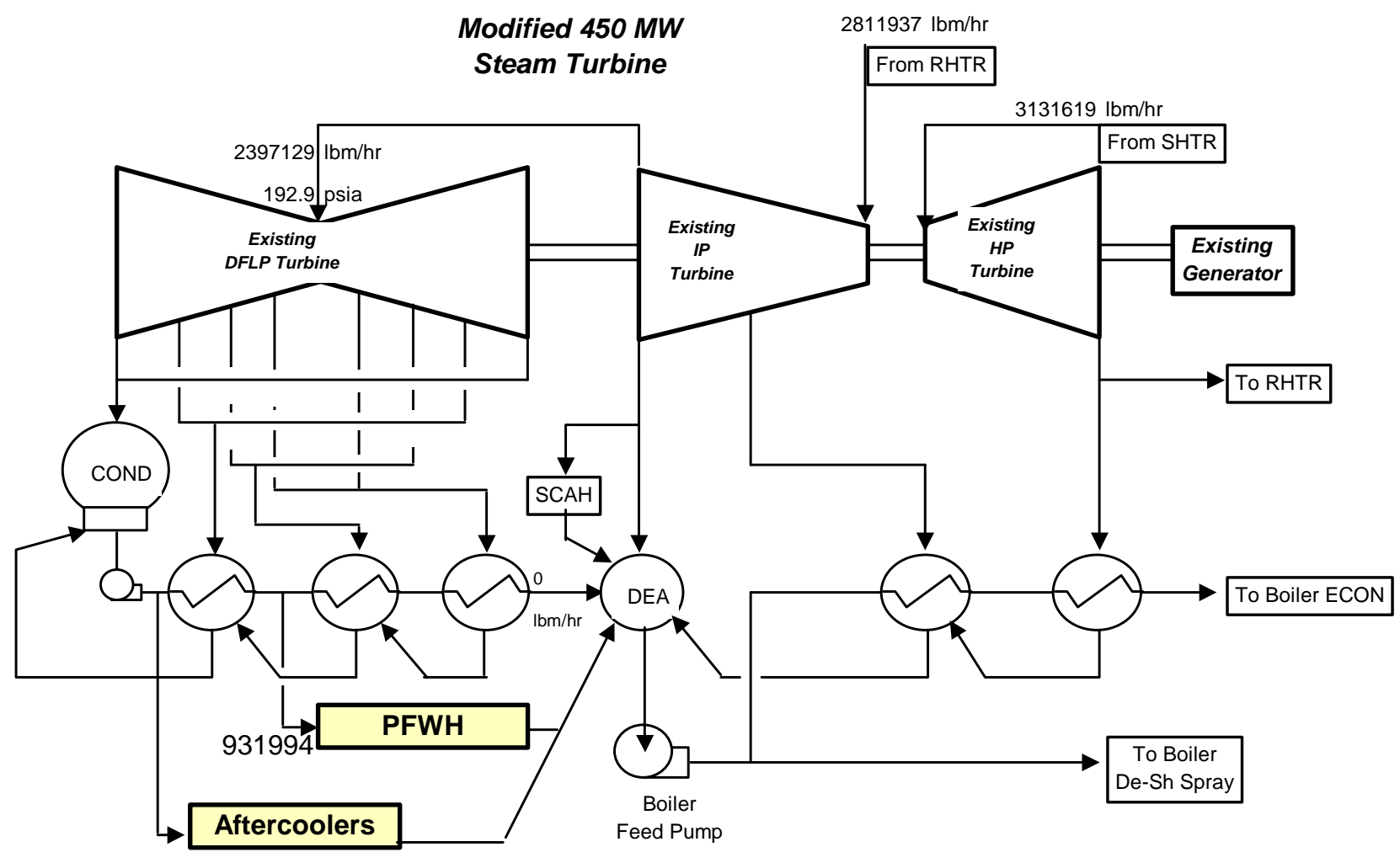

Figure 5-3: Modified Steam Cycle for Case 2

\subsubsection{Flue Gas Sweep Cases (3a, 3b, and 3c)}

The CAR cases with flue gas sweep (Cases 3a, 3b, and 3c) require steam to purge the beds as they are cycled between capturing oxygen from the air stream and releasing the captured oxygen to the flue gas sweep gas. The purge steam is taken from the IP-LP crossover pipe, as shown in Figure 5-4. 


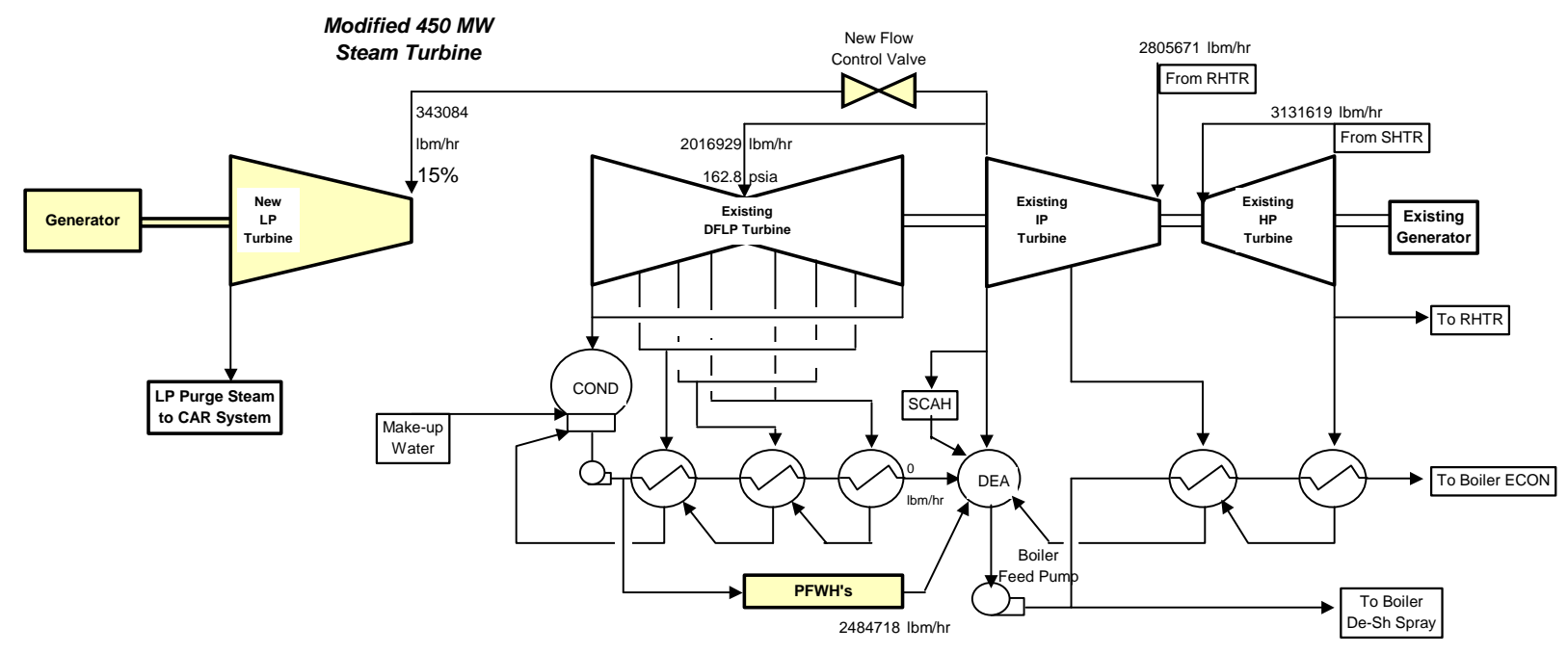

Figure 5-4: Modified Steam Cycle for Flue Gas Sweep Cases (3a, 3b, and 3c)

This steam is expanded through a new low-pressure (LP) turbine/generator, which is added in a parallel steam path with the existing LP turbine. The steam exiting from the new LP turbine (about $15 \%$ of the total LP steam flow) provides the purge steam for the CAR system.

Additionally, condensate is used to recover low-level heat rejected from various sources (CAR system, boiler flue gas, and gas processing unit) throughout the plant

\subsubsection{Steam Sweep Cases (4a and 4b)}

Cases $4 \mathrm{a}$ and $4 \mathrm{~b}$ use steam as the sweep gas medium. The steam is taken from the IP-LP crossover pipe, as shown in Figure 5-5, and it is expanded through a new letdown LP turbine/generator, which is added in a parallel steam path with the existing LP turbine. The steam exiting from the new LP turbine (about 58\% of the total LP steam flow) is preheated and then is used as the sweep gas for the CAR system where it picks up the oxygen from the bed material. The steam/oxygen mixture leaving the CAR system is cooled by providing heat to the incoming steam sweep gas, steam cycle feedwater, and finally to cooling water where most of the steam is condensed. The stream exiting the CAR system steam condenser contains mostly oxygen (about $90 \%$ by weight) although some $\mathrm{N}_{2}, \mathrm{CO}_{2}$ and water vapor are also present. This stream provides the oxygen source for the boiler.

Additionally, condensate is used to recover low-level heat rejected from various sources (CAR system, boiler flue gas, and gas processing unit) throughout the plant. 


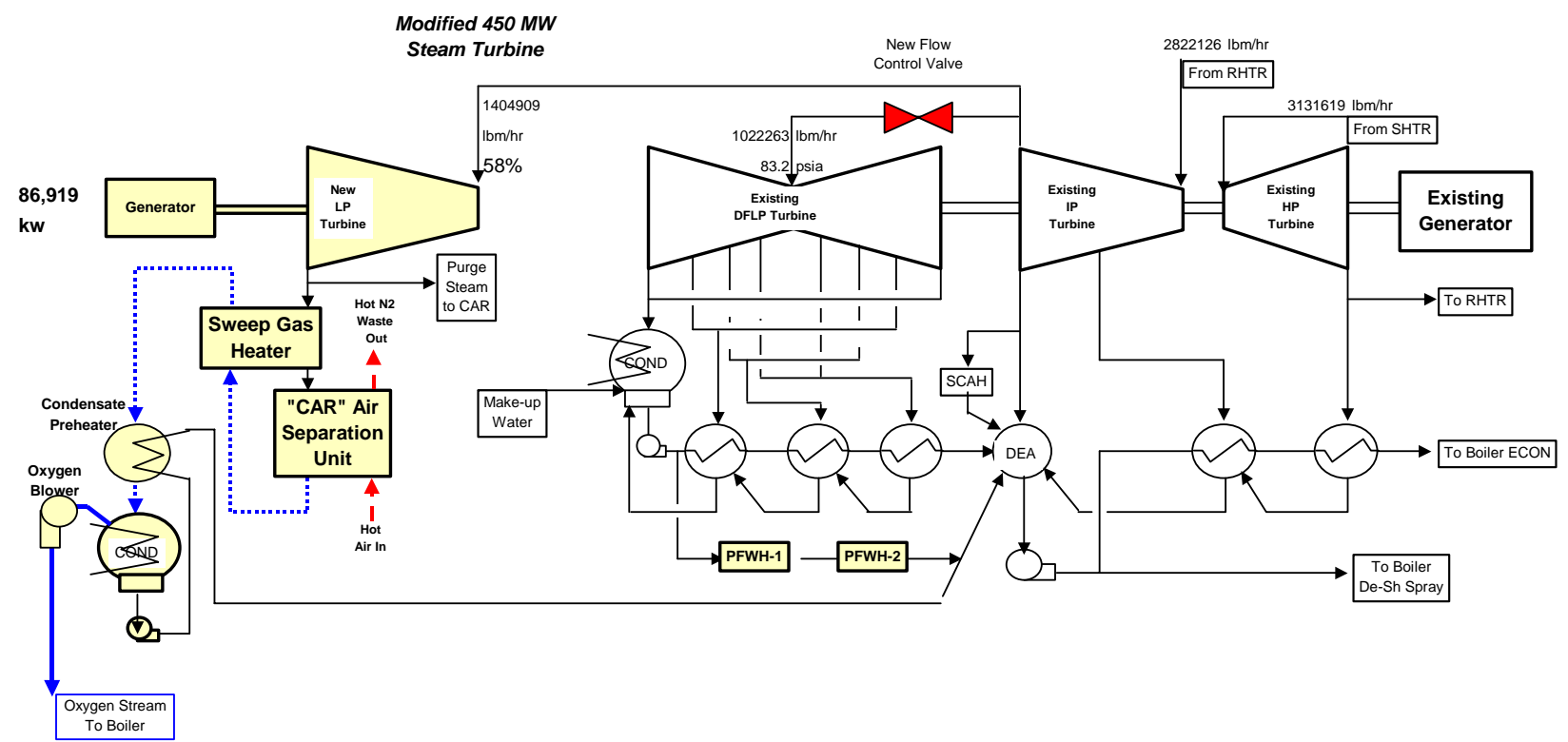

Figure 5-5: Modified Steam Cycle for Steam Sweep Cases (4a and 4b) 


\section{COST ANALYSIS}

The project capital cost estimates including engineering, procurement and construction (EPC basis), are presented in this section. All costs were estimated in March 2008 US dollars. These costs include all equipment required to complete the retrofit such as the new oxygen production systems, the new gas processing unit, which includes $\mathrm{CO}_{2}$ compression, dehydration, and liquefaction systems, boiler modifications, the modified FGD system (where applicable), and the minor steam cycle modifications.

In general, these costs were obtained in a simplified manner by escalating costs from previous estimates that were available. Escalation factors were obtained from the new Power Capital Costs Index (PCCI) developed by IHS and CERA (Holt, 2008). As shown in Figure 6-1, the new PCCI which tracks the costs of building coal, gas, wind and nuclear power plants indexed to a value of 100 for year 2000 registered 231 index points in the third quarter period ending in October 2007. This is shown by the upper red curve. Excluding nuclear plants, costs have risen 79 percent since 2000 as shown by the lower blue curve.

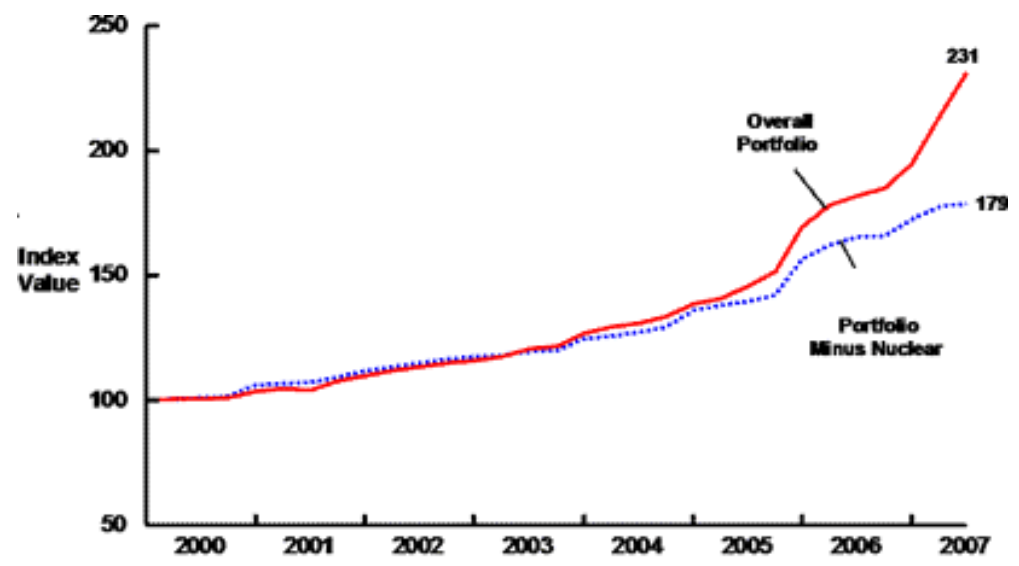

Figure 6-1: IHS/CERA Power Capital Costs Index

The previous cost estimates that were utilized as the base costs were developed using the cost estimation basis shown in Section 6.1.

Operating and maintenance (O\&M) costs were calculated for all systems. The O\&M costs for the Base Case (Conesville Unit \#5 - air fired without $\mathrm{CO}_{2}$ capture) were provided by American Electric Power (AEP) for a previous study (Ramezan, Nsakala, and Liljedahl, 2007). For the retrofit $\mathrm{CO}_{2}$ capture system evaluations, additional O\&M costs were calculated for the new equipment. The variable operating and maintenance (VOM) costs for the new equipment included such categories as chemicals and desiccants, waste handling, maintenance material and labor, and contracted services. The fixed operating and maintenance (FOM) costs for the new equipment includes operating labor only.

\subsection{Cost Estimation Basis}

The following assumptions were made in developing these cost estimates for each concept evaluated: 
- March 2008 \$US

- Outdoor installation

- Investment in new utility systems is outside the scope

- $\mathrm{CO}_{2}$ product pipeline is outside the scope

- No special limitations for transportation of large equipment

- No protection against unusual airborne contaminants (dust, salt, etc.)

- No unusual wind storms

- No earthquakes

- No piling required

- All releases can go to atmosphere - no flare provided

- Annual operating time is 7,008 hr/yr (80\% capacity factor)

- The retrofit investment cost estimate was developed as a factored estimate based on in-house data for the major equipment. Such an estimate can be expected to have accuracy of $+/-30 \%$.

- No purchases of utilities or charges for shutdown time have been charged against the project.

Other exclusions from the cost estimate are as follows:

- Soil investigation

- Environmental Permits

- Disposal of hazardous or toxic waste

- Disposal of existing materials

- Custom's and Import duties

- $\quad$ Sales/ Use tax.

- Forward Escalation

- Capital spare parts

- Chemical loading facilities

- Buildings except for Compressor building and electrical substation.

- Financing cost

- Owners cost

- Guards during construction

- Site Medical and Ambulance service

- $\quad$ Cost \& Fees of Authorities

- Overhead High voltage feed lines

- Cost to run a natural gas pipeline to the plant

- Excessive piling

- Contingency and risk

\subsection{Fuel Costs}

The costs used for consumption of fuel (coal \& natural gas) in this project are shown in Table 6-1.

Table 6-1: Prices for Consumables

\begin{tabular}{|l|c|c|}
\hline Item & $\left(\$ / 10^{6} \mathrm{Btu}\right)$ & $(\$ / \mathrm{GJ})$ \\
\hline Coal & 1.52 & 1.44 \\
\hline Natural Gas & 7.00 & 6.63 \\
\hline
\end{tabular}




\subsection{New Equipment and Plant Modification Costs}

\subsubsection{Oxygen Production System Costs}

This section provides the cost estimates for the oxygen production systems. Both cryogenic ASU costs and costs for the advanced CAR systems are provided.

\subsubsection{Cryogenic ASU System Costs}

The cost for the Case 1 ASU, which was designed for 99\% purity oxygen was calculated to be about $\$ 236$ x $10^{6}$ in March 2008 US\$. The original cost (from Bozzuto et al., 2001) was simply escalated from July 2001 to March 2008 using an escalation factor obtained from the new Power Capital Costs Index (PCCI) developed by IHS and CERA (Holt, 2008).

The cost for the Case 2 ASU, which was designed for 95\% purity oxygen, was about $\$ 219 \times 10^{6}$ in March 2008 US\$. This cost was prorated, based on delivered oxygen flowrate, from a previous estimate for a similarly sized ASU (Carney, 2008).

\subsubsection{CAR System Costs}

Linde provided the cost estimates for the CAR systems. Table 2-1 shows a breakdown of the estimates for Cases 3a and $3 b$ (flue gas sweep, internal heat exchange, 0.5 and $1.0 \% \mathrm{O}_{2}$ capacity, respectively). The cost for Case 3c (flue gas sweep, external heat exchange, $1.0 \% \mathrm{O}_{2}$ capacity) was calculated by Linde to be the same value as that for Case 3a $(\$ 178,250,865)$. The cost for Case $3 \mathrm{~b}$ (flue gas sweep, internal heat exchange, $1.0 \% \mathrm{O}_{2}$ capacity) was calculated to be $\$ 128,930,049$. The cost for Case 4 a (steam sweep, internal heat exchange, $1.0 \% \mathrm{O}_{2}$ capacity) was calculated to be $\$ 133,357,438$. The cost for Case $4 \mathrm{~b}$ was not estimated because the performance was significantly worse than Case $3 \mathrm{~b}$ and there was no expectation that CAR system costs would be lower for this case than case $3 b$.

As compared to Case 2, the cryogenic ASU benchmark case, the cost for Cases 3a and 3c was about $19 \%$ lower and the cost for Case 3 b was about $41 \%$ lower. The cost for Case 4 a was about 39\% lower than Case 2 but about 3\% higher than Case 3b. 
Table 6-2: CAR Oxygen Production System Investment Costs (EPC Basis) Cases 3a \& 3b

\begin{tabular}{|c|c|c|c|}
\hline \multirow[b]{2}{*}{ No. } & \multirow[b]{2}{*}{ Item } & \multicolumn{2}{|c|}{ Cost, March 2008 US\$ } \\
\hline & & $\begin{array}{c}\text { Case } 3 a: \text { CAR Catalyst } \mathrm{O}_{2} \\
\text { Capacity } 0.5 \% \text { by wt }\end{array}$ & $\begin{array}{c}\text { Case } 3 b: \text { : CAR Catalyst } \mathrm{O}_{2} \\
\text { Capacity } 1.0 \% \text { by wt }\end{array}$ \\
\hline 1 & Air Filters & 158,481 & 158,481 \\
\hline 2 & Air Compressors & $8,193,485$ & $8,193,485$ \\
\hline 3 & Flue Gas Compressors & $5,634,152$ & $5,634,152$ \\
\hline 4 & Adsorber Vessels & $4,747,432$ & $3,440,168$ \\
\hline 5 & Vessel Nozzle Assembly & 635,108 & 635,108 \\
\hline 6 & Refractory & $3,413,706$ & $2,236,109$ \\
\hline 7 & Changeover Valves & $6,203,243$ & $6,203,243$ \\
\hline 8 & Air/N2 Exhangers & 246,395 & 246,395 \\
\hline 9 & Discharge Silencers & $2,303,724$ & $2,303,724$ \\
\hline 10 & Buffer Tanks & 215,011 & 215,011 \\
\hline \multirow[t]{2}{*}{11} & Flowmeter Stations & $1,033,874$ & $1,033,874$ \\
\hline & Total Equipment & $32,784,611$ & $30,299,750$ \\
\hline 12 & Foundation & $10,266,360$ & $10,266,360$ \\
\hline 13 & Mechanical Installation & $14,753,075$ & $13,634,888$ \\
\hline 14 & Instrumentation & $4,927,902$ & $4,927,902$ \\
\hline 15 & Electricals & $6,159,878$ & $6,159,878$ \\
\hline 16 & Catalyst & $78,353,642$ & $39,176,821$ \\
\hline 17 & Ceramics & $1,164,217$ & $1,056,419$ \\
\hline 18 & $\begin{array}{l}\text { Instrument Air Compressor \& Dryer System } \\
\text { Installed Cost }\end{array}$ & 431,191 & 431,191 \\
\hline 19 & Engineering & $6,159,878$ & $6,159,878$ \\
\hline 20 & Land & 0 & 0 \\
\hline \multirow[t]{2}{*}{21} & Contingency @15\% & $23,250,113$ & $16,816,963$ \\
\hline & Total Estimated Installed Cost & $178,250,865$ & $128,930,049$ \\
\hline
\end{tabular}

\subsubsection{Gas Processing Unit Costs}

Table 6-3 summarizes the gas processing unit (GPU) cost estimates for all the cases in this study. These budgetary costs are provided on an EPC basis with March 2008 US\$. The cost for the Case 1 GPU was simply escalated in US\$ from July 2001 to March 2008 using the original cost estimate provided in Bozzuto et al., 2001 as a basis. This was done in order to make the costs and 
economics for this previous case comparable with the new cases in this study. Escalation factors were obtained from the new Power Capital Costs Index (PCCI) developed by IHS and CERA (Holt, 2008). The cost for the gas processing units for Case 2 and the CAR cases (3a, 3b, 3c, and 4a) were prorated based on $\mathrm{CO}_{2}$ product mass flow rate, from a similarly sized GPU from a previous estimate (Carney, 2008). The cost for the GPU for Case 4b was not estimated for reasons described previously.

Table 6-3: Gas Processing Unit Costs (EPC Basis)

\begin{tabular}{|c|c|c|c|c|c|c|}
\hline Cost Category & $\begin{array}{c}\text { Case 1 - ASU } \\
\text { cryogenic type } \\
\text { (OCDO with 2008 } \\
\text { US\$) }\end{array}$ & $\begin{array}{c}\text { Case 2 - ASU } \\
\text { cryogenic type } \\
\text { (Updated Analysis) }\end{array}$ & $\begin{array}{c}\text { Case 3a CAR with } \\
\text { Flue Gas Sweep } \\
\text { IHX (0.5\%) }\end{array}$ & $\begin{array}{c}\text { Case 3b CAR with } \\
\text { Flue Gas Sweep } \\
\text { IHX (1.0\%) }\end{array}$ & $\begin{array}{c}\text { Case 3c CAR with } \\
\text { Flue Gas Sweep } \\
\text { EHX (1.0\%) }\end{array}$ & $\begin{array}{c}\text { Case 4a - CAR } \\
\text { with Steam } \\
\text { Sweep IHX (1.0\%) }\end{array}$ \\
\hline Gas Processing Unit & $236,913,700$ & $185,375,000$ & $201,573,301$ & $201,573,301$ & $192,052,941$ & $191,029,085$ \\
\hline
\end{tabular}

\subsubsection{Boiler Modification Costs}

The boiler island equipment scope is indicated schematically in Section 4 for the various cases and includes the traditional boiler island equipment (coal mills, fans, boiler, precipitator, and flue gas desulfurization system) ending at the gas outlet duct of the FGD system.

Boiler modifications are described in Section 5 and include such items as sealing the boiler for air leaks, a seal gas system, new ductwork and dampers for the recirculated flue gas and oxygen, parallel low-pressure feedwater heaters, and modified controls and instrumentation.

The boiler modifications and associated costs are relatively minor as compared to the new oxygen production and gas processing equipment. Costs were developed for the boiler modifications in a simplified manner. Because the boiler modifications required did not differ substantially from case to case, a single boiler modification cost was developed which would apply to all cases. This cost was developed by modifying costs from the original July 2001 estimate to represent the current boiler modifications described in Section 5 and then escalating the July 2001costs to March 2008 using the new Power Capital Costs Index (PCCI) developed by IHS and CERA (Holt, 2008).

The total cost required for the boiler scope modifications is $\$ 12,750,000$ (budgetary level +/- 30\%; Ohio valley basis). This cost estimate includes material, engineering, procurement, and construction (EPC Basis).

\subsubsection{FGD System Modification Costs (Cases 3a, 3b, and 3c only)}

Each of the flue gas sweep cases (Cases 3a, 3b, and 3c) requires the addition of a secondary scrubber to the existing FGD system to reduce $\mathrm{SO}_{2}$ levels to $<10$ ppmv as described in Section 5.2.2. Costs were developed for the modified FGD system in a simplified manner. For each case, the FGD system modification cost was obtained by simply escalating costs from the original July 2001 estimate (Concept A FGD System Modification Cost; Bozzuto et al., 2001) to March 2008 using the new Power Capital Costs Index (PCCI) developed by IHS and CERA (Holt, 2008).

The total cost required for the FGD system modifications is \$26,860,000 (budgetary level +/$30 \%$; Ohio valley basis). This cost estimate includes material, engineering, procurement, and construction (EPC Basis). 


\subsubsection{Retrofit Investment Cost Summary}

Table 6-4 and Figure 6-2 show a summary of the total retrofit investment costs for all the cases investigated. Case 3b (CAR flue gas sweep, internal heat exchangers, 1.0\% oxygen capacity) was the lowest cost case investigated $(1,187 \$ / \mathrm{kWe})$. This case showed about a $20 \%$ lower total retrofit cost (\$/kWe-net basis) than Case $2(1,450 \$ / \mathrm{kWe})$, the updated cryogenic ASU benchmark case. The other CAR cases (Cases 3b, 3c, and 4a) ranged from about 5\% - 10\% lower total retrofit cost than Case 2 the benchmark case. Case 1, the cryogenic ASU case from the original study (Bozzuto et al., 2001), which had the costs escalated, was about 20\% higher than the updated cryogenic ASU case (Case 2). About half of the difference between Case 1 and Case 2 was due to the electrical output increase for Case 2 and half was due to the cost decrease for Case 2.

Table 6-4: Retrofit Investment Costs Summary - All Cases

\begin{tabular}{|c|c|c|c|c|c|c|}
\hline Cost Category & $\begin{array}{c}\text { Case 1 - ASU } \\
\text { cryogenic type } \\
\text { (OCDO with } 2008 \\
\text { US\$) }\end{array}$ & $\begin{array}{c}\text { Case } 2 \text { - ASU } \\
\text { cryogenic type } \\
\text { (Updated Analysis) }\end{array}$ & $\begin{array}{c}\text { Case 3a CAR with } \\
\text { Flue Gas Sweep } \\
\text { IHX (0.5\%) }\end{array}$ & $\begin{array}{c}\text { Case 3b CAR with } \\
\text { Flue Gas Sweep } \\
\text { IHX (1.0\%) }\end{array}$ & $\begin{array}{c}\text { Case 3c CAR with } \\
\text { Flue Gas Sweep } \\
\text { EHX }(1.0 \%)\end{array}$ & $\begin{array}{c}\text { Case 4a - CAR } \\
\text { with Steam } \\
\text { Sweep IHX (1.0\%) }\end{array}$ \\
\hline ASU - CAR System & 0 & 0 & $178,636,448$ & $129,357,428$ & $178,636,448$ & $133,357,428$ \\
\hline ASU - Cryogenic & $235,524,800$ & $219,010,000$ & 0 & 0 & 0 & 0 \\
\hline Gas Processing Unit & $236,913,700$ & $185,375,000$ & $201,573,301$ & $201,573,301$ & $192,052,941$ & $191,029,085$ \\
\hline Boiler Modifications & $11,900,000$ & $12,750,000$ & $12,750,000$ & $12,750,000$ & $12,750,000$ & $12,750,000$ \\
\hline Direct Contact Gas Cooler \& Bstr Fan & (incl. in GPS) & $25,000,000$ & $25,000,000$ & $25,000,000$ & $25,000,000$ & $25,000,000$ \\
\hline FGD System Modifications & 0 & 0 & $26,860,000$ & $26,860,000$ & $26,860,000$ & 0 \\
\hline Total & $484,338,500$ & $442,135,000$ & $453,399,596$ & $404,120,575$ & $443,605,088$ & $379,348,581$ \\
\hline$\$ / k W e$ & 1,772 & 1,450 & 1,332 & 1,187 & 1,372 & 1,305 \\
\hline
\end{tabular}

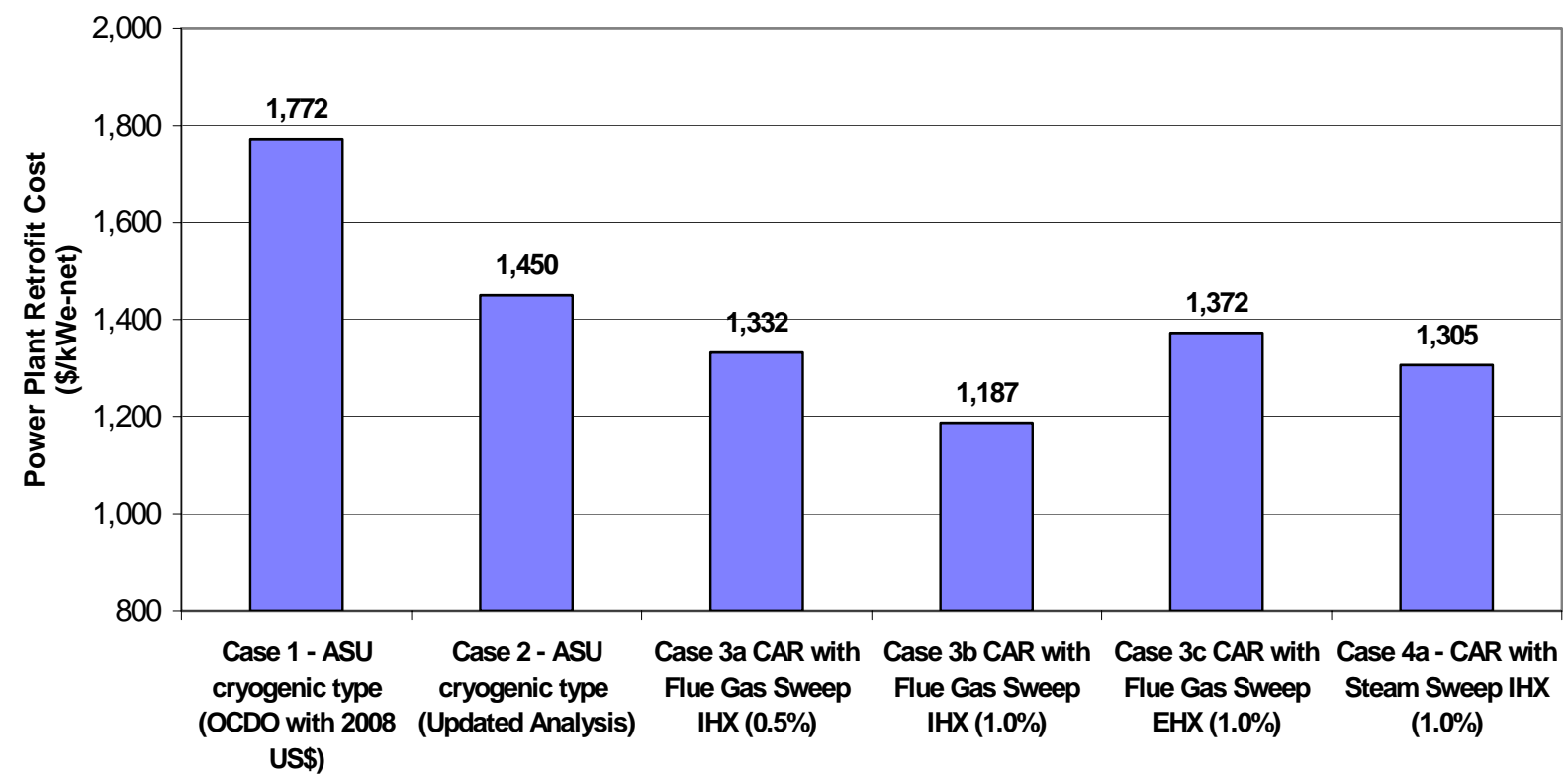

Figure 6-2: Retrofit Investment Costs Summary - All Cases 


\subsection{Operating and Maintenance Costs}

Operating and maintenance (O\&M) costs, for electric utility evaluations, form one of the components used in calculating the cost of electricity. Operating and maintenance costs are generally categorized as being either fixed or variable costs. The fixed operating and maintenance (FOM) costs, which are incurred whether the plant is operating or not, typically include operating labor only. The variable operating and maintenance (VOM) costs, which are incurred only when the plant is operating and depend on the output level of the plant, typically include such categories as chemicals and desiccants, waste handling, maintenance material and labor, and contracted services.

The O\&M costs for this study are incremental O\&M costs relative to the Base Case. The incremental operating and maintenance costs for this study were calculated in a simplified manner, as requested by Linde. The basic procedure that was used is described below. The O\&M costs for the Base Case (Conesville \#5 Unit) were provided by previously by American Electric Power (AEP) as a part of an earlier study (Ramezan, Nsakala, and Liljedahl, 2007) done by Alstom. The O\&M costs for Case 1, which were calculated rigorously as a part of an earlier study (Bozzuto et al., 2001) done by Alstom, were simply escalated to March 2008 \$US. The O\&M costs for Case 2, which were calculated rigorously as a part of an earlier study (Carney, 2008) were in March 2008 \$US.

The simplified O\&M cost calculations assumed that the total incremental dollars spent per year for both fixed and variable O\&M costs would be the same for all the new cases (i.e. Cases 2, 3a, 3b, 3c, and 4a) and were equivalent to the annual incremental costs incurred for Case $2(\$ 7,480,000)$ as shown in Table 6-5.

Table 6-5: Annual Operating \& Maintenance Costs - Case 2

\begin{tabular}{|l|r|r|}
\hline \multicolumn{3}{|c|}{ Annual O\&M Costs (\$/yr) } \\
\hline & ASU & GPS \\
\hline Labor & 970,000 & incl. in ASU \\
\hline Maint & $3,920,000$ & $2,050,000$ \\
\hline Chem Lube & 340,000 & 200,000 \\
\hline Total & $5,230,000$ & $2,250,000$ \\
\hline
\end{tabular}

Because the electrical output levels among the cases were somewhat different, the COE component for O\&M was slightly different among the cases. The cases with higher electrical output had a lower COE component for O\&M than the cases with less output. 


\section{ECONOMIC ANALYSIS}

A simplified economic evaluation comparing the Base Case study unit and various retrofit $\mathrm{CO}_{2}$ capture scenarios using oxygen firing was performed. The purpose of the evaluation was to determine which of the CAR configurations investigated was the best from an economic standpoint and also to quantify the impact of $\mathrm{CO}_{2}$ capture on the Cost of Electricity (COE) of this existing coal fired unit. $\mathrm{CO}_{2}$ mitigation costs were also determined as a part of this analysis. The economic evaluation results are presented as incremental Costs of Electricity (levelized basis). The reported costs of electricity are incremental relative to the Base Case (i.e. air fired without $\mathrm{CO}_{2}$ capture representing current operations for the AEP Conesville \#5 unit).

\subsection{Economic Study Scope, Outputs, and Assumptions}

Economic Study Scope:

A total of six $\mathrm{CO}_{2}$ capture cases were evaluated in this economic analysis in addition to the Base Case without $\mathrm{CO}_{2}$ capture. The following list summarizes these eight cases.

- Base Case: "business as usual” operation scenario for the existing plant (i.e., air fired without $\mathrm{CO}_{2}$ recovery)

- Case 1: oxygen fired retrofit (cryogenic type ASU - 99\% purity oxygen) of Conesville Unit \#5 from the original study (Bozzuto, et. al, 2001)

- Case 2: An update of the above Case 1 to a state of the art cryogenic ASU (95\% purity oxygen) and an updated gas processing unit (GPU). Plant performance, retrofit costs and economics have been updated.

- Cases 3a, 3b, and 3c: Retrofit of AEP Conesville Unit \#5 using the Ceramic Autothermal Recovery (CAR) oxygen production process with flue gas used as the sweep gas for the CAR process.

- Case 4a: Retrofit of Conesville Unit \#5 using the Ceramic Autothermal Recovery (CAR) oxygen production process with steam used as a sweep gas for the CAR process.

Economic Study Outputs:

The primary outputs from this economic analysis are the levelized incremental Cost of Electricity ( $\mathrm{COE}$ ) and $\mathrm{CO}_{2}$ mitigation costs relative to the Base Case. These two measures of economic merit were determined for all cases evaluated. $\mathrm{CO}_{2}$ mitigation costs were calculated according to Equation (7.1).

$\mathrm{CO}_{2}$ Mitigation Cost $=\left(\mathrm{COE}_{\mathrm{Cp}}-\mathrm{COE}_{\mathrm{Ref}}\right) /\left(\mathrm{CO}_{2 \mathrm{Ref}}-\mathrm{CO}_{2 \mathrm{Cp}}\right)$

(Equation 7.1)

Where:

$\mathrm{CO}_{2}$ Mitigation Cost $=\$ /$ ton of $\mathrm{CO}_{2}$ avoided

$\mathrm{COE}=$ Cost of electricity $(\$ / \mathrm{kWh})$

$\mathrm{CO}_{2}=$ Carbon dioxide emitted (ton/kWh)

$\mathrm{Cp}=$ Capture plant

Ref $=$ Reference plant 
Economic Study Assumptions:

The primary assumptions used to evaluate the Base Case (i.e., air fired without $\mathrm{CO}_{2}$ capture) and all other $\mathrm{CO}_{2}$ capture cases are given in Table 7-1. Additionally, the fixed charge rate used was about 13.4 percent, and the analysis horizon was 30 years. This approach enabled the evaluation of the impacts of $\mathrm{CO}_{2}$ capture in terms of incremental costs of electricity and $\mathrm{CO}_{2}$ mitigations costs.

Table 7-1: Base Economic Assumptions

\begin{tabular}{|l|c|c|}
\hline Parameter & Units & Value \\
\hline Investment Cost & $\$ / \mathrm{kW}$ & As estimated \\
\hline Capacity Factor & Percent & 80 \\
\hline Coal Cost & $\$ 110^{6} \mathrm{Btu}$ & 1.52 \\
\hline Natural Gas Cost & $\$ 110^{6} \mathrm{Btu}$ & 7.00 \\
\hline
\end{tabular}

Economic Sensitivity Study:

Additionally, a simple economic sensitivity study was developed for each of the cases. The sensitivity analysis was designed to show the effects on incremental $\mathrm{COE}$ and $\mathrm{CO}_{2}$ mitigation cost of variations in a hypothetical $\mathrm{CO}_{2}$ allowance price. The $\mathrm{CO}_{2}$ allowance price was varied from 050 \$/ton of $\mathrm{CO}_{2}$ emitted.

\subsection{Economic Analysis Results}

This section summarizes the economic analysis results obtained from this study. Results discussed were obtained while using the economic assumptions given in Table 7-1. Economic results are given in terms of incremental cost of electricity and $\mathrm{CO}_{2}$ mitigation costs. Incremental cost of electricity for these retrofit cases includes components for the cost of fuel, retrofit capital cost expenditures, incremental O\&M costs, and a hypothetical $\mathrm{CO}_{2}$ allowance price. $\mathrm{CO}_{2}$ mitigation costs were calculated in terms of $\$ /$ ton of $\mathrm{CO}_{2}$ avoided, relative to the Base Case with a 0.0 \$/ton $\mathrm{CO}_{2}$ allowance. A range of $\mathrm{CO}_{2}$ allowance prices from 0-50 \$/ton of $\mathrm{CO}_{2}$ emitted were investigated for all these cases.

Table 7-2 and associated Figure 7-1 show the incremental cost of electricity results while Table 7-3 and Figure 7-2 show $\mathrm{CO}_{2}$ mitigation cost results. 
Table 7-2: Incremental Cost of Electricity Relative to Base Case

\begin{tabular}{|c|c|c|c|c|c|c|}
\hline \multicolumn{7}{|c|}{ Incremental Cost of Electricity (Cents/kWhr) } \\
\hline $\begin{array}{c}\text { Co2 } \\
\text { Allowance } \\
\text { (\$/ton) }\end{array}$ & $\begin{array}{c}\text { Case 1 - ASU } \\
\text { cryogenic } \\
\text { type (OCDO } \\
\text { with 2008 } \\
\text { US\$) }\end{array}$ & $\begin{array}{c}\text { Case } \text { - ASU } \\
\text { cryogenic } \\
\text { type } \\
\text { (Updated } \\
\text { Analysis) }\end{array}$ & $\begin{array}{c}\text { Case 3c CAR } \\
\text { with Flue Gas } \\
\text { Sweep EHX } \\
(1.0 \%)\end{array}$ & $\begin{array}{c}\text { Case 3b CAR } \\
\text { with Flue Gas } \\
\text { Sweep IHX } \\
(1.0 \%)\end{array}$ & $\begin{array}{c}\text { Case 3a CAR } \\
\text { with Flue Gas } \\
\text { Sweep IHX } \\
(0.5 \%)\end{array}$ & $\begin{array}{c}\text { Case 4a - } \\
\text { CAR with } \\
\text { Steam Sweep } \\
\text { IHX (1.0\%) }\end{array}$ \\
\hline $\mathbf{0}$ & 4.95 & 3.76 & 3.76 & 3.64 & 3.91 & 3.87 \\
\hline $\mathbf{1 0}$ & 5.00 & 3.84 & 3.84 & 3.71 & 3.99 & 3.96 \\
\hline $\mathbf{2 0}$ & 5.06 & 3.92 & 3.92 & 3.79 & 4.07 & 4.04 \\
\hline $\mathbf{3 0}$ & 5.12 & 4.00 & 3.99 & 3.87 & 4.15 & 4.13 \\
\hline $\mathbf{4 0}$ & 5.18 & 4.08 & 4.07 & 3.95 & 4.23 & 4.22 \\
\hline $\mathbf{5 0}$ & 5.24 & 4.16 & 4.15 & 4.03 & 4.30 & 4.30 \\
\hline
\end{tabular}
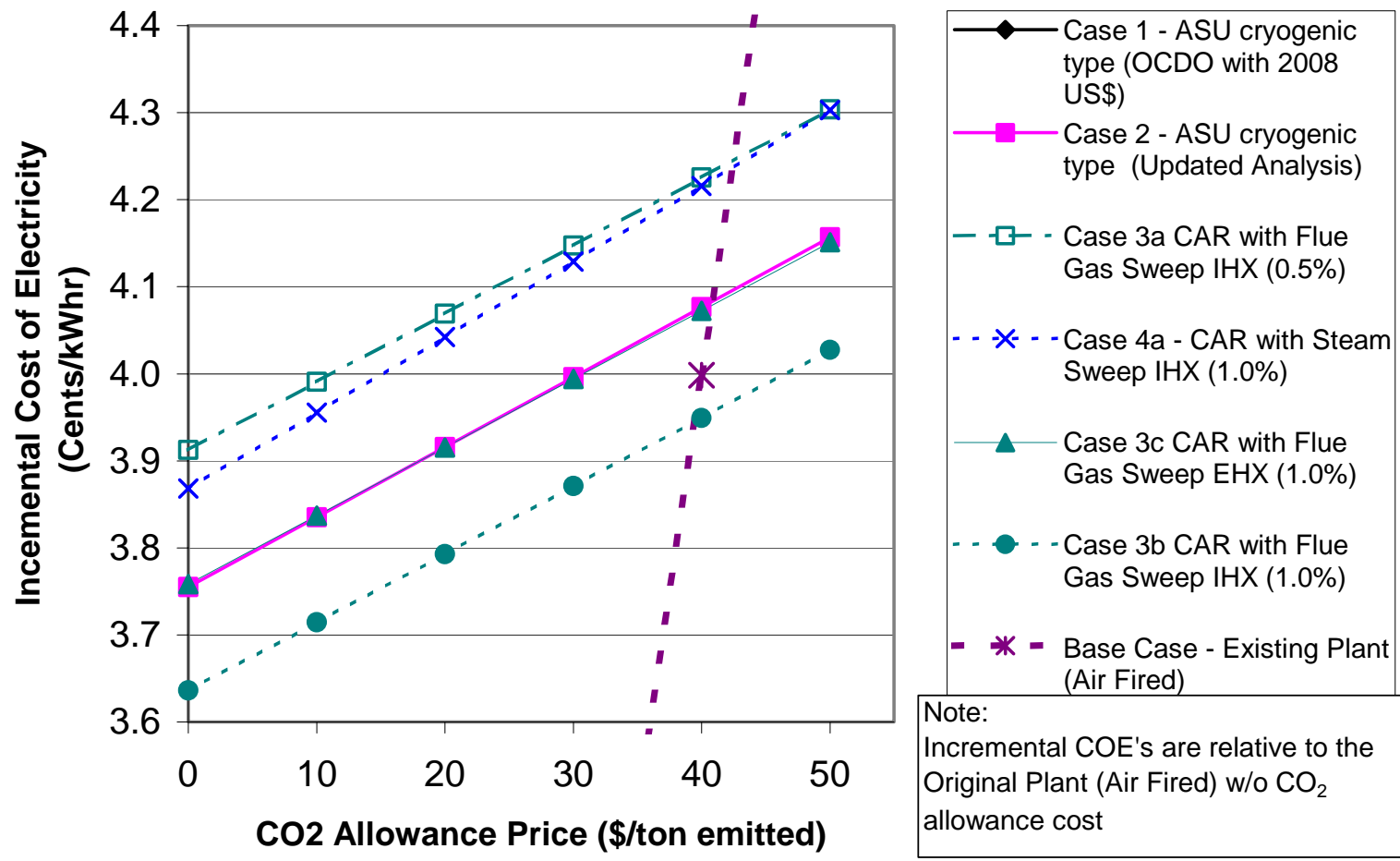

Figure 7-1: Incremental Cost of Electricity Relative to Base Case

The CAR Case 3b (flue gas sweep with integral heat exchange and 1.0\% oxygen capacity) shows the best economics of the cases studied. By way of comparison, Case 3b shows an incremental COE that is about 3\% lower than the incremental COE for Case 2 the updated cryogenic ASU case, which represents the benchmark case for this study. Were it not for the relatively large amount of natural gas usage for Case $3 \mathrm{~b}$ ( $\sim 7.8 \%$ of the coal heat input), the COE for this case would have been significantly better.

Case 3c (flue gas sweep with external heat exchange and 1.0\% oxygen capacity) was investigated in an effort to minimize the natural gas usage ( $\sim 3.6 \%$ of the coal heat input) but the increased 
capital costs for this case caused the COE to be about 3\% higher than for Case 3b. The incremental COE for Case 3c was about the same as Case 2.

Case 3a, which was the same configuration as Case 3b except with $0.5 \%$ oxygen capacity shows an incremental COE that is about 3-4\% higher than the incremental COE for Case 2 and about 7\% higher than Case 3b.

Case 4a (steam sweep with integral heat exchange and 1.0\% oxygen capacity) shows an incremental COE that is also about 3-4\% higher than the incremental COE for Case 2 and about $7 \%$ higher than Case 3b. Because costs were not estimated for Case $4 \mathrm{~b}$ for reasons described previously, economics were not developed for this case.

Figure 7-1 does not show Case 1 from the previous study because the graph is "zoomed in" to focus on the new cases from this study. The Case 1 incremental COE values ranged from 4.95$5.24 \mathbb{\$} / \mathrm{kWh}$ as shown in Table 7-2, which is about 30\% higher than Case 2.

From a purely cap and trade perspective, the owner/operator of this plant would not contemplate any of these retrofit scenarios unless the cost of $\mathrm{CO}_{2}$ allowance exceeded $\sim \$ 40 /$ ton of $\mathrm{CO}_{2}$ emitted.

As expected, the $\mathrm{CO}_{2}$ mitigation costs exhibit the same trends as the incremental COE results as shown in Table 7-3 and Figure 7-2 below.

Table 7-3: $\mathrm{CO}_{2}$ Mitigation Costs Relative to Base Case

\begin{tabular}{|c|c|c|c|c|c|c|}
\hline \multicolumn{7}{|c|}{$\mathbf{C O}_{2}$ Mitigation Cost (\$/Ton Avoided) } \\
\hline $\begin{array}{c}\text { CO2 } \\
\text { Allowance } \\
\text { (\$/ton) }\end{array}$ & $\begin{array}{c}\text { Case 1 - ASU } \\
\text { cryogenic type } \\
\text { (OCDO with } \\
\text { 2008 US } \$ \text { ) }\end{array}$ & $\begin{array}{c}\text { Casenenic } \\
\text { type } \\
\text { (Updated } \\
\text { Analysis) }\end{array}$ & $\begin{array}{c}\text { Case 3c CAR } \\
\text { with Flue Gas } \\
\text { Sweep EHX } \\
(1.0 \%)\end{array}$ & $\begin{array}{c}\text { Case 3b CAR } \\
\text { with Flue Gas } \\
\text { Sweep IHX } \\
(1.0 \%)\end{array}$ & $\begin{array}{c}\text { Case 3a CAR } \\
\text { with Flue Gas } \\
\text { Sweep IHX } \\
(0.5 \%)\end{array}$ & $\begin{array}{c}\text { Case 4a - } \\
\text { CAR with } \\
\text { Steam Sweep } \\
\text { IHX (1.0\%) }\end{array}$ \\
\hline $\mathbf{0}$ & 52.6 & 40.8 & 40.8 & 39.5 & 42.5 & 42.4 \\
\hline $\mathbf{1 0}$ & 53.2 & 41.7 & 41.7 & 40.3 & 43.3 & 43.3 \\
\hline $\mathbf{2 0}$ & 53.8 & 42.6 & 42.5 & 41.2 & 44.2 & 44.3 \\
\hline $\mathbf{3 0}$ & 54.5 & 43.5 & 43.4 & 42.0 & 45.0 & 45.2 \\
\hline $\mathbf{4 0}$ & 55.1 & 44.3 & 44.2 & 42.9 & 45.9 & 46.2 \\
\hline $\mathbf{5 0}$ & 55.7 & 45.2 & 45.1 & 43.7 & 46.7 & 47.1 \\
\hline
\end{tabular}



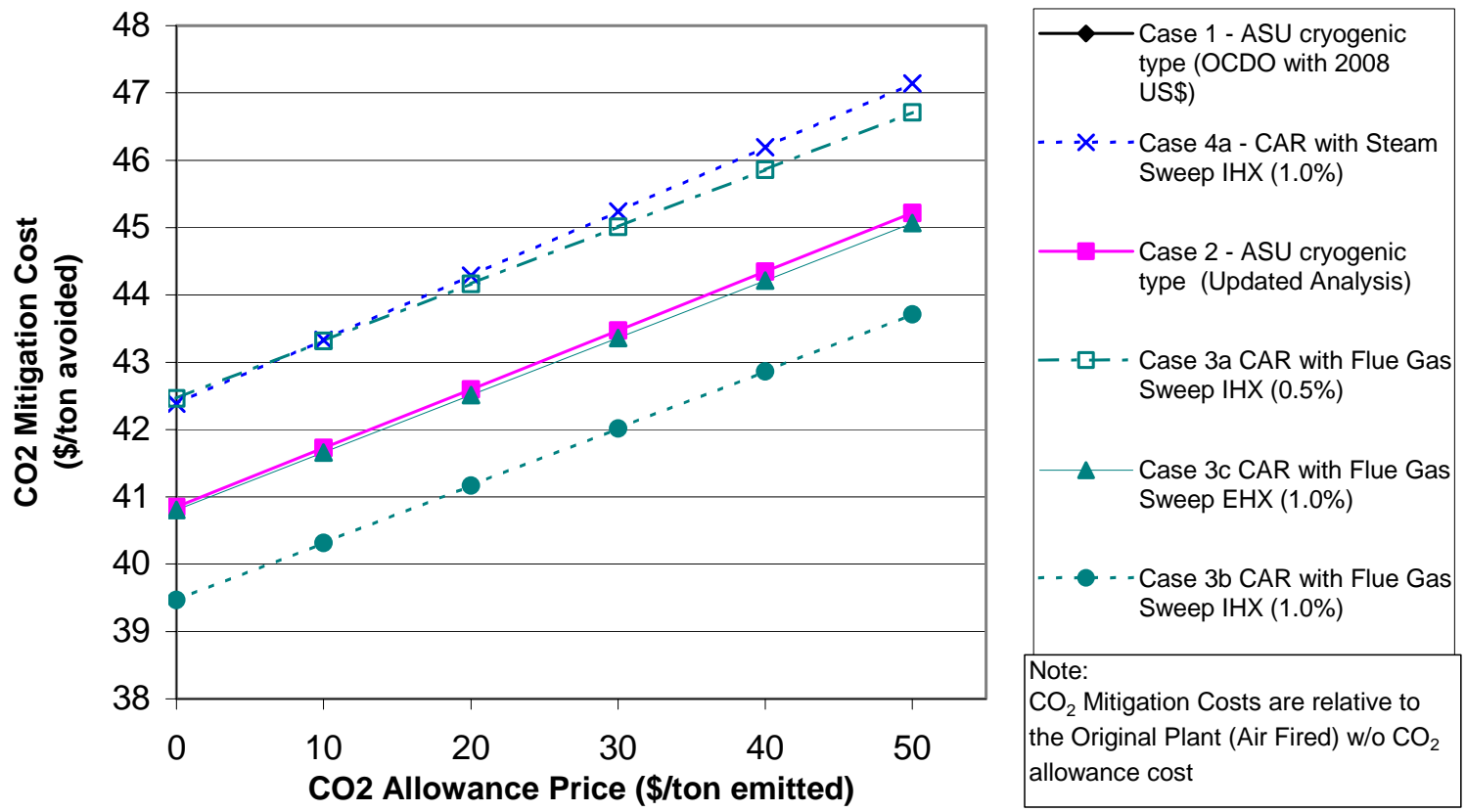

Figure 7-2: $\mathrm{CO}_{2}$ Mitigation Costs Relative to Base Case 


\section{RESULTS AND CONCLUSIONS}

The purpose of this study was to develop a conceptual level techno-economic evaluation of several process configurations for the CAR advanced oxygen production system integrated with an existing pulverized coal fired utility steam generator (AEP Conesville Unit \#5). The comparison of these CAR retrofit options would then indicate the most economic configuration for the CAR system in this application.

To benchmark these results, the CAR systems were compared to a retrofit of the same unit using a "state of the art" cryogenic type ASU for oxygen production. A Base Case, which was air fired and without $\mathrm{CO}_{2}$ capture (i.e. "business as usual”) was also used for comparison purposes to indicate the impacts of $\mathrm{CO}_{2}$ capture.

Five CAR system configurations were investigated. Three of the cases used flue gas as the sweep gas and two of the cases used steam as the sweep gas. These cases are identified below.

- Cases 3a, 3b, and 3c represent the retrofit of Conesville Unit \#5 using the Ceramic Autothermal Recovery (CAR) oxygen production process with recirculated flue gas used as the sweep gas for the CAR process. These three cases represent different arrangements with respect to sweep gas preheat and air preheat as well as different assumptions regarding the oxygen holding capacity for the CAR bed material. Case 3a represents a case which uses packed bed heat exchangers that are integral with the CAR bed and located at both the inlet and outlet of the CAR beds. This case assumes an oxygen capacity of $0.5 \%$ of the weight of the CAR bed material. Case $3 \mathrm{~b}$ is the same as Case 3a from a performance standpoint but assumes an oxygen capacity of $1.0 \%$ of the weight of the CAR bed material. This oxygen capacity increase decreases the number of CAR beds required and reduces the overall cost for the CAR system. Case 3c also assumes an oxygen capacity of $1.0 \%$ of the weight of the CAR bed material but instead of using integral packed bed heat exchangers, this case uses separate external heat exchangers for preheating the air and sweep gas. The external heat exchangers are significantly more expensive than the integral packed bed heat exchangers used in Cases 3a and $3 \mathrm{~b}$ but terminal differences can be lowered which reduces the amount of natural gas required in the CAR system.

- Cases 4a and 4b represent the retrofit of Conesville Unit \#5 using the Ceramic Autothermal Recovery (CAR) oxygen production process with steam used as a sweep gas for the CAR process. Similar to Case $3 \mathrm{~b}$, this case uses packed bed heat exchangers that are integral with the CAR bed and assumes an oxygen capacity of $1.0 \%$ of the weight of the CAR bed material. This case also uses an oxygen blower at the exit of the CAR process to supply the oxidant stream to the boiler. Because oxygen blowers are very expensive Linde recommended the investigation of Case 4b, which eliminates the use of the oxygen blower.

First, focusing just on the oxygen production process itself, the CAR system (Case 3b) showed a clear advantage over the cryogenic ASU system (Case 2) in both performance and cost. The specific power requirement for the CAR system was almost 50\% less than for the cryogenic ASU case (115 vs. $223 \mathrm{kWh} /$ ton of oxygen delivered, respectively). The specific oxygen production system cost for Case 3b was about $40 \%$ lower than the cryogenic ASU case ( 14,000 vs. $\sim 25,000$ $\$ /$ ton/day of oxygen delivered, respectively). The oxygen production process comparison however only tells part of the story. 
If we now focus on the complete plant retrofit, Case 3b (flue gas sweep, internal HX, 1.0\% oxygen capacity) was clearly the best configuration investigated for the CAR system from all measures of merit considered (i.e. plant performance, plant retrofit cost, and incremental cost of electricity). The plant performance analysis indicated a plant thermal efficiency loss for this case of 8.89 percentage points which was about one percentage point better than the cryogenic ASU case. The plant retrofit cost for Case 3b was almost 20\% lower than the cryogenic ASU case (1,187 vs. $1,450 \$ / \mathrm{kWe}$-net respectively). Although the performance and cost for the retrofit with the CAR system were substantially better than for the cryogenic ASU case, the incremental COE was only about 3\% lower for Case 3b than Case 2. Were it not for the relatively large amount of natural gas usage for Case $3 \mathrm{~b}$ ( $\sim 7.8 \%$ of the coal heat input), the COE for this case would have been significantly better. Case $3 c$ was investigated in an effort to minimize the natural gas usage ( $\sim 3.6 \%$ of the coal heat input) but the increased capital costs associated with the external heat exchangers for this case caused the incremental COE to be about 3\% higher than for Case 3b.

From a purely cap and trade perspective, the owner/operator of this plant would not contemplate any of these retrofit scenarios unless the cost of $\mathrm{CO}_{2}$ allowance exceeded $\sim \$ 40 /$ ton of $\mathrm{CO}_{2}$ emitted.

\section{CAR Process Development Unit Testing:}

It should be pointed out that there were significant problems encountered during the CAR Process Development Unit testing which was done at the Western Research Institute's facility in Laramie, WY. The problems were primarily related to high heat losses from the unit and an intolerance of the perovskite material to sulfur in the sweep gas. The high heat losses caused higher than expected amounts of Methane usage, lower than expected bed temperatures, and low oxygen removal. With respect to the sulfur intolerance of the perovskite material, some of the materials tested were mechanically unstable while others were shown to decline in performance with the increase in $\mathrm{SO}_{2}$ loading. 


\section{BIBLIOGRAPHY}

Bozzuto, C., Nsakala, N., Liljedahl, G., Palkes, M., Marion, J., Vogel, D., Gupta, J.C., Fugate, M., Guha, M., "Engineering Feasibility of $\mathrm{CO}_{2}$ Capture on an Existing Coal-Fired Power Plant," Final Report for OCDO / DOE-NETL, Prepared by Alstom Power Inc., June 29, 2001

Ramezan, M., Nsakala, N., Liljedahl, G., "Carbon Sequestration For Existing Power Plants Feasibility Study”, Final Report for DOE-NETL, Prepared by Alstom Power Inc., April 30, 2007

Houghton, J., “Global Warming: The Complete Briefing”, Cambridge University Press, 1997

Holt, Neville, "Preliminary Estimates of SCPC \& IGCC with CCS”, CURC, March 4, 2008

White, J. “Industrial Electrostatic Precipitation”, 1962

Carney, Steven R., Air Products and Chemicals Inc., Personal Communication, May 16, 2008 


\section{APPENDIX I}

This appendix was copied from Bozzuto et al, 2001 for purposes of conveniently being able to compare this earlier oxygen-fired analysis to the other oxygen-fired cases shown in this study.

\subsection{Concept B: $\mathbf{C O}_{2}$ Separation with Oxygen Firing and Flue Gas Recirculation}

The basic idea of the overall system for Concept B is to replace air with oxygen for combustion in the furnace in order to produces a high carbon dioxide content flue gas stream leaving the boiler island. A stream of re-circulated flue gas to the furnace is required to maintain thermal balance in the existing boiler between the lower furnace region where evaporation takes place and the convective heat transfer surfaces where steam is superheated and reheated to the required temperature level. This arrangement produces a high carbon dioxide content flue gas that after leaving the boiler system, is processed to provide high-pressure carbon dioxide liquid product for sequestration, enhanced oil recovery (EOR) or other uses.

\subsubsection{Overall System Description and Material and Energy Balance}

A simplified system diagram for the modified unit is shown in Figure 10-1. The system was designed to provide maximum flexibility of operation and to facilitate combustion of coal in either air or oxygen and recirculated flue gas mixture environment.
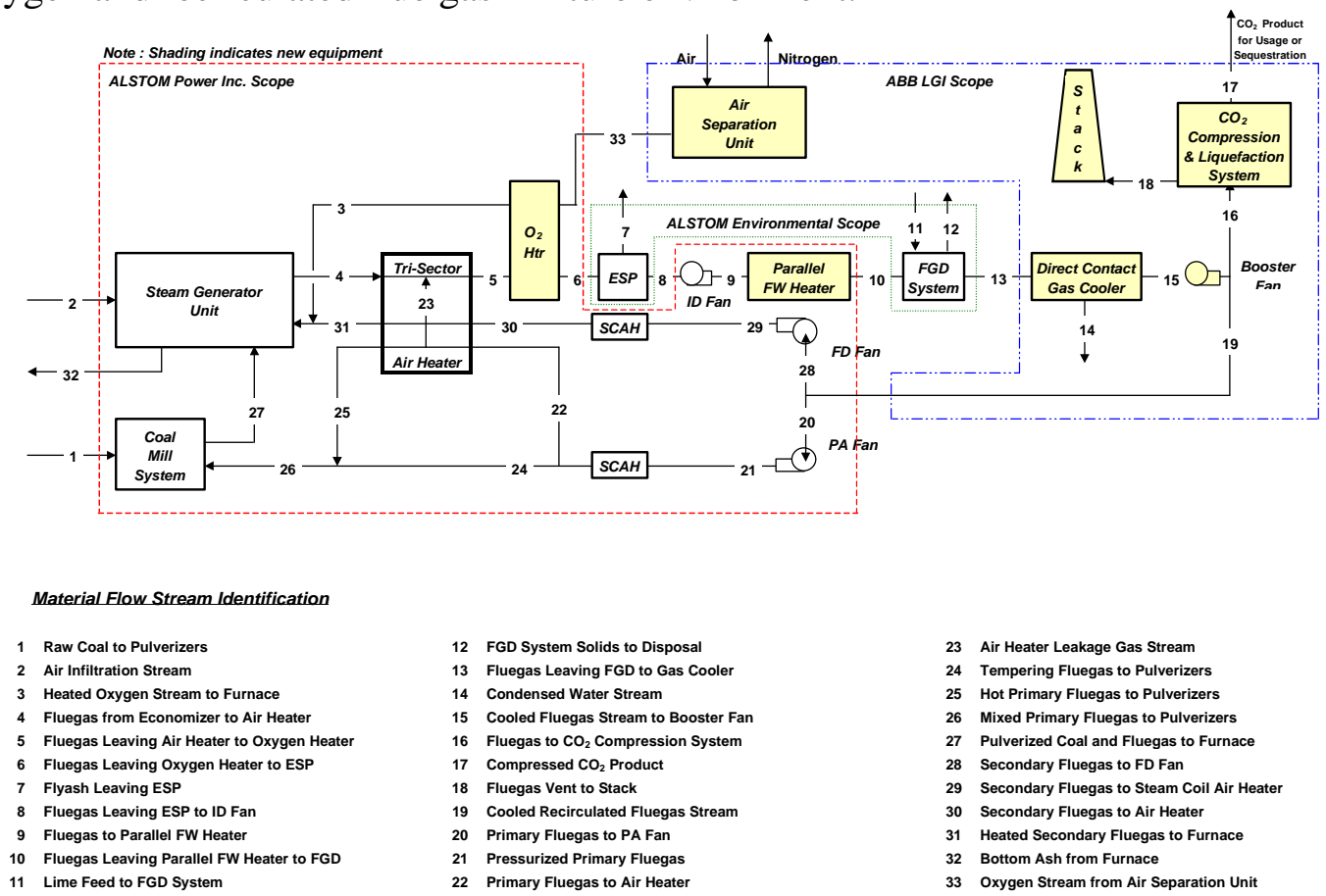

\section{Figure 10-1: Simplified Gas Side Process Flow Diagram for $\mathrm{CO}_{2}$ Separation with Oxygen Firing}

Raw coal (Stream 1) from the coal bunkers is supplied to the existing coal mills where it is pulverized and transported with recycled flue gas (Stream 27) to the furnace. The air separation unit (ASU) supplies the oxidant for the existing boiler. There is no air supply to the boiler except for air infiltration (Stream 2). The oxygen produced, about 8,924 tons per day, (Stream 33) flows 
through a heat exchanger where it is preheated by cooling the flue gas leaving the existing air heater (Stream 5). The pulverized coal is combusted in the furnace with a mixture of preheated oxygen (Stream 3) and preheated recycled flue gas (Stream 31).

The products of combustion leave the furnace and are cooled in a series of heat exchangers. The gas leaving the furnace first enters the existing convection pass of the unit where steam generated in the existing furnace walls is superheated and reheated in the existing convection pass heat exchangers. The flue gas leaves the convection pass (Stream 4) and is further cooled in the existing air heater of the unit. The air heater, however, is now used to heat recycled flue gas since air is no longer supplied to the unit in this mode of operation. The flue gas stream leaving the air heater (Stream 5) flows through the oxygen heater, electrostatic precipitator, induced draft fan, parallel feedwater heater, flue gas de-sulfurization unit, gas cooler and booster fan, in series, before it is split into two streams. One stream (Stream 16) represents the exhaust gas stream leaving the boiler island. This stream provides the feed stream for the Carbon Dioxide Separation and Compression System (described in detail in Section 10.1.7). The remaining flue gas (Stream 19), which is roughly twice as large as Stream 16, is recycled back to the unit with the forced draft and primary air fans. Figure 10-2 shows the cooling curve for the flue gas leaving the existing boiler.

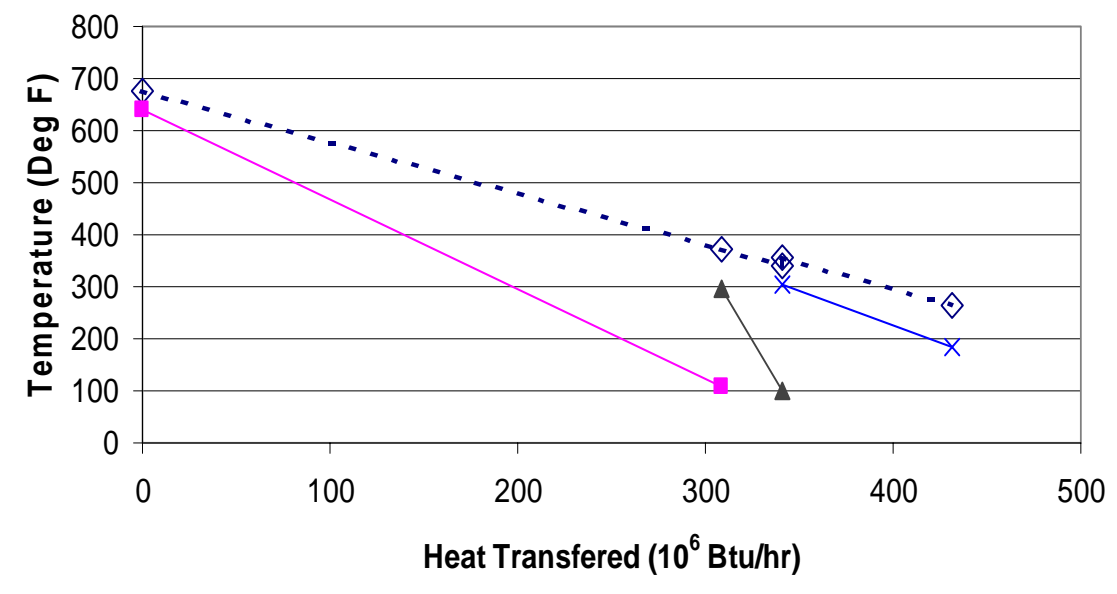

- - $\diamond-$ - Flue Gas $\longrightarrow$ Air Heater $\longleftarrow$ Oxygen Heater $\longleftarrow$ Feedwater Heater

Figure 10-2: Boiler Flue Gas Cooling Curve

The primary reason for the large recycle stream is to maintain the thermal balance between heat transferred in the radiant furnace and the convective heat transfer surfaces, and to generate required boiler performance. In addition, gas temperatures throughout the unit must be low enough to assure the ash, which is contained within the fuel, is maintained in a state where clean ability of the unit is not compromised. Additionally, the integrity of the existing metallurgy in the furnace walls and convective pass heat exchangers must be ensured. The recycled flue gas is supplied to the unit through a combination of new ducts and the existing air ducts. These recycle streams (Streams 29, 30, 31, 21, 22, 24, 25, and 26) provide the primary and secondary "air" streams for the air heater as well as the tempering "air" stream for outlet temperature control of the 
pulverizers. The modified system was designed to generate approximately $3.1 \times 10^{6} \mathrm{lbm} / \mathrm{hr}$ of steam, which represents the Maximum Continuous Rating (MCR) for the unit. Table 10-1, below, shows constituent mass flows, temperatures, pressures, enthalpies, and energy values (chemical, sensible, latent, and total) for all the points shown in the system diagram of Figure 10-1. This table therefore provides the gas side energy and material balance for the system. Two of the key assumptions used in the development of this material and energy balance were an oxygen stream purity of 99 percent by weight, and an air infiltration rate equivalent to one percent of the total oxygen required for the process. For the definition of state points 17 and 18, (not defined in Table 10-1) refer to Section 10.1.7.4, which provides the complete material and energy balance for the $\mathrm{CO}_{2}$ Compression and Liquefaction System. 
Table 10-1:Gas Side Material and Energy Balance for Concept B

\begin{tabular}{|c|c|c|c|c|c|c|c|c|c|c|c|c|}
\hline Constituent & (Units) & 1 & 2 & 3 & 4 & 5 & 6 & 7 & 8 & 9 & 10 & 11 \\
\hline $\mathrm{O}_{2}$ & (Lbm/hr) & 26029 & 7512 & 743640 & 98986 & 102586 & 102586 & & 102586 & 102586 & 102586 & \\
\hline $\mathrm{N}_{2}$ & $"$ & 4766 & 24884 & 7512 & 149080 & 154515 & 154515 & & 154515 & 154515 & 154515 & \\
\hline $\mathrm{H}_{2} \mathrm{O}$ & $"$ & 37027 & 420 & & 259201 & 263129 & 263129 & & 263129 & 263129 & 263129 & 159332 \\
\hline $\mathrm{CO}_{2}$ & $"$ & & & & 3402777 & 3526780 & 3526780 & & 3526780 & 3526780 & 3526780 & \\
\hline $\mathrm{SO}_{2}$ & $"$ & & & & 20546 & 20581 & 20581 & & 20581 & 20581 & 20581 & \\
\hline $\mathrm{H}_{2}$ & $"$ & 15764 & & & & & & & & & & \\
\hline Carbon & $"$ & 231693 & & & & & & & & & & \\
\hline Sulfur & $"$ & 9898 & & & & & & & & & & \\
\hline $\mathrm{CaO}$ & $"$ & & & & & & & & & & & 17784 \\
\hline MgO & $"$ & & & & & & & & & & & 988 \\
\hline $\mathrm{CaSO}_{3}$ & $"$ & & & & & & & & & & & \\
\hline $\mathrm{CaSO}_{4}$ & $"$ & & & & & & & & & & & \\
\hline $\mathrm{MgSO}_{3}$ & " & & & & & & & & & & & \\
\hline $\mathrm{MgSO}_{4}$ & $"$ & & & & & & & & & & & \\
\hline $\begin{array}{l}\mathrm{CaCO}_{3} \\
\text { Ash / Inerts }\end{array}$ & " & 41426 & & & 33141 & 33141 & 33141 & 33141 & & & & 988 \\
\hline & & Raw Coal & Leakage Air & Preheated Oxy & Fluegas to Air Htr & Fluegas to $\mathrm{O} 2 \mathrm{Htr}$ & Fluegas to ESP & Fly Ash & Fluegas to ID Fan & Fluegas to PFWH & Fluegas to FGD & Lime Slurry \\
\hline Total Gas & (Lbm/hr) & 0 & 32816 & 751151 & 3930554 & 4067554 & 4067591 & 0 & 4067591 & 4067591 & 4067591 & 0 \\
\hline Total Solids & $"$ & 366602 & 0 & 0 & 33141 & 33141 & 33141 & 33141 & 0 & 0 & 0 & 19760 \\
\hline Total Flow & $"$ & 366602 & 32816 & 751151 & 3963731 & 4100731 & 4100731 & 33141 & 4067591 & 4067591 & 4067591 & 179092 \\
\hline Temperature & $($ Deg F) & 80 & 80 & 296 & 676 & 371 & 339 & 339 & 339 & 355 & 265 & 80 \\
\hline Pressure & (Psia) & 14.7 & 14.7 & 19.6 & 14.6 & 14.3 & 14.0 & 14.7 & 13.9 & 15.0 & 14.9 & 14.7 \\
\hline $\mathbf{h}_{\text {sensible }}$ & Btu/lbm & 0.000 & 0.000 & 48.422 & 149.879 & 68.644 & 60.581 & 64.700 & 60.581 & 64.704 & 42.508 & 0.000 \\
\hline Chemical & $\left(10^{6} \mathrm{Btu} / \mathrm{hr}\right)$ & 4140.038 & 0.000 & 0.000 & 0.000 & 0.000 & 0.000 & 0.000 & 0.000 & 0.000 & 0.000 & 0.000 \\
\hline Sensible & $\left(10^{6} \mathrm{Btu} / \mathrm{hr}\right)$ & 0.000 & 0.000 & 36.372 & 594.050 & 281.625 & 248.563 & 2.144 & 246.419 & 263.188 & 172.906 & 0.000 \\
\hline Latent & $\left(10^{6} \mathrm{Btu} / \mathrm{hr}\right)$ & 0.000 & 0.441 & 0.000 & 272.161 & 276.285 & 276.285 & 0.000 & 276.285 & 276.285 & 276.285 & 0.000 \\
\hline Total Energy $^{(1)}$ & $\left(10^{6} \mathrm{Btu} / \mathrm{hr}\right)$ & 4140.038 & 0.441 & 36.372 & 866.212 & 557.910 & 524.848 & 2.144 & 522.704 & 539.473 & 449.191 & 0.000 \\
\hline
\end{tabular}




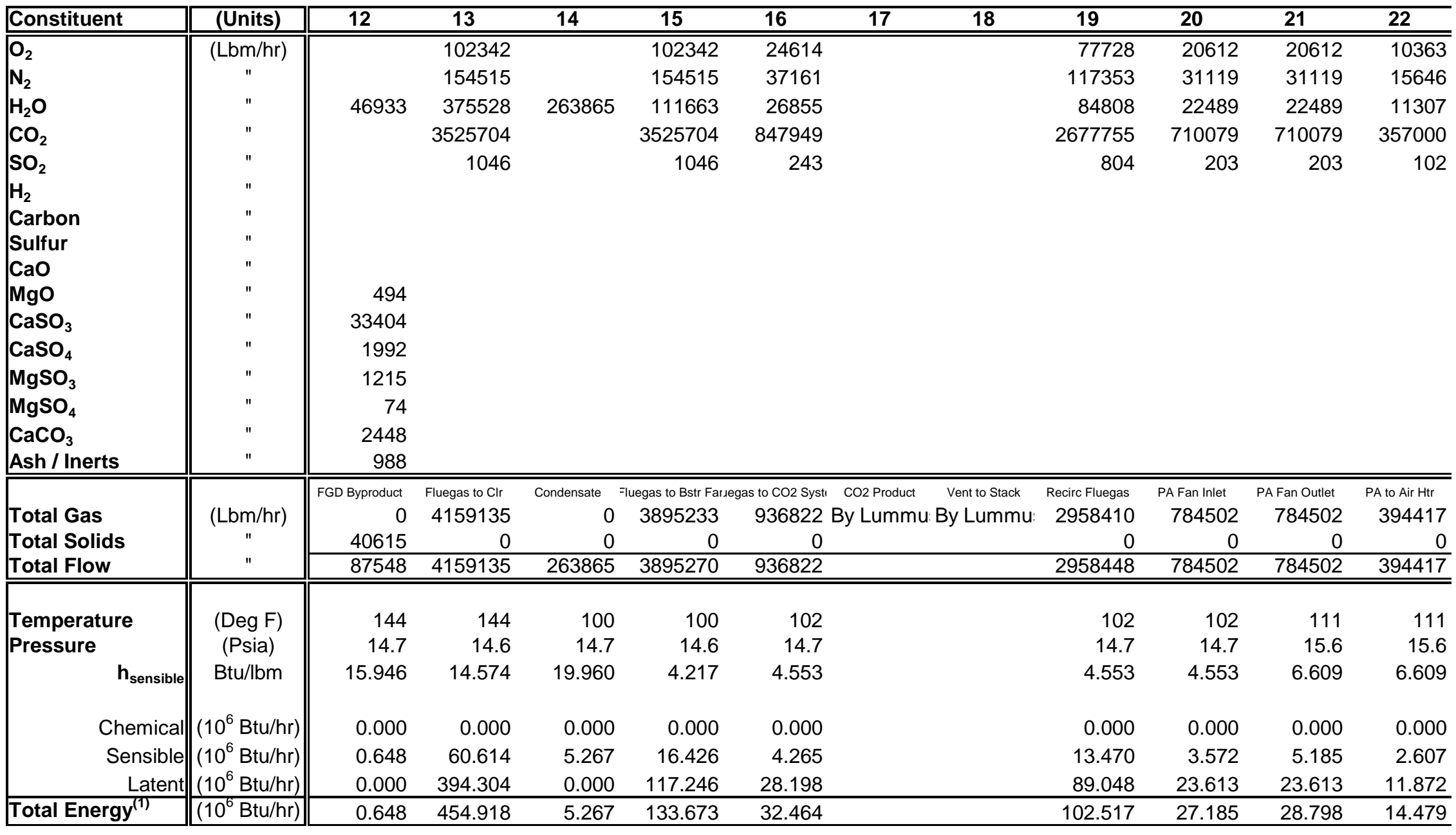




\begin{tabular}{|c|c|c|c|c|c|c|c|c|c|c|c|c|}
\hline Constituent & (Units) & 23 & 24 & 25 & 26 & 27 & 28 & 29 & 30 & 31 & 32 & 33 \\
\hline $\mathrm{O}_{2}$ & (Lbm/hr) & 3599 & 10249 & 7394 & 17643 & 43672 & 57116 & 57116 & 57116 & 56486 & & 743640 \\
\hline $\mathbf{N}_{2}$ & $"$ & 5434 & 15474 & 11163 & 26637 & 31403 & 86234 & 86234 & 86234 & 85282 & & 7512 \\
\hline $\mathrm{H}_{2} \mathrm{O}$ & $"$ & 3927 & 11182 & 8067 & 19250 & 56276 & 62319 & 62319 & 62319 & 61631 & & \\
\hline $\mathrm{CO}_{2}$ & $"$ & 124003 & 353079 & 254719 & 607799 & 607799 & 1967677 & 1967677 & 1967677 & 1945953 & & \\
\hline $\mathrm{SO}_{2}$ & $"$ & 35 & 101 & 73 & 174 & 174 & 563 & 563 & 563 & 557 & & \\
\hline $\mathrm{H}_{2}$ & $"$ & & & & & 15764 & & & & & & \\
\hline Carbon & $"$ & & & & & 231693 & & & & & & \\
\hline Sulfur & $"$ & & & & & 9898 & & & & & & \\
\hline $\mathrm{CaO}$ & $"$ & & & & & & & & & & & \\
\hline MgO & $"$ & & & & & & & & & & & \\
\hline $\mathrm{CaSO}_{3}$ & $"$ & & & & & & & & & & & \\
\hline $\mathrm{CaSO}_{4}$ & $"$ & & & & & & & & & & & \\
\hline $\mathrm{MgSO}_{3}$ & " & & & & & & & & & & & \\
\hline $\mathrm{MgSO}_{4}$ & $"$ & & & & & & & & & & & \\
\hline $\begin{array}{l}\mathrm{CaCO}_{3} \\
\text { Ash / Inerts }\end{array}$ & " & & & & & 41426 & & & & & 8285 & \\
\hline & & AH leakage gas & Temp. Fluegas & Hot Pri Air & Mixed Pri Air & Coal-Pri Air Mix & Sec Air to FD & Sec Air to SCAH & Sec Air to $A H$ & Sec Air to Furn & Bottom Ash & Oxy from ASU \\
\hline Total Gas & (Lbm/hr) & 137000 & 390085 & 281417 & 671502 & 671502 & 2173908 & 2173908 & 2173908 & 2149908 & 0 & 751151 \\
\hline Total Solids & $"$ & 0 & 0 & 0 & 0 & 366602 & 0 & 0 & 0 & 0 & 8285 & 0 \\
\hline Total Flow & " & 137000 & 390085 & 281417 & 671502 & 1038104 & 2173908 & 2173908 & 2173908 & 2149908 & 8285 & 751151 \\
\hline Temperature & $(\operatorname{Deg} F)$ & 111 & 111 & 622 & 339 & 0 & 102 & 106 & 106 & 639 & 2000 & 100 \\
\hline Pressure & (Psia) & 15.6 & 15.6 & 15.6 & 15.6 & 15.0 & 14.7 & 15.1 & 15.1 & 14.9 & 14.7 & 20.1 \\
\hline $\mathbf{h}_{\text {sensible }}$ & Btu/lbm & 6.609 & 6.609 & 130.462 & 58.516 & 0.000 & 4.553 & 5.528 & 5.528 & 135.045 & 480.000 & 4.407 \\
\hline Chemical & $\left(10^{6} \mathrm{Btu} / \mathrm{hr}\right)$ & 0.000 & 0.000 & 0.000 & 0.000 & 4140.038 & 0.000 & 0.000 & 0.000 & 0.000 & 0.000 & 0.000 \\
\hline Sensible & $\left(10^{6} \mathrm{Btu} / \mathrm{hr}\right)$ & 0.905 & 2.578 & 36.714 & 39.294 & 0.000 & 9.898 & 12.017 & 12.017 & 290.335 & 3.977 & 3.311 \\
\hline Latent & $\left(10^{6} \mathrm{Btu} / \mathrm{hr}\right)$ & 4.124 & 11.742 & 8.471 & 20.212 & 0.000 & 65.434 & 65.434 & 65.434 & 64.712 & 0.000 & 0.000 \\
\hline Total Energy $^{(1)}$ & $\left(10^{6} \mathrm{Btu} / \mathrm{hr}\right)$ & 5.029 & 14.320 & 45.185 & 59.506 & 4199.544 & 75.332 & 77.451 & 77.451 & 355.047 & 3.977 & 3.311 \\
\hline
\end{tabular}


Boiler efficiency for the modified system is calculated to be 90.47 percent (HHV basis).

This is increased significantly as compared to the Base Case (88.13 percent) due to Oxygen firing and the addition of the Oxygen Heater and Parallel Feedwater Heaters. The net plant heat rate (HHV basis) is increased significantly to $15,188 \mathrm{Btu} / \mathrm{kWhr}$ for this option as shown in Table 10-2, which also includes the Base Case for comparison. The plant thermal efficiency (HHV basis) for Concept B (22.47\%) is about 64 percent of the Base Case value of $35.01 \%$. This case represents the highest efficiency of the three $\mathrm{CO}_{2}$ removal cases studied in this project. Auxiliary power is increased to $189,709 \mathrm{~kW}$ as a result of the added Air Separation Unit and the $\mathrm{CO}_{2}$ Compression and Liquefaction System. Net plant output is reduced to 273,347 kW. Carbon dioxide emissions are 53,016 lbm/hr or about 0.194 $\mathrm{lbm} / \mathrm{kWh}$, which is about $9.7 \%$ of the Base Case value of $1.997 \mathrm{lbm} / \mathrm{kWh}$.

\section{Table 10-2: Overall Plant Performance Summary for Concept B}

\begin{tabular}{|c|c|c|c|}
\hline & (units) & $\begin{array}{c}\text { Original } \\
\text { Plant (Base) }\end{array}$ & $\begin{array}{c}\text { Concept B } \\
\text { O2 Fired }\end{array}$ \\
\hline \multicolumn{4}{|l|}{ Euel Paramaters } \\
\hline Coal Heat Input (HHV) & $\left(10^{6} \mathrm{Btu} / \mathrm{hr}\right)$ & 4228.7 & 4140.0 \\
\hline Natural Gas Heat Input (HHV) & $\left(10^{6} \mathrm{Btu} / \mathrm{hr}\right)$ & --- & 11.4 \\
\hline Total Fuel Heat Input (HHV) & $\left(10^{6} \mathrm{Btu} / \mathrm{hr}\right)$ & 4228.7 & 4151.5 \\
\hline \multicolumn{4}{|l|}{ Steam Cycle Paramaters } \\
\hline Existing Steam Turbine Generator Output & $(\mathrm{kW})$ & 463478 & 463056 \\
\hline CO2 Removal System Turbine Generator Output & $(\mathrm{kW})$ & 0 & 0 \\
\hline Total Turbine Generator Output & $(\mathrm{kW})$ & 463478 & 463056 \\
\hline Total Auxiliary Power & $(\mathrm{kW})$ & 29700 & 189709 \\
\hline Net Plant Output & $(\mathrm{kW})$ & 433778 & 273347 \\
\hline \multicolumn{4}{|l|}{ Overall Plant Performance Paramaters } \\
\hline Net Plant Efficiency (HHV) & (fraction) & 0.3501 & 0.2247 \\
\hline Net Plant Efficiency (LHV) & (fraction) & 0.3666 & 0.2354 \\
\hline Normalized Efficiency (HHV; Relative to Base Case) & (fraction) & 1.0000 & 0.6419 \\
\hline Net Plant Heat Rate (HHV) & (Btu/kwhr) & 9749 & 15188 \\
\hline Net Plant Heat Rate (LHV) & (Btu/kwhr) & 9309 & 14500 \\
\hline \multicolumn{4}{|l|}{ Overall Plant $\mathrm{CO}_{2}$ Emissions } \\
\hline Carbon Dioxide Emissions & $(\mathrm{lbm} / \mathrm{hr})$ & 866102 & 53016 \\
\hline Specific Carbon Dioxide Emissions & $(\mathrm{lbm} / \mathrm{kwhr})$ & 1.997 & 0.194 \\
\hline Normalized Specific CO2 Emissions (Relative to Base Case) & (fraction) & 1.000 & 0.097 \\
\hline Avoided Carbon Dioxide Emissions (as compared to Base) & $(\mathrm{lbm} / \mathrm{kwhr})$ & --- & 1.803 \\
\hline Specific Carbon Dioxide Emissions & (kg/kwhr) & 0.906 & 0.088 \\
\hline Avoided Carbon Dioxide Emissions (as compared to Base) & (kg/kwhr) & --- & 0.818 \\
\hline
\end{tabular}

\subsubsection{Air Separation Unit}

Concept B uses nearly pure oxygen instead of air for combustion of coal and therefore requires an Air Separation Unit (ASU) to provide the supply of oxygen to the furnace. The ASU selected is a cryogenic type design because of the large capacity required. 


\subsubsection{Background}

As stated above in Section 10.1.1, AEP's Conesville Unit \#5 requires 8,924 standard tons of $99 \%$ purity $\mathrm{O}_{2}$ per day (T/D) when fired at $100 \%$ of the maximum continuous rating (MCR). Hence it was necessary to design an Air Separation Unit (ASU) that would be capable of producing at least this amount of oxygen. Initial discussions between ABB and air separation plant vendors were about using two 3,685 T/D of oxygen trains and one 1,600 T/D train for a total of 8,950 T/D. This is due to the fact that a 3,685 T/D is the largest plant, which could be comfortably offered at this time. After factoring in capital cost considerations, it was decided to design an overall plant comprised of two identical 3,930 T/D trains and two identical 550 T/D trains, for a total capacity of 8,960 T/D. A variety of practical and technical issues are discussed below. A process flow diagram of a typical cryogenic air separation unit (BOC Webpage) showing all its major components is shown in Figure 10-3.

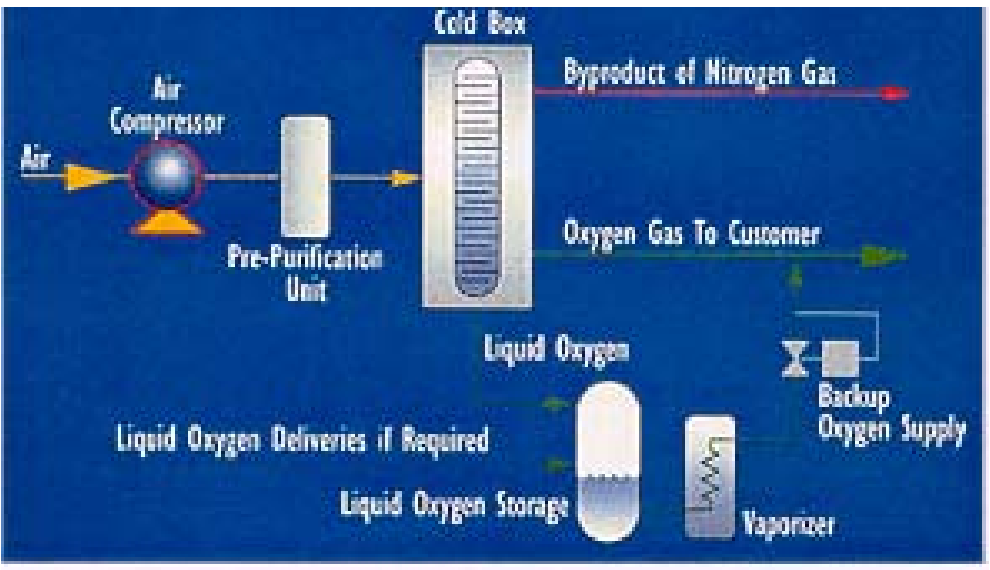

Figure 10-3: Process Flow Diagram of a BOC Improved Air Separation Unit

\subsubsection{Oxygen Purity Considerations}

Oxygen purities above 98\% have significant impacts on the cryogenic portion of the process. $\mathrm{O}_{2}$ purities below 95\% do not benefit in a cost reduction due to reduction in main air compressor discharge pressure requirements. The purities below $95 \%$ often require a frame size increase due to higher inlet volumetric flow rates. It also increases the size of the air adsorber system. The reduced discharge pressure requirements do save on energy of the main air compressor, but other process duties increase due to the higher flow rate of oxygen product. The overall energy consumption could increase if the product is gaseous oxygen with a significant battery limit pressure requirement.

Bottlenecks for building plants larger than 3,685 ST/D

The current largest single ASU in operation is 3,500 ST/D at Rozenburg, The Netherlands. However, sizes up to 4,950 ST/D have been designed on paper. Usually, larger size plants are cheaper than smaller plants due to economy of scale. However, it is believed that a break point somewhere near 3,685 ST/D is where increased plant size will actually cost more for the following reasons: 
- The compressor size, driver size, motor sizes, and line voltage drop at start-up are potential hurdles. The largest compressor size that ASU manufacturers have experience with are in the 40,000-hp range. There may not be any significant aspects of the larger compressors that would create problems over the voltage drop to the compressor if it is motor driven, however, there is no actual experience among the major manufacturers with compressors and drivers exceeding this size.

- Columns larger than 20 feet in diameter create transportation problems for the part of the trip, which is over land. Plants located adjacent to navigable bodies of water would not have any limitation like this. The impact could translate to the need to field fabricate the column.

- Large size pipe and valves become more job specific which create the loss of pricing economies of scale which can be attained when pipe and valve sizes fit many units being built at the same time.

\subsubsection{Major Vendors Experience}

A plant size of 3,685 ST/D of $\mathrm{O}_{2}$ production is larger than any vendor had operating as of May 2000. The following list represents the largest operating plant size that the three vendors had running at that time:

\begin{tabular}{cc}
\hline Vendor & $\begin{array}{c}\text { Largest size operating } \\
\text { plant }\end{array}$ \\
\hline & $\left(\mathrm{ST} / \mathrm{D} \mathrm{O}_{2}\right)$ \\
Air Liquide & 3,190 \\
Air Products & 3,500 \\
BOC & 2,640 \\
\hline
\end{tabular}

\subsubsection{Power Consumption}

The Air Separation unit (ASU) includes a cryogenic plant for air separation. Economic considerations for this application favored the selection of oxygen stream purity of 99 percent by weight. As stated above, four trains were required to produce the required oxygen mass flow rate of about 8,924 tons per day. This system consumes $95,822 \mathrm{~kW}$ of electric power or about 21 percent of the generator output. This energy consumption is equivalent to about $260 \mathrm{kWh} /$ ton of $\mathrm{O}_{2}$ produced. By contrast, Kobayashi and Prasad (Kobayashi and Prasad, 1999) state that the thermodynamic minimum energy requirement is about 40 $\mathrm{kWh} /$ ton of $\mathrm{O}_{2}$ produced. If this limit could be approached, it would represent a breakthrough technology that would enable Concept B to become nearly cost competitive with "business as usual” (coal-fired in air without $\mathrm{CO}_{2}$ capture) electricity generation.

\subsubsection{Plot Plan Requirements}

The required plot plan areas, supplied by Air Products, are 185 feet by 250 feet and 125 feet by 150 feet for the 3,930 T/D and 550 T/D plants, respectively. When the areas for storage and oxygen compressions are included, the required total plot plan amounts to 555 feet by 620 feet. Refer to Appendix I for the plant layout drawings for Concept B. 


\subsubsection{Investment and Operation and Maintenance Costs}

The investment, and operation and maintenance costs of the Air Separation Unit are presented in Section 5.3.2 of Bozzuto et al., 2001.

\subsubsection{Boiler Heat Transfer Analysis}

The primary objective of the systems analysis task for Concept B was to develop a system, which would produce high carbon dioxide content flue gas from an existing coal, fired boiler without requiring major pressure part modifications to the boiler. In order to access whether pressure part modifications would be necessary an accurate heat transfer analysis of the existing boiler was required.

The first step was to set up a steady state performance model of the Conesville Unit \#5 steam generator unit. This involved calculating or obtaining all the geometric information for the unit as required by the proprietary Reheat Boiler Program (RHBP). The RHBP provides an integrated performance model of the boiler island including, in addition to the steam generator unit, pulverizers, air heater, and steam temperature control logic. The RHBP is used to size components and/or predict performance of existing components. In this study, since the boiler island component sizes are known, the RHBP was used exclusively for calculating unit performance.

The next step in the heat transfer analysis of the system was to calibrate the RHBP model of the unit. This involved obtaining a set of test data (with air firing) for the existing unit and adjusting the performance model to match the test data. The required test data includes steam temperatures entering and leaving each major heat exchanger section in the unit, steam pressures, coal analysis, flue gas oxygen content, etc. The adjustments to the model are in the form of "surface effectiveness factors" and "fouling factors".

After the model was calibrated, additional adjustments were required in order to obtain an accurate heat transfer analysis with the high carbon dioxide content flue gas of the Concept B system. The combustion process occurs in a non-conventional environment, which produces gases of different physical and thermal properties. These gas property differences cause significant differences in the heat transfer processes, which occur within the steam generator unit. Analyses were made to determine the impact of the heat transfer differences on boiler behavior.

The RHBP accounts for three modes of heat transfer in the upper furnace and convective pass of the unit (direct radiation, non-luminous radiation and convection). The direct radiation is emitted from the furnace "fire-ball" and is absorbed in various areas of the unit depending on the geometry of the tube banks and the proximity to the "fire-ball". Since the distribution of direct radiation is only a function of geometry, no formulation modifications were necessary for this component of the heat transfer analysis. Investigation of the nonluminous radiation formulations within the RHBP indicated that current equations (based on the Hottel curves, 1957) would be accurate and formulation modifications would not be required. The convection formulations, however, were not set up with the capability of accurately analyzing convective heat transfer for flue gases which were this much different than the typical range of boiler flue gases. The appropriate corrections were made to properly model the convection process in the RHBP with oxygen firing. 


\subsubsection{Furnace Analysis}

Initially, it was expected that heat fluxes to the furnace walls might be increased or decreased somewhat for Concept $\mathrm{B}$ (oxygen firing) due to the higher $\mathrm{CO}_{2}$ and $\mathrm{H}_{2} \mathrm{O}$ content of the flue gas relative to the air fired Base Case for the following reasons:

- Higher gas emissivity and absorptivity of $\mathrm{CO}_{2}$ and $\mathrm{H}_{2} \mathrm{O}$ relative to $\mathrm{N}_{2}$. For an equivalent local gas temperature, the higher emissivity of $\mathrm{CO}_{2}$ and $\mathrm{H}_{2} \mathrm{O}$, relative to the optically transparent $\mathrm{N}_{2}$, should serve to increase the absorption coefficient and hence, the radiation to the walls in the recycled flue gas case (Concept-B) relative to the Base Case.

- Higher specific heat of $\mathrm{CO}_{2}$ and $\mathrm{H}_{2} \mathrm{O}$ relative to $\mathrm{N}_{2}$. For an equivalent local heat release and heat transfer, the higher specific heat of carbon dioxide will serve to decrease the overall flame temperatures of the recycled flue gas mixture in the Concept-B case, relative to the baseline case. This would tend to compensate for the higher gas emissivity.

In preparation for the Concept B furnace performance analysis, a review of pertinent literature and CFD furnace analysis results developed for this project (Bozzuto, et al., 2001) were completed. Explanations for the observed trends must rely on physical property differences between nitrogen, which dominates in the Base Case, and carbon dioxide, which largely supplants nitrogen in Concept-B.

\section{Literature Review:}

The first step in the furnace analysis was to review applicable results obtained from the literature regarding combustion of coal in an environment where $\mathrm{CO}_{2}$ displaces the $\mathrm{N}_{2}$ in the combustion air. Several investigators (Thambimuthu, 1998; Kiga, et al., 1997; and Weller, et al., 1985) have found from pilot-scale testing that when coal is burned in $\mathrm{O}_{2} / \mathrm{CO}_{2}$ environment whereby $\mathrm{CO}_{2}$ displaces the $\mathrm{N}_{2}$ in the combustion air (i.e., in $~ 30 \% \mathrm{O}_{2} / 70 \% \mathrm{CO}_{2}$ mixture, by volume), the heat absorption in the lower furnace is not significantly impacted.

To illustrate this point, the results of re-analyses of Thambimuthu's (Thambimuthu, 1998) data concerning the combustion of a sub-bituminous coal sample from Western Canada are presented in Figure 10-4. As can be seen in this figure, the radiative heat fluxes into the lower furnace were, for the three cases studied (air, 28\% $\mathrm{O}_{2} / 72 \% \mathrm{CO}_{2}$, and $35 \% \mathrm{O}_{2} / 65 \%$ $\mathrm{CO}_{2}$ ), roughly similar at gas temperatures greater than $1275^{\circ} \mathrm{C}$. 


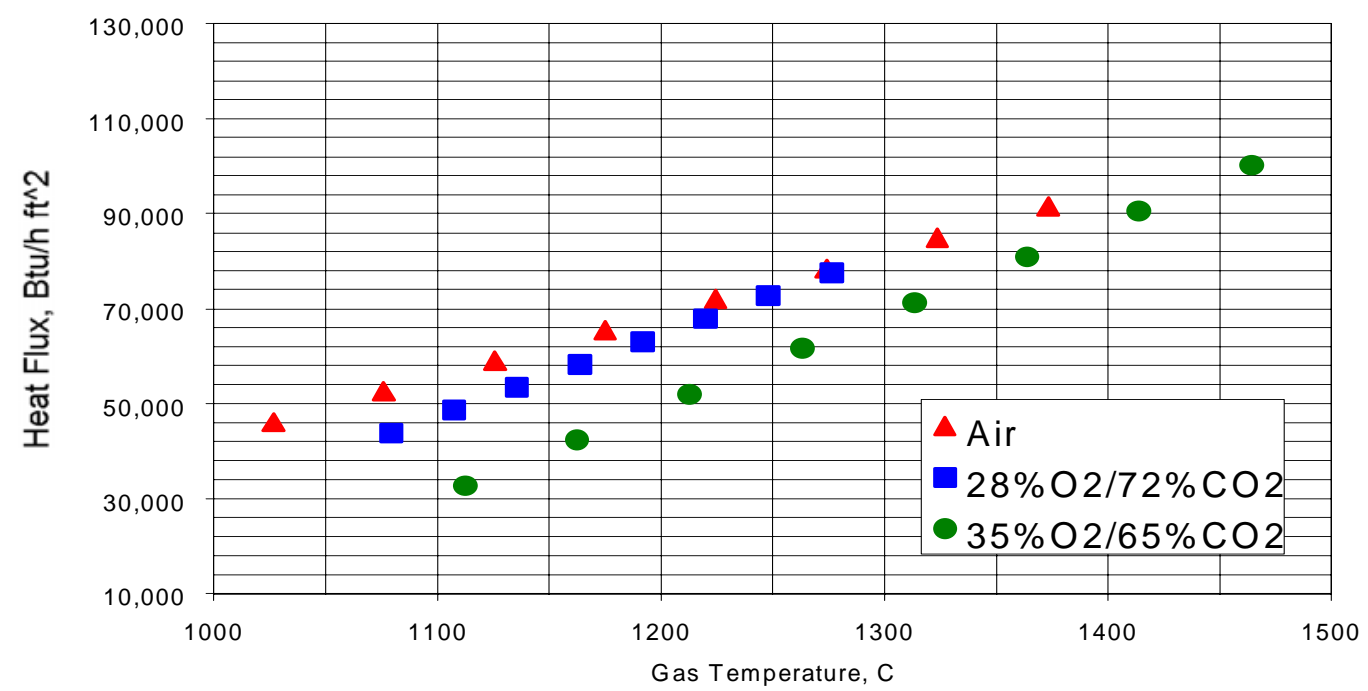

Figure 10-4: Variation of Radiative Heat Flux with Gas Temperature During Combustion in Air and $\mathrm{O}_{2} / \mathrm{CO}_{2}$ Mixtures (from Thambimuthu, 1998)

Results from a similar experiment, Chui, et al., (2001), were also investigated, in somewhat more detail, in order to assess the apparent overall change in gas emissive power that would occur in a furnace when switching from air-firing to a high $\mathrm{CO}_{2}-\mathrm{O}_{2}$ environment. The test facility, the same one used previously by Thambimuthu et al. (1998), is a pilot-scale, $0.3 \mathrm{MW}$ facility, and consists of a cylindrical, down-fired vertical combustor $(0.61 \mathrm{~m}$ I.D. and $6.7 \mathrm{~m}$ in length). The most relevant tests from the literature source are designated as Case-1 (baseline condition with air firing and a burner swirl setting of 11) and Case-2 (dry recycle with burner swirl setting of 10). The dry recycle case is representative of an oxygen fired case similar to Concept $\mathrm{B}$ with $28 \% \mathrm{O}_{2} / 72 \% \mathrm{CO}_{2}$ by volume. The principal conclusion of the work by Chui, et al., based on both experimental and simulated results, was that the dry recycle case demonstrated a distinct decrease in the incident radiant heat flux to the wall (by about $18 \%$ ) relative to the baseline case (Case-1).

The intent of the present re-analysis of this data was to utilize the incident heat flux measurements and measured centerline gas temperatures for the cases reported by Chui, et al., and then back-calculate the apparent gas emissivity for the furnace as a function of the longitudinal position. The desire was to verify whether the apparent emissivity differences between the baseline and dry recycle cases mirrored the known physical differences in radiative absorption properties between $\mathrm{N}_{2}$ and $\mathrm{CO}_{2}$ (corresponding to the baseline and dry recycle cases, respectively). The comparison of Case- 1 and Case-2, which have similar swirl settings (and thus similar flow patterns), should isolate the effects of gas emissive properties without introducing the strong effects of flow pattern changes as observed by Chui and reconfirmed by our analysis. Based on the incident heat flux measurements and the measured centerline gas temperatures, apparent gas emissivities for the furnace were calculated. These values are tabulated in Table 10-3 and plotted in Figure 10-5. 
Table 10-3: Apparent Combustor Gas Emissivities

\begin{tabular}{ccc}
\hline $\begin{array}{l}\text { Axial Distance } \\
\text { (m) }\end{array}$ & $\begin{array}{c}\text { Case-1 (Air } \\
\text { Firing) } \\
\text { Gas Emissivity }\end{array}$ & $\begin{array}{c}\text { Case-2 (Oxy- } \\
\text { Firing) } \\
\text { Gas Emissivity }\end{array}$ \\
\hline 0.95 & 0.685 & 0.782 \\
1.55 & 0.657 & 0.737 \\
2.15 & 0.611 & 0.796 \\
2.77 & 0.562 & 0.829 \\
3.40 & 0.532 & 0.766 \\
\hline
\end{tabular}

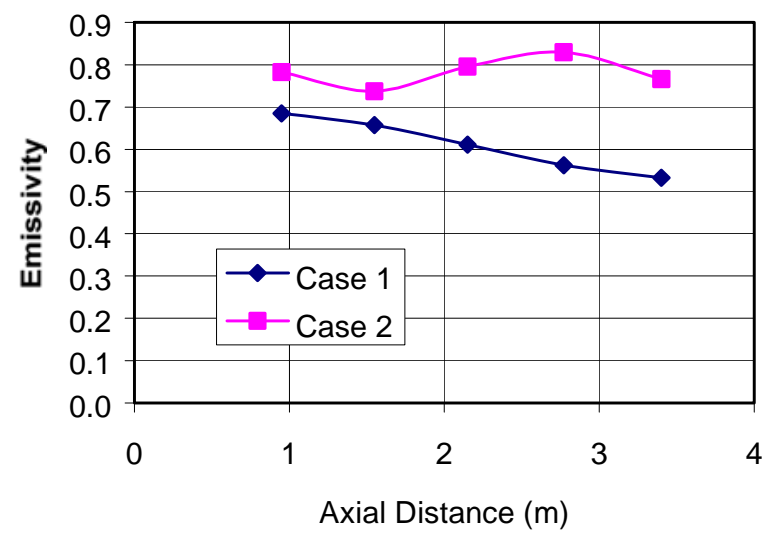

Figure 10-5: Apparent Combustor Gas Emissivities as a Function of Axial Distance

As shown in Figure 10-5, the apparent emissivity of the dry recycle case (Case-2) is higher than that of the baseline case (Case-1). Based on the substitution of the radiating gas $\mathrm{CO}_{2}$ for non-radiating nitrogen in the dry recycle case, the observed shift is what would be expected. It should be understood, however, that these results are only to be expected for cases with identical or similar flow patterns. The other test cases reported in Chui, et al. (2001) with swirl settings and corresponding aerodynamic and flame patterns that were different from those of Case-1 and Case-2, showed that such flow patterns have a dominant influence on the apparent gas radiative properties.

Another interesting aspect of the combustor results is the measured centerline gas temperature. Table 10-4 tabulates the corresponding temperatures measured in the Chui, et al. combustor, along with the Case- 1 to Case- 2 shift. The temperature shifts are plotted in Figure 10-6. The mean gas temperature shift, averaged over all measurement locations, is $214^{\circ} \mathrm{F}$. 
Table 10-4: Gas Temperature Profiles

\begin{tabular}{cccc}
\hline $\begin{array}{c}\text { Axial Distance } \\
(\mathrm{m})\end{array}$ & $\begin{array}{c}\text { Case-1 Centerline } \\
\text { Gas Temperature, } \\
{ }^{\circ} \mathrm{F}\end{array}$ & $\begin{array}{c}\text { Case-2 Centerline } \\
\text { Gas Temperature, } \\
{ }^{\circ} \mathrm{F}\end{array}$ & $\begin{array}{c}\text { Temperature Shift, } \\
{ }^{\circ} \mathrm{F} \\
\text { (Case 2 - Case 1) }\end{array}$ \\
\hline 0.95 & 2664 & 2419 & -245 \\
1.55 & 2552 & 2367 & -185 \\
2.15 & 2421 & 2215 & -205 \\
2.77 & 2284 & 2041 & -243 \\
3.40 & 2143 & 1953 & -191 \\
\hline
\end{tabular}

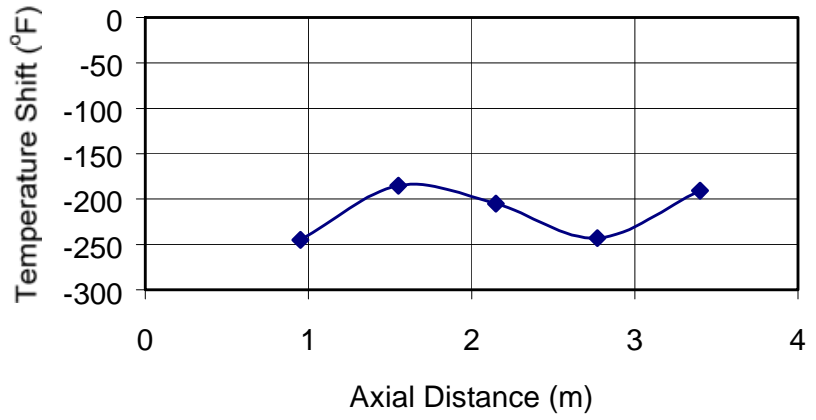

Figure 10-6: Centerline Gas Temperature Shift as a Function of Axial Distance (Case 2 - Case 1)

Calculations of adiabatic flame temperature $\left(\mathrm{T}_{\mathrm{ad}}\right)$ were performed for coal firing in AEP's Conesville Unit \#5 at maximum continuous rating (MCR). A number of scenarios were considered, namely: (1) Base Case (i.e., coal firing in air); (2) Constant Mass Case (i.e., the mass of nitrogen in air was replaced by the mass of $\mathrm{CO}_{2}$ in the flue gas recycle (FGR); and (3) Various $\mathrm{CO}_{2} / \mathrm{O}_{2}$ Mole Ratio Cases. Results (Figure 10-7) indicated that the $\mathrm{T}_{\text {ad }}$ for air firing was approximately $180{ }^{\circ} \mathrm{F}$ higher than for the Constant Mass Case. This difference is due to differences in specific heat (Cp) between $\mathrm{N}_{2}$ and $\mathrm{CO}_{2}$ (i.e., $\mathrm{CO}_{2} \mathrm{Cp}>\mathrm{N}_{2} \mathrm{Cp}$ at elevated temperatures, Figure 10-8). One implication is that the ultimate combustion efficiency difference between air firing and $\mathrm{O}_{2} / \mathrm{FGR}$ firing could be governed by opposing phenomena, i.e., potentially lower reaction rate, but longer residence time in $\mathrm{O}_{2} / \mathrm{FGR}$ than in air. Thermo-gravimetric analysis (TGA) and Drop Tube Furnace System-1 (DTFS-1) results -- obtained from combustion firing of both Conesville Unit \#5 and Pittsburgh Seam \#8 coals other (See Volume II Report of this work, Bozzuto, et al., 2001) -- indicate that these two phenomena indeed virtually cancel each other. 


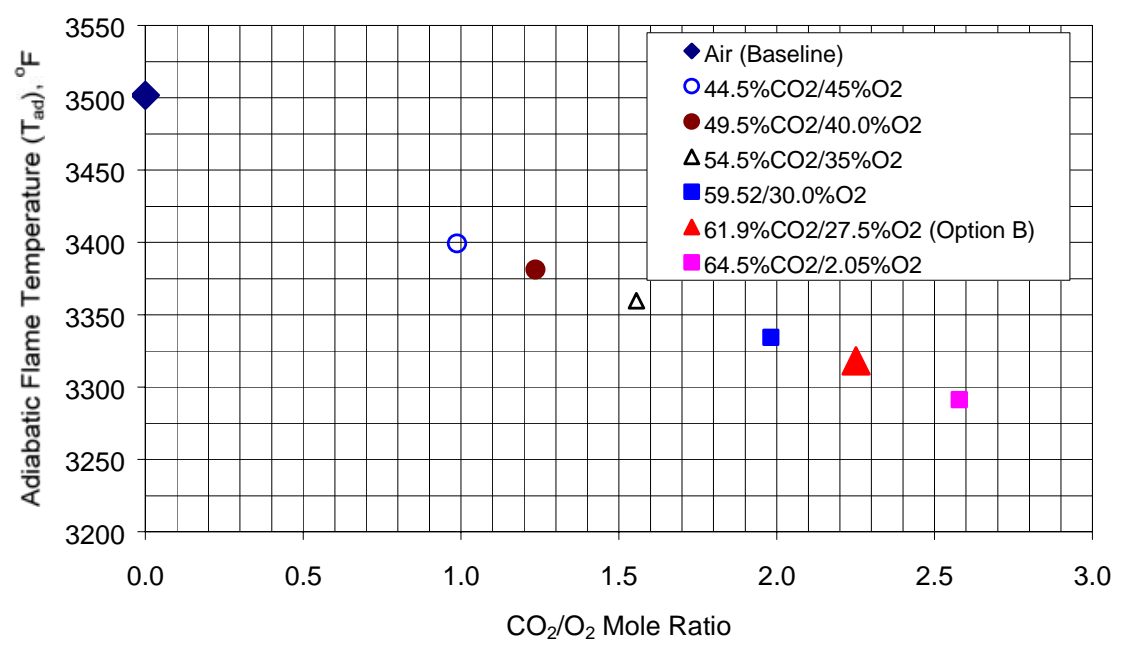

Figure 10-7:Calculated Adiabatic Flame Temperature as a Function of CO2/O2 Mole Ratio for Conesville Unit \#5

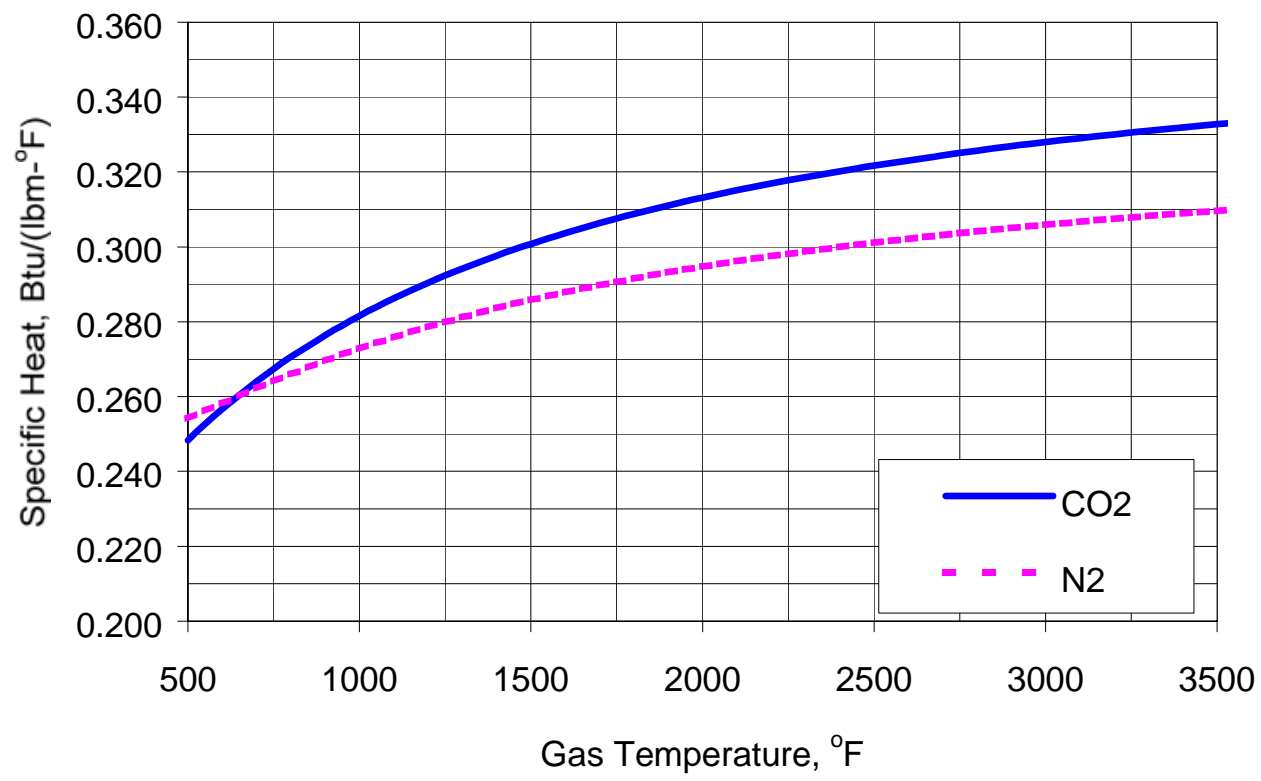

Figure 10-8: Specific Heats (Cp) of Nitrogen and Carbon Dioxide as a Function of Temperature

\section{CFD Furnace Model Results and Conclusions:}

Review of the CFD analysis results (Bozzuto, et al., 2001), which were developed for this project, indicated the following with respect to furnace heat transfer:

The baseline case (or Base Case) exhibits a slightly higher peak gas temperature (maximum difference of about $200^{\circ} \mathrm{F}$ ), and a correspondingly higher average (cross-sectional) gas temperature (difference of $90^{\circ} \mathrm{F}$ at the HFOT), than that of the Concept-B case. This result compares favorably with the approximate $-214^{\circ} \mathrm{F}$ shift found by Chui et al. Note, however, 
that this close correspondence may be somewhat fortuitous, particularly since the two furnaces are so different. Nevertheless, the correspondence may indicate that the baseline air case may be expected to exhibit consistently higher peak and averaged post-flame temperatures than an oxy-fired case (with similar flow and flame patterns).

The net wall absorption in the furnace region for the baseline case is larger (by less than 1\%) than that of the Concept-B case. Conversely, the net wall absorption for the baseline calculation with the proprietary in house Reheat Boiler Program (RHBP), as described below, was found to be about $6 \%$ lower than the Concept-B case calculated by the RHBP. The higher specific heat of the carbon dioxide, and the associated lower gas temperatures in the Concept-B case, will tend to offset somewhat or compensate for the expected increase in the wall absorption (i.e., anticipated due to the enhanced emissivity of the $\mathrm{CO}_{2}$.) Furthermore, the spatial distribution of the carbon dioxide across the cross-section may be important; it is hypothesized that high concentrations of $\mathrm{CO}_{2}$ in the cooler gas mixtures between the wall and the flame may actually act to inhibit the net radiative flux to the walls.

\section{Performance Model (RHBP) Results:}

The present study for Concept B involves coal combustion in a medium with $\sim 31 \% \mathrm{O}_{2} / 69 \%$ $\mathrm{CO}_{2}$ volume ratio. Heat transfer in the lower and upper furnace regions as calculated by the RHBP is compared in Figure 10-9. This figure compares heat fluxes (Btu/hr-ft2) in selected lower and upper furnace regions for air firing and oxygen firing. Lower furnace region results show firing zone heat flux to be about 11 percent higher with oxygen firing. Upper furnace region results show the reheat radiant wall is about 6 percent higher and the superheat division panels are about 13 percent higher with oxygen firing. Similarly, the upper furnace waterwall area is about 10 percent higher. The overall lower furnace heat absorption for Concept B was about 6\% higher than for the air fired Base Case. The horizontal furnace outlet temperature (HFOT) for Concept B was calculated to be $123{ }^{\circ} \mathrm{F}$ lower than for the Base Case.

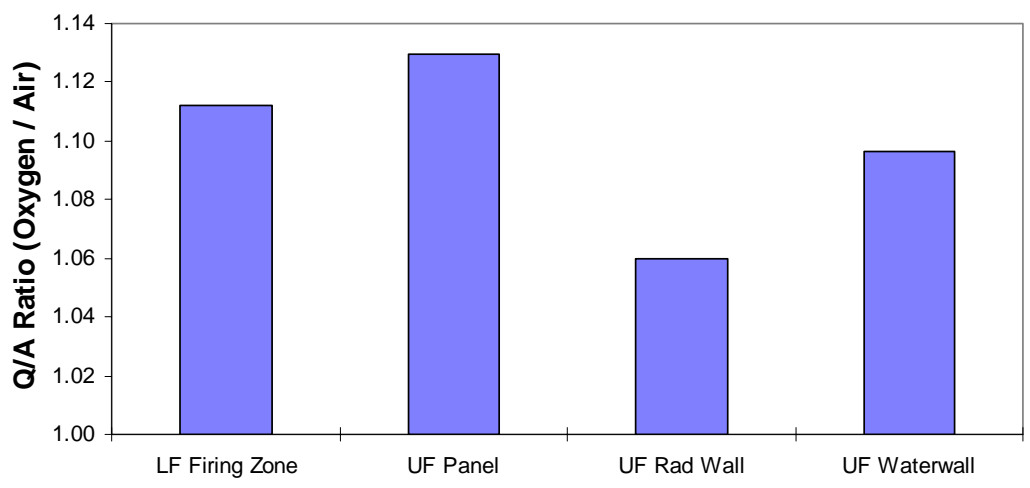

Figure 10-9: Furnace Region Heat Flux Comparison

The trend calculated by the CFD code, with respect to the furnace temperature at the HFOP, appears to be qualitatively aligned with the trend calculated by the in-house RHBP code. However, the difference in wall absorption for the Concept-B case relative to the baseline case, calculated by FLUENT (change of $-1 \%$ ), does not fully agree with the results of the RHBP (change of $+6 \%$ ). Computed and/or experimental trends that indicate that oxy-firing 
may induce either an increase in wall absorption or a decrease in wall absorption, relative to the baseline case, are supported in the literature. It is suggested that the absorptive properties of a local $\mathrm{CO}_{2}$-containing gas mixture in the vicinity of the wall may either act to enhance or inhibit the incident radiative flux to the wall, depending upon its relative spatial location and mixture temperature. For example, a low-temperature, $\mathrm{CO}_{2}$-rich mixture near the wall would absorb the radiative flux from the interior "fireball” region; a portion of the energy would be re-emitted at the lower gas temperature, and the remainder of the energy would be used to heat up the gas. The result would be a net reduction in the incident radiative flux to the wall. Conversely, a high-temperature, $\mathrm{CO}_{2}$-rich mixture near the wall would emit at its local gas temperature, thus enhancing the incident radiative flux to the wall. Therefore, it is suggested that the relative spatial relationships of the cool and hot gas mixtures, the relative composition of the absorbing media, and the proximity of that media to the wall (as induced by the furnace and firing system aerodynamics), may significantly impact the gas-phase irradiation to the wall. Indeed, the aerodynamic and flame patterns that prevail in a given airfired or oxy-fired furnace may conceivably have as strong an impact on the net wall absorption as the physical property differences themselves (gas-phase emissivity, specific heat, etc.)

The results of computational tools (such as CFD and the RHBP) should be viewed with some skepticism, particularly when they are asked to produce calculations outside of the experience base for which they have been validated. Certainly, the gas-phase and particlephase radiation property sub-models could be enhanced in both codes, and the impact of spatial gradients (caused by the interleaving of hot and cool regions of varying $\mathrm{CO}_{2}$ composition) on radiative wall flux needs to be investigated more fully. CFD computations have been utilized to gain a more in-depth qualitative understanding of aerodynamic and flame patterns in combustion systems, but have not yet been integrated into routine boiler design procedures. At the present time, the Alstom design standards are based upon the experience and expertise built into the RHBP and other design protocols, and those standards must be adhered to in any new design project in order to mitigate risk. Therefore, the results of the RHBP, as reported in this work, must be regarded as the current standard, both from an engineering experience viewpoint and from a rules-based design viewpoint. However, additional validation work needs to be done in order to confirm the trends for oxy-firing scenarios.

Although differences in physical properties of the transport gases (e.g., air-firing versus oxyfiring) may initially induce undesirable deviations from the performance goals of an existing field unit, the designer and engineer views such alterations as challenges rather than insurmountable obstacles. Much can be done in the way of operating condition optimization (e.g., spray, nozzle tilt, and amount of gas recirculation), without major modifications to the unit, to realign steam temperatures and wall absorption with their desired, target values. Design parameters are often in conflict, and the intelligent designer must work to balance various parameters and operating conditions to achieve the desired outcome. The CFD work performed here was based on certain constraints to maintain equivalency for comparison purposes, which would not necessarily be the case in the field. For example, a potential decrease in furnace wall absorption of several percentage points could be nullified through manipulation of the various operating parameters available. 


\subsubsection{Convection Pass Analysis}

Figure 10-10, Figure 10-11 and Figure 10-12 show the comparison of convective, nonluminous, and total heat transfer rates between air firing and oxygen firing for all the major sections contained in the existing convection pass of the unit at full load operating conditions as calculated by the RHBP.

Convective heat transfer in utility steam generator units is dependent upon many of the transport properties of the flue gas (viscosity, thermal conductivity, density, specific heat and others). Additionally, convection depends strongly on gas velocity. With the Concept B system there are significant changes in the flue gas analysis as compared with air firing. These gas analysis changes cause both transport property and gas velocity changes throughout the unit. The resulting convective heat transfer rates, as shown in Figure 10-10, ranged from about 80 to 105 percent as compared to air firing.

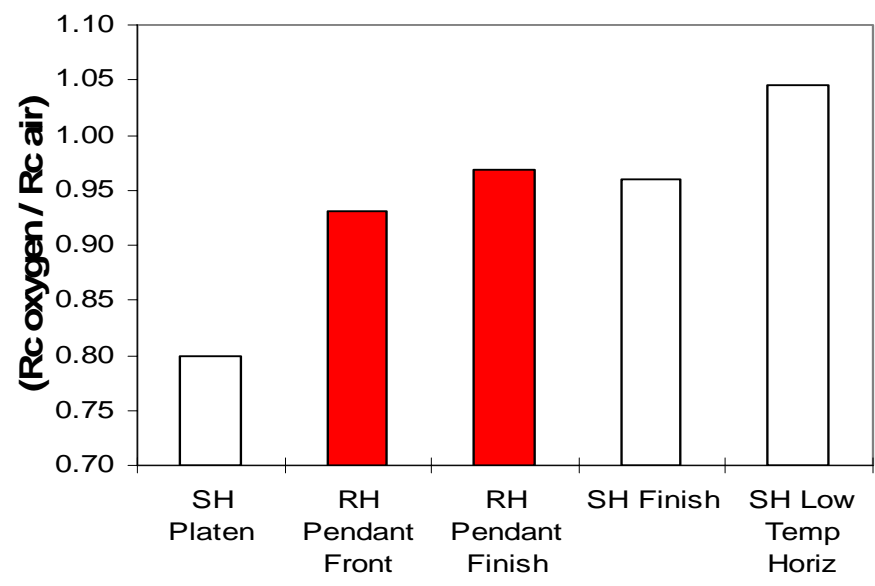

Figure 10-10: Convective Heat Transfer Rate Comparison

Significant differences in non-luminous radiant heat transfer are also expected. Of the gases produced by the complete combustion of a fuel, only carbon dioxide, water vapor and sulfur dioxide emit radiation over a sufficiently wide band of wavelengths to warrant consideration. With this system the primary change in the flue gas as compared to air firing is the large increase in the $\mathrm{CO}_{2}$ content and decrease in $\mathrm{N}_{2}$ content. The resulting enhancement in nonluminous heat transfer rates range from about 26 to 28 percent greater than air firing as shown in Figure 10-11. 


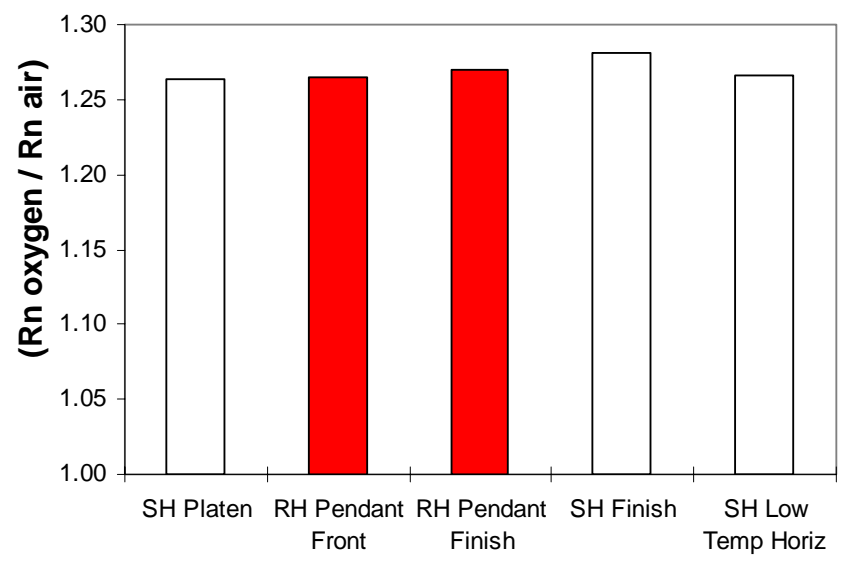

Figure 10-11: Non-luminous Heat Transfer Rate Comparison

Ultimately the convection pass total heat transfer rates, shown in Figure 10-12, were increased in the range of 1 to 8 percent over the values with air firing.

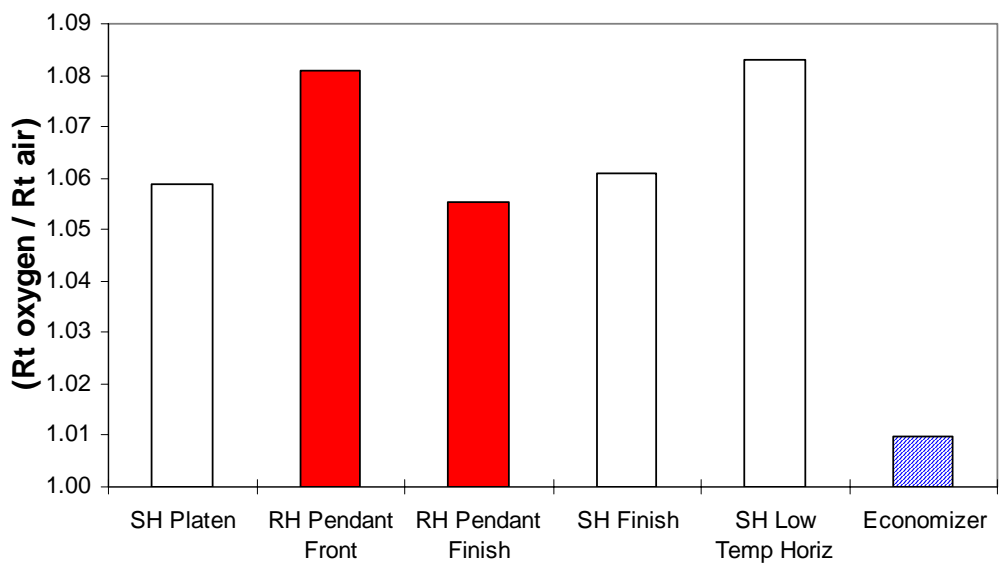

Figure 10-12: Total Heat Transfer Rate Comparison

Steam temperature control was achieved through the use of burner tilt and reheat spray. The performance analysis results indicated the reheater circuit required about 1.45 percent spray to maintain the reheat outlet temperature at the design value. The superheater circuit required about 0.34 percent spray to maintain the superheat outlet temperature at the design value. The burner tilt was set at -10 degrees, the minimum value the customer uses. The overall steam conditions produced are shown in Table 10-5 below. Furthermore, with this recycle gas system, flue gas recirculation is also available as an additional steam temperature control variable. In this study however, we did not utilize this as an additional steam temperature control variable. We decided, as a first approximation, to set the flue gas 
recirculation rate at a value such that the flue gas flow to coal flow ratio was the same as with air firing. As it turned out, this was an acceptable setting for the gas recirculation rate.

Table 10-5: Boiler/Turbine Steam Flows and Conditions for Concept B

\begin{tabular}{|c|c|c|c|c|c|}
\hline & SHO & FWI & ECO & RHO & RHI \\
\hline Flow (Ibm/hr) & 3131619 & 3131619 & 3131619 & 2808511 & 2808511 \\
\hline Pressure (psia) & 2535 & 3165 & 3070 & 590.8 & 656.5 \\
\hline Temperature (F) & 1000 & 493 & 622 & 1000 & 631 \\
\hline Enthalpy (Btu/lbm) & 1456.3 & 479.2 & 640.8 & 1517.6 & 1305.6 \\
\hline \multicolumn{5}{|c|}{ Qmain steam $\left(10^{6} \mathrm{Btu} / \mathrm{hr}\right)$} & 3059.9 \\
\hline \multicolumn{4}{|r|}{ Qreheat } & $\left(10^{\circ} \mathrm{Btu} / \mathrm{hr}\right)$ & 595.4 \\
\hline \multicolumn{4}{|r|}{ Q Total s/w } & $\left(10^{6} \mathrm{Btu} / \mathrm{hr}\right)$ & 3655.3 \\
\hline
\end{tabular}

With the increased heat transfer rates with oxygen firing and similar steam temperature profiles, there was concern regarding metal temperatures throughout the unit. A detailed analysis using the Metal Temperature Program (MTP) was however, beyond the scope of this study. The MTP, using thermal inputs from the RHBP, calculates steam and metal temperatures at any selected point along the length of the tube. All tubes of each heat exchanger bank are modeled. A very brief review of metal temperatures at only a few selected points was done in this study. In general, for the points investigated, the metal temperatures were found to be the same or slightly lower than with air firing. The primary reason for this result was that although the heat transfer rates were slightly higher and the steam temperature profile was similar, the gas temperatures were lower. This combination yields similar heat flux conditions and ultimately similar metal temperatures.

\subsubsection{Boiler System Modifications}

Listed below are the basic modifications required for the Conesville \#.5 unit to support firing with oxygen as required in Concept $\mathrm{B}$.

\subsubsection{Boiler}

The Boiler Island should be inspected for potential air leaks into the system and should be sealed to minimize any infiltration. Special attention should be given to all penetrations including seal boxes for convective surfaces, sootblowers, wall blowers, expansion joints, ductwork, fuel piping, fans and windbox.

\subsubsection{Ducts and Dampers and Fans}

Refer to the Duct and Damper Diagram (Figure 10-13) shown below for the required duct arrangement and associated cross-sectional areas for this system. New flue gas ductwork is required for the Oxygen Heater. Part of the existing ductwork from the Air Heater flue gas exit to the Electrostatic Precipitator inlet must be removed and replaced with new ductwork that accommodates the new Oxygen Heater. Additionally, oxygen supply ductwork from the ASU to the Oxygen Heater is required and hot oxygen supply ductwork from the Oxygen Heater to the existing secondary "air" duct must be provided. Similarly, New flue gas 
ductwork is required for the Parallel Feedwater Heater. Part of the existing ductwork from the Induced Draft fan outlet to the Scrubber inlet must be removed and replaced with new ductwork that accommodates the new Parallel Feedwater Heater. New ductwork and dampers are also required for the recycle flue gas streams that feed the existing Forced Draft and Primary Air fans.

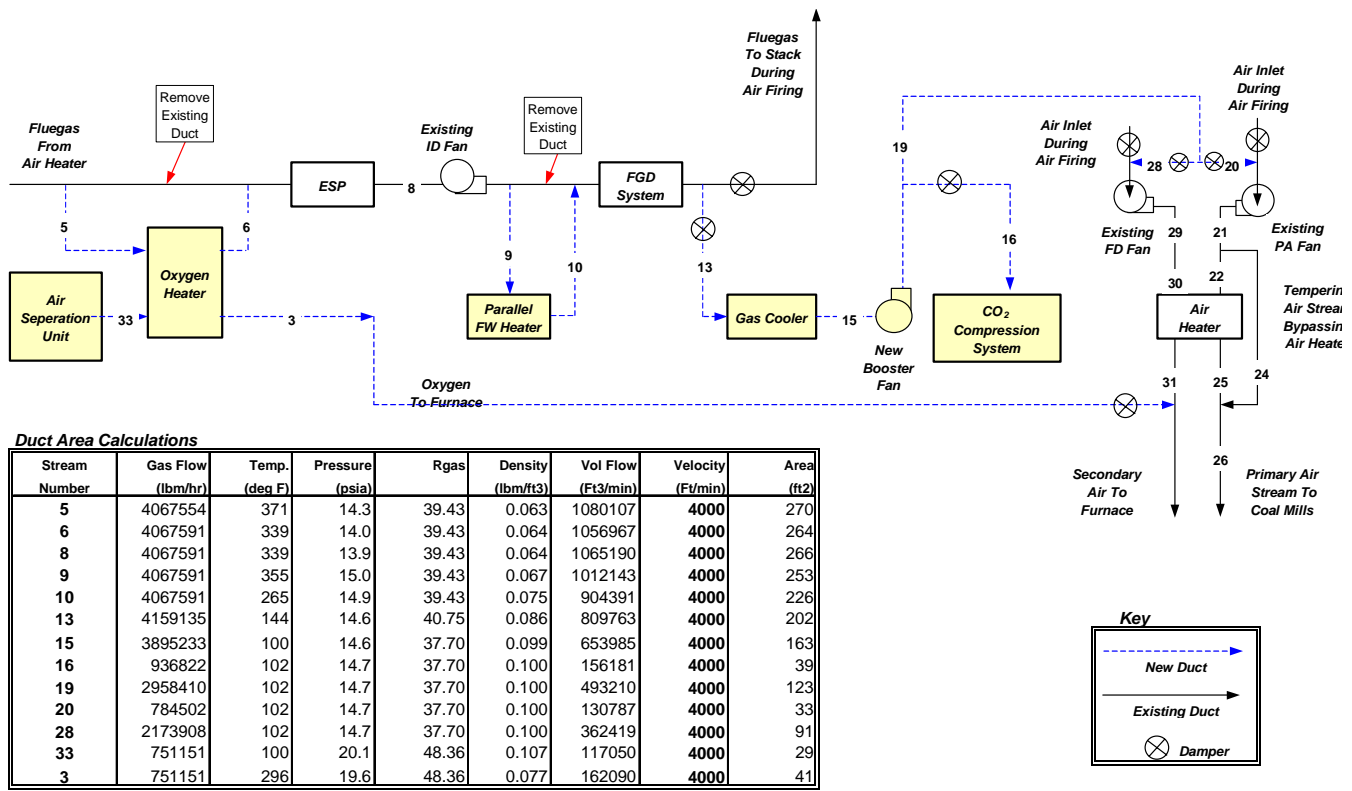

Figure 10-13: Duct and Damper Diagram for Concept B

A new booster fan will be required as a minimum. The booster fan is required to overcome the added draft loss of the various new heat exchanger components shown in Figure 10-1 previously. Specifications for the booster fan are shown in Table 10-6 below. The existing Induced Draft, Forced Draft and Primary Air fans should eventually be checked with the suppliers to see if they can handle the new conditions (Note: The molecular weight is now 37.7 for the FD and PA fans and 39.4 for the ID fan). For this study we have assumed that both fans are acceptable.

Table 10-6: Booster Fan Specification

\begin{tabular}{|c|c|c|}
\hline \multicolumn{3}{|c|}{ Booster Fan specification } \\
\hline \multicolumn{3}{|l|}{ Gas Analysis } \\
\hline Oxygen & (wt percent & 2.63 \\
\hline Nitrogen & $"$ & 3.97 \\
\hline W ater $V$ apor & $"$ & 2.87 \\
\hline Carbon Dioxide & $"$ & 90.51 \\
\hline Sulfur Dioxide & $"$ & 0.03 \\
\hline Total & $"$ & 100.00 \\
\hline Mass Flow Rate & $(\mathrm{lb} \mathrm{m} / \mathrm{hr})$ & 3895233 \\
\hline G as Inlet Temp & $=(D$ eg $F)$ & 100.0 \\
\hline Inlet Pressure & $(p s i a)$ & 14.56 \\
\hline O utlet Pressure & (psia) & 14.70 \\
\hline Pressure $R$ ise & (in $w g$ ) & 4.00 \\
\hline
\end{tabular}




\subsubsection{Oxygen Heater}

The flue gas exiting the Air Heater is at $371^{\circ} \mathrm{F}$. A large quantity of sensible heat is still available in this gas stream. The Oxygen heater is used to recover additional sensible heat in the flue gas as a result of reduced air heater performance with oxygen firing. This heat is partially recovered in the Oxygen Heater where cold O2 from the Air Separation Unit is preheated before being mixed with the gas recirculation stream prior to furnace injection. Part of the existing ductwork connecting the existing Air Heater flue gas exit stream to the Precipitator inlet is removed. New ductwork, which accommodates the addition of the new Oxygen Heater, is installed. Performance requirements and gas analyses for the Oxygen Heater are shown in Table 10-7. Table 10-8 shows the Oxygen Heater specifications. It should be noted that the flue gas stream, which provides the heat source for this heat exchanger, contains flyash, as the Oxygen Heater is located between the Air Heater and the Electrostatic Precipitator (ESP). A simple sketch of the oxygen heater, which is similar in design to a tubular air heater, is shown in Figure 10-14. Refer to Appendix I Concept B Boiler modification drawings for the proposed arrangement of this equipment.

Table 10-7: Oxygen Heater Performance Requirements and Gas Analysis

\begin{tabular}{|c|c|c|c|c|c|c|}
\hline \multicolumn{3}{|c|}{ Oxygen Heater Performance Requirements } & \multicolumn{2}{|c|}{ Gas Analysis } & \multirow{2}{*}{$\begin{array}{r}\text { Oxygen } \\
\text { Stream }\end{array}$} & \multirow{2}{*}{$\begin{array}{r}\text { Fluegas } \\
\text { Stream }\end{array}$} \\
\hline \multicolumn{3}{|c|}{ (units) } & Constituant & (units) & & \\
\hline Flue Gas Mass Flow & (lbm/hr) & 4067591 & $\mathrm{O}_{2}$ & (Wt Frac) & 0.9900 & 0.0252 \\
\hline Flue Gas Inlet Temperature & $(\operatorname{deg} F)$ & 371 & $\mathrm{~N}_{2}$ & " & 0.0100 & 0.0380 \\
\hline Flue Gas Outlet Temperature & $(\operatorname{deg} F)$ & 339 & $\mathrm{H}_{2} \mathrm{O}$ & $"$ & & 0.0647 \\
\hline Oxygen Mass Flow & (Ibm/hr) & 751151 & $\mathrm{CO}_{2}$ & $"$ & & 0.8670 \\
\hline Oxygen Inlet Temperature & $(\operatorname{deg} F)$ & 100 & $\mathrm{SO}_{2}$ & $"$ & & 0.0051 \\
\hline Oxygen Outlet Temperature & $(\operatorname{deg} F)$ & 296 & Total & & 1.0000 & 1.0000 \\
\hline $\begin{array}{l}\text { Oxygen Heater Heat Transfer } \\
\text { Oxygen Pressure }\end{array}$ & $\begin{array}{l}\left(10^{6} \mathrm{Btu} / \mathrm{hr}\right) \\
(\text { psia })\end{array}$ & $\begin{array}{r}33.062 \\
20\end{array}$ & & & & \\
\hline Flue Gas Pressure & (psia) & 14.281 & & & & \\
\hline
\end{tabular}


Table 10-8: Oxygen Heater Specifications

\begin{tabular}{|llr|}
\hline \multicolumn{2}{l}{ Oxygen Heater Specification } \\
\hline \hline Duct Height & $\mathrm{ft}$ & 20 \\
Duct Width & (ft) & 44.33 \\
Tube Outside Diameter & (Inches) \\
Tube Spacings St and SI & (Inches) & 2 \\
Tubing Thickness & (inches) \\
Number of tubes wide & (no.) & 3 \\
Number of tubes deep & (no.) & 177 \\
Height of tubes & (ft) & 19 \\
Total Number of Tubes & (no.) \\
Total Lineal length of tubinc (ft) & 20 \\
Tubing Outside Surface & (ft2) & 3363 \\
Total Weight of tubing & (tons) \\
Tubing type & & 35217 \\
Tubing Material & & 61.0 \\
\hline \hline
\end{tabular}

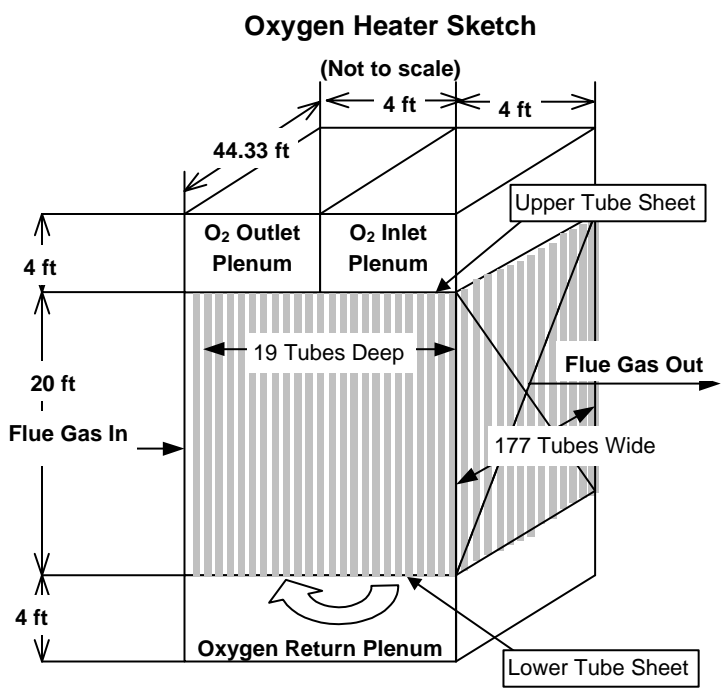

Figure 10-14: Oxygen Heater Sketch

\subsubsection{Parallel Low Pressure Feedwater Heater}

A parallel low-pressure feedwater heater (PFWH) is facilitated to remove remaining useful sensible heat in the flue gas. This heater is installed in a parallel feedwater stream with the existing extraction low-pressure feedwater heaters number 52 and 53. The heat source for the PFWH is flue gas leaving the ID fan as shown on the system diagram (Figure 10-1). In actuality, there are two ID fans on this unit and therefore two PFWH's are used. The flue gas temperature leaving the induced draft fans is $355 \mathrm{~F}$. The PFWH cools the flue gases down to $265 \mathrm{~F}$ by heating feedwater in a parallel stream with the feedwater being heated in the extraction feedwater heaters No. 52 and 53 as shown in Figure 10-15. About 29 percent of the total low-pressure feedwater flow leaving the No. 51 low-pressure feedwater heater is heated in the new PFWH. This heat exchanger is essentially a low temperature economizer section that is designed similar to Heat Recovery Steam Generator (HRSG) tube banks with finned tubing. The fin pitch can be quite high (6 fins/inch) since the flue gas at this point is particulate free.

These new components recover about 26,458 kW [90.3 x $106 \mathrm{Btu} / \mathrm{hr}]$. This causes the steam extractions to heaters No. 52 and No. 53 to be reduced proportionally and the steam flow through the low-pressure section of the existing steam turbine to be increased by approximately two percent. This increases the generator output proportionally. Performance requirements and specifications for the PFWH are shown in Table 10-9 and Table 10-10. Figure 10-16 shows a simple sketch of the new component. Refer to Appendix I Concept B Boiler modification drawings for the proposed arrangement of this equipment. 


\section{Table 10-9: Parallel Feedwater Heater Performance Requirements}
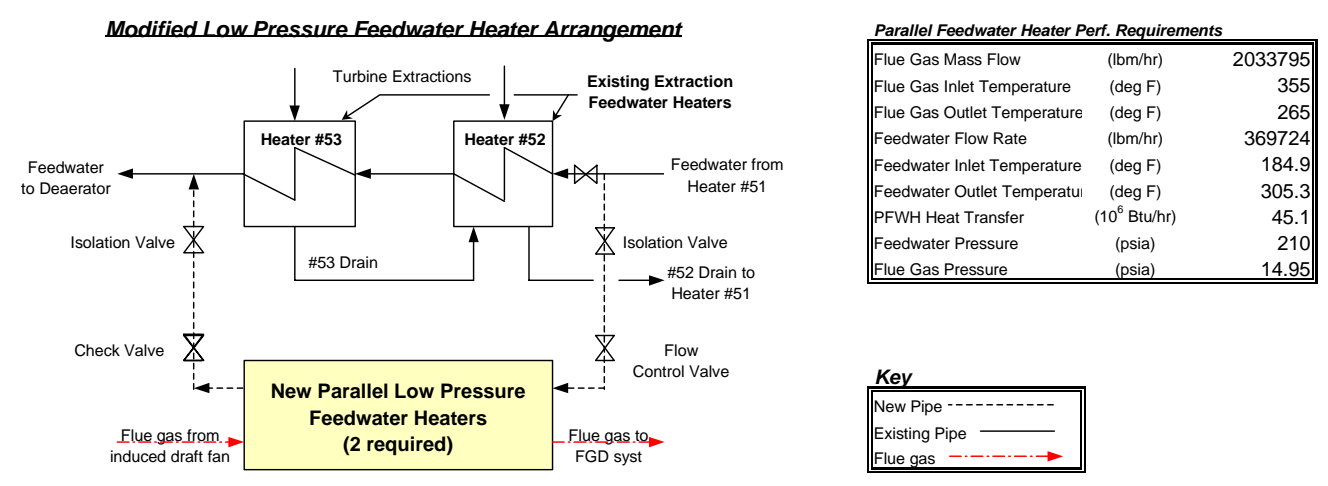

Figure 10-15: Parallel Feedwater Heater Arrangement

Table 10-10: Parallel Feedwater Heater Specification

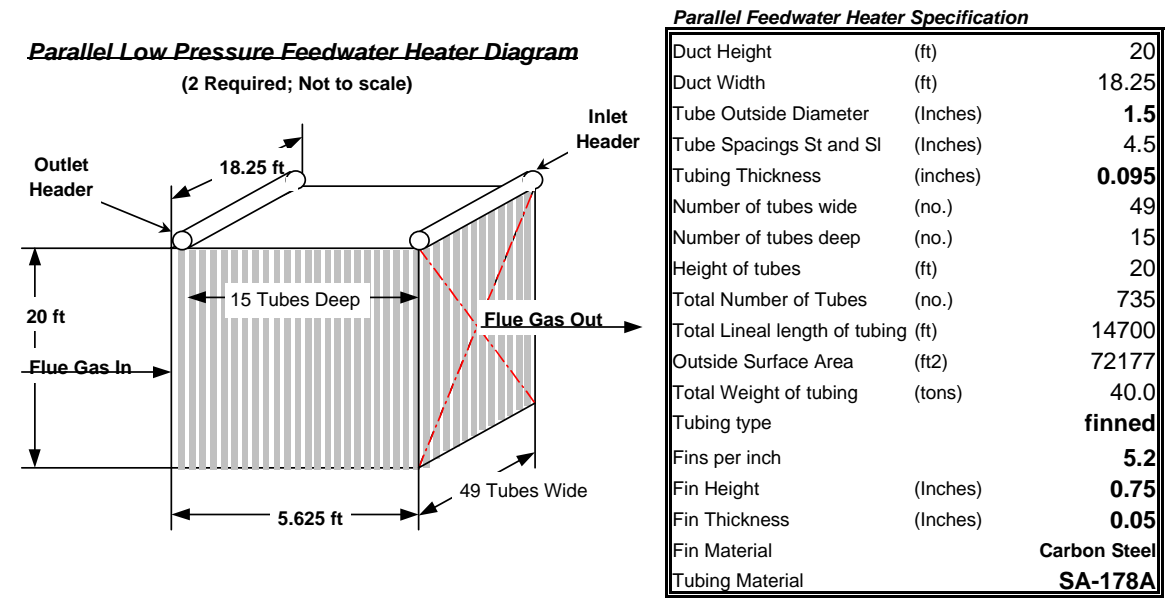

Figure 10-16: Parallel Feedwater Heater Sketch

Table 10-11 shows the specifications for the PFWH headers and piping. The piping runs from the feedwater pipe entering existing feedwater heater \#52 to the two PFWH unit inlet headers and returns from the to PFWH outlet headers to the feedwater pipe leaving existing feedwater heater \#53.

Table 10-11: Parallel Feedwater Heater Header and Piping Specifications

\begin{tabular}{|l|r|r|r|r|r|r|}
\hline & Outside Dia. & Nominal ID & Material & Weight & Length & Connections \\
\cline { 2 - 7 } & (inches) & (inches) & & $(\mathrm{lbm} / \mathrm{ft})$ & $(\mathrm{ft})$ & (number) \\
\hline Headers & 8.625 & 6.251 & SA-106C & 53.41 & 18.25 & $49-1.5^{\prime \prime} ; 1-6.625^{\prime \prime}$ \\
\hline Piping & 6.625 & SCH 120 & ASA B36.1 & 36.3 & 375 ea. 2 reqd & \\
\hline
\end{tabular}


10.1.4.5 Controls and Instrumentation:

Additional controls and instrumentation will be required for the new components and systems described. The transition between air firing and oxygen firing needs careful consideration.

\subsubsection{Modified Boiler Drawings}

Drawings of the modified boiler showing the existing and new equipment are listed below and contained in Appendix I.

- U00-E-0551R General Arrangement - Side Elevation for Concept B

- U00-E-0552R General Arrangement - Plan View "B-B" for Concept B

- U00-E-0585R General Arrangement - Plan View "A-A" for Concept B

\subsubsection{Steam Cycle System}

The steam cycle system for Concept B is modified slightly with the addition of a lowpressure feedwater heater arrangement in parallel with extraction feedwater heaters \# 52 and 53 as described in Section 10.1.4.4. The parallel feedwater heaters are used to recover additional sensible heat in the flue gas as a result of reduced air heater performance with oxygen firing. The modified steam cycle is shown in Figure 10-17. The associated Mollier diagram showing the modified steam cycle on enthalpy vs. entropy coordinates is shown in Figure 10-18. The modified steam cycle system produces 463,056 kWe with a steam turbine heat rate of $8,089 \mathrm{Btu} / \mathrm{kWhr}$.

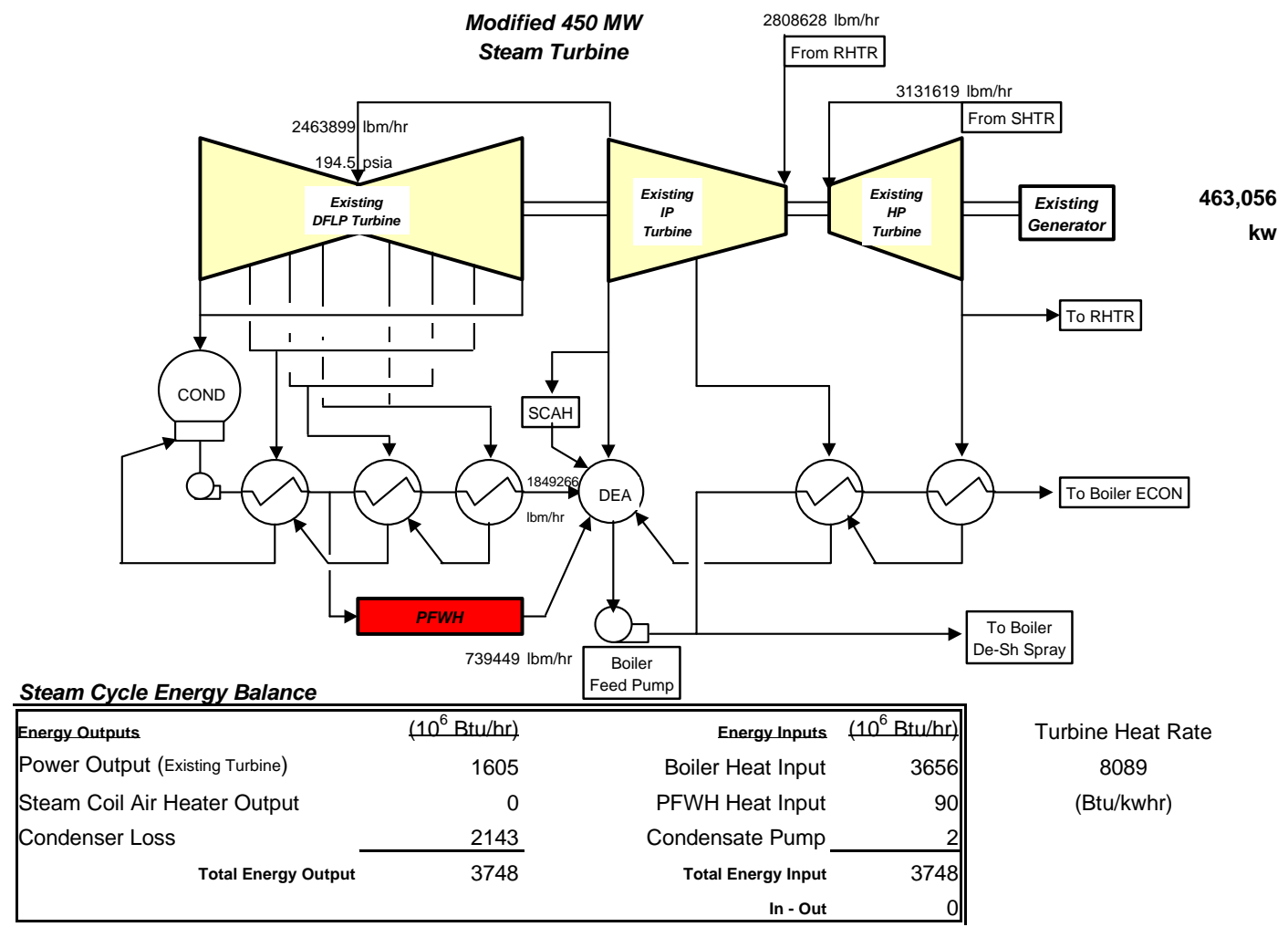


Figure 10-17: Modified Steam Cycle Diagram and Performance for Concept B

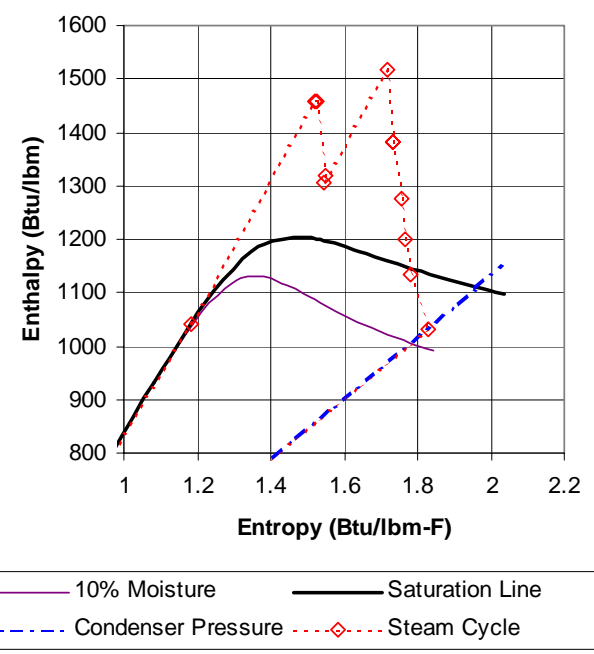

Figure 10-18: Modified Steam Cycle Mollier Diagram for Concept B

10.1.6 Flue Gas Desulfurization and Electrostatic Precipitator Systems Performance Issues

Because the flue gas for Concept B was significantly different in composition from the Base Case due to combustion with oxygen as opposed to air, analysis of the Flue Gas Desulfurization System (FGD) system and the Electrostatic Precipitator (ESP) system performance with these new conditions was investigated. The most noticeable differences regarding the flue gas composition for this case is that it contains significantly more $\mathrm{CO}_{2}$ and less $\mathrm{N}_{2}$ than with air firing. The overall mass flow rates for both cases are nearly identical. The effects of operating the Flue Gas Desulfurization System and the ESP with the high $\mathrm{CO}_{2}$ content flue gas of Concept B are discussed in this section.

\subsubsection{Flue Gas Desulfurization System Performance Issues}

Table 10-12 identifies the assumptions that were made in predicting the FGD system performance. Table 10-13 shows the gas constituents at the existing Absorber inlet and outlet locations. It should be noted that the $\mathrm{CO}_{2} / \mathrm{SO}_{2}$ mole ratio is 199 , as opposed to the value of 63 encountered previously for the Base Case and Concept A (refer to Section 3.2.4 of Bozzuto et al., 2001). Hence, it was necessary to assess the impact of high $\mathrm{CO}_{2}$ content in the flue gas on the performance of FGD System. It is important to note that $\mathrm{SO}_{2}$ forms a much stronger acid than $\mathrm{CO}_{2}$ (with a dissociation constant of 7.8E-3 vs. 5.2E-7). Additionally, $\mathrm{SO}_{2}$ is about 35 times more soluble in water than $\mathrm{CO}_{2}$. The absorbed $\mathrm{SO}_{2}$ will drop the $\mathrm{pH}$ of the scrubbing solution to about 4.5. At this level, the $\mathrm{CO}_{2}$ is basically insoluble in water. Alstom Power's Environmental Systems group predicted that, under these circumstances, the flue gas desulfurization systems $\mathrm{SO}_{2}$ capture efficiency would decrease by approximately $2 \%$. 
Table 10-12: FGD System Assumptions

\begin{tabular}{|l|c|c|}
\hline \multicolumn{3}{|c|}{ Concept $\mathrm{B}\left(\mathrm{O}_{2}\right.$ Fired $)$} \\
\hline Quantity & Unit & Existing Absorber \\
\hline $\mathrm{Ca} / \mathrm{S})$ & & \\
\hline $\mathrm{Solids}$ & Mol Ratio & 1.04 \\
\hline $\mathrm{CaO}$ & $\mathrm{Wt} \% \%$ & 20 \\
\hline $\mathrm{MgO}$ & $\mathrm{Wt} \% \%$ & 90 \\
\hline Inerts & $\mathrm{Wt} . \%$ & 5 \\
\hline By-pass Leakage & $\mathrm{Wt} . \%$ & 5 \\
\hline Liquid/Gas (L/G) Ratio & $\mathrm{Wt} \% \%$ & 2.5 \\
\hline $\mathrm{SO}_{2}$ Removal Efficiency & & 55 \\
\hline APC & $\%$ & \\
\hline Absorber & $\%$ & 94.9 \\
\hline
\end{tabular}

Table 10-13: FGD System Performance

\begin{tabular}{|c|c|c|c|c|c|c|}
\hline \multirow[b]{3}{*}{ Species } & \multicolumn{6}{|c|}{ Concept B $\left(\mathrm{O}_{2}\right.$ Fired $)$} \\
\hline & \multicolumn{3}{|c|}{ Existing Absorber Inlet } & \multicolumn{3}{|c|}{ Existing Absorber Outlet } \\
\hline & $\mathrm{Mol} / \mathrm{hr}$ & Vol.\% & Unit & $\mathrm{Mol} / \mathrm{hr}$ & Vol.\% & Unit \\
\hline $\mathrm{O}_{2}$ & 3,200 & 3.09 & Vol.\% & 3,190 & 2.87 & Vol.\% \\
\hline $\mathrm{N}_{2}$ & 5,467 & 5.27 & Vol.\% & 5,467 & 4.92 & Vol.\% \\
\hline $\mathrm{H}_{2} \mathrm{O}$ & 14,570 & 14.05 & Vol.\% & 22,400 & 20.16 & Vol.\% \\
\hline $\mathrm{CO}_{2}$ & 80,031 & 77.20 & Vol.\% & 80,021 & 72.03 & Vol.\% \\
\hline $\mathrm{SO}_{2}$ & 403 & 3,887 & vppm & 21 & 189 & vppm \\
\hline $\mathrm{SO}_{2}$ Removal Efficiency, \% & & & & & 94.8 & \\
\hline $\mathrm{CO}_{2} / \mathrm{SO}_{2}$ Mole Ratio & & 199 & & & & \\
\hline & & & & & & \\
\hline
\end{tabular}

\subsubsection{Electrostatic Precipitator (ESP) System Performance Issues}

The effects of operating the Electrostatic Precipitator (ESP) in the high $\mathrm{CO}_{2}$ content flue gas environment of Concept $\mathrm{B}$ are discussed in this section.

The electrostatic precipitation process can be characterized as four stages.

- Corona generation and flue gas ionization

- Particle charging resulting from ionization

- Migration of particles under the influence of the electric field

- Removal of particle cake from collecting electrodes 


\section{Background From White, J. “Industrial Electrostatic Precipitation” (1962):}

Corona discharge is vital to the electrical separation of particles from the gas stream. The dominant ion production mechanism in the corona is ionization by electron impact, in which free electrons in the gas acquire energy from an applied electric field and collide violently with gas molecules, literally knocking electrons out of the molecules. The net result is free electrons and positively charged gas ions.

The unipolar corona, used in electrical precipitation, is a stable, self-maintaining gas discharge between an emitting electrode and a receiving electrode. The ionization processes are confined to or near the glow region in the strong electric field adjacent to the emitting electrode. Most of the ionization is produced by free electrons that are accelerated to fairly high energies in this region and ionize by collision with molecules.

With negative corona free electrons from the ionization zone, upon entering the low-field region of the corona, combine with molecules of the gas to form negative ions. The ability to form negative ions is a fundamental property of the molecular species. Some gases such as nitrogen, hydrogen, helium, neon and argon, if sufficiently pure, have no affinity for electrons and hence do not form negative ions. Negative corona does not occur in these gases. Instead, when the voltage is raised to a point that would correspond to the corona onset point, spark over occurs. On the other hand, oxygen, chlorine, sulfur dioxide, and many other gases do have strong electron affinities, and, as would be expected, they produce highly stable negative coronas. Negative corona is possible only in gases, or mixtures of gases, that exhibit appreciable electron attachment. Consequently negative corona characteristics are highly sensitive to gas composition and can range from no corona to highly stable corona.

Fortunately practically all industrial furnaces, boilers and process gases as well as air contain electro-negative gases such as oxygen, water vapor, carbon dioxide and frequently sulfur dioxide. Electron attachment is the process by which electrons combine with neutral molecules to form negative ions. The probability of attachment varies greatly with the gas composition. It is zero for gases such as nitrogen and hydrogen, very small for ammonia, and relatively high for chlorine.

Theory and experiment show that the molecular composition of the gas profoundly influences its negative-corona characteristics (Please refer to Figure 10-19, Figure 10-20 and Figure 10-21 below, extracted from White, 1962). The general conclusion is that gases such as nitrogen that in the pure state have zero electron affinity, are incapable of supporting negative corona, and gases of the $\mathrm{CO}_{2}$ type that have moderate electron affinity do have considerable negative corona, and gases of the $\mathrm{SO}_{2}$ type have a very wide range of negative corona. 


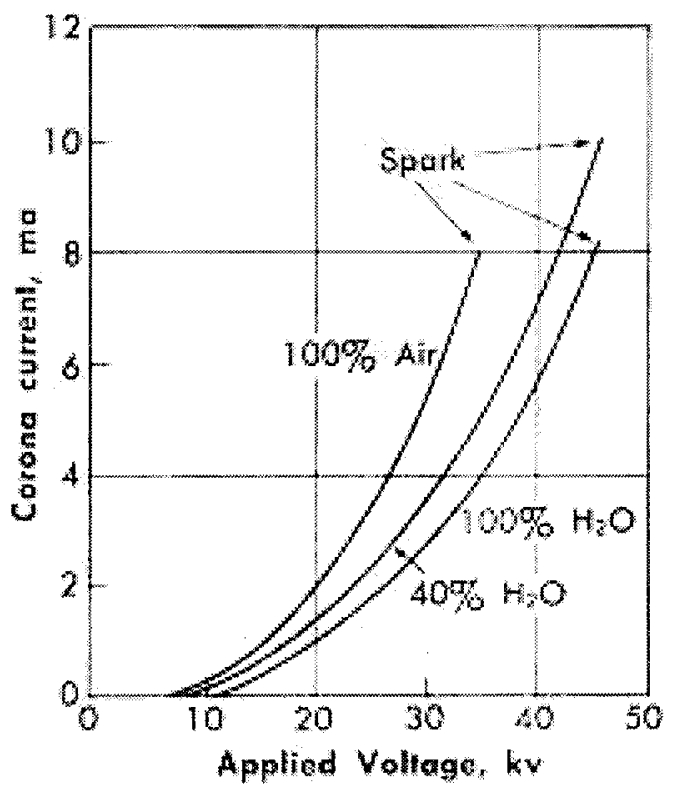

Figure 10-19: Negative Corona Curves for Air-water Vapor Mixtures at 400F; Atmospheric Pressure; 3-in. Tube; 0.010-in. Wire

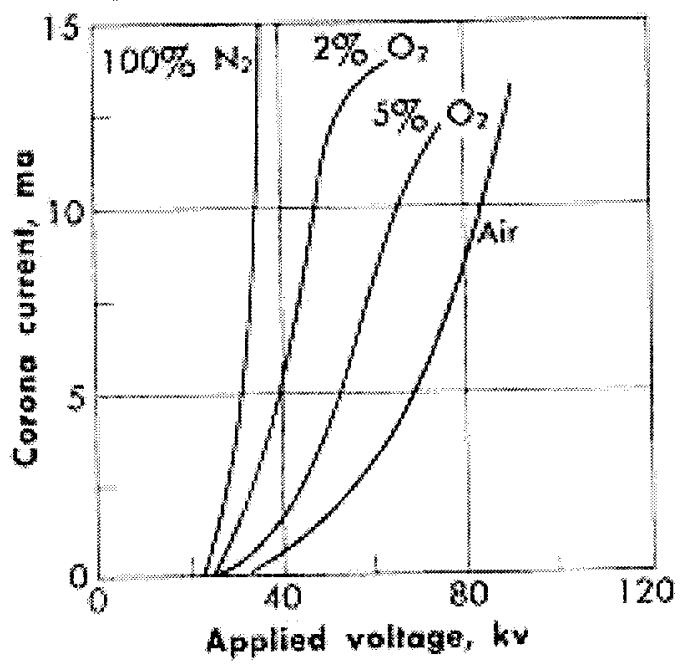

Figure 10-20:Negative Corona Characteristics for Nitrogen-Oxygen Mixtures; 6-in Tube; 0.109-in Wire 


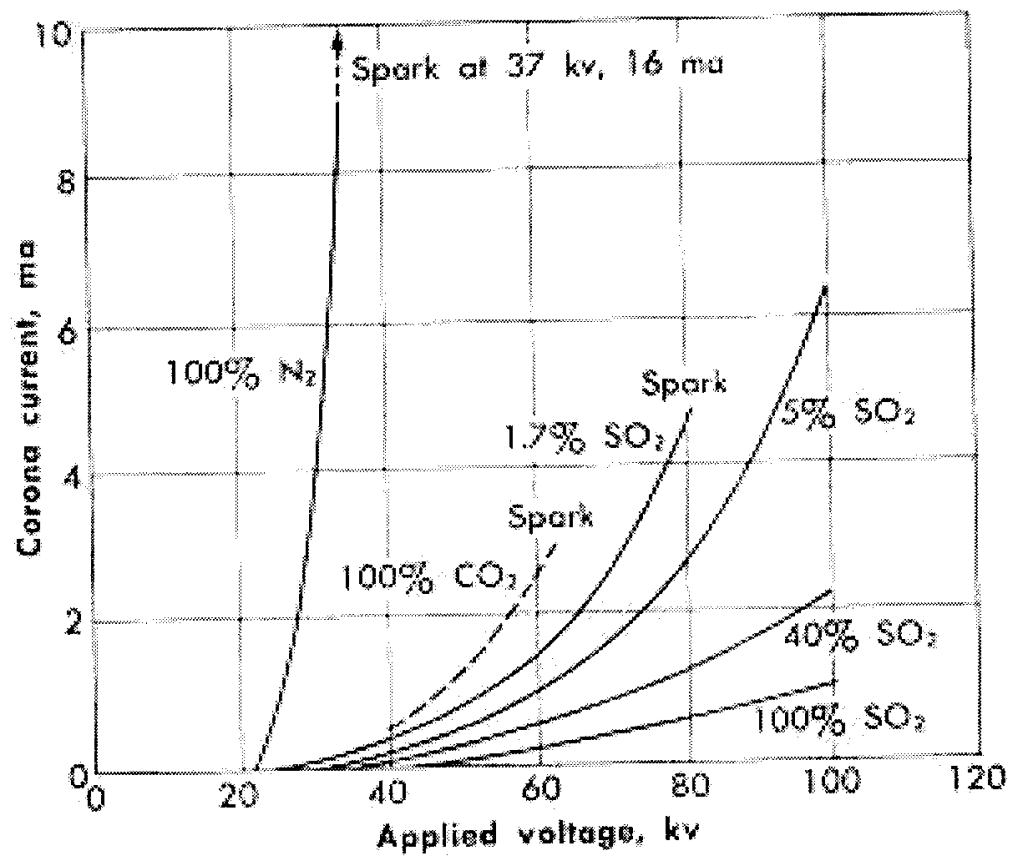

Figure 10-21: Negative Corona Curves for Nitrogen-Sulfur Dioxide Mixtures; 6-in. Tube; 0.019-in. Wire

Conditions with recycled flue gas:

Table 10-14 gives a comparison of the flue gas analysis for air firing and $\mathrm{O}_{2} /$ Recycled flue gas firing. The high nitrogen content, $73.7 \%$, found with the air firing is reduced to $5.3 \%$ where as the $\mathrm{CO}_{2}$ increases from $13.9 \%$ to $77.2 \%$. There is also a small increase in the moisture content from $9 \%$ to $14.1 \%$ and $\mathrm{SO}_{2}$ content from 2,212 ppmv to 3,887 ppmv.

Table 10-14: Composition of Flue Gases Entering the Electrostatic Precipitator (ESP)

\begin{tabular}{lccc}
\hline Species & Unit & $\begin{array}{c}\text { Air Firing: } \\
\text { (ESP Inlet Gas Composition) }\end{array}$ & $\begin{array}{c}\mathrm{O}_{2} / \text { Recycled Flue Gas Firing: } \\
\text { (ESP Inlet Gas Composition) }\end{array}$ \\
\hline $\mathrm{O}_{2}$ & vol.\% & 3.1 & 3.1 \\
$\mathrm{~N}_{2}$ & vol.\% & 73.7 & 5.27 \\
$\mathrm{H}_{2} \mathrm{O}$ & vol.\% & 9.0 & 14.1 \\
$\mathrm{CO}_{2}$ & vol.\% & 13.9 & 77.2 \\
$\mathrm{SO}_{2}$ & ppmv & 2,212 & 3,887 \\
\hline
\end{tabular}

If the gas was $100 \%$ Nitrogen, the negative corona precipitation process could not occur. Nitrogen has no affinity for electrons and hence cannot form negative ions. When the voltage is raised to a point that would correspond to the corona onset point, spark over occurs. Figure 10-20 shows that the introduction of $\mathrm{O}_{2}$ allows an increase in voltage to take place creating a stronger electrical field prior to spark over. Figure 10-21 shows again the 
$100 \%$ nitrogen gas and the effects of various levels of the electro-negative gas $\mathrm{SO}_{2}$. Also a comparison curve is given for $100 \% \mathrm{CO}_{2}$. It can be seen that $\mathrm{CO}_{2}$ has electron affinity resulting in a significant increase in voltage, beyond corona onset voltage, before spark break down occurs. The curve tends to the improved characteristic that is obtained with the presence of a small percentage of $\mathrm{SO}_{2}$.

Hence with all other gas components remaining constant the replacement of nitrogen by $\mathrm{CO}_{2}$ will result in a gas that is more beneficial for negative corona precipitation.

In Conclusion, for the gas analysis of Concept B shown above in Table 10-14, no ESP performance degradation is expected as a result of firing coal in $\mathrm{O}_{2} /$ Recycled flue gas environment.

\subsubsection{Carbon Dioxide Separation and Compression System}

This system processes the flue gas stream leaving the oxygen fired boiler system of Concept $\mathrm{B}$ to provide a liquid product $\mathrm{CO}_{2}$ stream with suitable conditions for sequestration or usage.

\subsubsection{Introduction:}

Traditionally, amine scrubbing has been used on industrial scale to recover $\mathrm{CO}_{2}$ from boiler flue gases. Monoethanolamine (MEA) is one of the most effective absorbents but reclamation of the absorbed $\mathrm{CO}_{2}$ from MEA solution consumes large amounts of energy. Therefore, a search is on for more energy efficient methods for recovering $\mathrm{CO}_{2}$ from flue gas streams. One proposed method is to replace combustion air of a power plant with nearly pure oxygen. Theoretically, the flue gas from such a plant would consist of only $\mathrm{CO}_{2}$ and water vapor. Because water can be separated from this gas relatively easily (by condensation) this method seems to offer a promising way to recover $\mathrm{CO}_{2}$ by simply compressing it to a high enough pressure so it can be disposed of or recovered for some useful purpose. Practically however, the stream leaving the Boiler Island contains many other components other than just $\mathrm{CO}_{2}$ and water vapor, which must be fully considered in the system design for Concept B.

\subsubsection{Process Description:}

Figure 10-22 (Refer to Section 10.1.7.3) shows the Flue Gas Cooling process flow diagram and Figure 10-23 shows the Flue Gas Compression and Liquefaction process flow diagram.

The following describes a $\mathrm{CO}_{2}$ recovery system that cools and then compresses a $\mathrm{CO}_{2}$ rich flue gas stream from an oxygen-fired boiler to a pressure high enough so $\mathrm{CO}_{2}$ can be liquefied. The resulting liquid $\mathrm{CO}_{2}$ is passed through a $\mathrm{CO}_{2}$ Stripper to reduce the $\mathrm{N}_{2} / \mathrm{O}_{2}$ content to an acceptable level. Then the liquid $\mathrm{CO}_{2}$ is pumped to a high pressure so it can be economically transported for sequestration or usage. Pressure in the transport pipeline will be maintained above the critical pressure of $\mathrm{CO}_{2}$ to avoid 2-phase flow. The overhead gas from the $\mathrm{CO}_{2}$ Stripper is vented to atmosphere.

The key process parameters (pressures, temperatures, duties etc.) are shown on the process schematics and will not be repeated here except in selected instances.

Later in this report there is a section titled "Design Considerations” (Section 10.1.7.8). This section covers design issues that are not discussed in the Process Description below.

\section{Flue Gas Cooling:}


Please refer to Figure 10-22 (drawing D 09484-01005R-0).

The feed to the $\mathrm{CO}_{2}$ Recovery System is the flue gas stream that leaves the FGD system of the Boiler Island. At this point, the flue gas is at the dew point of $\mathrm{H}_{2} \mathrm{O}$. All of the flue gas leaving the boiler is cooled to $100^{\circ} \mathrm{F}$ in Gas Cooler DA-101 A/B/C, which operates essentially under atmospheric pressure. A significant amount of water condenses out in this cooler. Approximately $2 / 3$ of the gas is then recycled back to the boiler while $1 / 3$ is fed forward to the $\mathrm{CO}_{2}$ compression area. The recycle stream is required to maintain thermal balance in the existing Conesville \#5 steam generator unit in order to avoid major pressure part modifications to the boiler. The Gas Cooler minimizes the volumetric flow rate to, and the resulting power consumption of, the Flue Gas Compression equipment located downstream. Excess condensate is blown down to the cooling water system. Three vessels have been provided for these coolers because a single vessel would be too large.

The Gas Cooler is configured in a packed tower arrangement where the flue gas is contacted with cold water in countercurrent fashion. Warm water from the bottom of the contactor is recycled back to the top of the contactor by Water Pump GA-101 A/B/C/D after first cooling it in an external water cooled heat exchanger, Water Cooler EB-101 (plate and frame exchanger). The cooling water for this exchanger comes from the new cooling tower.

Because the flue gas may carry a small amount of fly ash, the circulating water is filtered in Water Filter FD-101 to prevent solids build-up in the circulating water. Condensate blowdown is filtered and is taken out downstream of the filter. However, the stream is not cooled and is split off before EB-101. Thus the heat load to the cooling tower is minimized.

From the Gas Cooler, the flue gas stream enters a series of booster blowers that are located adjacent to the Gas Cooler. This design was developed to minimize the length of ducting operating at a slight vacuum and to minimize the temperature of the gas being recycled back to the boiler. This arrangement also minimizes energy consumption, as it does not needlessly over boost the pressure of the stream to be recycled back to the boiler. It is only necessary to boost the pressure of the fraction of the flue gas flow that proceeds to compression and liquefaction to overcome the pressure drop of the duct, which is about 1,200 feet long.

\section{Three-Stage Gas Compression System:}

Please refer to Figure 10-23 (drawing D 09484-01004R-0).

The compression section, where $\mathrm{CO}_{2}$ is compressed to 365 psig by a three-stage centrifugal compressor, includes Flue Gas Compressor GB-101. After the aftercoolers, the stream is then chilled in a propane chiller to a temperature of $-21^{\circ} \mathrm{F}$. Note that both the trim cooling water and water for the propane condenser comes from the new cooling tower. At this pressure and temperature, about 80 -mole \% of the stream can be condensed. The flash vapors contain approximately 80 -weight \% of the inlet oxygen and nitrogen, but also 12weight \% of the $\mathrm{CO}_{2}$. Therefore, a rectifier tower has been provided to reduce the loss of $\mathrm{CO}_{2}$ to an acceptable level (about 6 weight \%). Then the pressure of the liquid is boosted to 2,000 psig by $\mathrm{CO}_{2}$ Pipeline Pump GA-103. This stream is now available for sequestration or usage.

The volumetric flow to the compressor inlet is about 80,000 ACFM to each of the two trains and only a single frame is required in each train. The discharge pressures of the stages have 
been balanced to give reasonable power distribution and discharge temperatures across the various stages. They are:
- 1st Stage
28 psig
- 2nd Stage
108 psig
- 3rd Stage
365 psig

Power consumption for this large compressor has been estimated assuming adiabatic efficiency of $75 \%$.

The hot gas from each stage is first cooled in an air cooler to $120{ }^{\circ} \mathrm{F}$ (Flue Gas Compressor 1st/ 2nd / 3rd Stage Aftercooler EC-101/2/3) and then further cooled by a water-cooled heat exchanger to $95{ }^{\circ} \mathrm{F}$ (Flue Gas Compressor 1st/ 2nd Stage Trim Cooler EA-101/2). The flue gas compressor 3rd stage cooler (EA-103) cools the gas down to $90{ }^{\circ} \mathrm{F}$ to reduce the size of the dryers. Due to their large size, many of these heat exchangers consist of multiple shells. Because of highly corrosive conditions, the process side of the coolers must be stainless steel.

Because the flue gas stream leaving DA-101 is wet, some water condenses out in the three aftercoolers. The sour condensate is separated in knockout drums (FA-101/2/3) equipped with mist eliminator pads. Condensate from these drums is drained to the cooling tower or to waste water treatment. To prevent corrosion, these drums have a stainless steel liner.

Flue gas leaving the 3rd stage discharge knockout drum (FA-103) is fed to Flue Gas Drier FF-101 A/G where additional moisture is removed.

\section{Gas Drying:}

Please refer to Figure 10-23 (drawing D 09484-01004R-0).

It is necessary to dry the $\mathrm{CO}_{2}$ stream to meet the product specification. A mole sieve drier has been selected.

The performance of a fixed-bed drier improves as pressure increases. This favors locating the drier at the discharge of the compressor. However, as the operating pressure of the drier increases, so does the design pressure of the equipment. This favors low-pressure operation. But, at low pressure the diameter or number of the drier vessels grows, increasing the cost of the vessel. Having to process the recycle gas from the rectifier condenser cooling would also increase the diameter of the vessel. However, this is less than $10 \%$ of the forward flow. For this design the drier has been optimally located downstream of the 3rd stage compressor. The $\mathrm{CO}_{2}$ Drier system consists of six vessels; FF-101 A/G. One vessel is on line while the others are being regenerated. Flow direction is down during operation and up during regeneration.

The drier is regenerated with the non-condensable vent gas from the rectifier after it exits the third stage discharge trim cooler in a simple once through scheme. During regeneration, the gas is heated in Regeneration Heater FH-101 before passing it through the exhausted drier. After regeneration, heating is stopped while the gas flow continues. This cools the bed down to the normal operating range. The regeneration gas and the impurities contained in it are vented to the atmosphere.

Regeneration of a mole sieve bed requires relatively high temperature and, because HP steam pressure may fluctuate, a gas-fired heater has been specified for this service. 
Flue Gas Filter FD-102 has been provided at the drier outlet to remove any fines that the gas stream may pick up from the desiccant bed.

\section{$\mathrm{CO}_{2}$ Condensation and Stripping:}

Please refer to Figure 10-23 (drawing D 09484-01004R-0).

From the $\mathrm{CO}_{2}$ Drier, the gas stream is cooled down further to $-21 \mathrm{~F}$ with propane refrigeration in $\mathrm{CO}_{2}$ Condenser EA-104. From EA-104 the partially condensed flue gas stream continues on to $\mathrm{CO}_{2}$ Rectifier DA-102.

At this pressure and temperature 80 -mole $\%$ of the stream can be condensed. The flash vapors contain approximately 80 -weight \% of the inlet oxygen and nitrogen, but also 12weight \% of the $\mathrm{CO}_{2}$. Therefore, as mentioned, a rectifier tower has been provided to reduce the loss of $\mathrm{CO}_{2}$ to an acceptable level. The pressure of the liquid is boosted to 2,000 psig by $\mathrm{CO}_{2}$ Pipeline Pump GA-103 for delivery to a sequestration or usage location.

The vapors in the feed to the rectifier contain the nitrogen and the oxygen that flashed from the liquid $\mathrm{CO}_{2}$. To keep the $\mathrm{CO}_{2}$ loss to the minimum, the rectifier also has an overhead condenser, $\mathrm{CO}_{2}$ Rectifier Condenser EA-107. This is a flood back type condenser installed on top of the Rectifier. It cools the overhead vapor from the tower down to $-48{ }^{\circ} \mathrm{F}$. The condensed $\mathrm{CO}_{2}$ acts as cold reflux in the $\mathrm{CO}_{2}$ Rectifier.

Taking a slipstream from the inert-free liquid $\mathrm{CO}_{2}$ from the Rectifier bottoms and letting it down to the Flue Gas Compressor 3rd stage suction pressure cools EA-107. At this pressure, $\mathrm{CO}_{2}$ liquid boils at $-55^{\circ} \mathrm{F}$ thus providing the refrigeration necessary to condense some of the $\mathrm{CO}_{2}$ from the Stripper overhead gas. The process has been designed to achieve at least $94 \%$ $\mathrm{CO}_{2}$ recovery. The vaporized $\mathrm{CO}_{2}$ from the cold side of EA-107 is fed to the suction of the Flue Gas Compressor 3rd stage.

Any system containing liquefied gas such as $\mathrm{CO}_{2}$ is potentially subject to very low temperatures if the system is depressurized to atmospheric pressure while the system contains cryogenic liquid. If the $\mathrm{CO}_{2}$ Rectifier (and all other associated equipment that may contain liquid $\mathrm{CO}_{2}$ ) were to be designed for such a contingency, it would have to be made of stainless steel. However, through proper operating procedures and instrumentation such a scenario can be avoided and low temperature carbon steel (LTCS) can be used instead. Our choice here is LTCS. However, the condenser section will be made from stainless steel.

\section{$\mathrm{CO}_{2}$ Pumping and $\mathrm{CO}_{2}$ Pipeline:}

Please refer to Figure 10-23 (drawing D 09484-01004R-0).

The $\mathrm{CO}_{2}$ product must be increased in pressure to 2000 psig. A multistage heavy-duty pump (GA-103A/B) is required for this service. This is a highly reliable derivative of an API-class boiler feed-water pump.

It is important that the pipeline pressure be always maintained above the critical pressure of $\mathrm{CO}_{2}$ such that single-phase (dense-phase) flow is guaranteed. Therefore, pressure in the line should be controlled with a pressure controller and the associated control valve located at the destination end of the line.

\section{Offgas:}

Please refer to Figure 10-23 (drawing D 09484-01004R-0). 
The vent gas from the $\mathrm{CO}_{2}$ Rectifier overhead is at high pressure and there is an opportunity for power recovery using turbo-expanders. Because the gas cools down in the expansion process, there is also an opportunity for cold recovery. Heat recovery from the stream after let down via an expander was examined and it was determined that the amount of duty that could be recovered without the carbon dioxide in the stream freezing was small. Thus heat recovery could not be justified. The offgas leaves the Rectifier at $-48{ }^{\circ} \mathrm{F}$ approximately. The refrigeration recovery to condense $\mathrm{CO}_{2}$ was the best use for this cold since it also produces a reasonable temperature regeneration gas for the dryers.

\subsubsection{Process Flow Diagrams}

Two process flow diagrams are shown below for these systems:

- $\quad$ Figure 10-22 (drawing D 09484-01005R-0) Flue Gas Cooling PFD

- Figure 10-23 (drawing D 09484-01004R-0) $\mathrm{CO}_{2}$ Compression and Liquefaction PFD 


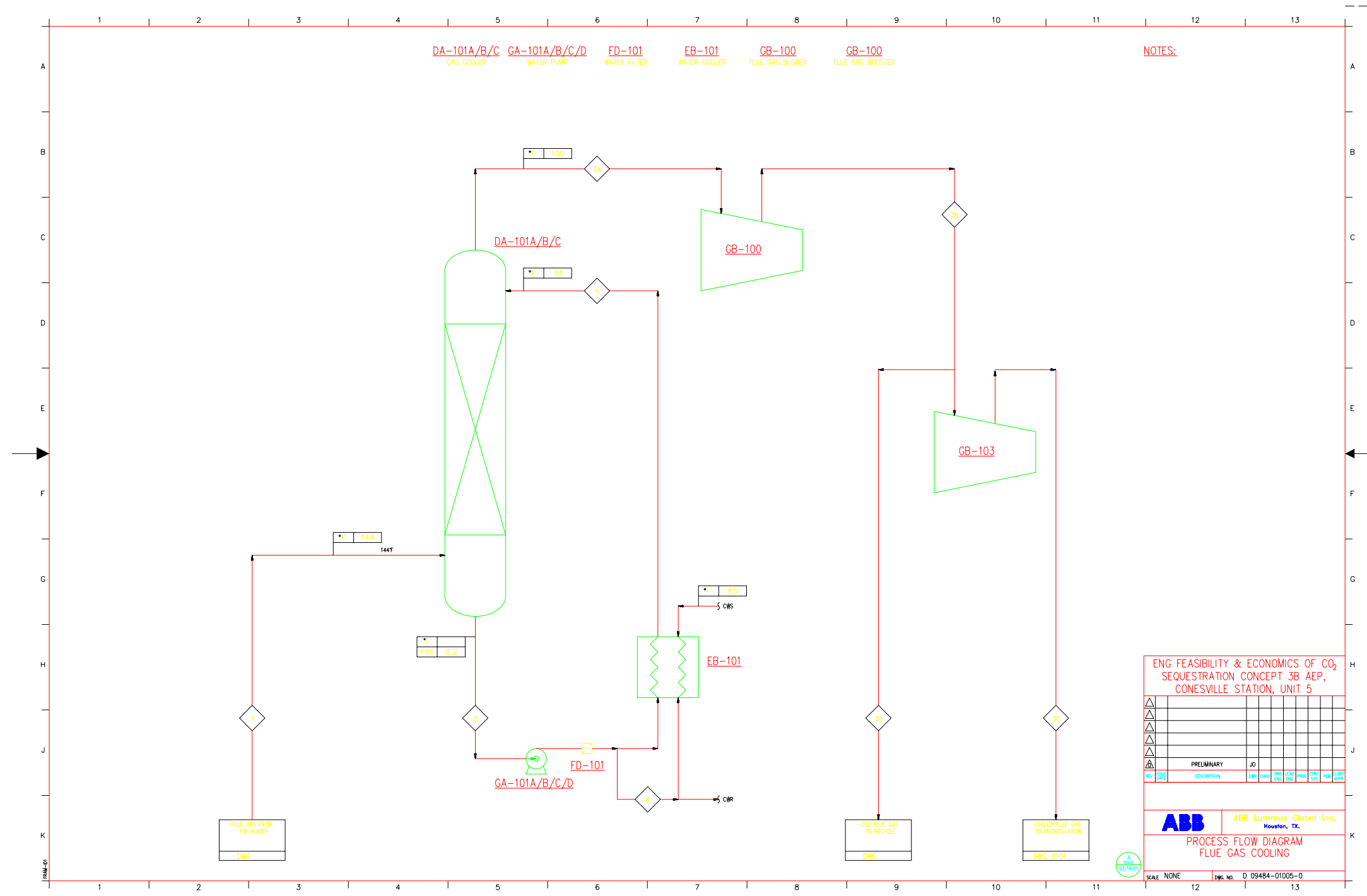

Figure 10-22: Process Flow Diagram for Concept B: Flue Gas Cooling 


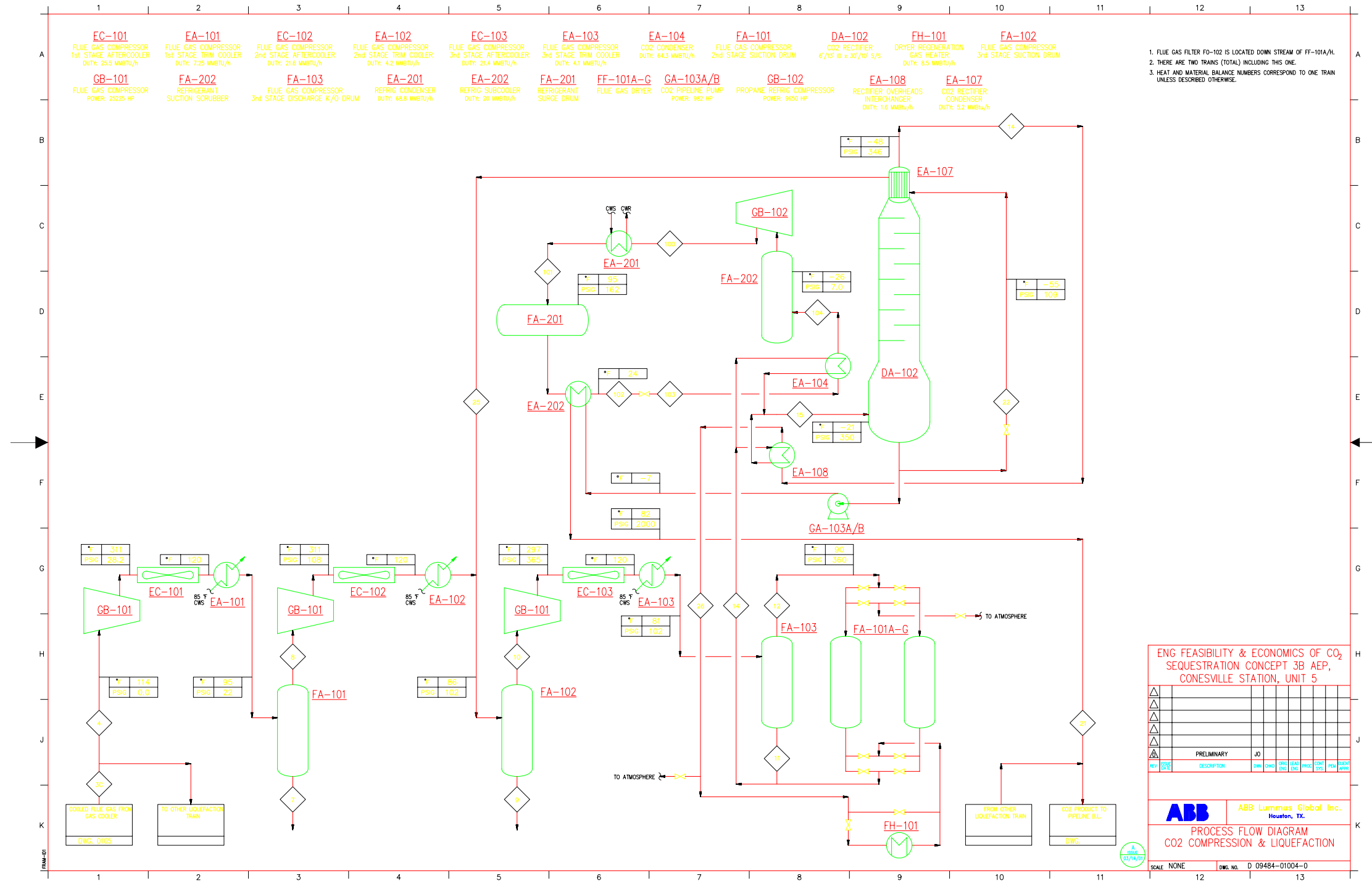

Figure 10-23: Process Flow Diagram for Concept B: $\mathrm{CO}_{2}$ Compression and Liquefaction 


\subsubsection{Overall Material and Energy Balance}

Table 10-15 contains the overall material balance for the Flue Gas Cooling System and the $\mathrm{CO}_{2}$ Compression and Liquefaction System. It is based on 94\% recovery of $\mathrm{CO}_{2}$. 
Table 10-15: Material and Energy Balance for Flue Gas Cooling, $\mathrm{CO}_{2}$ Compression and Liquefaction

\begin{tabular}{|c|c|c|c|c|c|c|c|c|c|c|c|c|c|c|}
\hline STREAM NAME & $\begin{array}{l}\text { To quench } \\
\text { columns }\end{array}$ & $\begin{array}{l}\text { From Quench } \\
\text { columns }\end{array}$ & Excess water & $\begin{array}{c}\text { From Large } \\
\text { blowers }\end{array}$ & $\begin{array}{c}\text { Quench water } \\
\text { out }\end{array}$ & $\begin{array}{c}\text { Quench water } \\
\text { in }\end{array}$ & $\underset{\text { trains }}{\text { To liquefaction }}$ & To boiler & $\begin{array}{l}\text { To Train A } \\
\text { liquefaction }\end{array}$ & First water KO & To 2nd stage & 2nd water KO & To 3rd stage & $\begin{array}{l}\text { Recycle from } \\
\text { condenser }\end{array}$ \\
\hline STREAM NO. & 1 & $3 a$ & 6 & $3 b$ & 2 & 5 & $3 c$ & $3 d$ & 4 & 7 & 8 & 9 & 10 & 25 \\
\hline VAPOR FRACTION & 1.000 & 1.000 & 0.000 & 1.000 & 1.000 & 1.000 & 1.000 & 1.000 & 1.000 & 0.000 & 1.000 & 0.000 & 1.000 & 1.000 \\
\hline TEMPERATURE & 144 & 100 & 100 & 108 & \#N/A & 91 & 114 & 108 & 114 & 95 & 95 & 86 & 86 & -50 \\
\hline PRESSURE & 0 & 0 & 0 & 1 & 1 & 1 & 0 & 1 & 0 & 22 & 22 & 102 & 102 & 102 \\
\hline MOLAR FLOW RATE & $109,760.00$ & $95,103.76$ & $14,659.53$ & $95,103.76$ & $\# N / A$ & & $22,857.50$ & $72,246.26$ & $11,428.75$ & 499.76 & $10,928.99$ & 15.06 & $11,675.19$ & 925.00 \\
\hline MASS FLOW RATE & \begin{tabular}{|l|}
$4,162,006$ \\
\end{tabular} & $3,897,793$ & 264,213 & $3,897,793$ & $\# N / A$ & & 936,806 & $2,960,987$ & 468,403 & 9,015 & 459,389 & 273 & 496,582 & 40,427 \\
\hline ENERGY & $5.24 \mathrm{E}+08$ & $4.16 \mathrm{E}+08$ & $-2.11 E+08$ & $4.23 E+08$ & - & & $1.03 E+08$ & $3.21 \mathrm{E}+08$ & $5.15 \mathrm{E}+07$ & $-7.24 E+06$ & $4.70 \mathrm{E}+07$ & $-2.20 E+05$ & $4.83 \mathrm{E}+07$ & $2.66 \mathrm{E}+06$ \\
\hline \multicolumn{15}{|l|}{$\begin{array}{ll}\text { COMPOSITON } & \text { Mol } \% \\
\end{array}$} \\
\hline $\mathrm{CO} 2$ & $73.04 \%$ & $84.29 \%$ & $0.03 \%$ & $84.29 \%$ & $0.03 \%$ & $0.03 \%$ & $84.29 \%$ & $84.29 \%$ & $84.29 \%$ & $0.09 \%$ & $88.14 \%$ & $0.30 \%$ & $90.26 \%$ & $97.82 \%$ \\
\hline $\mathrm{H} 2 \mathrm{O}$ & $19.01 \%$ & $6.53 \%$ & $99.97 \%$ & $6.53 \%$ & $99.97 \%$ & $99.97 \%$ & $6.53 \%$ & $6.53 \%$ & $6.53 \%$ & $99.91 \%$ & $2.26 \%$ & $99.69 \%$ & $0.59 \%$ & $0.00 \%$ \\
\hline Nitrogen & $5.03 \%$ & $5.80 \%$ & $0.00 \%$ & $5.80 \%$ & $0.00 \%$ & $0.00 \%$ & $5.80 \%$ & $5.80 \%$ & $5.80 \%$ & $0.00 \%$ & $6.07 \%$ & $0.00 \%$ & $5.78 \%$ & $1.24 \%$ \\
\hline Ammonia & $0.00 \%$ & $0.00 \%$ & $0.00 \%$ & $0.00 \%$ & $0.00 \%$ & $0.00 \%$ & $0.00 \%$ & $0.00 \%$ & $0.00 \%$ & $0.00 \%$ & $0.00 \%$ & $0.00 \%$ & $0.00 \%$ & $0.00 \%$ \\
\hline Propane & $0.00 \%$ & $0.00 \%$ & $0.00 \%$ & $0.00 \%$ & $0.00 \%$ & $0.00 \%$ & $0.00 \%$ & $0.00 \%$ & $0.00 \%$ & $0.00 \%$ & $0.00 \%$ & $0.00 \%$ & $0.00 \%$ & $0.00 \%$ \\
\hline Oxygen & $2.91 \%$ & $3.36 \%$ & $0.00 \%$ & $3.36 \%$ & $0.00 \%$ & $0.00 \%$ & $3.36 \%$ & $3.36 \%$ & $3.36 \%$ & $0.00 \%$ & $3.52 \%$ & $0.00 \%$ & $3.37 \%$ & $0.92 \%$ \\
\hline $\mathrm{SO} 2$ & $0.01 \%$ & $0.02 \%$ & $0.00 \%$ & $0.02 \%$ & $0.00 \%$ & $0.00 \%$ & $0.02 \%$ & $0.02 \%$ & $0.02 \%$ & $0.00 \%$ & $0.02 \%$ & $0.00 \%$ & $0.02 \%$ & $0.02 \%$ \\
\hline YAPOP & & & & & & & & & & & & & & \\
\hline $\begin{array}{l}\text { VAPOR } \\
\text { MOLAR FLOW RATE }\end{array}$ & $109,760.0$ & $95,103.8$ & & $95,103.8$ & & & $22,857.5$ & $72,246.3$ & $11,428.8$ & & $10,929.0$ & & $11,675.2$ & 925.0 \\
\hline MASS FLOW RATE & $4,162,006$ & $3,897,793$ & & $3,897,793$ & & & 936,806 & $2,960,987$ & 468,403 & & 459,389 & & 496,582 & 40,427 \\
\hline STD VOL. FLOW & 999.67 & 866.16 & & 866.16 & & & 208.18 & 657.99 & 104.09 & & 99.54 & & 106.33 & 8.42 \\
\hline ACTUAL VOL. FLOW & $806,220.00$ & $650,850.00$ & & $632,520.00$ & & & $158,940.00$ & $480,500.00$ & $79,470.00$ & & $29,015.79$ & & $9,406.50$ & 521.00 \\
\hline MOLECULAR WEIGHT & 37.92 & 40.98 & & 40.98 & & & 40.98 & 40.98 & 40.98 & & 42.03 & & 42.53 & 43.71 \\
\hline DENSITY & 0.09 & 0.10 & 0.10 & 0.10 & 0.1 & 0.1 & 0.10 & 0.10 & 0.10 & & 0.26 & & 0.88 & 1.29 \\
\hline VISCOSITY & 0.0147 & 0.0150 & 0.0150 & 0.0152 & 0.0 & 0.0 & 0.0154 & 0.0152 & 0.0154 & & 0.0154 & & 0.0155 & 0.0113 \\
\hline \multicolumn{15}{|l|}{ HYDROCARBON LIQUID } \\
\hline MOLAR FLOW RATE & & & & & & & & & & & & & & \\
\hline \multicolumn{15}{|l|}{ MASS FLOW RATE L Lb/Hr } \\
\hline \multirow{2}{*}{\multicolumn{15}{|c|}{ STD VOL. FLOW $\quad$ BPD }} \\
\hline \multirow{2}{*}{\multicolumn{15}{|c|}{$\begin{array}{|lc|}\text { ACTUAL VOL. FLOW } & \text { GPM } \\
\text { DENSITY } & \text { Lb/Ft } \\
\end{array}$}} \\
\hline & & & & & & & & & & & & & & \\
\hline \multicolumn{15}{|l|}{ MOLECULAR WEIGHT MW } \\
\hline \multicolumn{15}{|l|}{ VISCOSITY $c$ cP } \\
\hline SURFACE TENSION & & & & - & & & & & & & & & & \\
\hline
\end{tabular}




\begin{tabular}{|c|c|c|c|c|c|c|c|c|c|c|c|c|c|}
\hline STREAM NAME & To drier & 3rd water ko & $\begin{array}{c}\text { From drier/ } \\
\text { Condenser inlet }\end{array}$ & Condenser outlet & $\begin{array}{c}\text { Non-condensable } \\
\text { vent }\end{array}$ & $\begin{array}{c}\text { Rectifier } \\
\text { bottoms to } \\
\text { condenser }\end{array}$ & $\begin{array}{c}\text { Train A Co2 to } \\
\text { pipeline }\end{array}$ & $\begin{array}{c}\text { Refrig compressor } \\
\text { discharge }\end{array}$ & $\begin{array}{l}\text { Refrig condenser } \\
\text { out }\end{array}$ & $\begin{array}{c}\text { Refrig } \\
\text { subcooler out }\end{array}$ & \begin{tabular}{|c} 
Refrig to Co2 \\
condenser
\end{tabular} & $\begin{array}{l}\text { Refrig from } \\
\text { CO2 condenser }\end{array}$ & $\begin{array}{l}\text { Warm non } \\
\text { condensable }\end{array}$ \\
\hline STREAM NO. & 12 & 11 & 14 & 15 & 24 & 22 & 21 & 100 & 101 & 102 & 103 & 104 & 26 \\
\hline VAPOR FRACTION & 1.000 & 0.000 & 1.000 & 0.200 & 1.000 & 0.134 & 0.000 & 1.000 & 0.000 & 0.000 & 0.158 & 0.993 & 1.000 \\
\hline TEMPERATURE & 90 & 90 & 90 & -21 & -46 & -56 & 82 & 144 & 95 & 24 & -26 & -26 & 81 \\
\hline PRESSURE & 359 & 359 & 354 & 349 & 346 & 105 & 2,000 & 169 & 162 & 159 & 8 & 8 & 341 \\
\hline MOLAR FLOW RATE & $11,638.57$ & 36.62 & $11,606.46$ & $11,318.96$ & $1,421.61$ & 925.00 & $9,247.50$ & $9,750.00$ & $9,750.00$ & $9,750.00$ & $9,750.00$ & $9,750.00$ & $1,421.61$ \\
\hline MASS FLOW RATE & 495,913 & 668 & 495,335 & 483,065 & 50,218 & 40,427 & 404,163 & 429,946 & 429,946 & 429,946 & 429,946 & 429,946 & 50,218 \\
\hline ENERGY & $4.50 \mathrm{E}+07$ & $-5.28 \mathrm{E}+05$ & $4.50 \mathrm{E}+07$ & $-1.86 \mathrm{E}+07$ & $3.76 \mathrm{E}+06$ & $-2.55 E+06$ & $-3.13 E+06$ & $7.13 E+07$ & $2.54 \mathrm{E}+06$ & $-1.73 E+07$ & $-1.73 E+07$ & $4.67 \mathrm{E}+07$ & $5.35 \mathrm{E}+06$ \\
\hline COMPOSITON & & & & & & & & & & & & & \\
\hline $\mathrm{CO} 2$ & $90.54 \%$ & $0.88 \%$ & $90.79 \%$ & $90.79 \%$ & $40.47 \%$ & $97.82 \%$ & $97.82 \%$ & $0.00 \%$ & $0.00 \%$ & $0.00 \%$ & $0.00 \%$ & $0.00 \%$ & $40.47 \%$ \\
\hline $\mathrm{H} 2 \mathrm{O}$ & $0.28 \%$ & $99.11 \%$ & $0.00 \%$ & $0.00 \%$ & $0.00 \%$ & $0.00 \%$ & $0.00 \%$ & $0.00 \%$ & $0.00 \%$ & $0.00 \%$ & $0.00 \%$ & $0.00 \%$ & $0.00 \%$ \\
\hline Nitrogen & $5.79 \%$ & $0.00 \%$ & $5.81 \%$ & $5.81 \%$ & $38.53 \%$ & $1.24 \%$ & $1.24 \%$ & $0.00 \%$ & $0.00 \%$ & $0.00 \%$ & $0.00 \%$ & $0.00 \%$ & $38.53 \%$ \\
\hline Ammonia & $0.00 \%$ & $0.00 \%$ & $0.00 \%$ & $0.00 \%$ & $0.00 \%$ & $0.00 \%$ & $0.00 \%$ & $0.00 \%$ & $0.00 \%$ & $0.00 \%$ & $0.00 \%$ & $0.00 \%$ & $0.00 \%$ \\
\hline Propane & $0.00 \%$ & $0.00 \%$ & $0.00 \%$ & $0.00 \%$ & $0.00 \%$ & $0.00 \%$ & $0.00 \%$ & $100.00 \%$ & $100.00 \%$ & $100.00 \%$ & $100.00 \%$ & $100.00 \%$ & $0.00 \%$ \\
\hline Oxygen & $3.38 \%$ & $0.00 \%$ & $3.39 \%$ & $3.39 \%$ & $20.99 \%$ & $0.92 \%$ & $0.92 \%$ & $0.00 \%$ & $0.00 \%$ & $0.00 \%$ & $0.00 \%$ & $0.00 \%$ & $20.99 \%$ \\
\hline $\mathrm{SO} 2$ & $0.02 \%$ & $0.01 \%$ & $0.02 \%$ & $0.02 \%$ & $0.00 \%$ & $0.02 \%$ & $0.02 \%$ & $0.00 \%$ & $0.00 \%$ & $0.00 \%$ & $0.00 \%$ & $0.00 \%$ & $0.00 \%$ \\
\hline \multicolumn{14}{|l|}{ VAPOR } \\
\hline MOLAR FLOW RATE & $11,638.6$ & & $11,606.5$ & $2,263.8$ & $1,421.6$ & 124.2 & & $9,750.0$ & & & $1,539.9$ & $9,681.4$ & 1.421 .6 \\
\hline MASS FLOW RATE & 495,913 & & 495,335 & 87,306 & 50,218 & 5,207 & & 429,946 & & & 67,905 & 426,923 & 50,218 \\
\hline STD VOL. FLOW & 106.00 & & 105.71 & 20.62 & 12.95 & 1.13 & & 88.80 & & & 14.02 & 88.17 & 12.95 \\
\hline ACTUAL VOL. FLOW & $2,686.04$ & & $2,718.77$ & 407.73 & 253.59 & 67.90 & & 4.762 .22 & & & $5,111.32$ & $32,135.98$ & 366.87 \\
\hline MOLECULAR WEIGHT & 42.61 & & 42.68 & 38.57 & 35.32 & 41.94 & & 44.10 & & & 44.10 & 44.10 & 35.32 \\
\hline DENSITY & 3.08 & & 3.04 & 3.57 & 3.30 & 1.28 & & 1.50 & & & 0.22 & 0.22 & 2.28 \\
\hline VISCOSITY & 0.0164 & & 0.0164 & 0.0145 & 0.0146 & 0.0116 & & 0.0098 & & & 0.0066 & 0.0066 & 0.0185 \\
\hline \multicolumn{14}{|l|}{ HYDROCARBON LIOUID } \\
\hline MOLAR FLOW RATE & & & & $9,055.12$ & & 800.84 & $9,247.50$ & & $9,750.00$ & $9,750.00$ & $8,210.14$ & 68.56 & \\
\hline MASS FLOW RATE & & & & $395,757.44$ & & $35,219.85$ & $404,163.41$ & & $429,945.75$ & 429946 & 362042 & $3,023.15$ & \\
\hline STD VOL. FLOW & & & & 32,774 & & 2,921 & 33,471 & & 58,100 & 58,100 & 48,927 & 409 & \\
\hline ACTUAL VOL. FLOW & & & & 748.51 & & 61.47 & $1,008.54$ & & $1,802.87$ & $1,598.64$ & $1,268.98$ & 10.60 & \\
\hline DENSITY & & & & 65.92 & & 71.43 & 49.96 & & 29.73 & 33.53 & 35.57 & 35.57 & \\
\hline MOLECULAR WEIGHT & & & & 43.71 & & 43.98 & 43.71 & & 44.10 & 44.10 & 44.10 & 44.10 & \\
\hline VISCOSITY & & & & 0.1610 & & 0.2221 & 0.0558 & & 0.0906 & 0.1336 & 0.1771 & 0.1771 & \\
\hline SURFACE TENSION & & & & 15.05 & & 20.06 & 0.85 & & 5.74 & 10.54 & 14.13 & 14.13 & \\
\hline
\end{tabular}




\subsubsection{Equipment List with Data}

Equipment data for Concept B, summarized in Appendix II, has been tabulated in the socalled "short spec" format, which provides adequate data for a factored cost estimate.

\subsubsection{Consumption of Utilities}

In addition to the primary utilities listed below (Table 10-16), the plant will also need a supply of other utilities such as instrument air, plant air, process water, nitrogen etc. However, these needs are minor and in many cases are for maintenance purposes only. Consumption of these utilities has not been estimated.

Table 10-16: Concept B Utility Consumption

\begin{tabular}{|c|c|c|c|c|c|c|}
\hline & \multirow{2}{*}{\multicolumn{2}{|c|}{ Utility }} & \multirow[b]{2}{*}{$\begin{array}{l}\text { Amount } \\
\text { Consumed }\end{array}$} & \multirow[b]{2}{*}{ Units } & & \\
\hline & & & & & & \\
\hline & \multirow{3}{*}{\multicolumn{2}{|c|}{$\begin{array}{l}\text { Natural Gas } \\
\text { Steam } \\
\text { Cooling water } \\
\end{array}$}} & 0.26 & \multirow{3}{*}{\multicolumn{2}{|c|}{$\begin{array}{l}\text { MMSCFD } \\
\text { Lb/hr } \\
\text { Gpm }\end{array}$}} & \\
\hline & & & 0 & & & \\
\hline & & & 93,200 & & & \\
\hline & & & & \multicolumn{3}{|c|}{$\begin{array}{c}\text { Power } \\
\text { (ea) }\end{array}$} \\
\hline & & & & Number & including & \\
\hline $\begin{array}{l}\text { Number } \\
\text { of }\end{array}$ & Item & & & Operating & 0.95 & Total \\
\hline Trains & Number & & Service & per train & $\begin{array}{l}\text { motor eff } \\
(\mathrm{kW})\end{array}$ & $\begin{array}{l}\text { all trains } \\
(\mathrm{kW})\end{array}$ \\
\hline 2 & EC-101 & $\begin{array}{r}\text { Flue Gas } \\
\text { Stage }\end{array}$ & $\begin{array}{l}\text { Compressor 1st } \\
\text { Aftercooler }\end{array}$ & 1 & 81 & 163 \\
\hline 2 & EC-102 & Flue Gá & $\begin{array}{l}\text { as Compressor } \\
\text { 2nd }\end{array}$ & 1 & 69 & 138 \\
\hline 2 & EC-103 & $\begin{array}{r}\text { Stage } \\
\text { Flue Gas } \\
\text { Stage }\end{array}$ & $\begin{array}{l}\text { Aftercooler } \\
\text { Compressor 3rd } \\
\text { Aftercooler }\end{array}$ & 1 & 68 & 137 \\
\hline 1 & PA-101A/B & Large & $\begin{array}{l}\text { Air Separation } \\
\text { Unit }\end{array}$ & 2 & 40,255 & 80,511 \\
\hline 1 & PA-102 & Small & $\begin{array}{l}\text { Air Separation } \\
\text { Unit }\end{array}$ & 1 & 15,311 & 15,311 \\
\hline 1 & PA-103 & Coo & ling Tower & 1 & 4,074 & 4,074 \\
\hline 2 & GB-101 & & 1 Stage & 1 & 6,416 & 12,831 \\
\hline 2 & & & 2 Stage & 1 & 6,675 & 13,349 \\
\hline 2 & & & 3 Stage & 1 & 6,718 & 13,436 \\
\hline 2 & GB-102 & & 1 stage & 1 & 2,362 & 4,724 \\
\hline 2 & & & 2 stage & 1 & 5,204 & 10,408 \\
\hline
\end{tabular}




\begin{tabular}{|c|c|c|c|c|c|}
\hline 1 & GB-100 & Flue Gas Blower & 1 & 2,173 & 2,173 \\
\hline 1 & GB-103 & Flue Gas Booster & 1 & 396 & 396 \\
\hline 1 & $\begin{array}{l}\text { GA-101 } \\
\text { A/B/C/D }\end{array}$ & Water pump & 3 & 104 & 311 \\
\hline 2 & GA-103A/B & $\begin{array}{c}\text { CO2 Pipeline pump } \\
\text { Total }\end{array}$ & 1 & 1,045 & $\begin{array}{c}2,089 \\
160,051\end{array}$ \\
\hline
\end{tabular}

\subsubsection{Consumption of Chemical and Desiccants}

The $\mathrm{CO}_{2}$ compression system does not need any chemicals for its operation. Naturally, there will be a minor demand of lube oil and similar supplies. These have not been estimated.

It has been assumed that the mole sieve desiccant in the $\mathrm{CO}_{2}$ Drier must be replaced once every 3 years. The estimated consumption of mole sieve and other chemicals can be found in Table 10-17.

\section{Table 10-17: Concept B Chemical and Desiccant Consumption}

\begin{tabular}{ll}
\hline Chemical & $\begin{array}{l}\text { Consumption per day } \\
\text { (lbs.) }\end{array}$ \\
\hline Sodium & 15,300 \\
$\begin{array}{l}\text { Hypochlorite } \\
\text { Sodium Bisulfite }\end{array}$ & 86 \\
Mole Sieves & 136 \\
\hline
\end{tabular}

The totals shown in Table 10-17 do not include chemicals provided by the cooling tower service personnel. This is handled as a component of operating costs referred to as contracted services. It also does not include air separation plant chemicals and lubricants that were presented as monetary value only. They will appear in the operating expense break down.

\subsubsection{Design Considerations}

The process and equipment specifications presented for Concept $\mathrm{B}$ were the result of a number of optimizations. The areas of optimizations in the $\mathrm{CO}_{2}$ Compression and Liquefaction System were:

- $\mathrm{O}_{2}$ purity

- $\mathrm{CO}_{2}$ purity

- $\mathrm{CO}_{2}$ condensation pressure and temperature 
$\mathrm{O}_{2}$ Purity:

Initial analysis included an Air Separation Unit (ASU) producing oxygen of 95\% purity. Additionally, 5\% of the total oxygen demand was assumed to be from infiltration of ambient air into the boiler, which is typical for a boiler of this type and age. These operating conditions combined with the need for nominally $15 \%$ excess oxygen for combustion, resulted in almost 15 -wt\% of nitrogen and oxygen in the flue gas. This concentration is much higher than typically accepted for EOR applications. The conclusion then was that the bulk of the inerts must be separated from $\mathrm{CO}_{2}$ before it can be used for EOR. Thus, direct compression to the pipeline is not an option. Instead, $\mathrm{CO}_{2}$ would have to be condensed so the inerts could be separated.

It soon became obvious that it is impossible to condense $\mathrm{CO}_{2}$ from such a mixture at pressures below the critical pressure of $\mathrm{CO}_{2}$ and temperatures achievable with cooling water. This is illustrated by Figure 10-24, which shows the achievable $\mathrm{CO}_{2}$ recovery (the ratio of pure $\mathrm{CO}_{2}$ product recovered to the $\mathrm{CO}_{2}$ in the flue gas entering the system) as a function of pressure and temperature. Pressure was limited to 1,000 psig, which is just slightly below the critical pressure of $\mathrm{CO}_{2}(1,070$ psia).

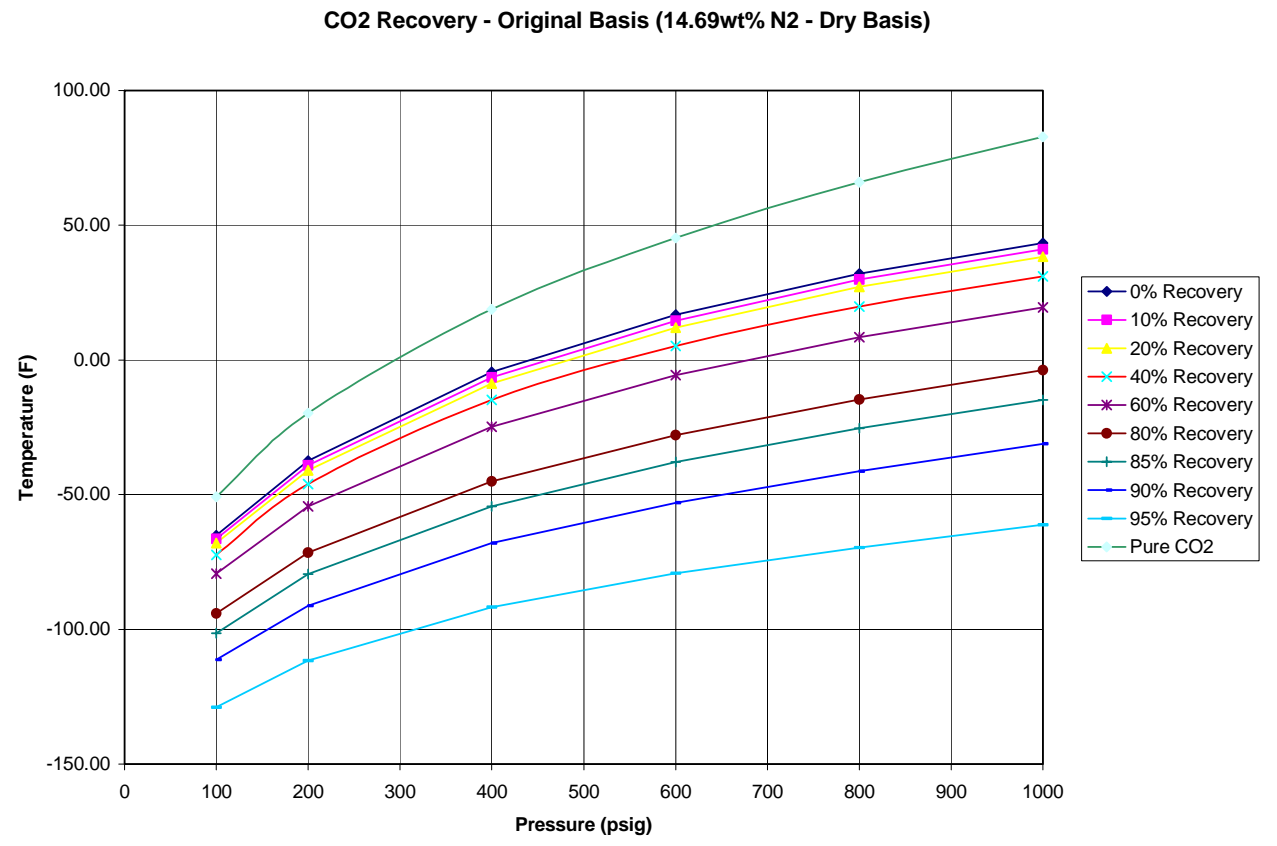

Figure 10-24: $\mathrm{CO}_{2}$ Recovery from Boiler Flue Gas (Combustion with 95\% Pure $\mathrm{O}_{2}$ and $5 \%$ Air Infiltration)

Because the combustion process requires excess oxygen (typically 15-20\% with coal firing), the flue gas will always contain at least some oxygen. Furthermore, it is not easy to completely eliminate nitrogen. Some infiltration of air will always occur as long as the combustion chamber of the boiler operates under slight vacuum, as is the current practice with coal firing, thus some $\mathrm{N}_{2}$ will also be present. Additionally, increasing oxygen 
purity from the ASU beyond 99\% is expensive because the remaining $1 \%$ is mainly argon and the separation becomes more difficult.

Because the inert gases have a strong effect on the dew point of the flue gas, the only way to condense a substantial fraction of the $\mathrm{CO}_{2}$ is by refrigeration. One should keep in mind that the critical temperature of $\mathrm{CO}_{2}$ is approximately $88^{\circ} \mathrm{F}$ and condensation of $\mathrm{CO}_{2}$ without some form of refrigeration may not be feasible in the warmer regions of the world even when inerts are not present in the $\mathrm{CO}_{2}$ stream.

Figure 10-25 shows the achievable $\mathrm{CO}_{2}$ recovery as a function of pressure and temperature using $99 \%$ pure $\mathrm{O}_{2}$ and $1 \%$ air infiltration as combustion process assumptions. One comparison which emphasizes the impact of flue gas purity is that with $95 \% \mathrm{O}_{2}$ purity, the temperature for $95 \%$ recovery at 1,000 psig is $-60^{\circ} \mathrm{F}$ (Figure $10-24$ ) whereas it is $30^{\circ} \mathrm{F}$ (Figure 10-25) with 99\% pure oxygen.

CO2 Recovery - Revised Basis (3.56 wt\% N2 - Dry Basis)

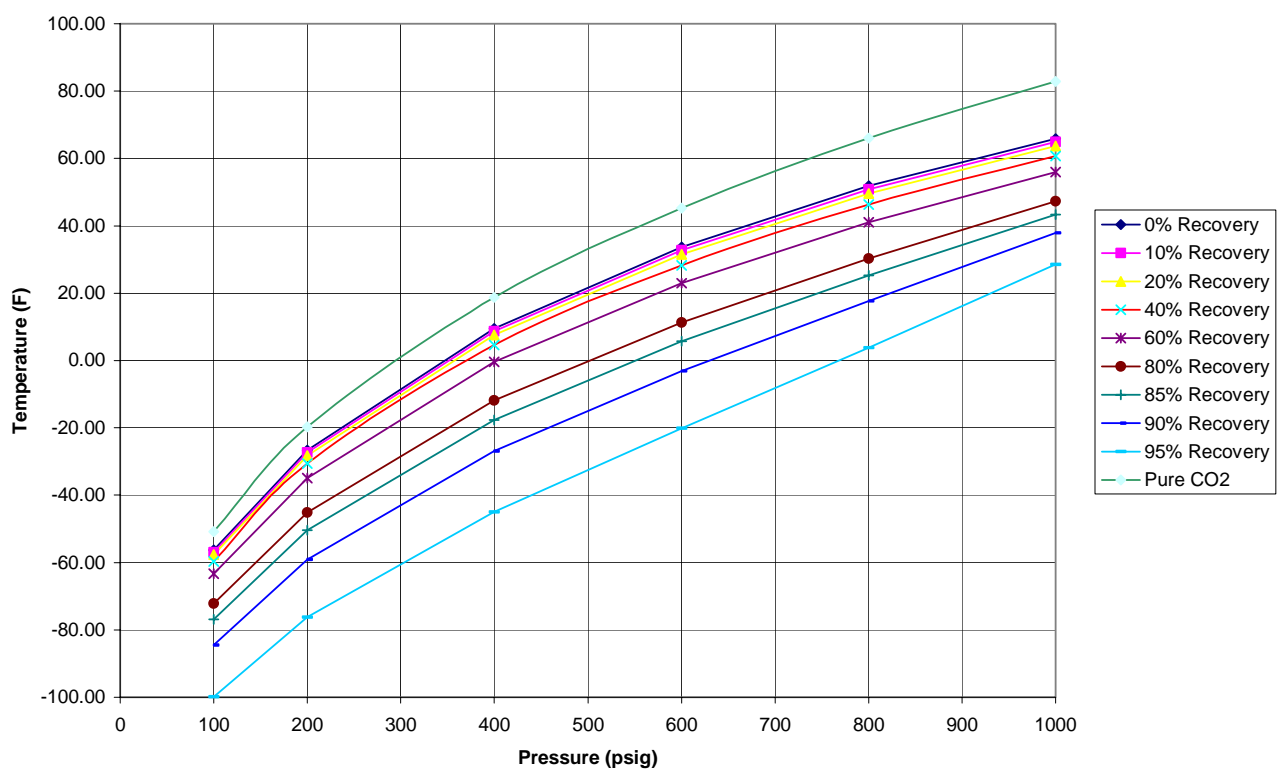

Figure 10-25: $\mathrm{CO}_{2}$ Recovery Boiler Flue Gas (Combustion with 99\% Pure $\mathrm{O}_{2}$ and 1\% Air Infiltration)

\section{$\mathrm{CO}_{2}$ purity:}

Simulations were made to evaluate modifications to the liquefaction flow scheme presented in Sections 10.1.7.2 \& 10.1.7.3 for this concept. The alternate schemes evaluated included total product condensation and having a reboiler on the rectifier (turning it into a complete distillation column). The result was that total condensation, even with the use of $99 \%$ pure oxygen, left the product with approximately $11 \%$ inerts, which cast doubt according to experts that it could be sequestered in a body of water. The result of having a reboiler on the bottom of the rectifier showed that it improved the $\mathrm{CO}_{2}$ product purity, but could never be feasibly made to produce a product, which contained less than $10 \mathrm{ppm} \mathrm{O}_{2}$ that would be required for EOR applications. The reason 
that a reboiler was not presented in the final design was that all of the heat of reboiling was added to the condenser, which required refrigeration at a much lower temperature than the refrigeration, which was recovered in the reboiler. The result was a significant work of liquefaction increase.

$\mathrm{CO}_{2}$ condensation pressure and temperature:

The range of condensation pressures evaluated ranged from 995 psia to 70 psia. The range of condensation temperatures evaluated ranged from $41^{\circ} \mathrm{F}$ to $-69^{\circ} \mathrm{F}$. The optimum was found to be 350 psig and $-22^{\circ} \mathrm{F}$.

\subsubsection{OSBL Systems}

Concept $\mathrm{B}$ has equipment associated with the liquefaction of $\mathrm{CO}_{2}$ in four different areas. The areas include the cooling tower, flue gas cooling section, air separation plant, and the compression and liquefaction equipment.

For this Concept, all of the cooling water must come from a new cooling tower since there is no diversion of steam to supply process heat. The clarifier producing make-up water for the cooling tower produces a blowdown sludge that must be sent to the existing clarifier blowdown handling system. The blowdown from the cooling tower itself can be discharged to the river after the free chlorine is removed by injection of sodium bisulfite.

The air separation plant utilizes the bulk of the cooling water. It also consumes electric power. The original design of the air separation plant involved the consumption of steam for molecular sieve drier regeneration. This duty was converted to an electric load to get the $\mathrm{CO}_{2}$ recovery process isolated from swings in steam pressures that can occur with changes in throughput. The only other utility it takes in is instrument air.

The $\mathrm{CO}_{2}$ compression and liquefaction section requires less supplemental utilities and chemicals than its amine counterparts. Only cooling water and electric power are required. Once every three years the molecular sieve in the dryers may need to be replaced.

\subsubsection{Plant Layout}

The gas from the flue gas desulfurizer arrives at the nozzles of the flue gas coolers at atmospheric pressure. In order to avoid any additional inflow of oxygen, the flue gas coolers must be placed as close to the power boilers as possible. The coolers are located just west of the existing FGD system.

Initially there were concerns about the piping between the air separation plant and the power boiler. The oxygen is produced at the air separation plant at $5 \mathrm{psig}$. Therefore it should not be subject to more than 3 psi of frictional pressure loss in the duct connecting it to the power boiler. Calculations reveal that two 36-inch supply lines can carry the oxygen from the ASU to the Boiler, a distance of about 1,500 feet. The wall thickness of standard pipe should provide more than enough protection from most incidents that could be envisioned for a pipe spanning this distance. There may be even scope to reduce the wall thickness to less than standard wall if calculations permit. Air Products also had concerns about putting the Air Separation plant too close to the power plant where the inlet air may be high in $\mathrm{CO}_{2}$. This $\mathrm{CO}_{2}$ could affect the drier operation. Due to the fact 
that this $\mathrm{CO}_{2}$ liquefaction unit reduces gases going up the stack, there should be no problem.

The layout of the compression and liquefaction unit offers few areas to comment on. At the low-pressure section of the plant, elbows are quite large making spacing allowances on the plot plan difficult without a rigorous design being made.

Plant layout drawings for Concept B (listed below) are included in Appendix I of the original report (Bozzuto et al., 2001) and are not included in this report. This new equipment requires about 5.5 acres of plot area.

- U01-D-0203 Plot Plan - Concept B: Air Separation Plants

- U01-D-0209 Plot Plan - Concept B: Flue Gas Cooling

- U01-D-0205 Plot Plan - Concept B: $\mathrm{CO}_{2}$ Compression \& Liquefaction

- U01-D-0212 Plot Plan - Concept B: Overall Layout Conceptual Plan

- U01-D-0201R Plot Plan - Concept B: Modified Overall Site Plan 


\title{
Pilot Scale Demonstration of a Novel Low Cost Oxygen Supply Process and its Integration with Oxy-Fuel Coal Fired Boilers
}

\author{
Department of Energy - DE-FC26-06NT42478
}

\section{Task 4 Final Report}

Report Title: $\quad$ Long Duration Tests - Long Term Operability of Perovskite Material Report Authors: Khalid F. Omar

Western Research Institute, Advanced technology Center, 350 North $9^{\text {th }}$ Street, Laramie, Wyoming 82072-3380

Date Prepared: $\quad$ September 29, 2008 


\section{Task 4: Long Duration Tests - Long Term Operability of Perovskite Material}

\section{Objectives}

1. Evaluation of perovskite material performance utilizing flue gas generated from coal combustion.

2. Determine the mechanical stability of the perovskite under long duration of cycling operation.

\section{Method}

A bench scale CAR unit provided by BOC was utilized in the evaluation of the above stated objectives. The general arrangement for the unit is presented in Figure 1. The interface between the combustion test facility and the bench scale unit is shown in Figure 2.

The procedure followed to conduct the experiment is as follows:

A total of 452 gram of perovskite pellets was loaded in a 38-mm diameter reactor between upper and lower layers of alumina beads. Following the loading process, the system goes through a leak check followed by calibration of the flow rates through the mass flow meters with both the air and the purge gas. Once the perovskite reaches $800^{\circ} \mathrm{C}$, the cycling operation begins under the following operating conditions.

\begin{tabular}{llll}
\hline Cycle Time & Air Flow Rate & $\begin{array}{l}\text { Purge Gas } \\
\left(\mathrm{CO}_{2} \text { or Flue Gas }\right)\end{array}$ & $\begin{array}{l}\text { Perovskite Material } \\
\text { Temperature in the Reactor }\end{array}$ \\
\hline 30 seconds & 13 SLPM & 7.8 SLPM & $800{ }^{\circ} \mathrm{C}$ \\
\hline
\end{tabular}

The backpressures of both the product and waste gases were maintained constant throughout all tests for consistency.

Upon reaching steady state conditions, samples of the inlet and the outlet streams were taken periodically using gas bombs. These sample bombs were analyzed using gas chromatograph for $\mathrm{CO}_{2}, \mathrm{~N}_{2}$, and $\mathrm{O}_{2}$. In parallel to this analysis, a NOVA continuous emissions analyzer was utilized to determine $\mathrm{O}_{2}$ and $\mathrm{CO}_{2}$ in the inlet and outlet stream form the reactor. Additionally, the combustion test facility analyzers were used to determine NOx, SOx and $\mathrm{CO}$ when flue gas was used as a purge gas.

Performance evaluation of the perovskite material was determined by operating the bench scale CAR unit at identical conditions as with the fresh material utilizing $\mathrm{CO}_{2}$ gas as a purge fluid. The percentage of oxygen in the inlet and outlet streams and their flow rates were utilized to determine the net adsorption capacity of oxygen achieved by the perovskite material.

Table 1 lists all the tests that were conducted for material evaluation 


\section{Results}

A comprehensive matrix of flue gas exposure tests was conducted for three different CAR perovskite materials using a slipstream of the CTF flue gas to understand the impact of contaminants on the material performance. The results of the flue gas exposure tests for the three types of perovskite material are presented in Figures 3 and 4. These results reveal that the materials lose oxygen capacity significantly when exposed to high concentration $\mathrm{SO}_{2}$ containing flue gas. A progressive loss in material activity with $\mathrm{SO}_{2}$ loading was observed with all three materials tested.

The distribution of flue gas pollutants in the waste and product streams of the bench scale unit for BOC-10 and BOC-2 are presented in Figures 5 and 6. As indicated from these plots, most of the $\mathrm{SO}_{2}$ is captured by the perovskite material while the majority of $\mathrm{NOx}$ ends up in the product stream. The low levels of $\mathrm{SO}_{2}$ and NOx in the waste stream result from displacement of flue gas from the dead volume of the reactor.

X-Ray diffraction (XRD) studies showed that the bulk perovskite phases were largely unaffected by the flue gas treatment, although low levels of $\mathrm{SrSO}_{4}$ were found in the exposed samples. Electron microprobe studies of sectioned pellets of flue gas exposed samples shows that pellets throughout the BOC-2 packed bed had picked up sulfur, and for all three materials, sulfur was present only in the surface layers of many of the pellets. This is illustrated in Figure 7. It appears that surface sulfate formation may block the oxygen exchange reaction, leaving much of the perovskite intact, but unavailable for the CAR process.

In order to investigate the impact of lower levels of contaminants on the CAR materials, long term exposure tests were then conducted using the bench-scale CAR unit. Two types of perovskite material were evaluated, BOC-2 (the reference material) and BOC-10 (a higher surface area material). Each was exposed to $\mathrm{SO}_{2}$ concentration levels of about $10 \mathrm{ppm}$ (balance $\mathrm{CO}_{2}$ ) continuously for 32 days in 30 seconds cyclic mode at an operating temperature of $800^{\circ} \mathrm{C}$. Graphical representation of the exposure tests are presented in Figures 8 and 9. BOC-10 showed little loss on activity but it was mechanically unstable. The void space was reduced over time as was evidenced by an increase in the pressure drop across the packing. The cause of this mechanical damage may be due to exposure conditions during operation or an unknown event during start up or shut down. Following this test, the more stable material, BOC-2, was exposed to $10 \mathrm{ppm}$ of $\mathrm{SO}_{2}$ continuously for 32 days. The results confirmed the high mechanical stability of the BOC-2 material but indicated a decline in performance with the increase in $\mathrm{SO}_{2}$ loading that was similar to that found in the high concentration $\mathrm{SO}_{2}$ exposure trials at similar total $\mathrm{S}$ exposure levels.

X-Ray Fluorescence (XRF) studies confirmed the presence of sulfur in the low level $\mathrm{SO}_{2}$ treated samples. From the following list of contaminant elements of interest in typical coals: $\mathrm{Hg}, \mathrm{Cd}, \mathrm{Pb}, \mathrm{Zn}, \mathrm{Mn}, \mathrm{As}, \mathrm{V}$, $\mathrm{Ni}, \mathrm{Cr}$, Se, Be and Sb all but Be should also be detected by semi-quantitative XRF if present at above the minimum detection limits. The BOC-2 and BOC-10 samples from the low level exposure trials both appeared to have also picked up mercury, but not the samples from the corresponding high level $\mathrm{SO}_{2}$ exposure trials. There was no sign of vanadium, arsenic, cadmium, antimony or lead contamination. XRD showed significant levels of strontium carbonate in the exposed BOC-10 pellets, together with other decomposition products from the LSCF perovskite, but no $\mathrm{SrSO}_{4}$. Less damage was indicated in the case of BOC-2, but low levels of both $\mathrm{SrCO}_{3}$ and $\mathrm{SrSO}_{4}$ were found together with other decomposition products from LSCF perovskite. 


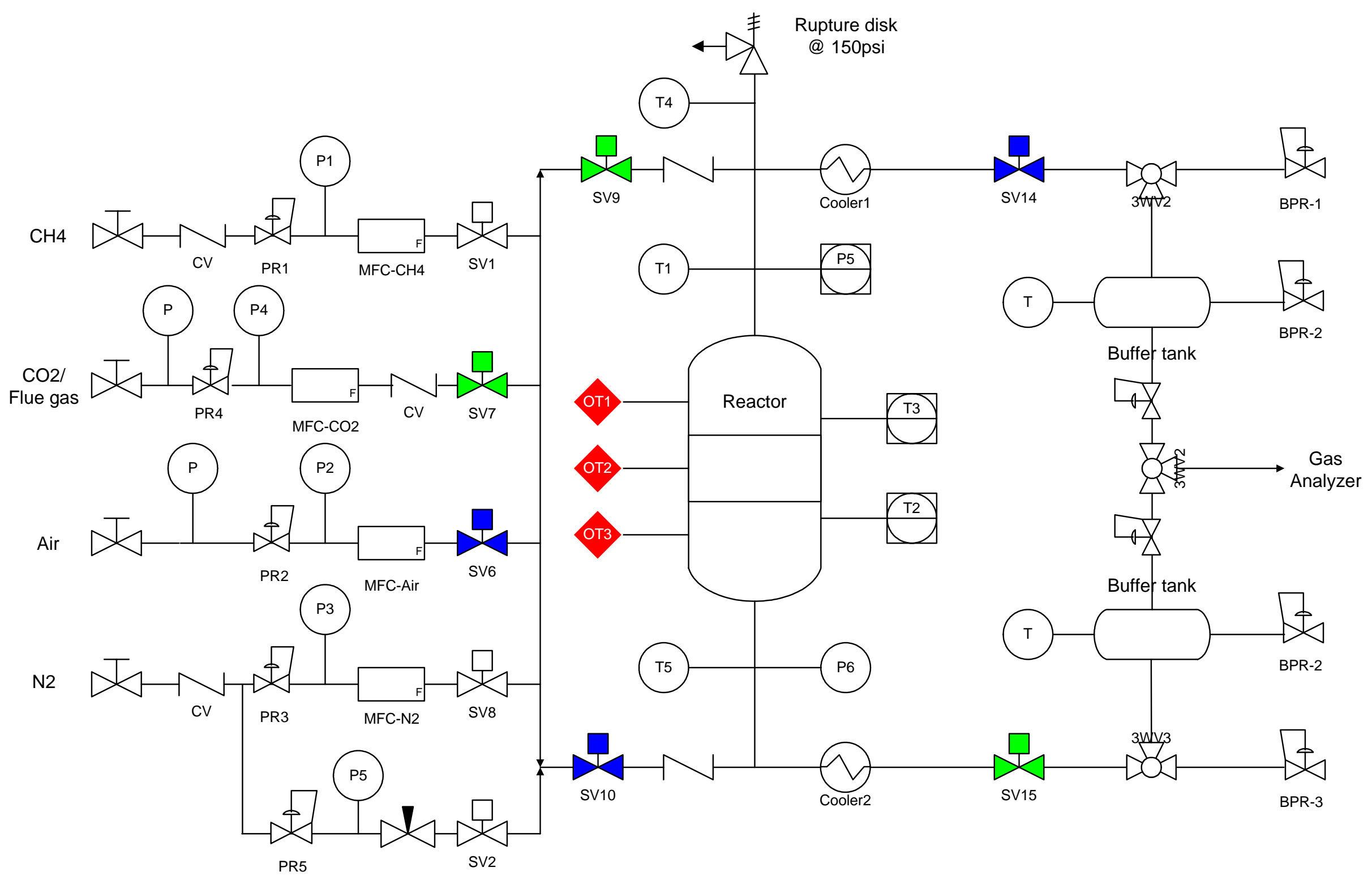

Figure 1. Schematic of BOC Bench-Scale CAR Unit 


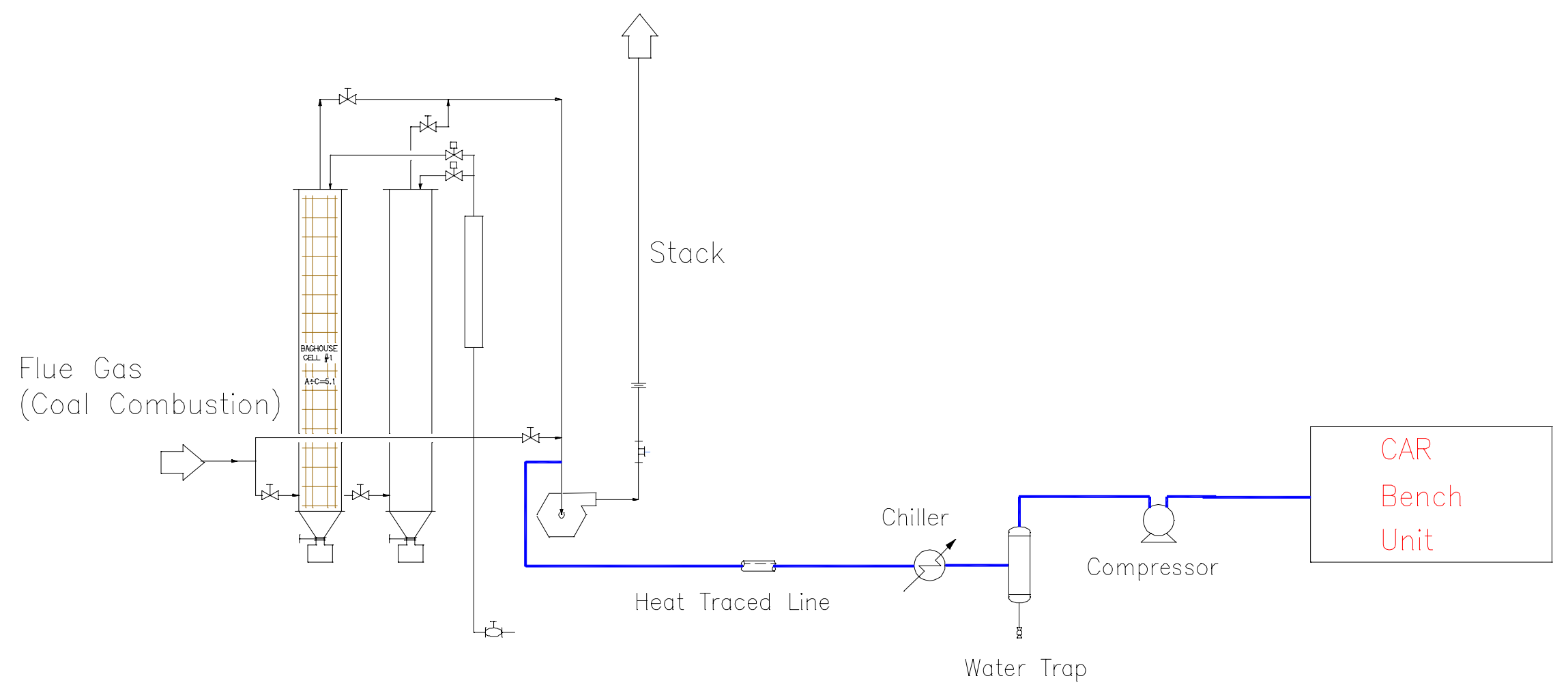

Figure 2. Interface between the Combustion Test Facility and Bench-Scale CAR Unit 
Table 1. Test Matrix

\begin{tabular}{|c|c|c|c|c|c|}
\hline Time & $\begin{array}{l}\text { Material } \\
\text { Type }\end{array}$ & $\begin{array}{l}\text { Material } \\
\text { Form }\end{array}$ & Gas Type & $\mathrm{SO}_{2}$ Level & Duration \\
\hline $2^{\text {nd }}$ Quarter 2007 & BOC-2 & Pellets & Flue Gas & $\begin{array}{l}\mathrm{SO}_{2}-740 \text { ppm (avg.), } \\
\mathrm{NOx}-300 \text { ppm (avg.), CO, Hg } \\
\text { Refer to Table A.1 for detail composition }\end{array}$ & 40 hour \\
\hline $2^{\text {nd }}$ Quarter 2007 & BOC-10 & Pellets & Flue Gas & $\begin{array}{l}\mathrm{SO}_{2}-740 \text { ppm (avg.), } \\
\mathrm{NOx}-300 \mathrm{ppm} \text { (avg.), CO, Hg } \\
\text { Refer to Table A.1 for detail composition }\end{array}$ & 40 hour \\
\hline $2^{\text {nd }}$ Quarter 2007 & Ni-coated BOC-2 & Pellets & Flue Gas & $\begin{array}{l}\mathrm{SO}_{2}-740 \text { ppm (avg.), } \\
\mathrm{NOx}-300 \mathrm{ppm} \text { (avg.), CO, Hg } \\
\text { Refer to Table A.1 for detail composition }\end{array}$ & 40 hour \\
\hline $3^{\text {rd }}$ Quarter 2007 & BOC-10 & Pellets & Carbon Dioxide $+\mathrm{SO}_{2}$ & 8-10 ppm & 32 days \\
\hline $1^{\text {st }}$ Quarter 2008 & BOC-2 & Pellets & Carbon Dioxide $+\mathrm{SO}_{2}$ & 8-10 ppm & 32 days \\
\hline $4^{\text {rd }}$ Quarter 2007 & BOC-2 & Powder & Carbon Dioxide $+\mathrm{SO}_{2}$ & 1470 ppm & 1 hour \\
\hline $4^{\text {rd }}$ Quarter 2007 & BOC-10 & Powder & Carbon Dioxide $+\mathrm{SO}_{2}$ & 1470 ppm & 1 hour \\
\hline $4^{\text {rd }}$ Quarter 2007 & BOC-2 & Powder & Carbon Dioxide $+\mathrm{SO}_{2}$ & 1470 ppm & 10 hour \\
\hline $4^{\text {rd }}$ Quarter 2007 & BOC-10 & Powder & Carbon Dioxide $+\mathrm{SO}_{2}$ & 1470 ppm & 10 hour \\
\hline $4^{\text {rd }}$ Quarter 2007 & BOC-10 & Powder & Flue Gas & 8 -10 ppm, NOx, CO, etc... & 1 hour \\
\hline $4^{\text {rd }}$ Quarter 2007 & BOC-2 & Powder & Flue Gas & 8 -10 ppm, NOx, CO, etc... & 1 hour \\
\hline $4^{\text {rd }}$ Quarter 2007 & BOC-10 & Powder & Flue Gas & 8 -10 ppm, NOx, CO, etc... & 10 hour \\
\hline $4^{\text {rd }}$ Quarter 2007 & BOC-2 & Powder & Flue Gas & 8 -10 ppm, NOx, CO, etc... & 10 hour \\
\hline
\end{tabular}




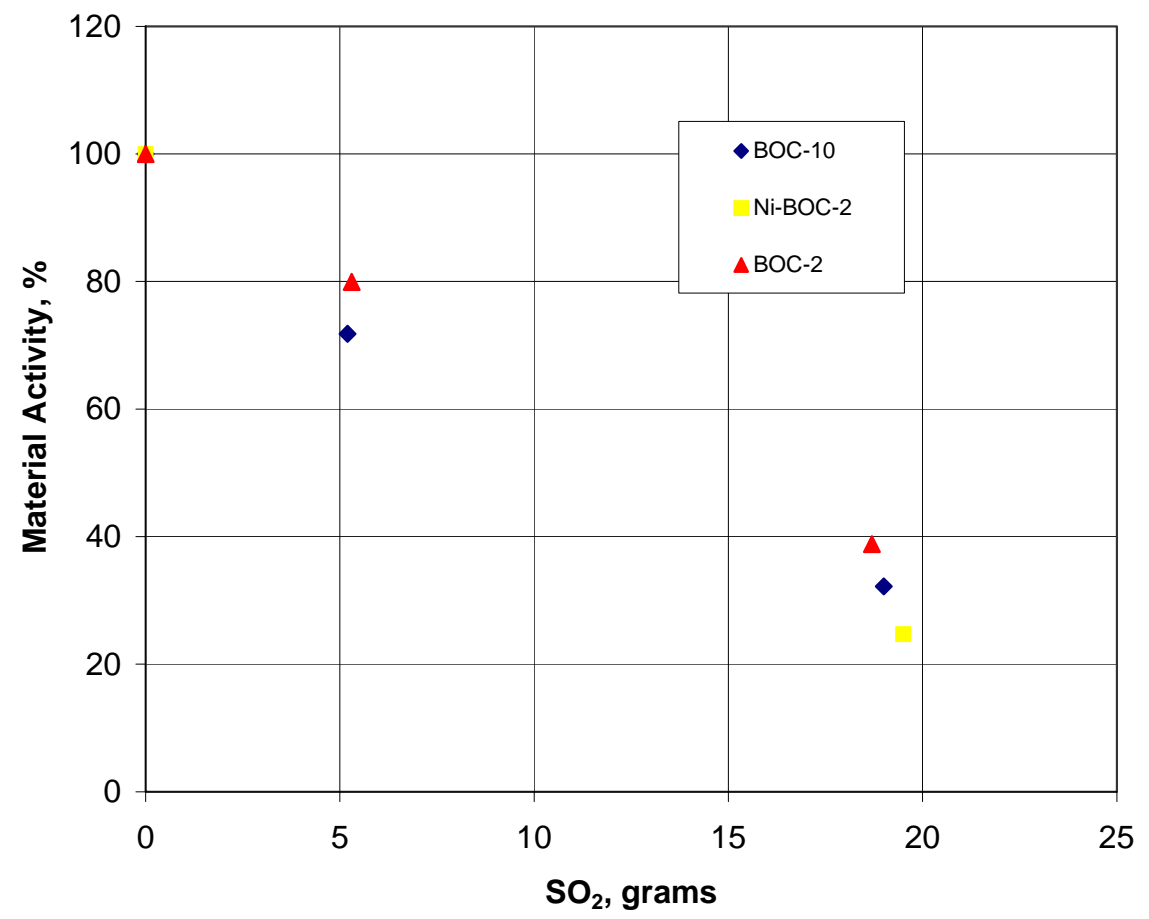

Figure 3. Perovskite Material Activity vs. $\mathrm{SO}_{2}$ Loading at $\mathrm{High} \mathrm{SO}_{2}$ concentration

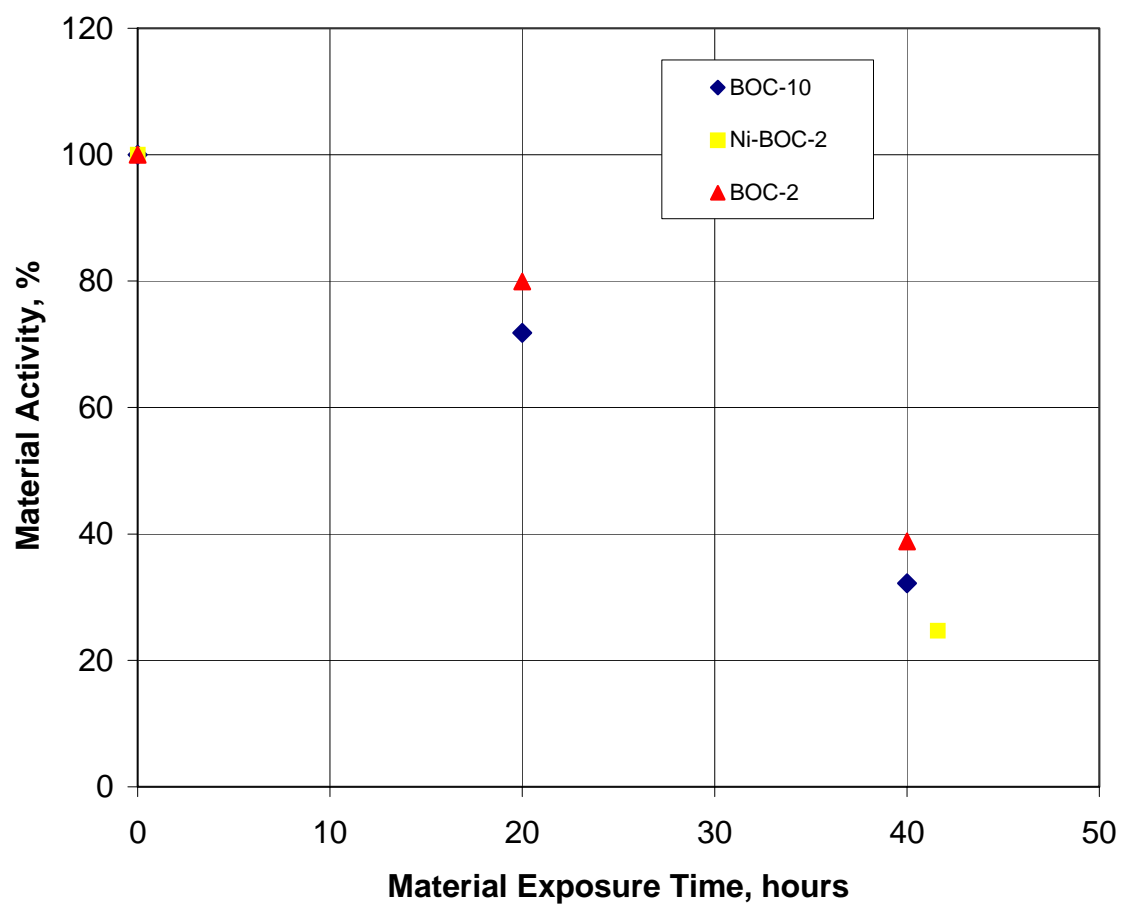

Figure 4. Perovskite Material Activity vs. Exposure Time at $\mathrm{High} \mathrm{SO}_{2}$ Concentrations 


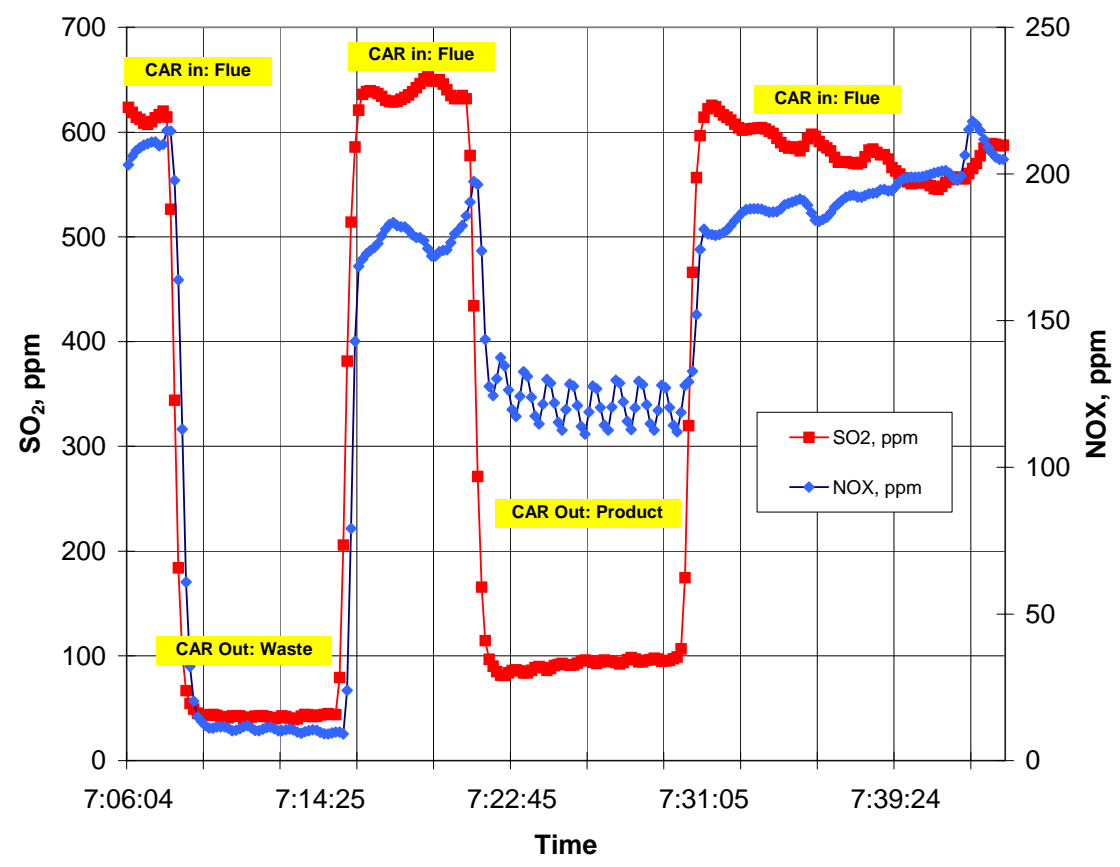

Figure 5. Distribution of Flue Gas Contaminants in the Material and the Outlet Streams for BOC-2

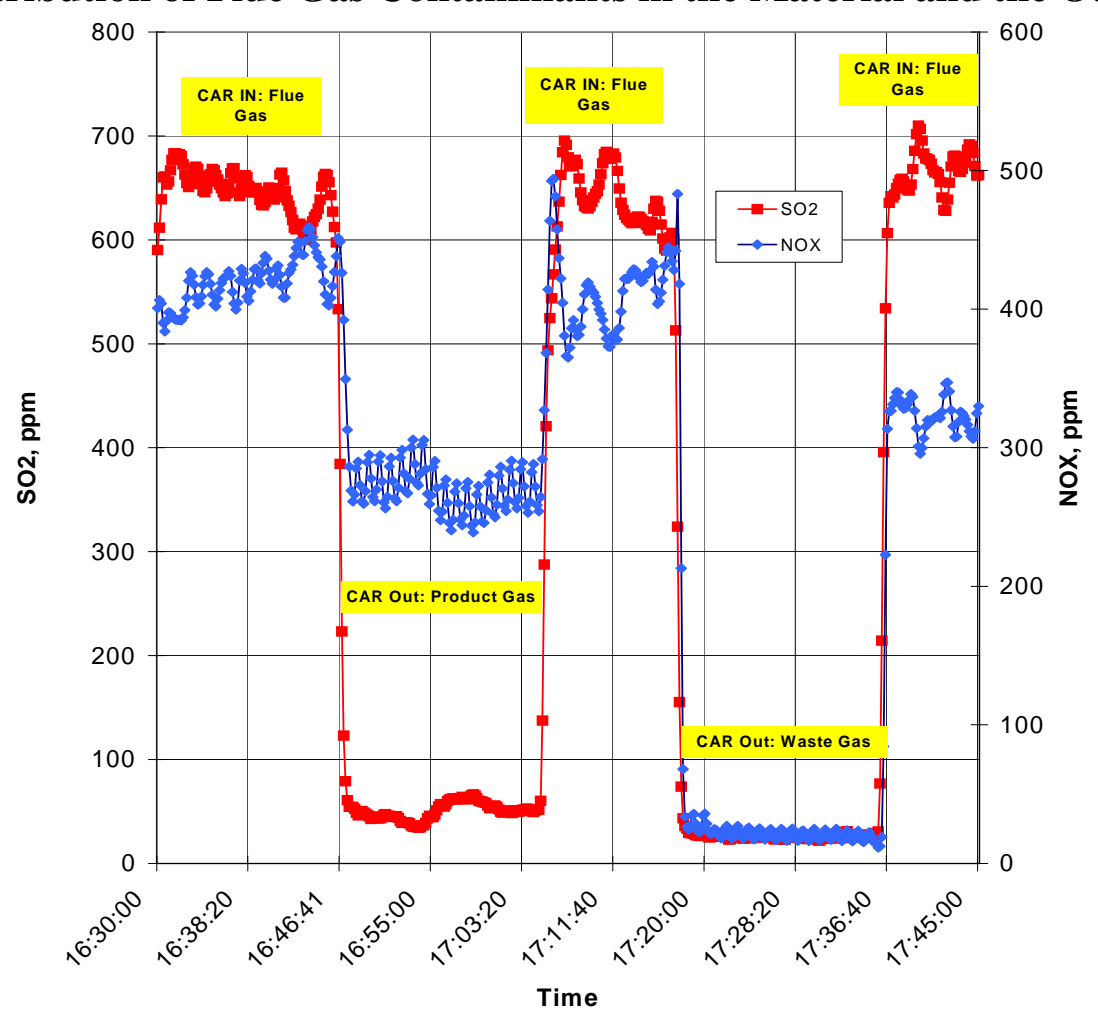

Figure 6. Distribution of Flue Gas Contaminants in the Material and the Outlet Streams for BOC-10 

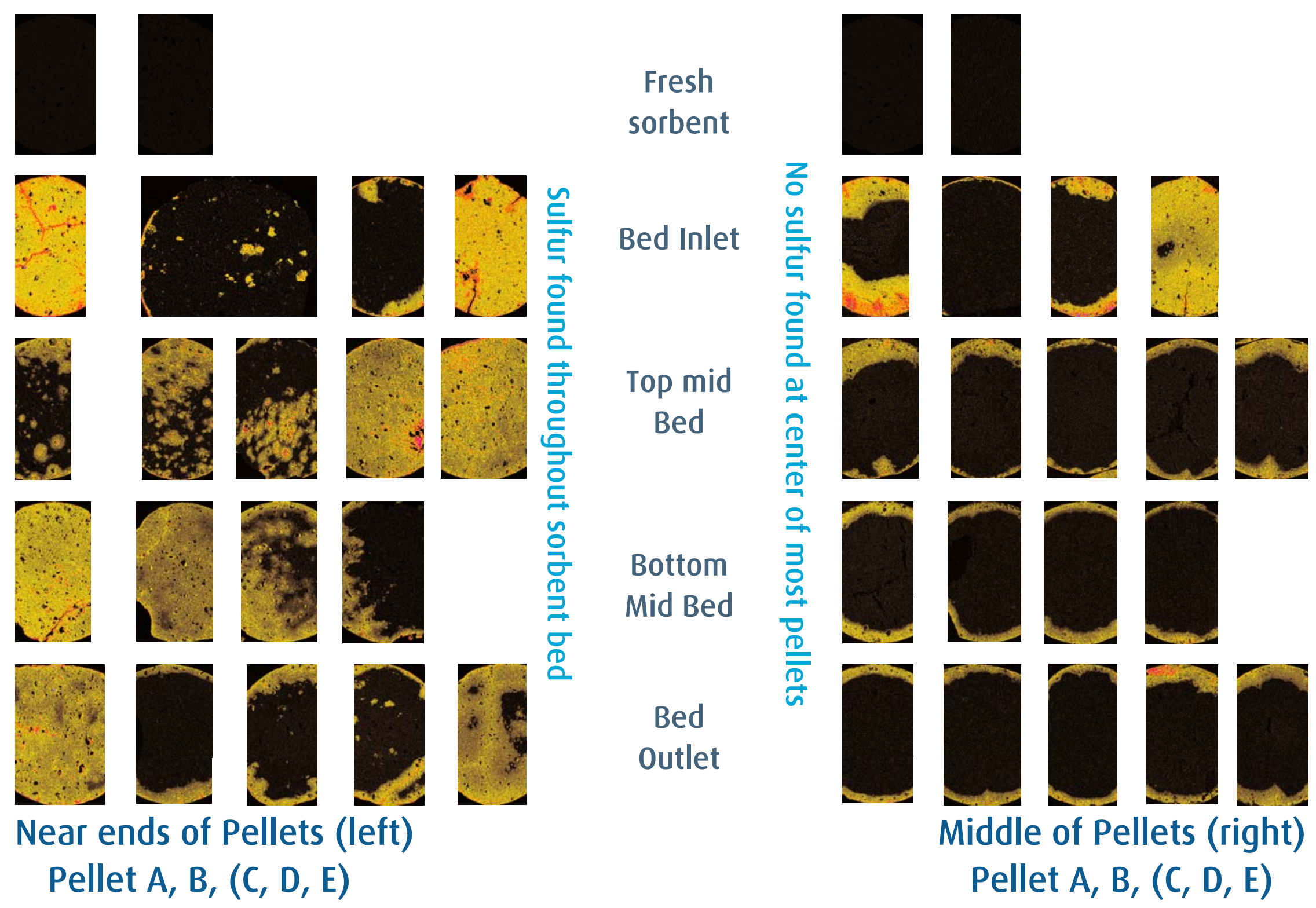

Figure 7. Electron Microprobe Sulfur Maps of Flue-gas Exposed BOC-2 Pellets 


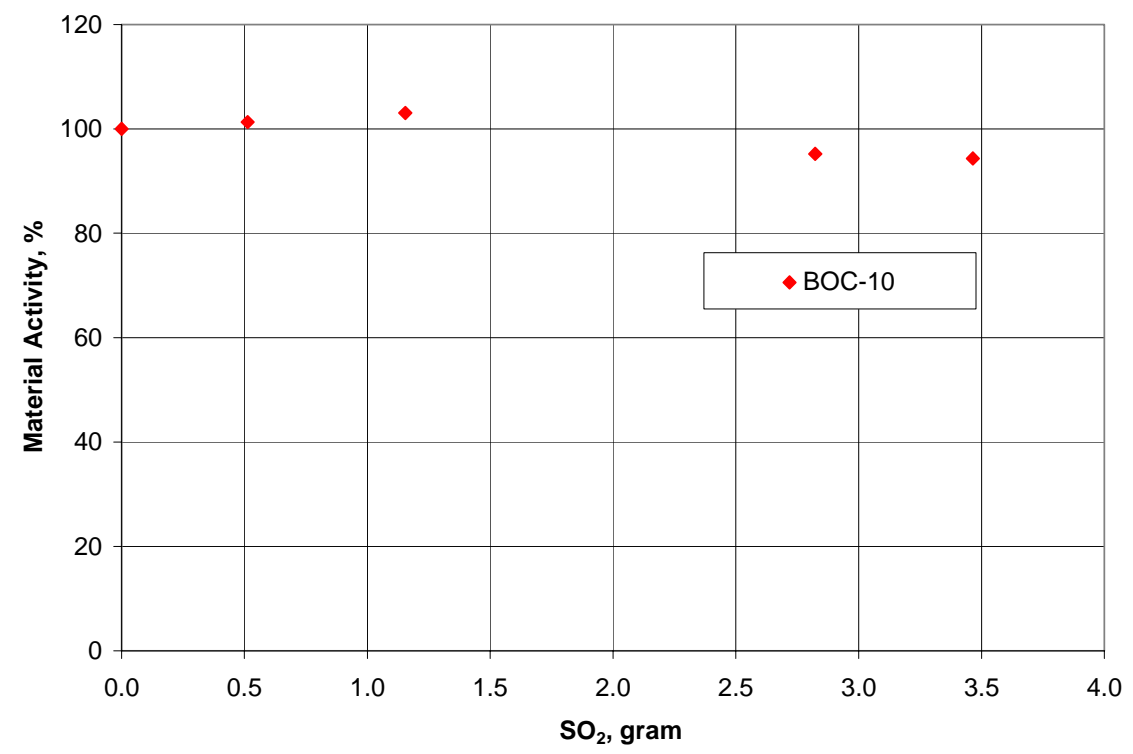

Figure 8. BOC-10 Material Activity vs. Exposure Time at $\mathrm{Low} \mathrm{SO}_{2}$ Concentrations

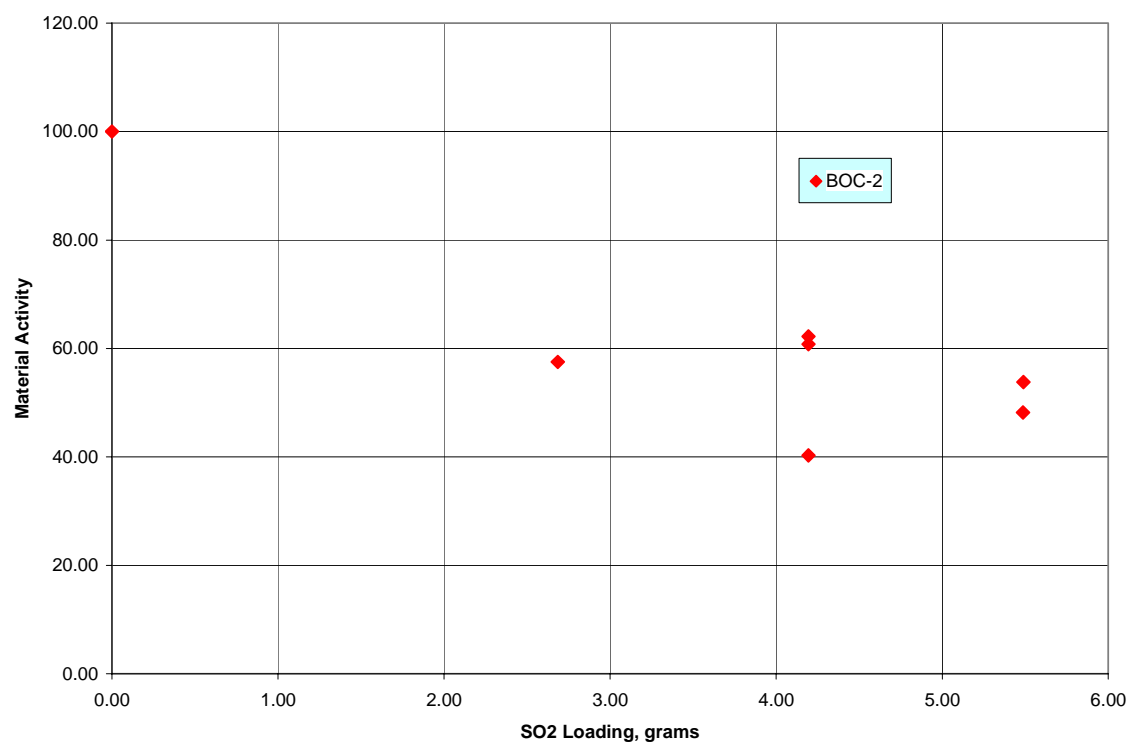

Figure 9. BOC-2 Material Activity vs. Exposure Time at $\mathrm{Low} \mathrm{SO}_{2}$ Concentrations 
Grinding of flue-gas exposed pellets would likely yield a mixture of "fresh" and deactivated perovskite because of the non-uniform distribution of $S$ found in the exposed pellets. In order to further elucidate the effects of contaminants on the perovskite CAR materials, powder samples of both BOC-2 and BOC-10 were exposed to high level of $\mathrm{SO}_{2}$ (i.e., $1470 \mathrm{ppm}$ with the balance carbon dioxide) and to flue gas with $\mathrm{SO}_{2}$ concentration around $10 \mathrm{ppm}$ in the bench-scale CAR for a short and long durations (i.e., one and ten hours). Due to the limited amount of powder material available, only 100 grams of perovskite was loaded in the reactor during each test. Glass wool plugs were utilized to hold the material in place. The $\mathrm{SO}_{2}$ concentration in the flue gas was maintained in the range 10 -12 ppm by scrubbing a portion of the flue gas with $\mathrm{NaHCO}_{3}$ solution then blending it with the main flue gas stream (refer to Table 2).

Table 2. Composition of Flue Gas for the Powder Material Exposure Test

\begin{tabular}{|l|l|l|l|l|l|l|l|l|}
\hline Material & $\begin{array}{l}\text { Exposure } \\
\text { Time } \\
(\text { hour })\end{array}$ & $\begin{array}{l}\text { Flow Rate } \\
(\mathrm{SLPM})\end{array}$ & $\begin{array}{l}\mathrm{O}_{2} \\
(\%)\end{array}$ & $\begin{array}{l}\mathrm{CO}_{2} \\
(\%)\end{array}$ & $\begin{array}{l}\mathrm{SO}_{2} \\
(\mathrm{ppm})\end{array}$ & NOx & $\begin{array}{l}\mathrm{CO} \\
(\mathrm{ppm})\end{array}$ & $\begin{array}{l}\mathrm{SO}_{2} \\
\text { Loaded } \\
(\mathrm{grams})\end{array}$ \\
\hline BOC-2 & 1.14 & 7.8 & 4.3 & 13.8 & 10.4 & 391 & 42.8 & 0.008 \\
\hline BOC-2 & 10.0 & 7.3 & 6.8 & c 12.5 & 10.9 & 471 & 28 & 0.068 \\
\hline & & & & & & & & \\
\hline BOC-10 & 1.55 & 6.6 & 5.7 & 12.45 & 12.3 & 417 & 24 & 0.011 \\
\hline BOC-10 & 9.82 & 7.64 & 4.6 & c 12.5 & 12.1 & 567 & 27 & 0.078 \\
\hline
\end{tabular}

XRF confirmed presence of sulfur in all samples $\mathrm{SO}_{2}$ exposed powder samples. Reitveld XRD studies confirmed the progressive formation of $\mathrm{SrSO}_{4}$ in the high level $\mathrm{SO}_{2}$ exposed powder samples. Little damage to powder perovskite samples exposed to low levels of contaminant (c.

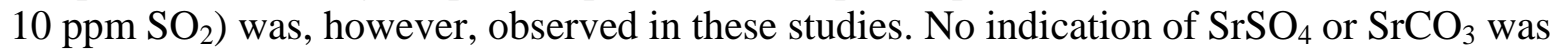
found, but again some indication of $\mathrm{SrS}$ and $\mathrm{Co}_{3} \mathrm{O}_{4}$ decomposition products from LSCF perovskite. 
APPENDIX A

Flue Gas Composition 
Table A.1 - Flue Gas Composition

\section{Material: BOC-10}

\begin{tabular}{|c|c|c|c|c|c|c|c|c|c|}
\hline $\begin{array}{l}\text { Coal } \\
\text { Type }\end{array}$ & $\begin{array}{c}\text { Duration } \\
\text { hour }\end{array}$ & & $\begin{array}{l}\mathrm{O}_{2} \\
\%\end{array}$ & $\begin{array}{l}\mathrm{SO}_{2} \\
\mathrm{ppm}\end{array}$ & $\begin{array}{l}\mathrm{NO}_{x} \\
\mathrm{ppm}\end{array}$ & $\begin{array}{c}\text { Actual } \\
\text { Exposure } \\
\mathrm{hr}\end{array}$ & $\begin{array}{l}\text { Flow rate } \\
\text { liter/min }\end{array}$ & $\begin{array}{l}\text { Total flow } \\
\text { of flue gas } \\
\text { gram mole }\end{array}$ & $\begin{array}{c}\mathrm{SO}_{2} \\
\text { grams }\end{array}$ \\
\hline \multirow[t]{2}{*}{ Black Thunder (Subbituminous) } & 9 & avg. & 5.3 & 202 & 263 & 4.5 & 7.8 & $\overline{94}$ & 1.2 \\
\hline & & Stdev. & 2.8 & 53 & 88 & & & & \\
\hline \multirow{2}{*}{ Wyodak (Subbituminous) } & 9 & avg. & 3.6 & 243 & 231 & 4.5 & 7.8 & 94 & 1.5 \\
\hline & & Stdev. & 1.0 & 53 & 33 & & & & \\
\hline \multirow[t]{2}{*}{ Richmond (Bituminous) } & 9 & avg. & 3.0 & 1857 & 351 & 4.5 & 7.8 & 94 & 11.2 \\
\hline & & Stdev. & 0.8 & 112 & 29 & & & & \\
\hline \multirow[t]{2}{*}{ BNI (Lignite) } & 7 & avg. & 4.7 & 559 & 312 & 3.5 & 7.8 & 73 & 2.6 \\
\hline & & Stdev. & 0.6 & 113 & 28 & & & & \\
\hline \multirow[t]{2}{*}{ BNI/Cape Fear Blend (Lignite/Bituminous) } & 3 & avg. & 4.6 & 705 & 321 & 1.5 & 7.8 & 31 & 1.4 \\
\hline & & Stdev. & 1.5 & 195 & 80 & & & & \\
\hline \multirow[t]{2}{*}{ Lee Ranch (Subbituminous) } & 3 & avg. & 6.2 & 543 & 311 & 1.5 & 7.8 & 31 & 1.1 \\
\hline & & Stdev. & 4.8 & 388 & 132 & & & & \\
\hline
\end{tabular}

\section{Material: Ni-Coated BOC-2}

\begin{tabular}{|c|c|c|c|c|c|c|c|c|c|c|}
\hline $\begin{array}{l}\text { Coal } \\
\text { Type }\end{array}$ & $\begin{array}{c}\text { Duration } \\
\mathrm{hr}\end{array}$ & & $\begin{array}{l}\mathrm{O}_{2} \\
\%\end{array}$ & $\begin{array}{l}\mathrm{SO}_{2} \\
\mathrm{ppm}\end{array}$ & $\begin{array}{l}\mathrm{NO}_{\mathrm{x}} \\
\mathrm{ppm}\end{array}$ & $\begin{array}{c}\mathrm{CO} \\
\mathrm{ppm}\end{array}$ & $\begin{array}{c}\text { Actual } \\
\text { Exposure } \\
\text { hr }\end{array}$ & $\begin{array}{l}\text { Flow rate } \\
\text { liter/min }\end{array}$ & $\begin{array}{l}\text { Total flow } \\
\text { of flue gas } \\
\text { gram mole }\end{array}$ & $\begin{array}{c}\mathrm{SO}_{2} \\
\text { grams }\end{array}$ \\
\hline \multirow[t]{2}{*}{ Black Thunder (Subbituminous) } & 9 & avg. & 4.5 & 228 & 341 & 112 & 4.5 & 7.8 & 94 & 1.4 \\
\hline & & Stdev. & 1.2 & 32 & 56 & 212 & & & & \\
\hline \multirow[t]{2}{*}{ Wyodak (Subbituminous) } & 9 & avg. & 4.8 & 263 & 320 & 58 & 4.5 & 7.8 & 94 & 1.6 \\
\hline & & Stdev. & 1.3 & 37 & 54 & 147 & & & & \\
\hline \multirow[t]{2}{*}{ Richmond (Bituminous) } & 9 & avg. & 3.3 & 1767 & 343 & 281 & 4.5 & 7.8 & 94 & 10.6 \\
\hline & & Stdev. & 1.6 & 197 & 74 & 271 & & & & \\
\hline \multirow[t]{2}{*}{ BNI (Lignite) } & 7 & avg. & 5.0 & 558 & 245 & 40 & 3.5 & 7.8 & 73 & 2.6 \\
\hline & & Stdev. & 1.9 & 168 & 63 & 77 & & & & \\
\hline \multirow[t]{2}{*}{ BNI/Cape Fear Blend (Lignite/Bituminous) } & 3 & avg. & 4.7 & 766 & 302 & 43 & 1.5 & 7.8 & 31 & 1.5 \\
\hline & & Stdev. & 0.8 & 66 & 37 & 70 & & & & \\
\hline \multirow{2}{*}{ Lee Ranch (Subbituminous) } & 4.6 & avg. & 4.9 & 585 & 329 & 423 & 2.28 & 7.8 & 48 & 1.8 \\
\hline & & Stdev. & 3.5 & 472 & 182 & 468 & & & & \\
\hline
\end{tabular}


Material: BOC-2

\begin{tabular}{|c|c|c|c|c|c|c|c|c|c|c|}
\hline $\begin{array}{l}\text { Coal } \\
\text { Type }\end{array}$ & $\begin{array}{c}\text { Duration } \\
\text { hours }\end{array}$ & & $\begin{array}{l}\mathrm{O}_{2} \\
\%\end{array}$ & $\begin{array}{l}\mathrm{SO}_{2} \\
\mathrm{ppm}\end{array}$ & $\begin{array}{l}\text { NOX } \\
\text { ppm }\end{array}$ & $\begin{array}{l}\mathrm{CO} \\
\mathrm{ppm}\end{array}$ & $\begin{array}{c}\text { Actual } \\
\text { Exposure } \\
\text { hr }\end{array}$ & $\begin{array}{l}\text { Flow rate } \\
\text { liter/min }\end{array}$ & $\begin{array}{l}\text { Total flow } \\
\text { of flue gas } \\
\text { gram mole }\end{array}$ & $\begin{array}{c}\mathrm{SO}_{2} \\
\text { grams }\end{array}$ \\
\hline \multirow[t]{2}{*}{ Black Thunder (Subbituminous) } & 9 & avg. & 4.6 & 220 & 225 & 22 & 4.5 & 7.8 & 94 & 1.3 \\
\hline & & Stdev. & 1.3 & 40 & 38 & 117 & & & & \\
\hline \multirow[t]{2}{*}{ Wyodak (Subbituminous) } & 9 & avg. & 3.8 & 281 & 195 & 18 & 4.5 & 7.8 & 94 & 1.7 \\
\hline & & Stdev. & 0.8 & 33 & 31 & 106 & & & & \\
\hline \multirow[t]{2}{*}{ Richmond (Bituminous) } & 9 & avg. & 4.1 & 1687 & 308 & 298 & 4.5 & 7.8 & 94 & 10.1 \\
\hline & & Stdev. & 1.6 & 388 & 86 & 360 & & & & \\
\hline \multirow[t]{2}{*}{ BNI (Lignite) } & 7 & avg. & 5.1 & 557 & 201 & 0 & 3.5 & 7.8 & 73 & 2.6 \\
\hline & & Stdev. & 2.1 & 164 & 46 & 22 & & & & \\
\hline \multirow{2}{*}{ BNI/Cape Fear Blend (Lignite/Bituminous) } & 3 & avg. & 4.6 & 752 & 246 & 6 & 1.5 & 7.8 & 31 & 1.5 \\
\hline & & Stdev. & 1.4 & 118 & 31 & 111 & & & & \\
\hline \multirow[t]{2}{*}{ Lee Ranch (Subbituminous) } & 3 & avg. & 4.3 & 697 & 276 & 49 & 1.5 & 7.8 & 31 & 1.4 \\
\hline & & Stdev. & 1.5 & 114 & 44 & 172 & & & & \\
\hline
\end{tabular}

